\title{
Spatiotemporal analysis of repeating earthquakes near Porangahau, Hikurangi Margin, New Zealand
}

\author{
By \\ OLIVIA DIANARA PITA SLLIM \\ A thesis \\ submitted to Victoria University of Wellington \\ in fulfilment of the requirements for the degree of \\ Master of Science in Geophysics.
}

Victoria University of Wellington

2021 


\section{Abstract}

The Hikurangi subduction zone beneath the eastern North Island, New Zealand exhibits a variety of fault-slip related phenomena including tsunami earthquakes, nonvolcanic tremor, low-frequency earthquakes, episodic slow slip, and repeating earthquakes. The northern Hikurangi margin hosts shallow slow-slip and is weakly coupled to shallow depths. In contrast, the southern Hikurangi margin is strongly coupled, and only deep slow-slip has been observed. The transition in coupling occurs beneath the township of Porangahau, and is an exemplary focus region for studying how this change in locking is accommodated.

To examine slip processes beneath Porangahau, we have constructed and analysed a catalogue of repeating earthquakes that occurred between 2004 and 2018. Repeating earthquakes are thought to re-rupture the same fault patch at different times, and thus have nearly identical waveforms, locations and magnitudes. Because repeating earthquakes represent cyclic loading, they can be used to detect temporal and spatial changes of slip-rate at depth and hence monitor how stress is transferred to seismogenic zones.

To build a catalogue of repeating earthquakes we first clustered the GeoNet earthquake catalogue by distance and correlation to identify potential repeating events. We then used a stronger cross-correlation threshold of at least 0.95 normalised cross-correlation value at three or more stations to identify repeating earthquakes from the initial clusters. This threshold was determined by our group's previous work on the northern Hikurangi margin. We identified 225 families of repeating earthquakes, with each family having two or more earthquakes in the 14-year study period from 2004 to 2018.

We carried out manual phase picking and polarity identification for the most recent event in each family and computed absolute locations, local magnitudes calibrated with moment magnitude, and high-quality focal mechanisms. For the rest of the events in each family, we conducted cross-correlation re-picking to obtain precise relative locations and relative magnitudes. With precise locations and well-constrained focal mech- 
anisms, we determined whether the repeating earthquake families originated within the Pacific Plate, Australian Plate or on the subduction interface. Most of the families are located within the Pacific Plate, and the majority of families that originate on the subduction interface are located near the township of Porangahau. At least 220 of the 532 identified repeating earthquakes locate at the transition from strong- to weak-coupling of the subduction interface near the township of Porangahau.

A variety of slow slip events have been detected near Porangahau in the last two decades. Even though some repeating earthquakes correlate spatially and temporally with slow slip events, temporal and spatial correlations between slow slip events and repeating earthquakes are scarce and sparse. The majority of repeating earthquakes are located up-dip or down-dip of modelled slow slip patches, with very few families having spatial correlation with slow slip events. We obtained a moment-recurrence interval relationship for the catalogue of repeating earthquakes near Porangahau and compared it to the relationship obtained by Nadeau and Johnson (1998) at Parkfield, California. Finally, we computed slip-rates using the families located on the subduction interface and obtained an average slip-rate of $13 \mathrm{~mm} / \mathrm{yr}$. The insights gained from this study lay the groundwork for future work constraining processes of strain accumulation at the creeping-to-locked transition zone near Porangahau. 


\section{Acknowledgements}

I would like to thank my supervisors Calum Chamberlain and John Townend for their guidance, support and help throughout this process. I am grateful for your patience and I appreciate the time and energy you have put into this project. I have learned so much in this past year from you, from coding to what to do in windy Wellington. Thank you for the amazing fieldwork opportunity on the West Coast and the encouragement to present my work at GSNZ and AGU. I also thank Laura Wallace for the opportunity to go on a voyage to offshore Porangahau, the stars at night and sunrises were breathtaking. I thank the examiners Rupert Sutherland and Katie Jacobs for their comments and suggestions, which have helped me to improve this thesis.

This project was funded by a Marsden grant (Project ID: 17-VUW-121), the Frank Evison Research Scholarship in Geophysics, and the EQC Programme in Seismology \& Tectonic Geodesy.

Thank you to all my amazing friends in New Zealand for all their support and amazing moments shared together. A huge thank you to the uni crew, Carmen, Yaas, Theo, Emily, Brenton, Sam, Josh and Calvin, for all the lunch time company, the fun nights in town and the occasional beers. Thank you to latinos @VUW, Andrea, Guillermo, Javier, Jenny, William and Daniel, for the fun trips, the company at the postgrad association breakfasts and all the great moments spent together around Wellington! And of course, special thanks to Carmen for being such an amazing friend and a huge support throughout this year!!

Thank you to all the Ollin Yolitzlti dance group for giving me the opportunity to go back to dancing, thank you for all the hugs and the unforgettable performances. Can't wait to fully return to rehearsals and enjoy dancing again with all of you. 
To my parents, thank you for all the encouragement and support you have always given me. Thank you for supporting my dream of becoming a seismologist, even if that meant moving to the other side of the world. To Alfredo, thank you for always being there for me, even though we are thousands of kilometres apart. Siempre los llevo en lo profundo de mi corazón, pronto nos veremos.

Gracias, gracias, gracias. 


\section{Contents}

Abstract

$\begin{array}{lll}\text { Acknowledgments } & \text { v }\end{array}$

List of Figures $\quad$ xi

List of Tables $\quad$ xiii

1 Introduction 1

1.1 Motivation and objectives .................... 2

1.2 Study location: Porangahau . . . . . . . . . . . . . . . 4

1.2.1 The Hikurangi margin . . . . . . . . . . . . . . . . . 4

1.2.2 Seismic and aseismic phenomena near Porangahau . . . . . . . 5

1.3 Thesis structure . . . . . . . . . . . . . . . . . . . . . . 9

2 Background 11

2.1 Repeating earthquakes definition . . . . . . . . . . . . . . 11

2.1.1 Nomenclature . . . . . . . . . . . . . . . . . . . . . 12

2.2 Identification of repeating earthquakes . . . . . . . . . . . . . . . 13

2.2.1 Identification using waveform similarity . . . . . . . . . . . . 14

2.2 .2 Identification using other criteria . . . . . . . . . . . 16

2.3 Mechanics of repeating earthquakes . . . . . . . . . . . . . 17

2.3.1 Earthquake cycle models . . . . . . . . . . . . . . . 17

2.3.2 Recurrence intervals of repeating earthquakes . . . . . . . . 20

2.4 Repeating earthquakes in different settings . . . . . . . . . . . . . . 21

3 Data and Methodology 25 


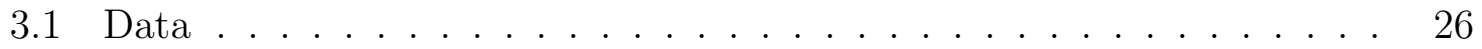

3.2 Repeating earthquake identification . . . . . . . . . . . . . 28

3.3 Clustering into repeating earthquake families . . . . . . . . . . . . . . 32

3.4 First arrivals and polarity identification . . . . . . . . . . . . . 33

3.4.1 Pick corrections . . . . . . . . . . . . . . . 35

3.5 Location of repeating earthquakes . . . . . . . . . . . . . . 37

3.5.1 Absolute locations of repeating earthquakes . . . . . . . . . . 38

3.5.2 Relative locations of repeating earthquakes . . . . . . . . . . 38

3.6 Local magnitude calculation . . . . . . . . . . . . . . . . . 40

3.7 Focal mechanism calculation . . . . . . . . . . . . . . . . 43

4 Results $\quad 45$

4.1 Nomenclature of repeating earthquake families . . . . . . . . . . . 45

4.2 Repeating earthquake locations . . . . . . . . . . . . . . . 47

4.2.1 Absolute locations . . . . . . . . . . . . . . . 47

4.2 .2 Relative locations . . . . . . . . . . . . . . . . . . . . . 49

4.3 Repeating earthquake magnitudes . . . . . . . . . . . . . 52

4.4 Repeating earthquake focal mechanisms . . . . . . . . . . . . 55

4.5 Results summary . . . . . . . . . . . . . . . . 59

5 Discussion and Conclusions $\quad 61$

5.1 Repeating earthquake catalogue completeness . . . . . . . . . . . 61

5.2 Repeating earthquake locations . . . . . . . . . . . . . 68

5.2.1 Families in the Australian Plate . . . . . . . . . . . . 68

5.2.2 Families in the Pacific Plate . . . . . . . . . . . . . . 70

5.2.3 Families on the subduction plate interface . . . . . . . . . 71

5.3 Repeating earthquakes and other phenomena . . . . . . . . . . 71

5.4 Seismic moment-recurrence interval relationship . . . . . . . . . . . . 84

5.5 Slip-rate relationships . . . . . . . . . . . . . . 86

5.6 Conclusions and future work . . . . . . . . . . . . . . . 90 
A Repeating Earthquake Catalogue Information 108

A.1 Catalogue of repeating earthquakes near Porangahau . . . . . . . . . . 108

A.2 Stations corrections from magnitude inversion . . . . . . . . . . 115

A.3 Focal Mechanism Solutions . . . . . . . . . . . . . . . . . 117

A.4 Focal Mechanism Plots . . . . . . . . . . . . . . . . . 120

B Earthquake Location Input Files $\quad 137$

B.1 NonLinLoc input file . . . . . . . . . . . . . . . . . 137

B.2 GrowClust input file . . . . . . . . . . . . . . . . . . 139 


\section{List of Figures}

1.1 Tectonic setting of New Zealand . . . . . . . . . . . . . . 6

1.2 Map of seismic phenomena in the North Island . . . . . . . . . . . . . 7

1.3 Map of aseismic phenomena in the North Island relevant to this study. 8

2.1 Schematic model of repeating earthquakes on a creeping fault with locked area. . . . . . . . . . . . . . . . . . . 12

2.2 Diagram of recurrence interval and family duration of repeating earthquake families. ......................... 13

2.3 Recurrence model of an idealised earthquake cycle. . . . . . . . . . . 17

2.4 Recurrence models of time-Predictable and slip-predictable models . . . 18

2.5 Asperity model of repeating earthquakes . . . . . . . . . . . . . . . . . 19

2.6 Repeating earthquake studies in New Zealand . . . . . . . . . . . . . . 24

3.1 Flow diagram outlining the steps undertaken in this thesis. . . . . . . . 25

3.2 Location of the stations used in this research . . . . . . . . . . . . . . 27

3.3 Waveform pre-processing and multisegment normalized cross-correlation. 30

3.4 Correlated waveforms of the same family on two different stations. . . . 31

3.5 Dendrogram of an initial family showing the final clusters obtained . . 32

$3.6 \mathrm{P}$ and $\mathrm{S}$ phase identification . . . . . . . . . . . . . . . 34

3.7 Correction of the $\mathrm{P}$ and $\mathrm{S}$ phase arrivals using cross-correlation . . . . . 36

3.8 Map with the locations of earthquakes used to calibrate the local magnitudes . . . . . . . . . . . . . . . . . . . . . . 42

3.9 Diagram illustrating different take-off angles due to the uncertainties in P-wave arrival times. . . . . . . . . . . . . . . . . 44

4.1 Map of the geographical groups of the repeating earthquakes families. . 46

4.2 Map and cross-sections of the absolute locations obtained for the most recent events of each family using NonLinLoc . . . . . . . . . . . . . . 48 
4.3 Map and cross-sections of the hypocentral probability density function computed with NonLinLoc. . . . . . . . . . . . . . . .

4.4 Map and cross-sections illustrating the final location of all the repeating earthquakes, containing both absolute and relative locations. . . . . . .

4.5 Calculated local magnitudes of all the events through the 12 years study period. . . . . . . . . . . . . . . .

4.6 Local magnitude changes through time of families with five or more events. 54

4.7 Histogram illustrating the difference between local magnitudes calculated and the mean of the family. . . . . . . . . . . . . . .

4.8 Stereonets and P-T contour plots of two events from the focal focal mechanisms catalogue. . . . . . . . . . . . . . . .

4.9 Map and cross-sections of the selected focal mechanisms coloured using a ternary diagram classification . . . . . . . . . . . . .

5.1 Magnitude of completeness of the GeoNet catalogue near Porangahau from 2004 to 2020 . . . . . . . . . . . . . . . . .

5.2 Amplitude spectrograms and signal-to-noise ratios for three earthquakes of different local magnitudes. . . . . . . . . . . . . . . . . . .

5.3 Calculated source radii of the repeating earthquakes using constant val-

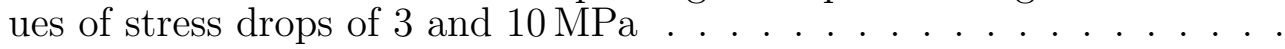

5.4 Map illustrating the locations of the repeating earthquake families in relation to the the interface locking model and the cumulative slip of slow slip events. . . . . . . . . . . . . . . . . . .

5.5 Local magnitudes of continual- and burst-type repeating events through time with seismic and aseismic phenomena. . . . . . . . . . .

5.6 Cumulative moment of continual- and burst-type repeating events through time with seismic and aseismic phenomena. . . . . . . . . . . .

5.7 Time-series and map illustrating the repeating earthquakes that occur close in time to the 2009 Riversdale slow slip event . . . . . . . . . . .

5.8 Time-series and map illustrating the repeating earthquakes that occur close in time to the 2016 triggered East Coast slow slip event . . . . . .

5.9 Time-series and map illustrating the repeating earthquakes that occur close in time to the $2010 / 2011$ Manawatu slow slip event . . . . . . . .

5.10 Time-series and map illustrating the repeating earthquakes that occur close in time to the 2008 Kaimanawa slow slip event . . . . . . . . . . .

5.11 Relationship between moment and recurrence interval for repeating earthquake families near Porangahau and other published studies. . . . . . .

5.12 Box plot illustrating the distribution of slip-rate values obtain from repeating earthquakes near Porangahau . . . . . . . . . . . . 


\section{List of Tables}

4.1 Summary of errors associated with the absolute locations obtained using NonLinLoc. . . . . . . . . . . . . . . . .

4.2 Summary of standard errors associated with the relative locations obtained using GrowClust. . . . . . . . . . . . . . .

5.1 Dates and locations of the seismic and aseismic phenomena to which we are spatially and temporarily comparing the repeating earthquake

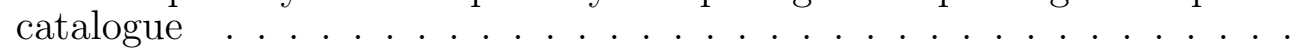

5.2 Summary of the seismic moment-recurrence interval relationship identified for repeating earthquakes near Porangahau. . . . . . . . . . . .

5.3 Slip-rates calculated from the slip-seismic moment relationship derived by Nadeau and Johnson (1998). . . . . . . . . . . . . . .

A.1 Summary of the repeating earthquake families identified near Porangahau in this study. . . . . . . . . . . . . . . . . . . . 108

A.2 Stations corrections from magnitude inversion. . . . . . . . . . . 116

A.3 Focal Mechanism Solutions . . . . . . . . . . . . . . . . 117 


\section{Chapter 1}

\section{Introduction}

Geodetic methods provide a means of monitoring the inter-seismic strain accumulation across faults (Avouac, 2015), but do not provide direct on-fault evidence of strain accumulation, or the rate of strain accumulation at seismogenic depths. However, repeating earthquakes may provide a way of monitoring slip-rates and the changing strain and stress fields of seismogenic zones (Nadeau and Johnson, 1998; Nadeau and McEvilly, 1999). Repeating earthquakes are thought to re-rupture the same patch of fault (Uchida et al., 2003). The cumulative slip from each rupture represents the slip in the region surrounding the patch. For this reason, repeating earthquakes can be used to quantify temporal and spatial changes of slip rates at depth and monitor the changing strain field of seismogenic zones (Nadeau and McEvilly, 1999).

The Hikurangi margin, located east of the North Island, New Zealand, exhibits a variety of seismic and aseismic phenomena including tsunami earthquakes, tremor, slow-slip events and repeating earthquakes (Wallace et al., 2009). Porangahau is a particularly intriguing area as it is located in the transition between creeping and locked zones beneath the North Island (Wallace et al., 2012b; Hughes et al., 2021). In this thesis, we ${ }^{1}$ construct and analyse a catalogue of repeating earthquakes near Porangahau from 2004 to 2018 to provide a starting point for monitoring strain accumulation at the creeping to locked transition zone.

In this chapter we first introduce the motivations and objectives of this research in Section 1.1. In Section 1.2 we provide an overview of the tectonic setting of the Hikurangi margin (Section 1.2.1) and the seismic and aseismic phenomena observed near

\footnotetext{
${ }^{1}$ This thesis documents original research conducted by me, Olivia Dianara Pita Sllim, under the supervision of Dr. Calum John Chamberlain and Prof. John Townend. To reflect standard scientific practice and my supervisors' input throughout the project and to facilitate publication of these results in a peer-reviewed journal, this thesis is written in the first person plural ("we").
} 
and surrounding Porangahau (Section 1.2.2). The final section of this chapter outlines the structure of the rest of this thesis (Section 1.3).

\subsection{Motivation and objectives}

Geodetic observations have shown variations in interface interseismic coupling at the Hikurangi subduction margin (Wallace et al., 2004, 2009, 2012b). Interseismic coupling is defined as the ratio of slip deficit during the interseismic period divided by the long term slip that would have happened if the fault had been slipping at the long-term average slip rate (Kaneko et al., 2010). A coupling coefficient of 1 means there is no relative motion between the two sides of a fault and they are "locked" together. In contrast, a coupling coefficient of 0 corresponds to "creeping" at the long-term slip rate. Observations suggest that large interplate earthquakes tend to rupture regions that were locked and accumulating strain during the interseismic period (Wallace et al., 2004; Bürgmann et al., 2005; Loveless and Meade, 2011; Avouac, 2015).

The subduction interface beneath southern North Island has a high interseismic coupling coefficient, meaning that the Pacific and Australian Plate are locked together. The coupling coefficient decreases northward along the margin, where the subduction interface is creeping or freely sliding. The transition in coupling occurs in southern Hawkes Bay, making this area an exemplary region for studying how this along-strike change in locking is accommodated. In addition to this, the Hikurangi margin has not had a subduction interface earthquake larger than $M_{w} 7.2$ since historical records began in A.D. 1840 (Doser and Webb, 2003; Wallace et al., 2009; Clark et al., 2019), and the interface may produce earthquakes as large as $M_{w} 9$ (Stirling et al., 2012). Understanding how this region is loaded may be useful for understanding earthquake nucleation processes in general and the seismogenic potential of the Hikurangi margin.

Repeating earthquakes are one group of seismic events with the peculiarity of having nearly-identical waveforms, locations and magnitudes (Geller and Mueller, 1980; Vidale et al., 1994; Nadeau et al., 1994). These earthquakes are interpreted as the repeated rupture of the same patch caused by stress accumulation on the locked patch due to aseismic slip on the surrounding area (Nadeau et al., 1995; Beeler et al., 2001; Uchida and Bürgmann, 2019). Under this assumption, the cumulative slip of repeating earthquakes is assumed to be equal to the fault creep and provide a direct in situ measurement of on-fault deformation at seismogenic depths (Nadeau and McEvilly, 1999; Igarashi et al., 2003; Uchida, 2019). For example, Uchida and Matsuzawa (2011) 
used repeating earthquakes to better constrain the spatial distribution of interplate coupling along the Japan Trench before the M9.0 Tohoku earthquake, and found that the seismic coupling in the area was stronger than previously thought.

Extensive research of repeating earthquakes has been carried out at other plate boundary zones, particularly at the San Andreas Fault system (Nadeau et al., 1994, 1995; Nadeau and Johnson, 1998; Schaff et al., 1998; Chen and Lapusta, 2009), the Japan Trench (Uchida et al., 2003; Igarashi et al., 2003; Kimura et al., 2006; Mavrommatis et al., 2015; Gardonio et al., 2018), Taiwan (Rau et al., 2007; Chen et al., 2008) and China (Schaff and Beroza, 2004; Schaff and Richards, 2011). In New Zealand, repeating earthquakes remain relatively unstudied. The first decadal-scale catalogue of tectonic repeating earthquakes in New Zealand was recently obtained by Hughes et al. (2021), along with a composite criterion for identifying repeating earthquakes. Wallace et al. (2017) constructed a repeating earthquake catalogue around Porangahau using lessstrong criteria than Hughes et al. (2021), who demonstrated the need for broad-band widths and waveforms including significant coda.

This research aims to further develop the catalogue of repeating earthquakes in New Zealand and to lay the basis for monitoring fault slip rates at depth in the transition from creeping to locked near Porangahau using repeating earthquakes. This project addresses the following four objectives:

1. Detect repeating earthquakes near Porangahau using cross-correlation techniques using a clustered GeoNet catalogue created by Chamberlain et al. (2019) and a threshold for identification of repeating earthquakes in New Zealand determined by Hughes et al. (2021).

2. Create a catalogue of repeating earthquakes near Porangahau containing precise locations and seismic parameters, including recurrence interval, focal mechanism, magnitude and seismic moment.

3. Analyse the spatial and temporal distribution of the repeating earthquakes in relation to other seismic and aseismic phenomena.

4. Analyse the relationship between seismic moment and recurrence interval and calculate slip-rates for repeating earthquakes located on the subduction interface using the parameters obtained via Objective 2 . 


\subsection{Study location: Porangahau}

The study area of this thesis encompasses the region between Cape Kidnappers and Castlepoint, including Porangahau on the east coast of North Island, New Zealand. In this section, we describe the regional tectonic setting and the observed seismic and aseismic phenomena occurring in the region.

\subsubsection{The Hikurangi margin}

New Zealand is located on the boundary between the Australian and Pacific Plates (Figure 1.1). Beneath the North Island, the Pacific Plate is subducting under the Australian Plate at the Hikurangi margin. This subduction margin transitions into a transpressional regime at northern South Island, forming the Marlborough faults which coalesce into the Alpine Fault: the main plate-boundary fault through South Island. Further south, plate-motion is accommodated by subduction of the Australian Plate beneath the Pacific Plate at the Puysegur margin (Mortimer et al., 2017).

The active tectonics in the North Island are dominated by subduction at the Hikurangi margin, back-arc rifting in the Taupō Volcanic Zone (TVZ), and strike-slip faulting in the North Island dextral fault belt (NIDFB) (Beanland and Haines, 1998; Wallace et al., 2004, 2009). Subduction at the Hikurangi margin began at approximately $24 \mathrm{Ma}$ (Ballance, 1976; Kamp, 1999; Nicol et al., 2007) with the subduction of the Hikurangi Plateau, a Cretaceous basaltic oceanic plateau (Mortimer and Parkinson, 1996).

The forearc of the eastern North Island is currently rotating clockwise at $\sim 4^{\circ} /$ Myr relative to the Australian plate (Wallace et al., 2004; Lamb, 2011). Through the inversion of 10-15 years of global navigation satellite system (GNSS) data, Nicol and Wallace (2007) determined that the majority of plate convergence is principally accommodated on the plate interface, while most of the margin-parallel motion is accommodated by strike-slip faulting and tectonic rotation of the Australian Plate. Lamb (2011) reconstructed the plate motion using paleomagnetic measurements and found that since $4 \mathrm{Ma}$ the rotation has increased in the northern part of the Hikurangi Margin, with $20-25^{\circ}$ of clockwise rotation near Hawkes Bay and $\sim 10^{\circ}$ further south in Wairarapa. A variation of the convergence rate along the Hikurangi Trough is observed, from $\sim 60 \mathrm{~mm} / \mathrm{yr}$ in the north to $\sim 20 \mathrm{~mm} / \mathrm{yr}$ in the south (Wallace et al., 2004; DeMets et al., 2010).

There are also changes in the characteristics of the subduction margin offshore the east coast of the North Island. At the northern end of the Hikurangi margin, the 
Hikurangi Plateau is $\sim 4-9 \mathrm{~km}$ thick, the sedimentary sequence overlaying the plateau is less than $1 \mathrm{~km}$ thick, and the accretionary wedge is less than $20 \mathrm{~km}$ wide (Davy and Wood, 1994; Wallace et al., 2009; Barker et al., 2009; Bassett et al., 2010). In comparison, at the central and southern Hikurangi margin, the Hikurangi Plateau, the sedimentary sequence, and the accretionary wedge are thicker: $\sim 12-15 \mathrm{~km}, \sim 5 \mathrm{~km}$, and 30-70 km respectively (Davy and Wood, 1994; Mochizuki et al., 2019; Wallace et al., 2009; Barnes et al., 2010; Barker et al., 2009). Barker et al. (2009) suggested that the northward reduction in thickness combined with the increase in convergence rate, lead to differences in dip and kinking of the subduction interface. At the northern Hikurangi margin, the subduction thrust near the coast has a kink downward at angles of $>8^{\circ}$ at depths of $10-15 \mathrm{~km}$, and towards the southern margin the dip of the subduction is $<8^{\circ}$ for the same depths (Barker et al., 2009).

\subsubsection{Seismic and aseismic phenomena near Porangahau}

The Hikurangi subduction margin has not produced a subduction interface earthquake larger than $M_{w} 7.2$ since historical records began in $\sim$ A.D. 1840 (Wallace et al., 2009), although there is stratigraphic evidence of previous subduction earthquakes (Clark et al., 2015, 2019). The January $2014 M_{w} 6.3$ normal-faulting Eketāhuna earthquake (Wallace et al., 2014) is the only earthquake larger than M6.0 to have occurred near Porangahau in the last 21 years (red stars in Figure 1.2), but there were three large earthquakes during the twentieth century in the region (yellow stars in Figure 1.2). Two of these earthquakes were part of the 1990 Weber sequence, one involving obliquenormal faulting within the subducting Pacific Plate $\left(M_{w} 6.2\right)$ and the other thrustfaulting within the Australian Plate $\left(M_{w}\right.$ 6.4) (Robinson, 1994; Webb and Anderson, 1998; Doser and Webb, 2003). The third twentieth century earthquake larger than M6.0 is the mainshock of the Hawkes Bay sequence of 1931 of $M_{w} 7.4-7.6$ and involving strike-slip faulting in the Australian Plate (Hull, 1990; Doser and Webb, 2003).

Several slow slip events (SSEs) have been recorded on the Hikurangi margin since the installation of GNSS in New Zealand (see Wallace (2020) for a review). The characteristics of SSEs on the Hikurangi margin change along-strike: The northern and central Hikurangi margin presents shallow $(<15 \mathrm{~km})$, short $(<1 \mathrm{month})$ and frequent slow-slip, while in the southern margin deep $(>30 \mathrm{~km})$, long ( $>1$ year) and less frequent slow slip events have been observed (Wallace, 2020; Ikari et al., 2020, and references therein).

In the region surrounding Porangahau, SSEs with diverse characteristics have been 


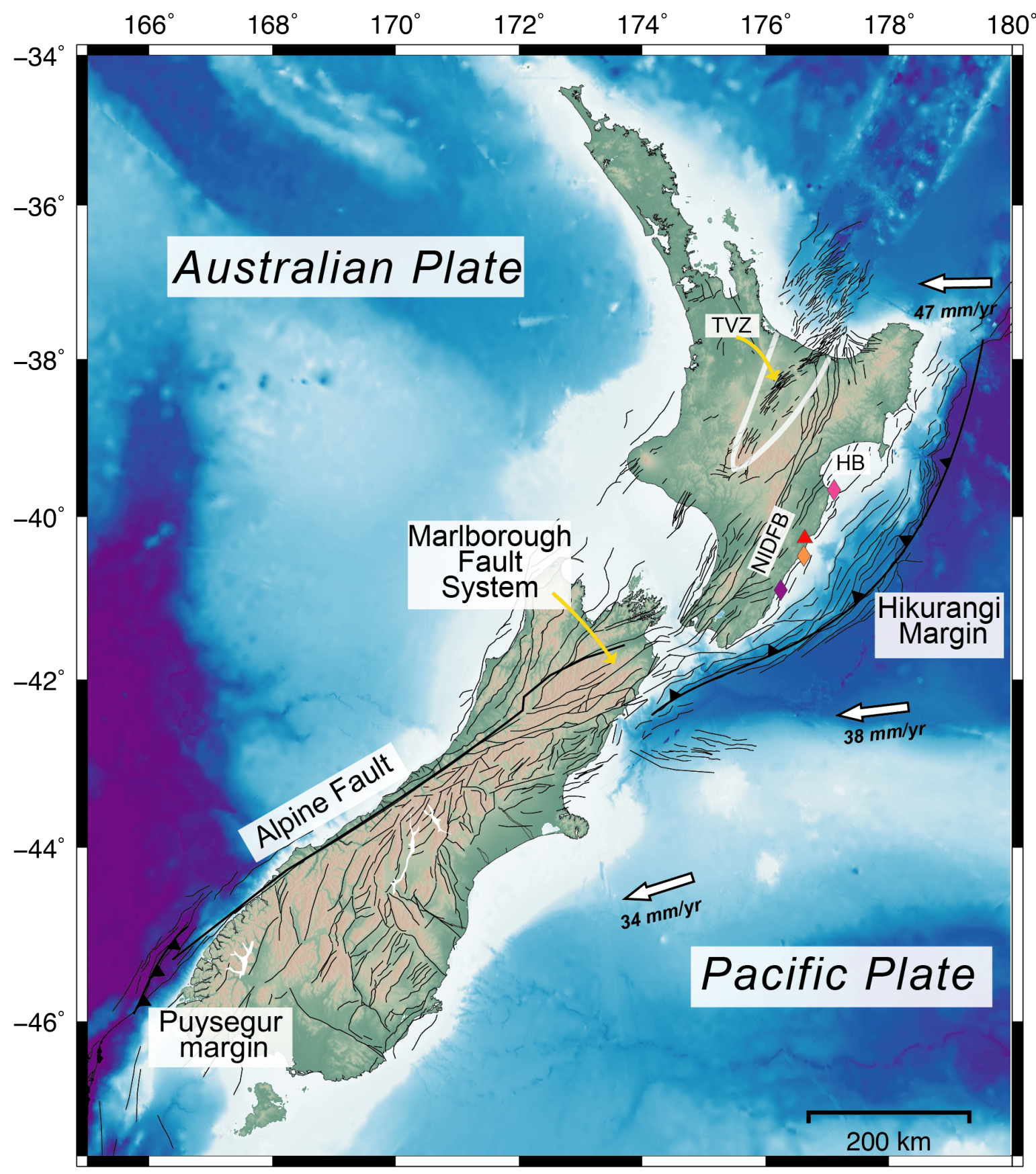

Figure 1.1: Tectonic setting of New Zealand showing the Australian-Pacific plate boundary zone. Vectors show the motion of the Pacific Plate relative to the Australian Plate (DeMets et al., 2010). The township of Porangahau is marked with a red triangle. Cape Kidnappers, Cape Turnagain and Castlepoint are marked with pink, orange and purple diamonds, respectively. TVZ - Taupo Volcanic Zone, HB - Hawkes Bay, NIDFB - North Island Dextral Fault Belt. Faults from The New Zealand Community Fault Model (Van Dissen et al., 2021). 


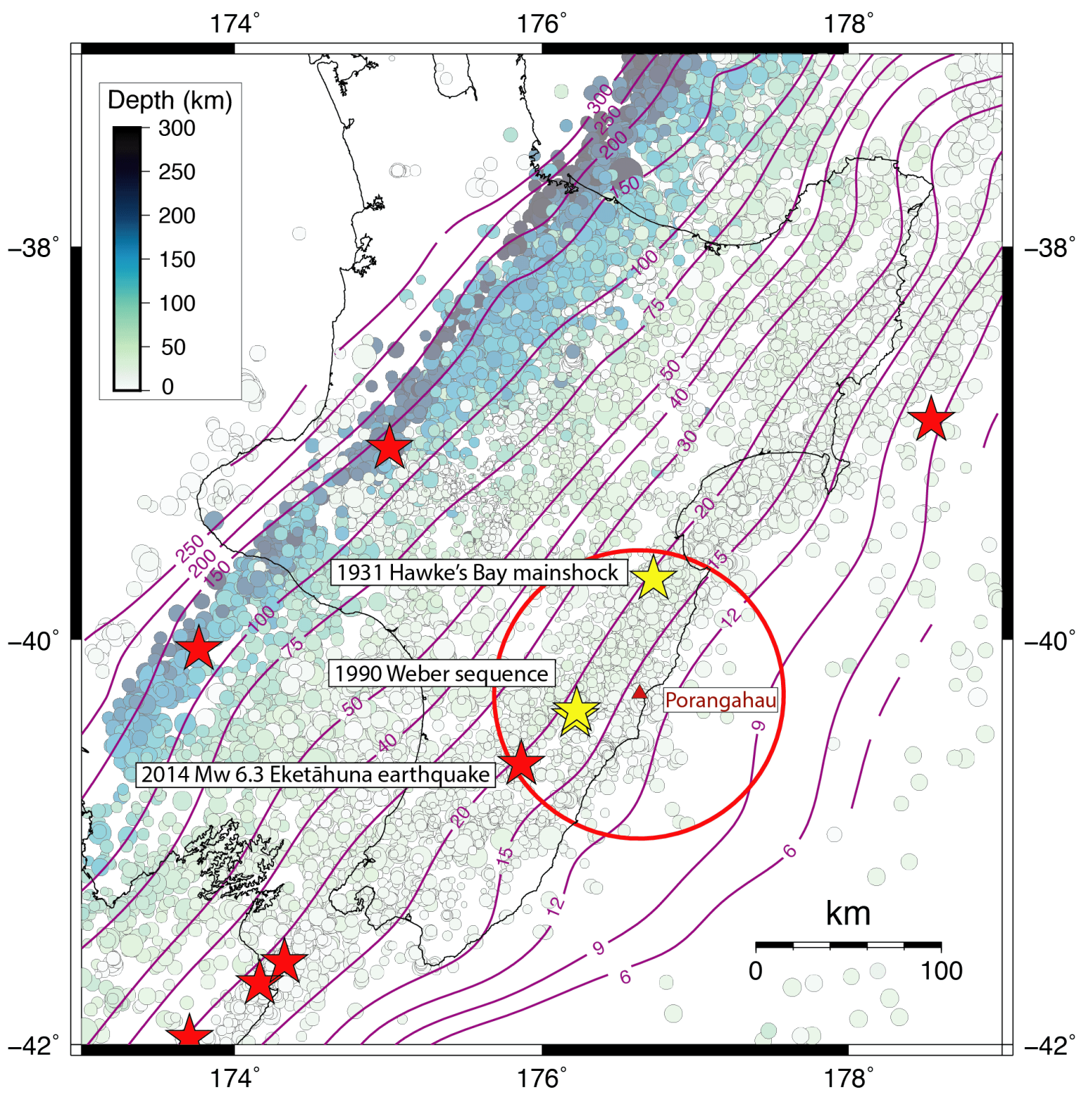

Figure 1.2: Map illustrating the seismic phenomena in the North Island, New Zealand. The study area is indicated with the red circle. Circles in the background represent the seismicity in 2014 catalogued by GeoNet ${ }^{1}$. Red stars represent the earthquakes above magnitude 6.0 that have been recorded by GeoNet since $2000^{2}$. Yellow stars represent large historical earthquakes near the study of area mentioned in the text. Red contours represent the subduction interface depth model of Williams et al. (2013).

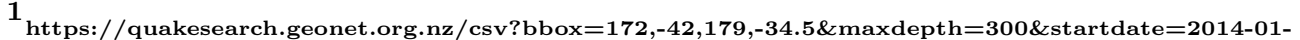
01T0:00:00\&enddate=2015-01-01T0:00:00

https: / quakesearch.geonet.org.nz/csv?bbox $=172,-42,179,-34.5 \& \mathrm{minmag}=6 \&$ startdate $=2000-01-$ 01T0:00:00\&enddate=2021-01-01T0:00:00
} 


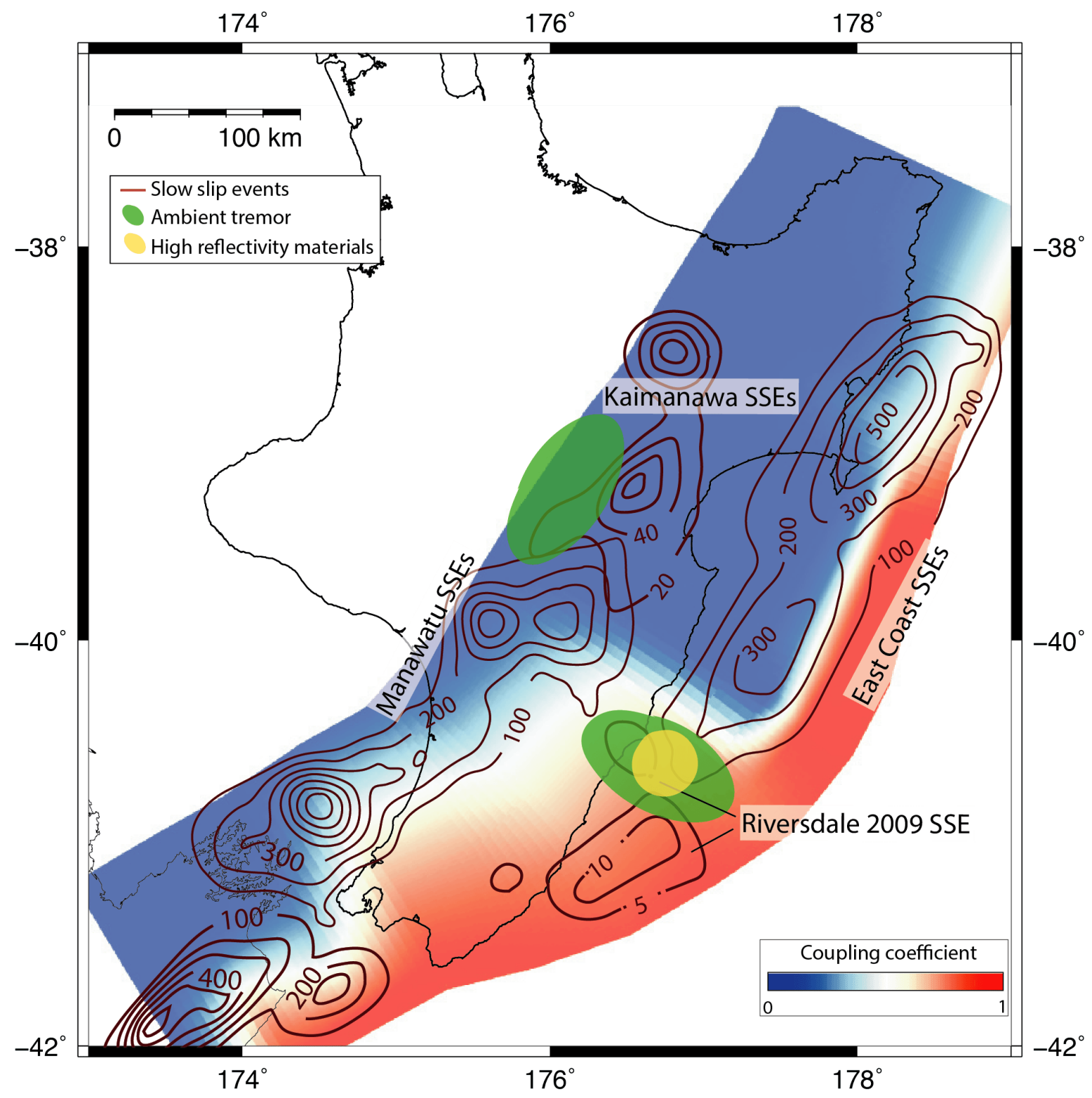

Figure 1.3: Map illustrating the aseismic phenomena in the North Island relevant to this study. Red contours indicate the cumulative slip of slow slip events in mm, modified from Wallace (2020). The blue colours of the interseismic coupling represent a low coupling coefficient and red colours represent high coupling coefficient (Wallace et al., 2012b). Green and yellow shaded areas indicate areas of observed ambient tremor (Romanet and Ide, 2019) and high reflectivity materials(Barker et al., 2009), respectively. 
observed (Figure 1.3). Between Cape Turnagain and southern Hawkes Bay, several shallow slow-slip events have been observed, which we refer to here as East Coast slow slip events.

SSEs south of Hawkes Bay occur every 1-2 years and SSEs offshore Cape Turnagain every $\sim 5$ years. The duration of the events is usually $2-3$ weeks with magnitudes equivalent to $M_{w}$ 6.1-6.8 (Ikari et al., 2020). One shallow SSE that occurred offshore from Porangahau is the 2009 Riversdale SSE (Wallace et al., 2012b). There is little information available regarding this event, but Jacobs et al. (2016) observed an increase in seismicity on the southern edge of the slow-slip patch, outside our study area.

Further inland and west of Porangahau, deep ( $>25 \mathrm{~km}$ ) Manawatu SSEs occur every 4-5years and have a duration of 1-2 years. These deep Manawatu events occur in different stages and represent total moment release equivalent to $M_{w} \sim 7.1$. Three Manawatu events have been observed, in 2004/2005, 2012/2011 and 2014/2015 (Wallace and Beavan, 2010; Wallace et al., 2018; Wallace, 2020). The Kaimanawa SSEs are also included in this category of deep SSEs. The Kaimanawa SSEs occurred in 2006 and 2008 beneath the Kaimanawa Ranges, down-dip of the shallow East Coast SSEs and lasted between 2-3 months Wallace and Eberhart-Phillips (2013).

Slow slip events have been observed in conjunction, in space and time, with tectonic tremor near or offshore Porangahau. Romanet and Ide (2019) observed tremor occurring offshore Cape Turnagain during three East Coast slow slip events, in 2006, 2011 and 2016. Triggered (Fry et al., 2011) and ambient tremor (Ide, 2012; Romanet and Ide, 2019) have also been observed related to the deep Manawatu SSEs, although the area of observation is north of our area of study.

The diverse slip behaviour that occurs at the transition from locking to creeping of the plate interface beneath Porangahau provides an intriguing environment to study the interplay between seismic and aseismic processes.

\subsection{Thesis structure}

This thesis consists of five chapters including this Introduction. The structure of the remaining chapters is as follows:

\section{Chapter 2. Background}

Chapter 2 contains a review of the prevailing theory regarding how repeating earth- 
quakes are generated and includes: the definition and nomenclature of repeating earthquakes, the different criteria for identification, the mechanical processes underlying their occurrence, and the observations of repeating earthquakes in different settings.

\section{Chapter 3. Data and Methodology}

Chapter 3 describes the data used and the methodology followed to identify repeating earthquakes. This chapter also covers the methods used to calculate locations, magnitudes and focal mechanisms of repeating earthquakes.

\section{Chapter 4. Results}

Chapter 4 presents the main results of this research: a catalogue of repeating earthquakes near Porangahau.

\section{Chapter 5. Discussion and Conclusions}

Chapter 5 reviews the catalogue of repeating earthquakes in the context of the literature and existing knowledge of the region near Porangahau. At the end of the chapter, concluding statements are presented.

\section{Appendices}

Appendix A.1 contains a table with the families that each geographical group contains. Appendix A.2 lists the station corrections from the local magnitude inversion.

Appendix A.3 contains the final focal mechanism solutions and their corresponding calculated error.

Appendix A.4 contains the stereonets and PT axis contour plots of the final focal mechanism catalogue.

Appendix B.1 contains the input file for NonLinLoc.

Appendix B.2 contains the parameters used as input for Growclust. 


\section{Chapter 2}

\section{Background}

This chapter reviews the definition and theoretical understandings of repeating earthquakes (Section 2.1) and their nomenclature (Section 2.1.1). Section 2.2 outlines the different criteria used to identify repeating earthquakes. Mechanics and models regarding repeating earthquakes are presented in Section 2.3. Studies of repeating earthquakes in the world and New Zealand are reviewed at the end of this chapter in Section 2.4.

\subsection{Repeating earthquakes definition}

Seismograms represent the time-varying seismic wavefield recorded at a point by a seismograph. The resulting seismogram can be thought of as the output of a source signal convolved with a number of linear filters. Therefore, a seismogram $u$ can be described as a source signal $(x)$ convolved with effects of earth structure $(g)$ and the response of a seismometer $(i)$ (Stein and Wysession, 2003):

$$
u(t)=x(t) * g(t) * i(t)
$$

Repeating earthquakes are groups of earthquakes with nearly identical waveforms $(u)$, source locations and fault geometries (Aster and Scott, 1993; Nadeau et al., 1994, 1995; Uchida, 2019). Neglecting any changes in instrument characteristics (i.e. $i(t)$ ) and minimal variations in path, nearly identical locations and fault geometries are interpreted as the repeated rupture of the same fault patch at different times (Geller and Mueller, 1980; Poupinet et al., 1984; Vidale et al., 1994; Nadeau et al., 1994, 1995).

This process is represented in Figure 2.1, where two almost identical waveforms are 


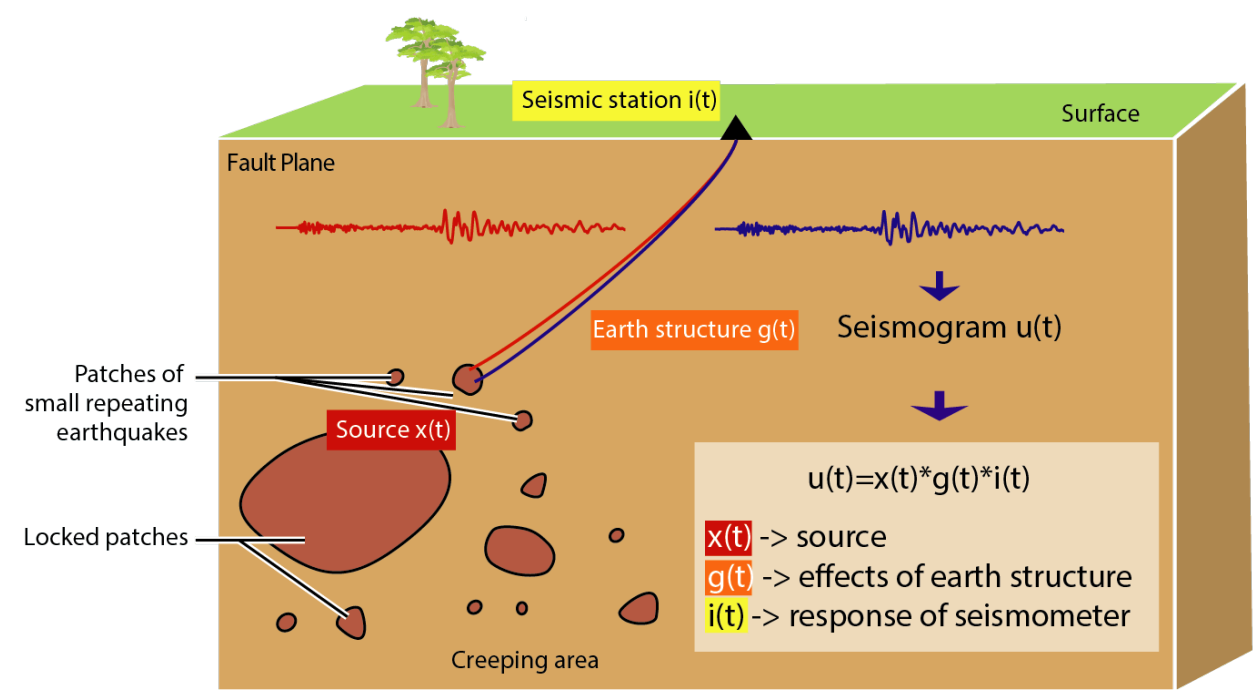

Figure 2.1: Schematic model of repeating earthquakes on a creeping fault with locked area (patches). Waveforms of two repeating earthquakes obtained in this research are shown in red and blue. The red seismogram was recorded in 2018 and the blue one in 2010, both were recorded at station PRHZ located in the township of Porangahau. Below the blue waveform, the components of a seismogram are described. Figure modified from Uchida and Bürgmann (2019).

assumed to have nearly identical source processes $(x)$ and then go through the same medium $(g)$ until reaching the seismometer. For this reason, repeating earthquakes are used to examine temporal and spatial variations in source processes (e.g. Uchida et al., 2007), medium (e.g Poupinet et al., 1984), and fault zone properties (e.g. Nadeau et al., 1994; Igarashi et al., 2003).

\subsubsection{Nomenclature}

A family is one of the names given to a group of events that have met a specific criterion and declared to be repeating earthquakes. The terms Doublets, triplets and multiplets are also used (e.g. Poupinet et al., 1984; Nadeau et al., 1994) and indicate more directly the number of events that form a group. The terms sequence or cluster are also used in repeating earthquake studies (e.g. Nadeau et al., 1994; Li et al., 2007; Templeton et al., 2008; Igarashi et al., 2003; Uchida and Bürgmann, 2019). Sequence or cluster make no reference to a number of events but they have been used to indicate groups of events that are not repeating earthquakes. For this reason, in this thesis we use the term family as it can be used no matter the number of events and it is not commonly used outside the repeating earthquakes context.

Families of repeating earthquakes are formed by two or more events. The family 


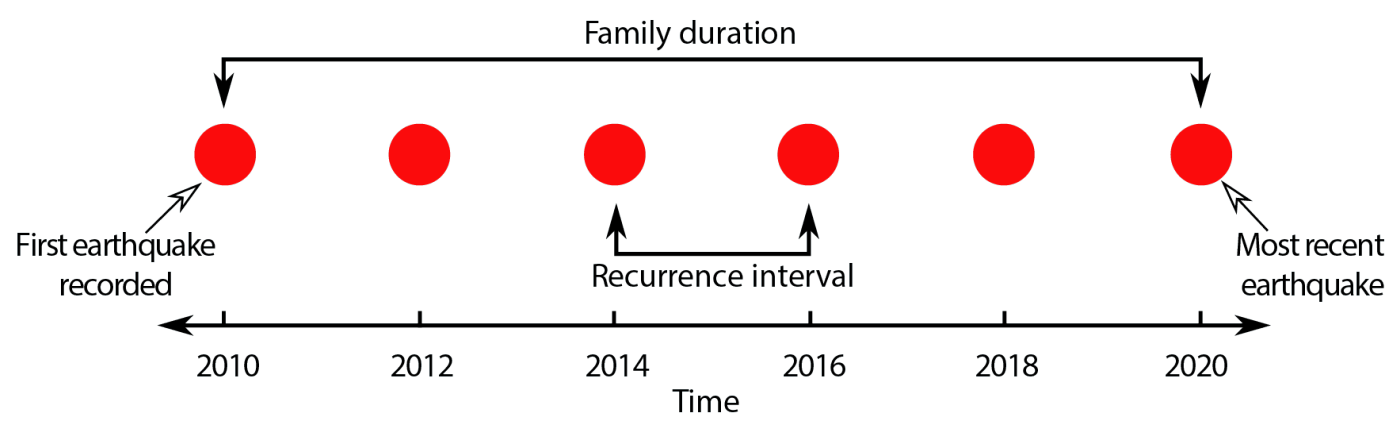

Figure 2.2: Components of a repeating earthquake family. Red circles are earthquakes belonging to the same family. The difference between recurrence interval and family duration is illustrated. Modified from Hughes et al. (2021)

duration is the time difference between the most recent event, or youngest, and the first recorded earthquake, or oldest (Figure 2.2). The family duration is influenced by the duration of the catalogue analysed and the magnitude of completeness of the catalogue analysed (Hughes et al., 2021). Family duration is not to be confused with recurrence interval, which indicates the average time between events also referred to as inter-event time (Mesimeri and Karakostas, 2018; Hughes et al., 2021). As illustrated in Figure 2.2, for example, events occur every two years (e.g. 2010, 2012, $2014 \ldots)$ so the recurrence interval of the family is $\sim 2$ years and the duration of the family is 10 years.

Burst-type and continual-type repeating earthquake families are categories formed based on the family duration and recurrence interval. Burst-type families are characterised by having short recurrence interval times, lasting from a few hours to a few days (Igarashi et al., 2003; Templeton et al., 2008; Mesimeri and Karakostas, 2018) and as a result also have short family durations that are often less than a year, but which vary among authors: e.g. Yamashita et al. (2012) established a family duration of less than three years and Mesimeri and Karakostas (2018) of one year to define burst-type families. On the other hand, continual-type families have longer recurrence intervals and family durations compared to burst-type (Igarashi et al., 2003; Mesimeri and Karakostas, 2018).

\section{$2.2 \quad$ Identification of repeating earthquakes}

Repeating earthquakes have been identified using different criteria including waveform similarity, hypocentre location, magnitude, and time interval between events (e.g. Geller and Mueller, 1980; Poupinet et al., 1984; Rubin et al., 1999; Gibowicz 
and Lasocki, 2007). There is not an established single criterion to identify repeating earthquakes as different tectonic settings, networks, instruments, and periods of time are analysed. In this section we review the rationale behind the dominant classification metrics, waveform similarity, and discuss other criteria.

\subsubsection{Identification using waveform similarity}

One of the most used criteria for identifying repeating earthquakes is waveform similarity (e.g. Nadeau et al., 1995; Igarashi et al., 2003; Schaff and Beroza, 2004; Li et al., 2011; Hughes et al., 2021). The cross-correlation coefficient $(C C)$ is used to measure the degree of similarity between two signals by performing a normalized cross-correlation as shown in equation 2.2:

$$
C C_{x y}(l)=\frac{1}{N} \sum_{n=0}^{N-1} f_{x}(n) f_{y}(n-l)
$$

where $f_{x}$ and $f_{y}$ represent two signals (waveforms), $l$ is the lag time shift between $f_{x}$ and $f_{y}$, and $N$ is the number of samples (Proakis and Dimitris, 1990; Rao and Swamy, 2018). Equation 2.2 is defined as a "normalized" cross-correlation because it is scaled by a normalization factor, which in this case is $\frac{1}{N}$ (Proakis and Dimitris, 1990). There are other normalization techniques, such as using the the square root of the energy of one of the signals to normalize both of them or to remove the mean from both signals (Martin and Crowley, 1995). In this thesis we use a normalized cross-correlation implemented in EQcorrscan (Chamberlain et al., 2018):

$$
c(t)=\frac{\sum_{y}\left(a_{y}-\bar{a}\right)\left(b_{t+y}-\bar{b}_{t}\right)}{\sqrt{\sum_{y}\left(a_{y}-\bar{a}\right)\left(a_{y}-\bar{a}\right) \sum_{y}\left(b_{t+y}-\bar{b}_{t}\right)\left(b_{t+y}-\bar{b}_{t}\right)}}
$$

where $c(t)$ is the normalized cross-correlation at time $t$ and the two waveforms being cross-correlated are represented as $a$ and $b$. This normalized cross-correlation function also removes the mean from $b$ at every time-step, which reduces the effects of jumps in average amplitude (Chamberlain et al., 2018). Chapter 3 contains the details regarding the process followed in this study to identify repeating earthquakes using normalized cross-correlation.

Several studies have used cross-correlation to identify repeating earthquakes (e.g. Geller and Mueller, 1980; Nadeau et al., 1994; Igarashi et al., 2003; Uchida et al., 2003; Schaff and Beroza, 2004; Rau et al., 2007; Zhang et al., 2008; Yu, 2013; Schmittbuhl et al., 
2016; Hughes et al., 2021). The minimum cross-correlation threshold varies from study to study, but it typically ranges from 0.90 to 0.98 (Uchida and Bürgmann, 2019) and can be as low as 0.75 (Rubinstein et al., 2012).

The operational parameters such as window length and filter frequency band have a significant effect on the correlation values obtained (Gao and Kao, 2020; Uchida, 2019). Window lengths range from seconds to minutes, and this choice typically depends on the distance between the earthquake and the recording station, making the lengths unique for each waveform (Gao and Kao, 2020, and references therein). When using longer time windows, more phases are being compared and may contain low signal-tonoise ratio coda waves. In this instance a high cross-correlation threshold may be too strict a criterion and events may be missed (Uchida, 2019). If shorter time windows are used, high cross-correlation values are statistically less robust and large-amplitude phases may bias the correlations and result in the detection of events that are not really repeating earthquakes (Gao and Kao, 2020; Uchida and Bürgmann, 2019). Using a fixed time window for all the waveforms is not ideal, due to the length of seismic wave trains increasing with source-receiver distance (Gao and Kao, 2020).

Selecting an appropriate filter frequency-band is also important, as waveforms are frequently filtered to enhance certain features and suppress others such as noise (Havskov and Ottemoller, 2010). Gao and Kao (2020) examined the effects of using different filter frequency-bands to compute the cross-correlation value and found that the crosscorrelation coefficient value drops significantly once the dominant seismic energy (in the 1-2 Hz frequency band) is filtered out. Furthermore, a low frequency pass-band may not yield sufficient spatial resolution to identify neighbouring events (Uchida, 2019; Gao and Kao, 2020). Geller and Mueller (1980) suggested that for events to have nearly-identical waveforms, they must be located within a quarter wavelength.

Some other researchers (e.g. Geller and Mueller, 1980; Poupinet et al., 1984; Lengliné and Marsan, 2009; Uchida et al., 2009; Rubinstein and Ellsworth, 2010; Mavrommatis et al., 2015) have used coherence as a measure of waveform similarity to classify repeating earthquakes. Coherence (coh) is a measure of similarity between two signals in the frequency domain $(\omega)$ :

$$
\operatorname{coh}_{x y}(\omega)=\sqrt{\frac{\left|S_{x y}(\omega)\right|^{2}}{S_{x x}(\omega) S_{y y}(\omega)}}
$$

where $S_{x y}$ is the cross-spectrum between earthquakes $x$ and $y$ obtained after computing the Fourier transform of the original waveforms $f_{x}$ and $f_{y}$ (Uchida, 2019; Uchida and Bürgmann, 2019). For two events to be selected as repeating earthquakes, the coherence 
value must be higher than a minimum threshold, which is usually 0.95 , across a range of frequencies (Uchida, 2019; Uchida et al., 2006; Uchida and Bürgmann, 2019). In most cases, a mean coherence range is obtained for a frequency range which is commonly 1-8 Hz (Uchida, 2019).

In most previous studies of repeating earthquakes, either the cross-correlation or coherence threshold must be exceeded at several stations for two events to be identified as repeating earthquakes. The required minimum number of stations is usually two, although other studies have used only one (Schaff and Beroza, 2004) and as many as five (Lengliné and Marsan, 2009).

To reduce computation time, cross-correlations or coherence calculations are normally made only for events that already passed a simple preliminary criterion (Aster and Scott, 1993), usually based on either distance or magnitude. For example, Uchida et al. (2003, 2006); Igarashi et al. (2003); Materna et al. (2018) only computed crosscorrelation or coherence for pairs of events less than $30 \mathrm{~km}$ apart. Similarly Igarashi et al. (2003) required a preliminary magnitude threshold to be exceeded, and only compared events with magnitudes larger than 3 .

\subsubsection{Identification using other criteria}

Although waveform similarity is the most common criterion to identify repeating earthquakes, it is not the only one that has been used. Since repeating earthquakes are thought to rupture the same fault area, similarity of hypocentre locations has been used as a classification criterion (e.g. Vidale et al., 1994; Nadeau and Johnson, 1998; Yu, 2013; Yao et al., 2017; Bohnhoff et al., 2017). However, the confidence of the result is strongly based on how precise the relative locations of the earthquakes are. Accordingly, hypocentral distance has not been used as the only criteria with which to identify repeating earthquakes.

Some studies have also used the time between events (e.g. a minimum of 30 days) to distinguish repeating earthquakes from swarms (Gibowicz and Lasocki, 2007; Bohnhoff et al., 2017; Schaff and Richards, 2011). Others use more than one criterion to select repeating earthquakes. In addition to waveform similarity and hypocentral distance, the similarity of differential S-P times can be used as a threshold (Chen et al., 2008; Rau et al., 2007; Uchida et al., 2006). Hughes et al. (2021) and Uchida (2019) have both provided detailed and complete information of the criteria that have been used to identify repeating earthquakes. 


\subsection{Mechanics of repeating earthquakes}

\subsubsection{Earthquake cycle models}

Reid (1910) proposed the theory of elastic rebound, which is one of the central ideas regarding earthquake mechanics. The elastic rebound theory states that crustal stresses resulting from distant large-scale shearing motions (e.g. tectonic plate movements) cause elastic strain to accumulate near faults. Abrupt frictional sliding occurs (i.e. an earthquake) when the resulting shear stress on the fault reaches a threshold determined by the rock properties of the fault. During the earthquake, some of the elastic strain is released and after the earthquake elastic strain begins to accumulate again. This behaviour is called stick-slip, as earthquakes are "slip" episodes followed by periods of no slip ("stick").

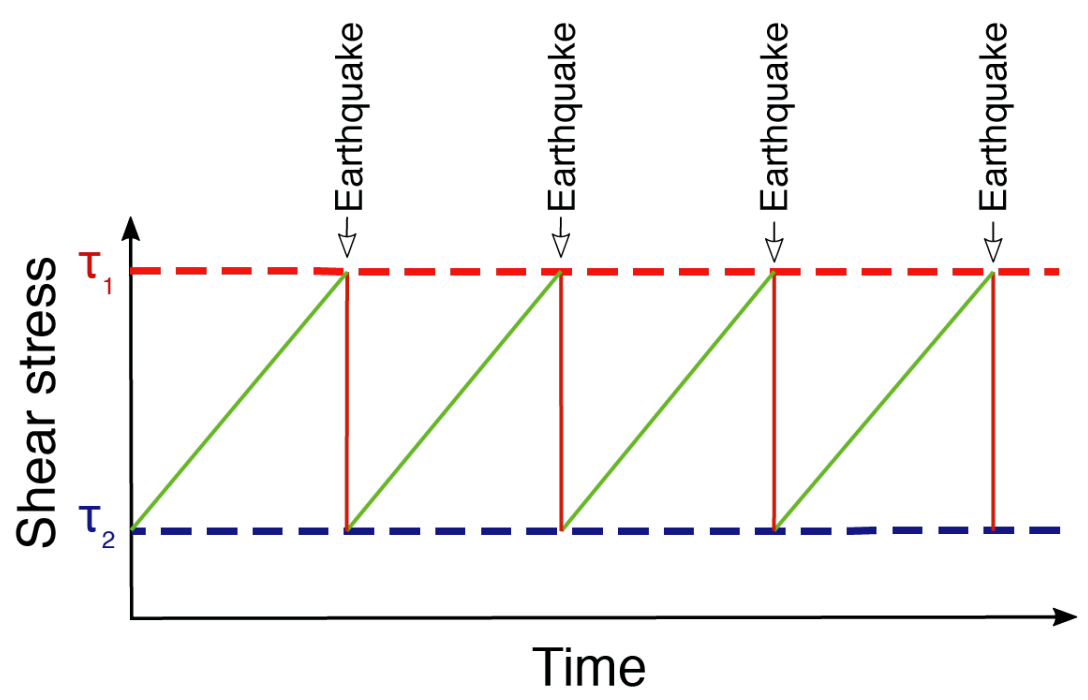

Figure 2.3: Recurrence model of an idealised earthquake cycle in which all earthquakes have the same stress drop and coseismic slip. Red vertical lines represent earthquakes and green lines represent the inter-seismic phase with a constant loading rate. Figure modified from Shimazaki and Nakata (1980).

Variants of the elastic rebound theory that also assume a constant loading rate have been proposed. Figure 2.3 is the characteristic earthquake model (Schwartz and Coppersmith, 1984) in which shear stress accumulates to the level of fault strength $\tau_{1}$. When the shear stress reaches $\tau_{1}$, the fault ruptures and the shear stress then decreases to the same level as the friction on the fault $\tau_{2}$. In this model, the shear stress released during each earthquake is the same, as is the slip on the fault and the recur- 
rence interval between earthquakes. This model leads to perfect periodicity. Figure 2.4 shows the (a) time-predictable and (b) slip-predictable models (Shimazaki and Nakata, 1980). In the time-predictable model, fault strength is constant, the fault will always rupture when reaching $\tau_{1}$ but slip on the fault can be different every rupture. In the slip-predictable model, every rupture reduces the shear stress to $\tau_{2}$ and the shear stress is proportional to the potential fault slip.
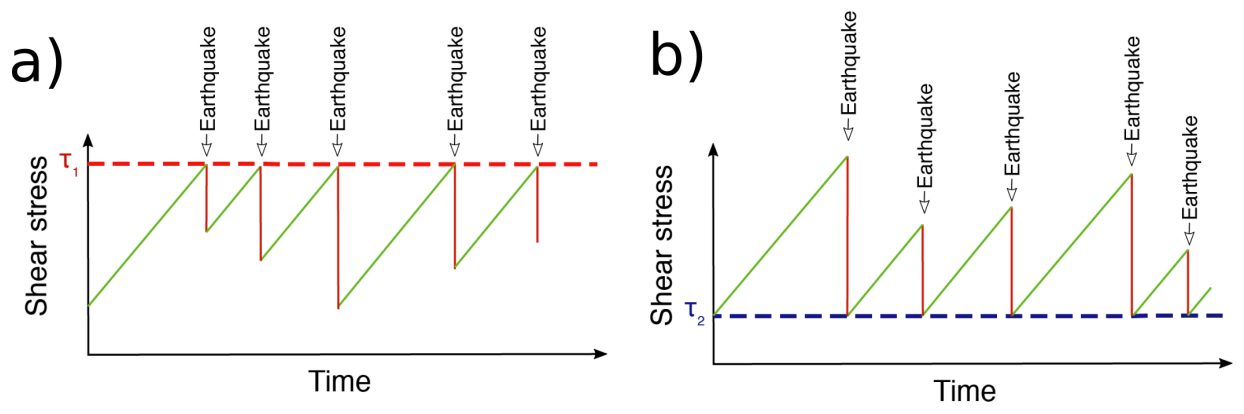

Figure 2.4: Recurrence models of (a) Time-Predictable and (b) Slippredictable models. Red vertical lines represent earthquakes and green lines represent the inter-seismic phase with a constant loading rate. For both models, the time between earthquakes is not necessarily the same. In the time-predictable model, the fault will always rupture when reaching $\tau_{1}$. In the slip-predictable model, every rupture reduces the shear stress to $\tau_{2}$.

If we define repeating earthquakes as earthquakes of similar magnitude rupturing the same fault patch at different times (e.g. Nadeau et al., 1994; Vidale et al., 1994; Ellsworth, 1995), in theory, they could be explained by the characteristic earthquake model. High waveform similarity supports the fact that they are located close to each other, in the same fault area. The similarity in magnitudes indicates that the shear stress released in every rupture is constant and if the recurrence times between events is also constant, there must be a constant loading rate.

The reality is that not all repeating earthquakes can be explained by the characteristic model, or even the time- and slip-predictable models, and there is evidence that the assumptions made (e.g. long constant loading rate, constant $\tau_{1}$, all the slip in the region being liberated by the rupture) do not hold true in field and laboratory observations (Rubinstein et al., 2012, and references therein).

The most questionable assumption from the previous mentioned models is the constant loading rate. Previous models assume that the cause of accumulating shearing stress are large-scale shearing motions, but the observed values of crustal stress accumulation rates $(1-50 \mathrm{kPa} /$ year) are small in relation to typical earthquake stress drops $(1-10$ MPa) (Uchida and Bürgmann, 2019). With these observed values, it should take at 


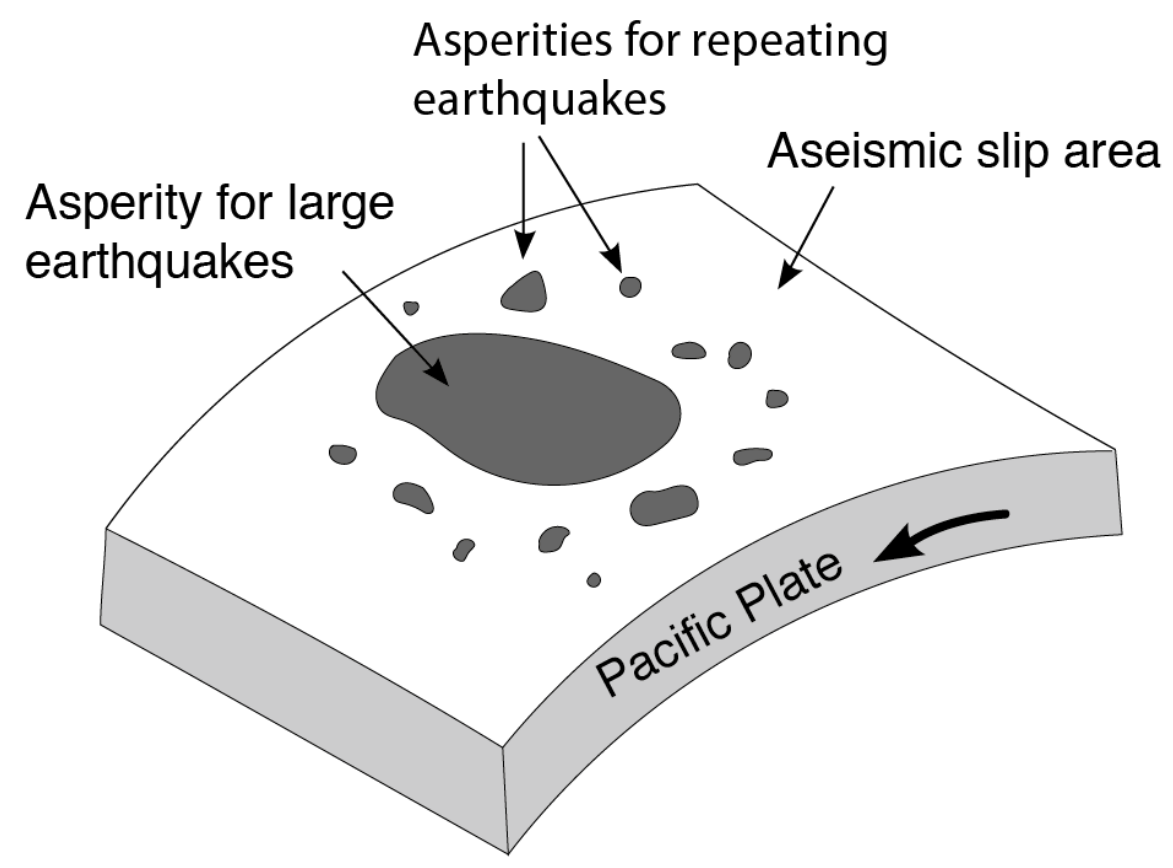

Figure 2.5: Asperity model of repeating earthquakes. Repeating earthquakes rupture locked asperities in an aseismically sliding area (creeping). Figure from Uchida et al. (2003).

least a thousand years for the shear stress to accumulate and reach $\tau_{1}$. Therefore, repeating earthquakes with recurrence intervals of a few years or less must be driven by a faster loading.

The most used model of repeating earthquakes occurrence portrays them as the rerupturing of locked asperities within an aseismically sliding (creeping) area (Figure 2.5) (Ellsworth, 1995; Nadeau and Johnson, 1998; Igarashi et al., 2003; Uchida et al., 2003; Johnson, 2010). The term asperity refers to locked patches of the fault plane that are resistive to breaking (Aki, 1984). The area of the asperity is presumed to be proportional to the size of the earthquake when it ruptures, meaning that large asperities generate large earthquakes. As illustrated in Figure 2.5, large locked asperities that previously rupture are surrounded by a creeping area with small locked asperities. According to this interpretation, repeating earthquakes are the ruptures of these small asperities (Nadeau et al., 1994; Beeler et al., 2001; Ellsworth, 1995; Igarashi et al., 2003; Uchida et al., 2003).

Some studies have proposed different rupture processes for burst- and continual-type repeating earthquakes. Continual-type repeating earthquakes are thought to rupture small asperities quasi-periodically (Ellsworth, 1995; Nadeau and Johnson, 1998; Igarashi et al., 2003; Beeler et al., 2001). When an asperity is locked, it accumulates shear stress as the surrounding area is aseismically slipping (creeping) until a critical 
threshold is reached and rupture occurs. That being so, the cumulative slip of repeating earthquakes of an asperity reflects the cumulative slip occurring in the area surrounding that asperity (Nadeau and Johnson, 1998). If the asperity always slips seismically, the amount of aseismic slip in the area surrounding the asperity can be estimated from continual-type repeating earthquakes. (Nadeau and Johnson, 1998; Nadeau and McEvilly, 1999; Igarashi et al., 2003; Uchida et al., 2003).

Burst-type repeating earthquakes can not be explained by the constant loading-rate models due to this short family durations. This may explain why burst-type repeating earthquakes have been associated with swarm activities, aftershocks of large earthquakes (e.g. Igarashi et al., 2003; Kimura et al., 2006; Templeton et al., 2008; Yao et al., 2017) and fluid intrusion (e.g. Mesimeri and Karakostas, 2018; Shaddox and Schwartz, 2019). As an example of this distinction, Mesimeri and Karakostas (2018) found streaks of continuous-type repeating earthquakes at $10 \mathrm{~km}$ depth near two mayor faults, indicating creeping along the brittle-ductile transition zone. In contrast, bursttype repeating earthquakes were associated with small fault segments dipping at high angles and triggering due to fluid intrusion.

\subsubsection{Recurrence intervals of repeating earthquakes}

On the basis that earthquake renewal processes are cyclic, the source characteristics of repeating earthquakes have long been studied in relation to their recurrence intervals times. Nadeau and Johnson (1998) developed a scaling relationship between seismic moment $\left(M_{0}\right)$ and recurrence interval $\left(T_{r}\right)$ :

$$
T_{r} \propto M_{0}^{\frac{1}{6}}
$$

According to Equation 2.5, events with larger magnitudes are expected to have longer recurrence intervals. This relationship was developed using repeating earthquakes from, California but appears to hold in other regions including Japan (Chen et al., 2007), Taiwan (Chen et al., 2007), the Tonga-Kermadec-Vanuatu subduction zones (Yu, 2013) and the Guerrero subduction zone in Mexico (Dominguez et al., 2016). The application of this relationship to the repeating earthquakes obtained in this thesis is considered in Chapter 5.

In some cases, the $M_{0}-T_{r}$ relationship does not follow Equation 2.5. Chen et al. (2010) observed that after an M6 in Parkfield, California, some families increased in seismic moment while their recurrence intervals decreased. This was interpreted as 
faster loading rates due to the nearby earthquake. This behaviour was also observed in repeating earthquake families after the M9.0 Tohoku-Oki earthquake in Japan (Uchida, 2015). Peng et al. (2005) also observed a negative dependency between $M_{0}$ and $T_{r}$ for deep $(5.5 \mathrm{~km})$ repeating earthquakes in the southern San Francisco Bay and attributed this to changes in the medium due to the postseismic period of the M6.2 Morgan Hill earthquake nearby.

The triggering of repeating earthquakes has also been observed and studied. In addition to the studies mentioned in the paragraph above, Hatakeyama et al. (2017) observed new families of repeating earthquakes located where the M9.0 Tohoku-Oki earthquake ruptured. The magnitudes of events within these families decreased over time and some families disappeared within a year. The triggering and interaction of repeating earthquakes was studied by Chen et al. (2013) using data from repeating earthquakes in Parkfield, California. Chen et al. (2013) outlined three mechanisms that could produce short apparent or actual recurrence intervals: (1) cross-triggering of closely spaced repeating asperities (e.g. Nadeau et al., 1995; Nadeau and McEvitty, 2004; Lengliné and Marsan, 2009); (2) high aseismic loading rates due to nearby large events (e.g. Vidale et al., 1994; Schaff et al., 1998); and (3) burst-type behaviour due to large nearby earthquakes (e.g. Kimura et al., 2006; Templeton et al., 2008). The recurrence intervals of repeating earthquake families have been shown to be strongly related to the regional loading rate and distribution of creep on a fault in different repeating earthquake studies around the world (Chen et al., 2013).

\subsection{Repeating earthquakes in different settings}

The faults in California have been the most studied of any in the world using repeating earthquakes. The availability of long-duration high-quality data has made it possible to record and analyse repeating earthquakes (Ellsworth, 1995). Nadeau et al. (1994, 1995); Rubin et al. (1999); Lengliné and Marsan (2009) among others, detected repeating earthquakes using correlation and coherence in the San Andreas Fault near the creeping segment at Parkfield, California. These catalogues of repeating earthquakes have since been analysed extensively: Nadeau and Johnson (1998) found that moment is being released as a function of time in a regular manner and established a relationship between recurrence interval and seismic moment. To explain this relationship, Beeler et al. (2001) proposed a stick-slip and creep-slip model which includes aseismic slip. Rubinstein and Ellsworth (2010) precisely estimated the relative size of repeating earthquakes using singular value decomposition and Abercrombie (2014) 
obtained stress drops of the repeating earthquakes. Chen et al. (2013) studied the triggering effects on repeating earthquakes from nearby seismicity and Zechar and Nadeau (2012) investigated the temporal predictability of the sequences using retrospective forecast experiments. Nomura et al. (2014) proposed a stochastic model to estimate spatiotemoral changes. Several others have calculated slow slip at depth on the San Andreas fault by using repeating earthquakes (e.g. Nadeau et al., 1994, 1995; Turner et al., 2013) and illuminated fault structure (e.g. Waldhauser et al., 2004; Rubin et al., 1999)

At the Calaveras fault, also in California, Vidale et al. (1994); Poupinet et al. (1984); Ellsworth (1995); Templeton et al. (2008) have identified sequences of repeating earthquakes. Although studies of the Calaveras fault have not yet been as extensive as those of the San Andreas fault, repeating earthquakes have been used to measure velocity changes after >M6 earthquakes (Poupinet et al., 1984; Schaff and Beroza, 2004), study variations of stress drops (Marone et al., 1995; Vidale et al., 1994), calculate fault creep (Templeton et al., 2008), to illuminate fault structure (Schaff et al., 2002) and even to correct earthquake catalogues (Rubin, 2002).

On the other side of the Pacific Ocean, repeating earthquakes have been studied in the subduction zones surrounding Japan. Repeatin earthquakes have been detected, from the Ryukyu trench at the south of the Kuril trench at the north (Igarashi, 2010) using mainly waveform similarity (e.g. Uchida et al., 2003, 2009; Igarashi et al., 2003; Kimura et al., 2006; Yamashita et al., 2012). In Japan, the application of repeating earthquakes is extensive: to study interplate coupling (e.g. Igarashi et al., 2003; Igarashi, 2010; Uchida et al., 2009; Uchida and Matsuzawa, 2011; Nomura et al., 2017), to analyse variation in creep/quasi-static slip (Uchida and Matsuzawa, 2011; Uchida, 2015, 2016) and recurrence intervals (Mavrommatis et al., 2015) before and after big earthquakes such as the Mw 9.0 Tohoku-Oki, and to estimate source parameters (Uchida et al., 2007, 2012; Uchida, 2016).

Repeating earthquakes have also been identified and studied in Taiwan (Chen et al., 2008; Chen and Lapusta, 2009), China (Schaff and Beroza, 2004; Schaff and Richards, 2011; Li et al., 2007), Turkey (Peng et al., 2005; Uchida et al., 2019), Greece (Mesimeri and Karakostas, 2018), Tonga (Yu and Wen, 2012; Yu, 2013), Mexico (Dominguez et al., 2016) and Canada (Hayward and Bostock, 2017). Repeating earthquakes have also been found in nontectonic settings: in active volcanoes, landslides, mining induced micro-earthquakes, glaciers and even on the moon (Uchida and Bürgmann, 2019). 


\section{Studies in New Zealand}

In New Zealand, few studies have yet been undertaken in relation to tectonic repeating earthquakes (Figure 2.6). Offshore the Raukumara Peninsula, Shaddox and Schwartz (2019) identified burst-type repeating earthquakes using data from ocean-bottom seismometers. These repeating earthquakes were interpreted as have been triggered by fluid migration during a plate-interface slow slip event due to being co-located within a subducted seamount fracture network. On account of this, repeating earthquakes were postulated to be seismic indicators of shallow slow slip and thus useful for identifying fracture networks. Wallace et al. (2017) identified repeating earthquakes between 2010 and 2017 near Porangahau with a possible association to nearby shallow slow slip events.

Hughes et al. (2021) is the most extensive study to date of repeating earthquakes in New Zealand, and developed a composite criterion for their detection. This criterion was used to identify repeating earthquakes in the Raukumara Peninsula. Hughes et al. (2021) then estimated some of the source properties of the identified repeating earthquakes and attempted to calculate plate-interface slip-rates. The composite criterion that Hughes et al. (2021) developed was also tested in Marlborough and Fiordland to ensure it could be applied successfully in other regions of New Zealand.

We have used the criterion developed by Hughes et al. (2021) to identify repeating earthquakes near Porangahau, Hikurangi Margin to further extend the studies of repeating earthquakes in New Zealand. 


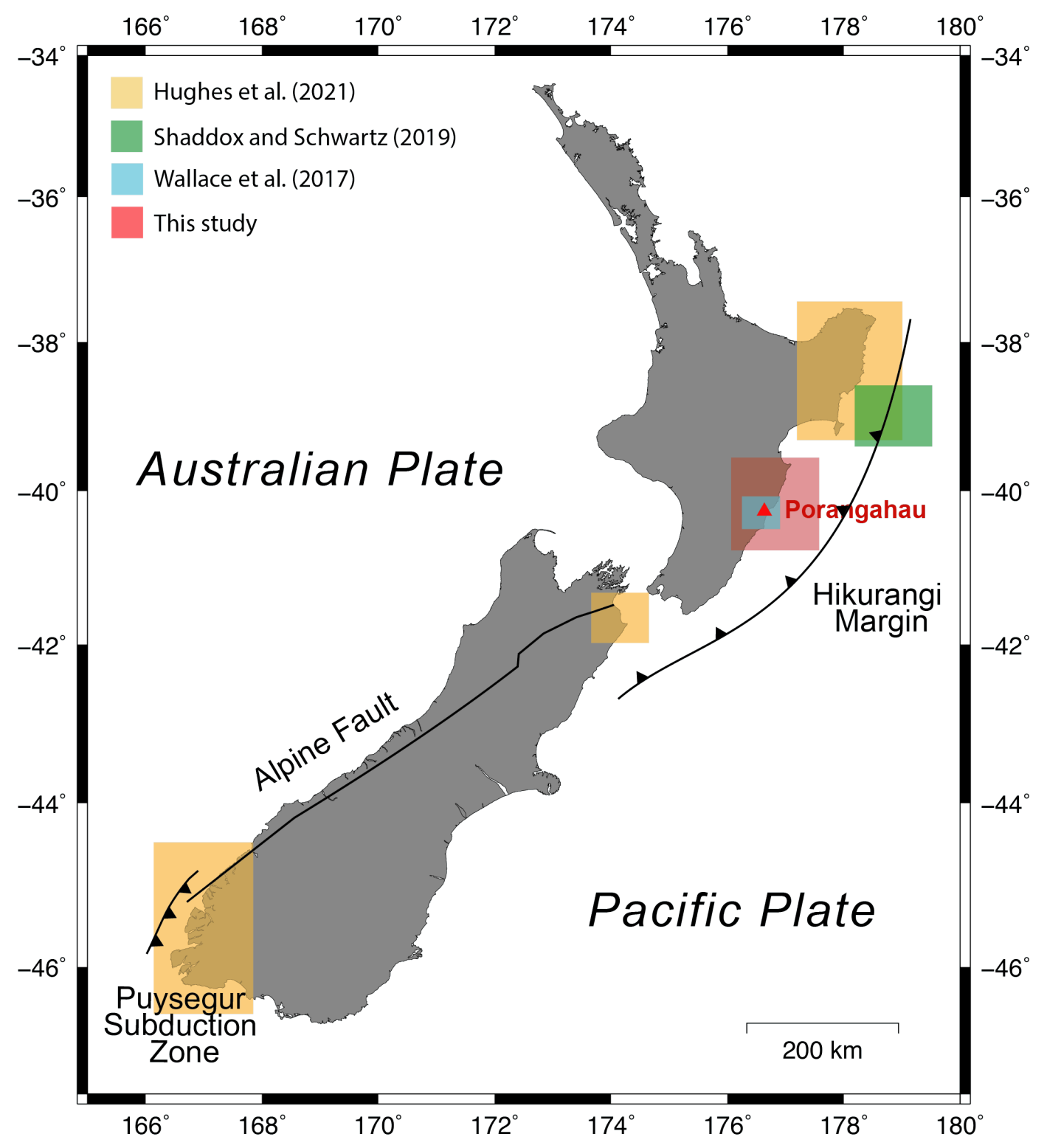

Figure 2.6: Locations of repeating earthquake studies in New Zealand. The study of Wallace et al. (2017) overlaps with the study area of this thesis. 


\section{Chapter 3}

\section{Data and Methodology}

This chapter presents the data and processes employed to construct the final catalogue of repeating earthquakes near Porangahau. In Section 3.1 we describe the data used in this study. The methodology used to identify repeating earthquakes is described in detail in Section 3.2. The clustering of events to form repeating earthquake families is outlined in Section 3.3. Section 3.4 describes the process of manual picking and polarity identification. The methodologies we used to obtain locations for all the events are described in Section 3.5, followed by the details of the magnitude calculations in Section 3.6. This chapter ends with a description of the methodology used to obtain focal mechanisms, in Section 3.7. Figure 3.1 provides a general overview of the steps undertaken:

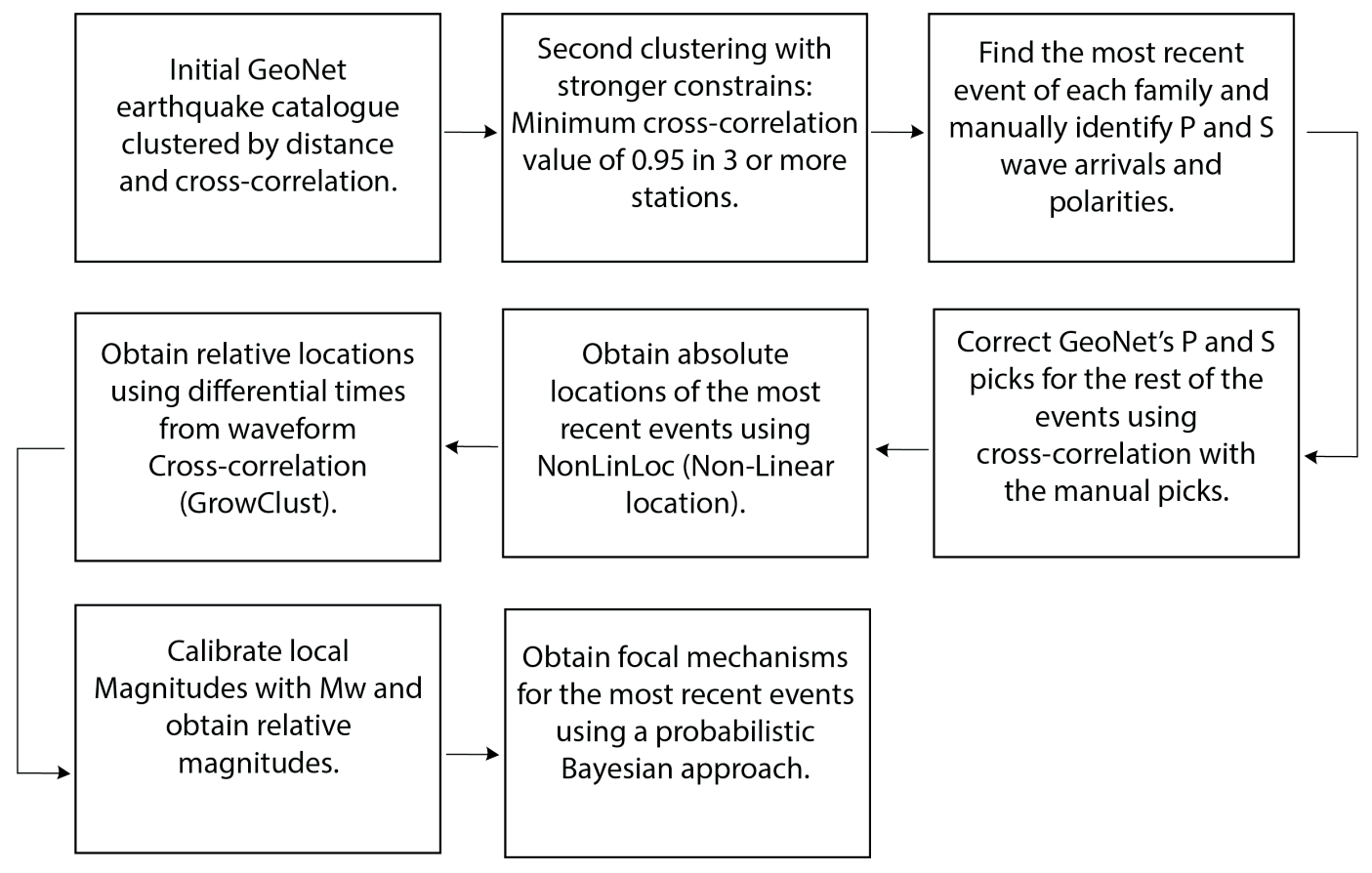

Figure 3.1: Flow diagram outlining the steps undertaken in this thesis. 


\subsection{Data}

The starting point for our analysis is a catalogue of potential repeating families for all New Zealand obtained by Chamberlain et al. (2019). This initial catalogue contains clustered events from GeoNet's catalogue (Petersen et al., 2011) identified using a composite criterion of a minimum normalized cross-correlation threshold of 0.7 and hypocentral separation of $<30 \mathrm{~km}$. This clustering was the starting point for finding repeating earthquakes in the area surrounding Porangahau.

To aid comparison between our final catalogue and the original GeoNet catalogue we maintained the GeoNet event IDs throughout our analysis. For our area of study, we selected earthquakes from the initial catalogue located within $80 \mathrm{~km}$ of the township of Porangahau (Figure 3.2) and occurring between 2004 and 2018. After selecting the events, we downloaded the waveforms that GeoNet recorded for these earthquakes using the International Federation of Digital Seismograph Networks (FDSN) service via ObsPy (Beyreuther et al., 2010). Waveforms from broadband and short-period stations located within an epicentral distance of $150 \mathrm{~km}$ were downloaded regardless of whether they had been used previously by GeoNet to obtain locations. A total of 73 stations were used (Figure 3.2), available at different periods of time and with different instrumental characteristics.

The initial catalogue details and the waveforms used to identify repeating earthquakes both come from GeoNet. As a result, the completeness of our final repeating earthquake catalogue depends directly on the completeness of GeoNet's earthquake catalogue. There have been several changes in the GeoNet seismic network within the time span of this study such as the number of stations, the type of recording instruments, the methodologies used to locate events and calculate magnitudes, velocity models, and detection methods. We are aware of these variants in GeoNet's catalogue and have taken measures to diminish their effects in the identification of repeating earthquakes. The measures taken are briefly mentioned in this chapter and later discussed in Chapter 5. 


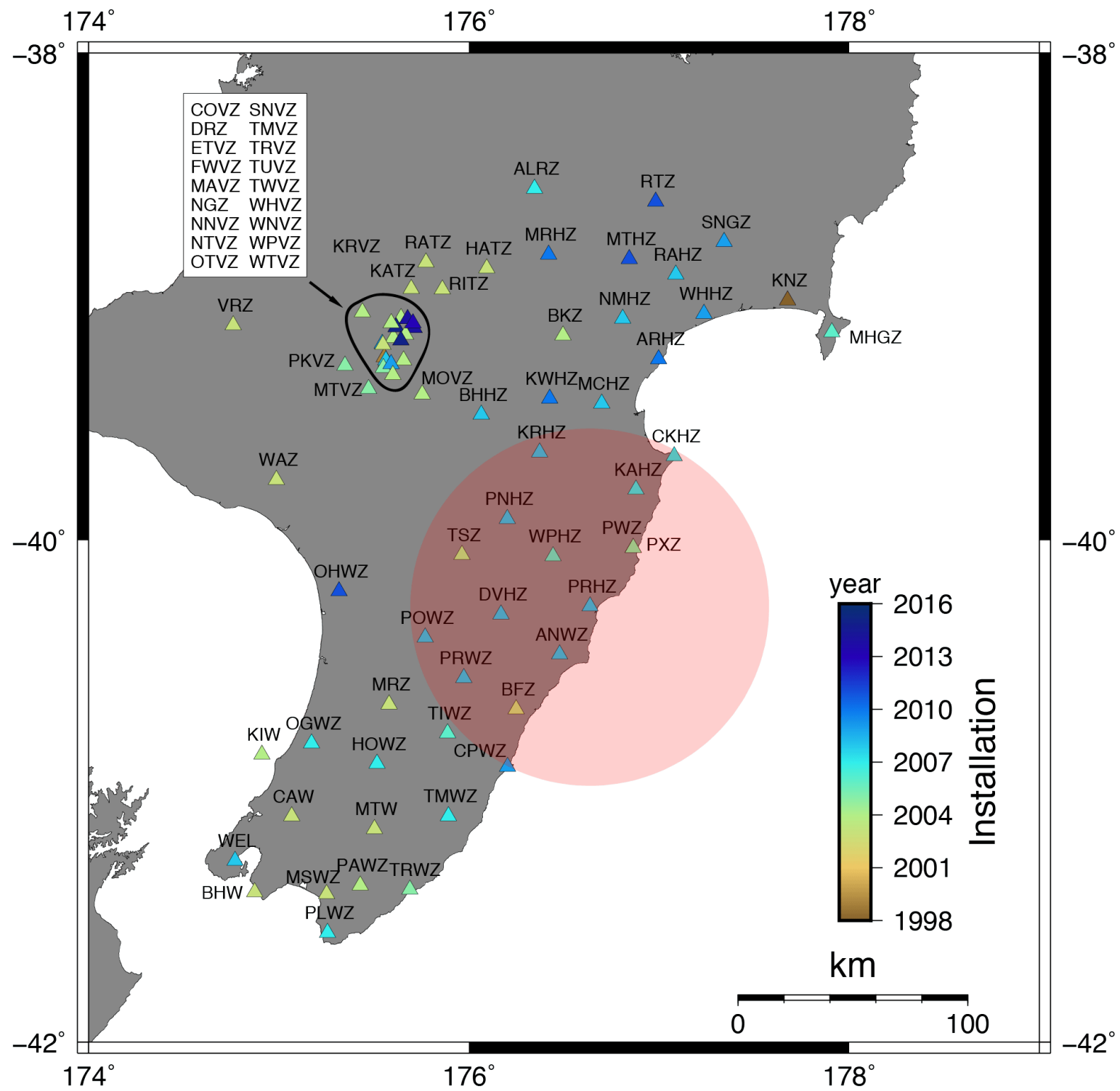

Figure 3.2: Map of the study area showing the stations in this study. Stations are coloured according to the year of installation. The circle shows the $80 \mathrm{~km}$ radius area of interest. 


\subsection{Repeating earthquake identification}

In order to identify repeating earthquakes, we have employed a cross-correlation identification method based on the work of Hughes et al. (2021) and informed by the review of previous repeating earthquake studies outlined in Section 2.2. Here, we first describe the waveform reprocessing undertaken, which includes instrument response removal, filtering, and defining the end of the signal and window length. We then detail the cross-correlation method used to identify repeating earthquakes.

As noted in the previous section, the instruments used to record earthquakes of interest near Porangahau have changed through time. As indicated by Equation 2.1, the instrument response (i.e. $i(t))$ is convolved to form the seismogram, which means that the measured waveform similarity for two truly repeating earthquakes can be affected by a change of instruments. To account for this, we removed the instrument response from the waveforms prior to correlation.

Filtering is an important operational parameter for repeating earthquake detection (Section 2.2.1). We applied a fourth-order bandpass filter between 2-20 Hz to remove the low-frequency noise from the signals while retaining the dominant seismic energy. After applying this filter, the end of the signal was determined using a signal-to-noise (SNR) ratio. We computed the SNR every sample using the root mean square (rms) amplitude of the $15 \mathrm{~s}$ signal window divided by the rms amplitude of $15 \mathrm{~s}$ of data before the P-pick (noise). The end of the signal was determined when the SNR first fell below 1.1 and remained below this for 0.5 seconds. Once we calculated the end of the signal, we identified the window length to be $75 \%$ of the signal and $1 \mathrm{~s}$ before the P-pick based on the work from Hughes et al. (2021). We established a window length of minimum $15 \mathrm{~s}$ and maximum $100 \mathrm{~s}$ for cases where the end of the signal was not found using SNR or for when the end of the signal was $>100 \mathrm{~s}$. We refer to this signal window as a template.

Prior to computing multisegment normalized cross-correlations, we aligned the templates using pick times and their maximum correlation allowing up to $0.9 \mathrm{~s}$ shift to account for uncertainty in pick times. We used the pick times reported by GeoNet to align the templates. For the templates that had no pick time from GeoNet, we used calculated expected pick times based on picks from GeoNet from the same family. We performed a multisegment normalized cross-correlation following the methodology proposed by Gao and Kao (2020). The template was divided into four equal segments and each segment was cross-correlated with the corresponding segment from the other waveform using a module in EQcorrscan (Chamberlain et al., 2018). The final cross- 
correlation coefficient was the average of the cross-correlation values obtained for the four successive segments. This procedure is illustrated in Figure 3.3. We used this approach in order to minimise bias arising due to large-amplitude phases when computing the cross-correlation (Gao and Kao, 2020). Following Hughes et al. (2021), we decided to employ a minimum cross-correlation value of 0.95 at three or more stations for earthquakes to be considered repeating earthquakes. Figure 3.4 shows the waveforms of an identified repeating earthquake family in this study. 
a)
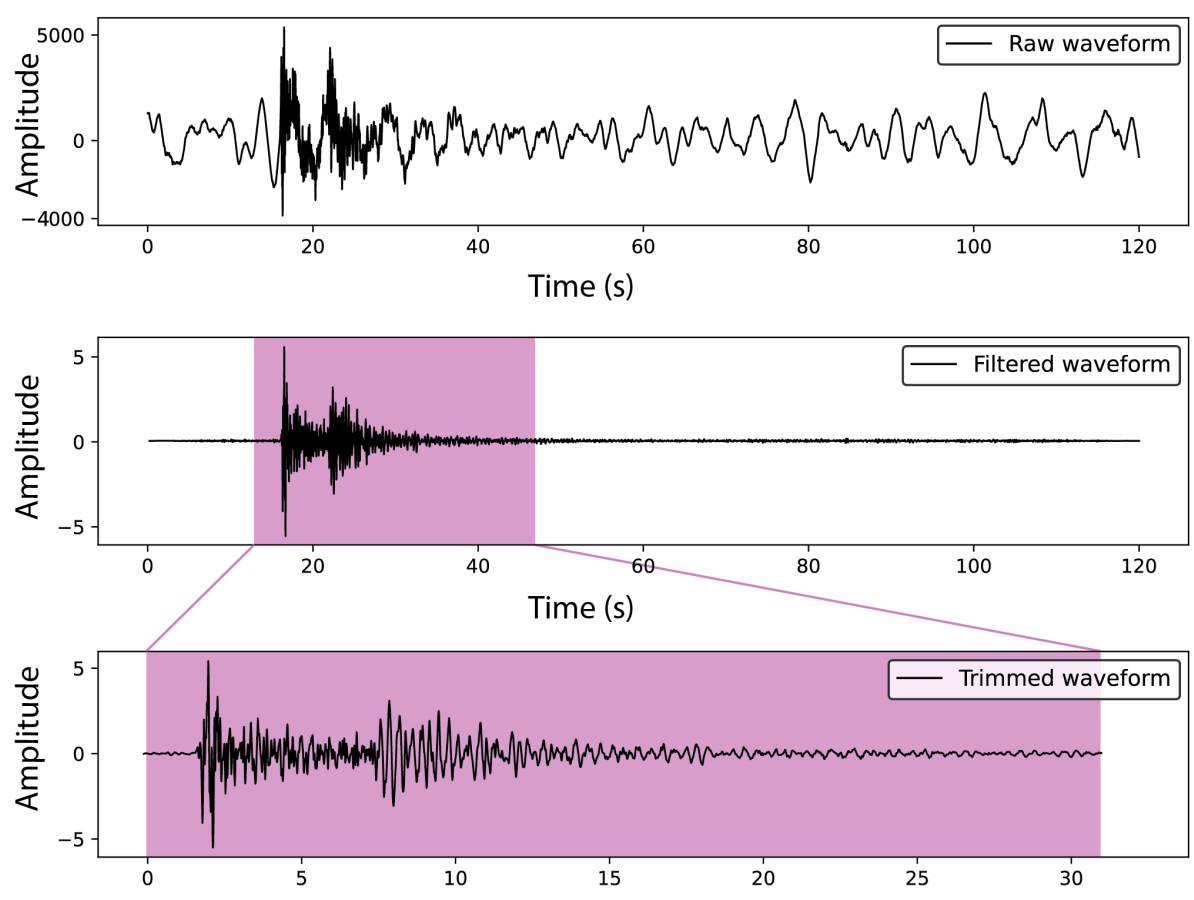

b)

Time (s)
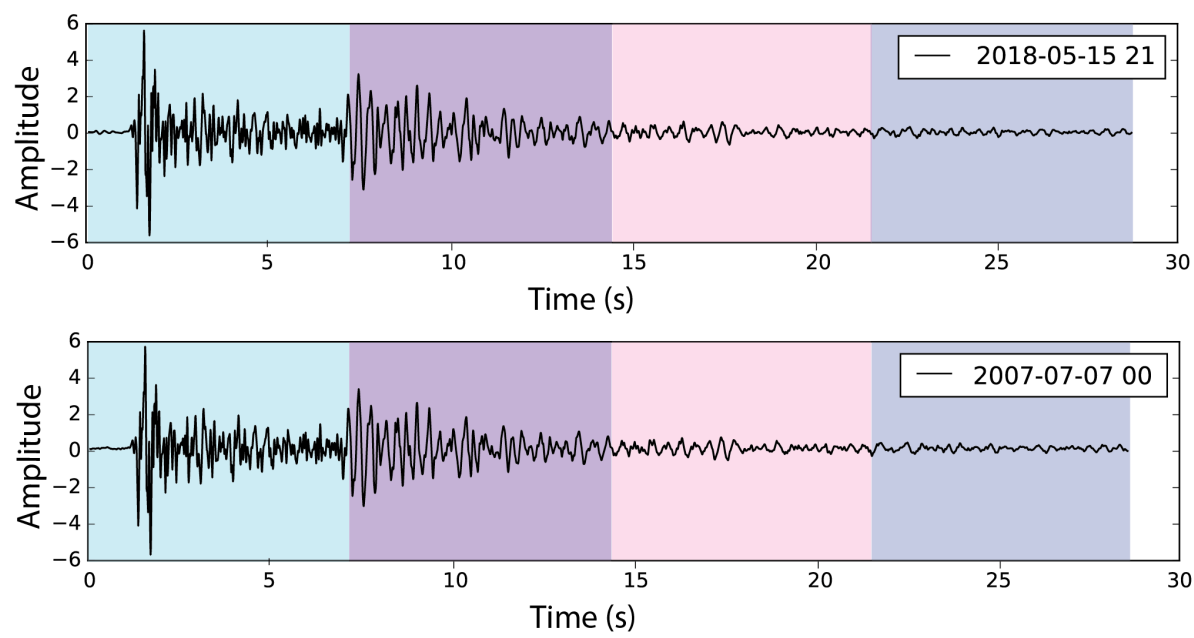

Figure 3.3: Figure illustrating waveform pre-processing (a) and multisegment normalized cross-correlation (b). a) Top: Raw waveform of event 2018p364597; Middle: Signal filtered with a $2-20 \mathrm{~Hz}$ bandpass filter and instrument response removed with a pink background indicating the trimmed waveform; Bottom: Zoom of the filtered and trimmed waveform. b) Filtered, trimmed, normalized and aligned waveforms (templates) of the same event as a) (Top) and event 2763013 (Bottom). Shaded areas indicate the template windows used in the multisegment cross-correlation, each segment with a different colour. All traces shown in this figure are vertical components recorded at station $\mathrm{PXZ}$. 

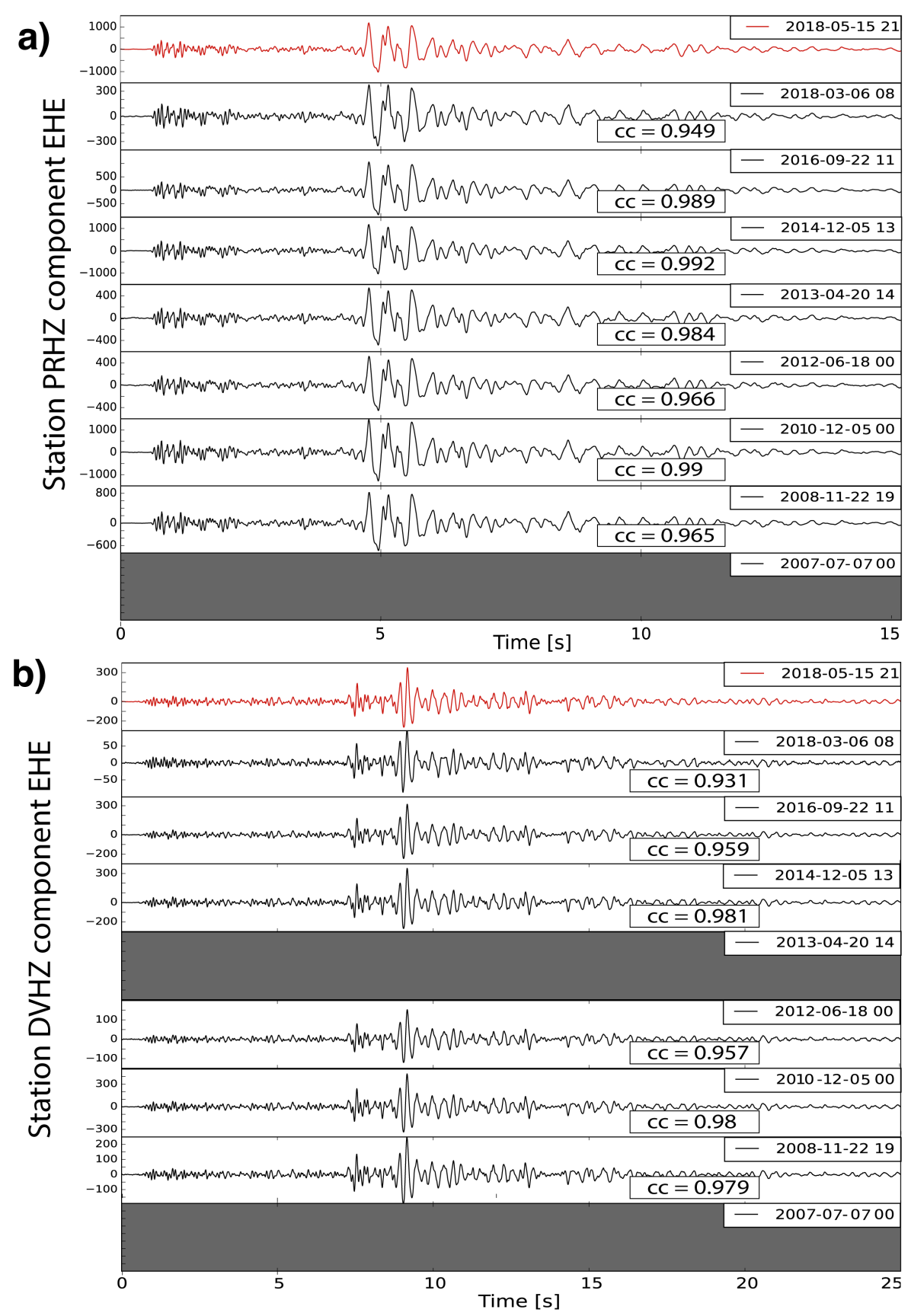

Figure 3.4: Correlated waveforms of the same family on two different stations: a) PRHZ East component and b) DVHZ East component. The red trace indicates the most recent (youngest) event of the family. Events are ordered by time with the correlation coefficients (cc) of each trace with the most recent event (red waveform). Gray backgrounds indicate that no cross-correlation was performed for that event at that station due to lack of data. This is the biggest family obtained, which consists of nine events in the lapse of 11 years (2007-2018). 


\subsection{Clustering into repeating earthquake families}

To cluster events into discrete families of repeating earthquakes, we implemented a hierarchical clustering approach using an UPGMA (Unweighted Pair Group Method with Arithmetic Mean) algorithm by (Müllner, 2011). We implemented this clustering as an extension of the methodology described by Hughes et al. (2021) because of the large number of high correlations from the initial clusters. The hierarchical clustering was implemented using the SciPy clustering package (Virtanen et al., 2020), in which a rooted tree is constructed using a distance matrix. The average correlation values across all stations were converted into a distance matrix, where high correlation values correspond to short distances. The distance matrix was used as the input data for the hierarchical clustering method. In the UPGMA algorithm, each element of the distance matrix starts as being a cluster on its own. Next, the closest two elements are joined together and the distances to the rest of the elements or clusters are recalculated by using an average of the element's distances inside the cluster. The closest clusters are joined again and the process is repeated until all elements are connected in a single cluster.

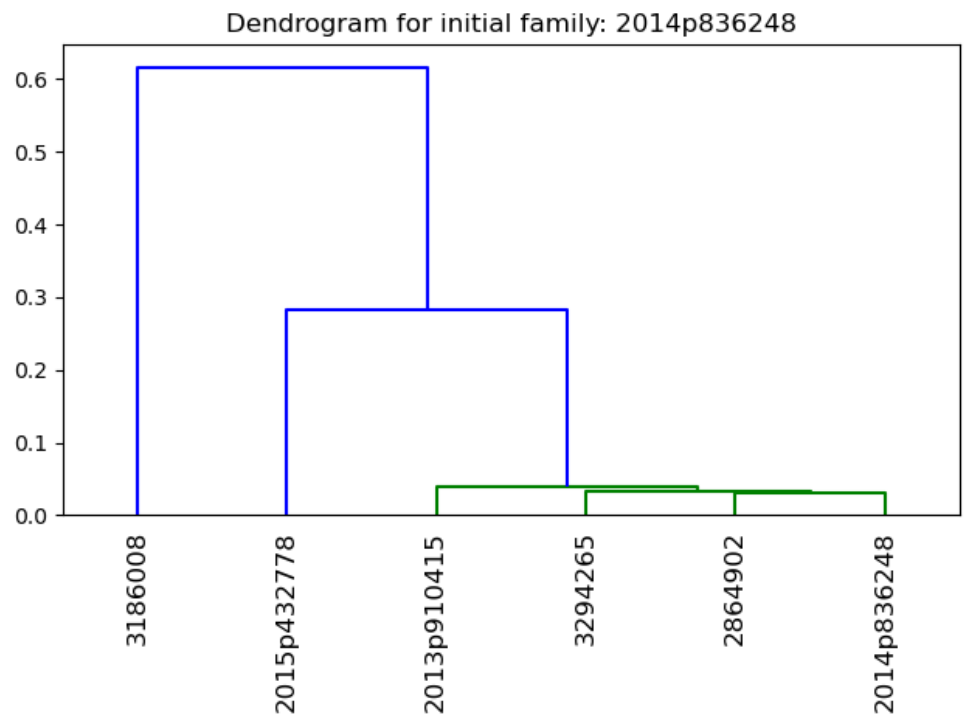

Figure 3.5: Dendrogram of an initial family showing the final clusters obtained. The two events on the left with blue branches did not pass the minimum cross-correlation threshold. The four events with green branches on the right side passed the minimum threshold and formed as a family of repeating earthquakes.

Hierarchical clustering does not determine unique clusters, as illustrated by Figure 3.5, in which the branch colours help distinguish the subtrees within a bigger cluster. SciPy includes a leaf-ordering algorithm (Bar-Joseph et al., 2001) to cluster events obtained 
from the UPGMA algorithm. These new groups or clusters constitute the repeating earthquake families, which only contain events with a minimum cross-correlation value of 0.95 at three or more stations.

Using this second leaf-ordering clustering, a total of 225 families from 2,170 initial clusters were identified. The families were grouped into geographical groups and named based on this grouping, as discussed in detail in Section 4.1.

\subsection{First arrivals and polarity identification}

To this point in the analysis, all the information about each earthquake has been provided by GeoNet. Earthquake locations calculated by GeoNet, in particular, have not been consistent though the years as location methods, velocity models and analysis methods have changed. The number of stations in the GeoNet network has been increasing though the years, which means that the most recent events are recorded on more stations and in general have more arrivals and polarities. For our catalogue to be internally consistent, we manually picked the $\mathrm{P}$ and $\mathrm{S}$ phase arrivals of the most recent event in each family. Alongside the improved consistency in phase-arrival picking, our manual phase analysis also allowed us to pick additional arrivals at stations not picked by GeoNet and to add S-arrivals, which have not been routinely picked by GeoNet in the past.

We picked a total of 4,699 P-phases and 4,680 S-phases at 73 stations using SeisAn (Havskov and Ottemöller, 1999). We also recorded confidence weights for each pick, with weights of 0 marking high-confidence picks, and weights of 4 being zero-confidence. We also manually picked $\mathrm{P}$-wave first-arrival polarities for later use in determining focal mechanisms. Figure 3.6 shows an example of high-confidence picks (weights of 0 ) on station PRHZ and lower-confidence picks (weights of 1 and 2) at TIWZ due to differences in noise. Polarities were not added to all $\mathrm{P}$ arrivals, due to the lack of clear identification of the polarity against the noise in some cases. Filters were used to aid in the identification of arrivals, but all polarities and arrivals were picked on unfiltered traces to avoid possible filter-induced phase shifts. 


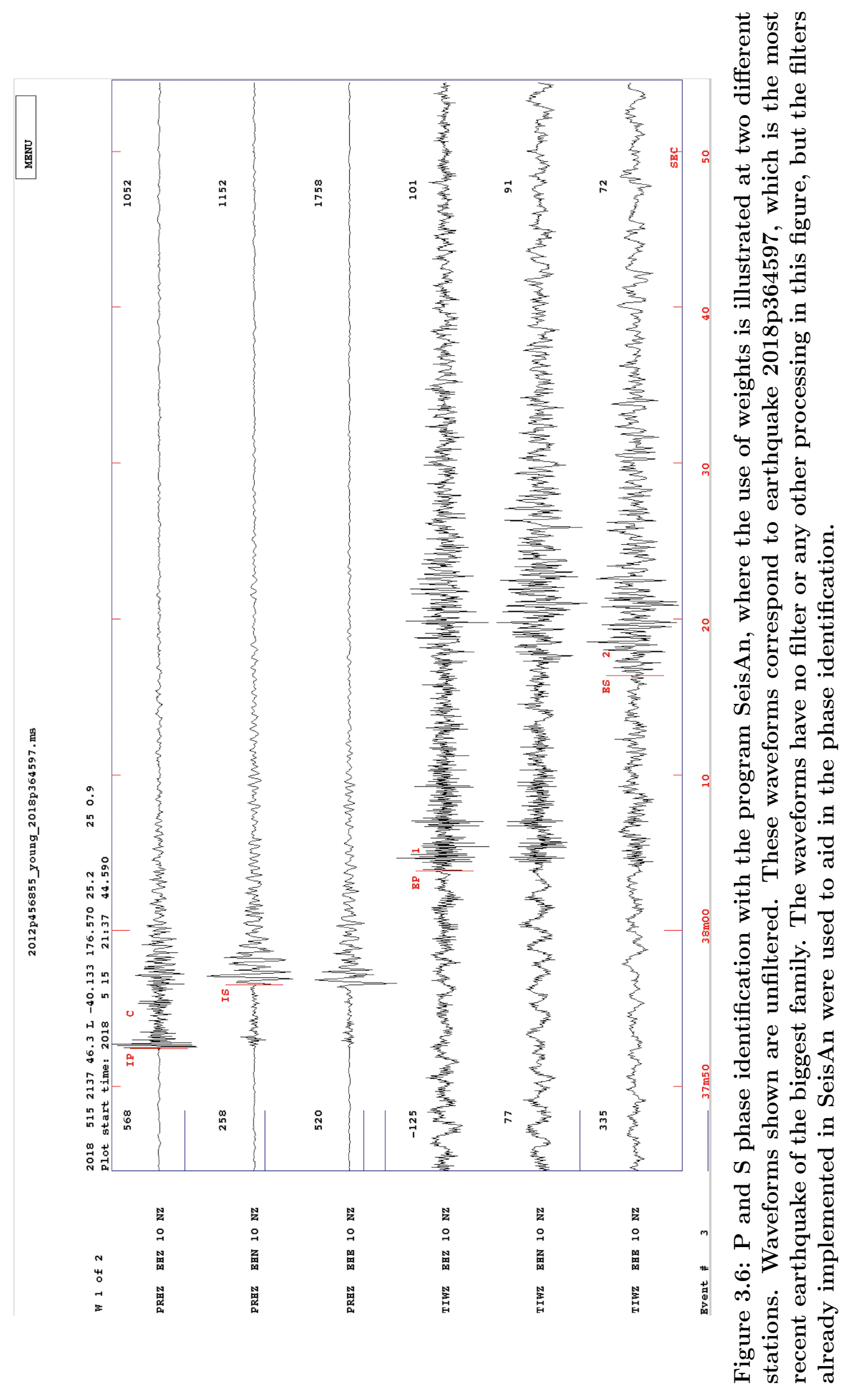




\subsubsection{Pick corrections}

Only the most recent event of each family was picked manually, leaving the remaining events in the family with the phase arrivals from GeoNet. In order to have homogeneous picks without picking manually all the events, we corrected the remaining phase arrivals from GeoNet using cross-correlation. For the picks to be corrected using crosscorrelation, they have to be from the same family, station and channel as the ones from the most recent event. For traces without GeoNet picks, temporary picks were added using the move-out from the manual pick and the origin time from GeoNet. Move-outs are the time difference between the earthquake origin time and the P-phase arrival at a station.

Using the corresponding temporary and GeoNet picks, we used a function from EQcorrscan to obtain phase arrivals relative to the most recent event picks. This function computed cross-correlation derived pick corrections following the method of Deichmann and Garcia-Fernandez (1992) to obtain sub-sample precision pick accuracy. We only retained phase arrivals when the cross-correlation value exceeded 0.4 . We chose 0.4 as a minimum value after trying different thresholds and plotting the corrected picks. We did not adopt a higher threshold because of noise in the waveforms. Figure 3.7 shows some of the final relative phase arrivals of one event. 


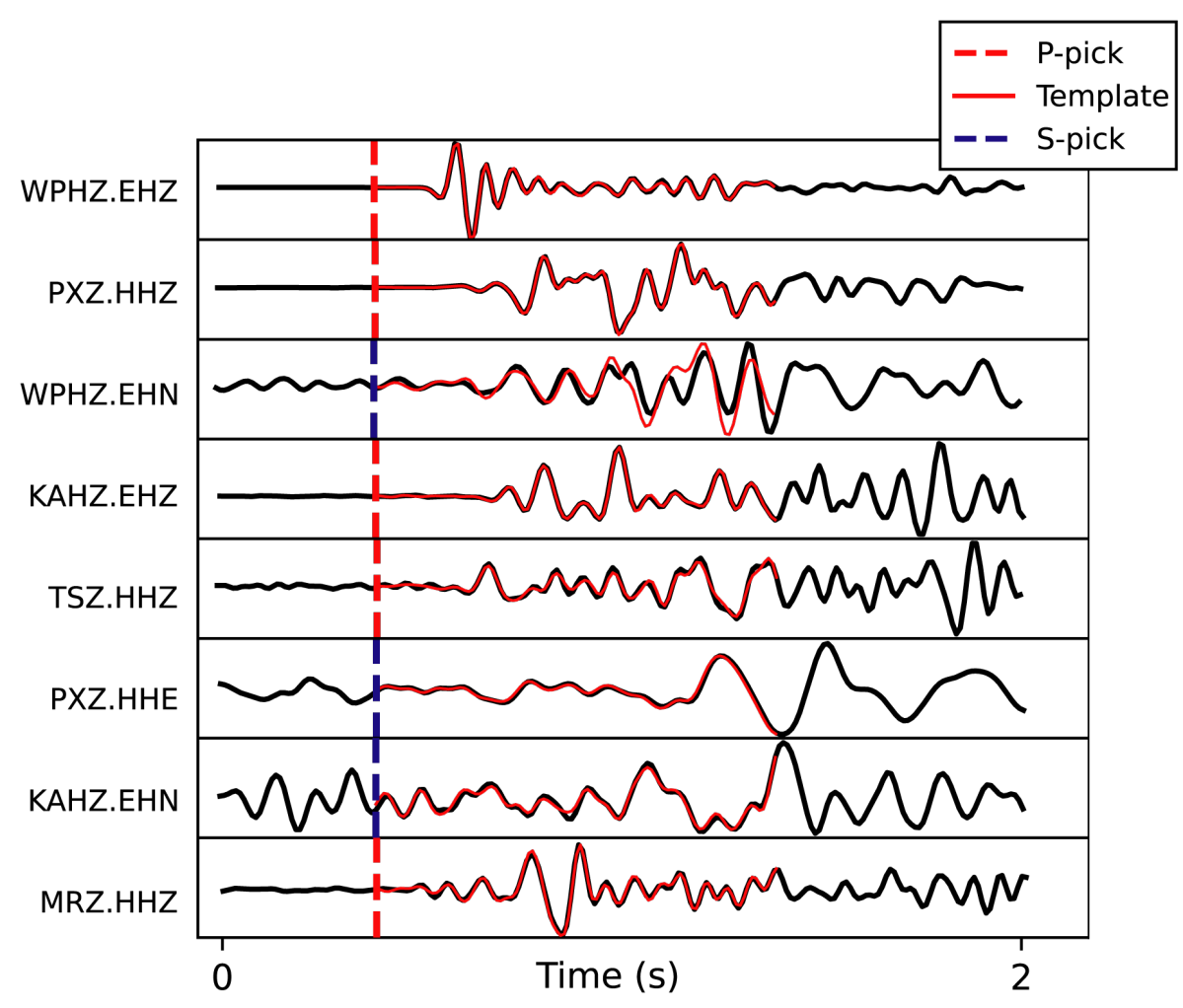

Figure 3.7: Correction of the $P$ and $S$ phase arrivals of event 2763013. The manual picks of event 2018p364597 were used as templates (red waveforms). P-pick correction was performed on the vertical component and S-pick correction on the horizontal components. This figure shows 8 of the 22 corrected traces for illustrative purposes. Waveforms are shifted and aligned on pick-time 


\subsection{Location of repeating earthquakes}

Each earthquake is parameterized by its hypocentre and origin time $(T)$. The hypocentre is the physical location: distance east $(X)$, distance north $(Y)$ and depth $(Z)$. According to Lomax et al. (2000), a location is said to be absolute when it is specified within a fixed, geographic coordinate system and a fixed time base. When the location is determined with respect to another object (e.g. another earthquake), it is said to be a relative location. Locating an earthquake and finding the origin time can be stated as an inverse problem using the first arrival times of the seismic phases recorded at several stations. The observed arrival time $(t)$ at station $i$ can be written as:

$$
t_{i}=t_{c a l c}\left(X, Y, Z, x_{i}, y_{i}, z_{i}\right)+T
$$

where $t_{\text {calc }}$ is the calculated travel time as a function of the station location $\left(x_{i}, y_{i}, z_{i}\right)$ and hypocentre location $(X, Y, Z)$ (Havskov and Ottemoller, 2010).

From Equation 3.1, we know each station location and can assume a velocity model, which leaves four unknown variables: $X, Y, Z$ and $T$. The hypocentre and origin time could be determined with only four arrival time observations, but in reality there are usually more than four stations providing $n$ equations from $n$ observations. When the number of equations surpasses the number of unknown variables, the system is overdetermined and other approach is needed to calculate an hypocentre and origin time. Although we can't obtain an exact solution, a location and time that "best" solves the over-determined, inconsistent equation can be calculated (Stein and Wysession, 2003). The "best" solution is said to be found when the sum of the square residuals $(r)$ between the observed $(t)$ and calculated $\left(t^{\text {calc }}\right)$ arrival times at each of the stations $i$ is minimized (Havskov and Ottemoller, 2010):

$$
R S S=\sum_{i} r_{i}^{2}=\sum_{i}\left(t_{i}-t_{i}^{\text {calc }}\right)^{2}
$$

Although minimizing the sum of squared residuals seems straightforward, the travel time function is a nonlinear function, which cannot, in general, be solved analytically (Havskov and Ottemoller, 2010). $\Delta X, \Delta Y, \Delta Z$, and $\Delta T$ are the adjustments to the origin time and location for the residuals to be minimized. When the adjustments are relatively small, the residual can be calculated by approximating the travel time function with the expansion of the first-order Taylor series (Equation 3.3).

$$
r_{i}=\frac{\partial t_{i}}{\partial X} \Delta X+\frac{\partial t_{i}}{\partial Y} \Delta Y+\frac{\partial t_{i}}{\partial Z} \Delta Z+\Delta T
$$


There are several methods to solve the inverse problem of locating an earthquake, including linearizing the equations and non-linear methods such as grid search or iterative methods (Havskov and Ottemoller, 2010). To obtain the absolute locations we used a probabilistic non-linear method.

\subsubsection{Absolute locations of repeating earthquakes}

For this thesis we used NonLinLoc (Lomax et al., 2000) to obtain absolute locations of the most recent earthquake of each family. NonLinLoc uses a systematic grid search algorithm to obtain a misfit function, "optimal" hypocentres, and an estimate of the posterior probability density function (PDF) for the spatial hypocentre location (Lo$\max$ et al., 2000). NonLinLoc allows the use of 3-D velocity models, which made it possible to use the NZ3D2.1 velocity model created by Eberhart-Phillips et al. (2017) without any modifications. In addition, NonLinLoc has the option of transforming the location results into geographical co-ordinates. When using a $3-\mathrm{D}$ velocity model in NonLinLoc, the travel times between each station and all the nodes of the velocity grid are calculated and stored. The gradients of travel times are then used to estimate the ray take-off angles at each node. With NonLinLoc, the PDF or misfit value is determined using a grid-search algorithm, providing a non-linear spatial solution to the earthquake location problem (Lomax et al., 2000).

To efficiently search the model-space we used the NonLinLoc Oct-Tree search algorithm which recursively subdivides and samples the grid in cells in three dimensions, computing the PDF within each cell. The cell with the largest probability is subdivided into a number of smaller cells and for each cell a PDF is computed. This process is repeated until a minimum cell size or a maximum iteration number is reached. As location method we selected an equal differential time likelihood function with weights, which reduces the $\mathrm{PDF}$ values at points with inconsistent Oct-Tree estimates and leads to more compact PDF locations (Lomax et al., 2000). With these parameters in NonLinLoc, we obtained absolute locations for all of our 225 most recent events. The input file containing the parameters used to compute the absolute locations is in Appendix B.1.

\subsubsection{Relative locations of repeating earthquakes}

We obtained relative locations for two main purposes: 1) to obtain more accurate relative locations for closely spaced repeating earthquake families; and 2) to verify that events within the same family actually had overlapping hypocentres. Relative 
locations were computed using GrowClust (Trugman and Shearer, 2017), which is a double-difference algorithm that uses differential travel times and cross-correlation in a hybrid, hierarchical clustering algorithm.

With the double difference algorithm, the relative location of an earthquake is found by minimising the double difference residual $\left(d r_{k}^{i j}\right)$ between earthquakes $i$ and $j$ for each observation at station $k$ (Equation 3.4; Waldhauser and Ellsworth (2000)):

$$
d r_{k}^{i j}=\left(t_{k}^{i}-t_{k}^{j}\right)^{c a l c}-\left(t_{k}^{i}-t_{k}^{j}\right)^{o b s}
$$

Equation 3.4 strongly depends on the assumption that the travel paths for both events are similar and does not work when events are not close enough. The change in hypocentral distance between events $i$ and $j$ can be obtained with the following equation:

$$
d r_{k}^{i j}=\frac{\delta t_{k}^{i}}{\delta x} \Delta x^{i}+\frac{\delta t_{k}^{i}}{\delta y} \Delta y^{i}+\frac{\delta t_{k}^{i}}{\delta z} \Delta z^{i}+\delta \tau^{i}-\frac{\delta t_{k}^{j}}{\delta x} \Delta x^{j}-\frac{\delta t_{k}^{j}}{\delta y} \Delta y^{j}-\frac{\delta t_{k}^{j}}{\delta z} \Delta z^{j}-\delta \tau^{j}
$$

where $t$ is the travel times vector of events $i$ and $j$ with locations $x, y$ and $z$ and origin times $\tau$ (Waldhauser and Ellsworth, 2000). $\delta x, \delta x, \delta x$ and $\delta x$ are the changes needed in the hypocentral parameters for the model to better fit the data. These changes are calculated using linear techniques for all stations and hypocentral pairs (Waldhauser and Ellsworth, 2000).

GrowCLust uses the L1 norm for residual minimisation which is less sensitive to outliers in comparison to the L2 norms used in other algorithms. However, one disadvantage we encountered is that GrowClust is currently only able to use 1-D velocity models. The differential travel times are obtained from the cross-correlation of pairs of events registered at the same stations. The calculations to obtain the differential travel times from cross-correlation, were obtained using EQcorrscan functions from the package catalog_to_dd. These functions allowed us to compute cross-correlations between events and to obtain their respective differential-times required as input for GrowClust. For GrowClust we set a minimum cross-correlation coefficient of 0.5, a maximum station distance of $100 \mathrm{~km}$ and a maximum root-mean-square error of $0.5 \mathrm{~s}$. The arrival times are weighted by the correlation values. The input file containing the parameters used to compute the relative locations is in Appendix B.2

The input to GrowClust was a catalogue of all the repeating events, including the most recent ones which had absolute locations. For the events without absolute location, we set their initial location to be the absolute location of the most recent event in the 
same family. GrowClust relocated the initial hypocentres using differential times from waveform cross-correlation, providing relative locations for 304 out of the 307 events that did not have an absolute location.

\subsection{Local magnitude calculation}

The magnitude of an earthquake is used to quantify its size (Stein and Wysession, 2003; Lay and Wallace, 1995). Amplitudes of seismic phases have been used to obtain magnitudes (e.g. Richter, 1935): when using phase amplitudes, the bigger the amplitude, the bigger the size of the earthquake. However, this is only true when the waveforms have been corrected for attenuation and geometric spreading (Stein and Wysession, 2003) and until the values reach a saturation magnitude. One way to construct a magnitude scale is the following (Stein and Wysession, 2003):

$$
M=\log (A / T)_{\max }+F(h, \Delta)+C
$$

where $A$ is the amplitude of the signal, $T$ is the period of the signal, $F$ is a correction for earthquake depth $(h)$ and epicentral distance $(\Delta)$ and $C$ is a regional scale factor (Stein and Wysession, 2003; Lay and Wallace, 1995).

Richter (1935) was the first to introduce the concept of magnitude scale with the local magnitude $M_{L}$ or the "Richter scale". This magnitude scale was designed for earthquakes with hypocentres in southern California that were recorded on a WoodAnderson seismograph. By using equation 3.7, the relative size of an event is calculated by comparison to a reference event:

$$
M_{L}=\log A(\Delta)-\log A_{0}(\Delta)+S
$$

where $A$ is the maximum amplitude recorded at a Wood-Anderson seismometer, $A_{0}$ is the maximum amplitude of the reference event, $\Delta$ is the epicentral distance and $S$ is a correction factor for the station. The reference event has $M_{L}=0$ and was chosen by Richter so that $A_{0}$ (maximum amplitude) was $1 \times 10^{-3} \mathrm{~m}$ at an epicentral distance of 100 km (Richter, 1935; Gutenberg and Richter, 1942; Lay and Wallace, 1995).

Although we are not working with earthquakes from southern California recorded on Wood-Anderson seismometers, we can obtain a local scaled magnitude (Gutenberg and 
Richter, 1942) for our earthquakes using equation 3.8 (Havskov and Ottemoller, 2010):

$$
M_{L}=\log A(\Delta)+a \log (\Delta)+b \Delta+S
$$

where $A$ is the observed amplitude and $a, b$, and $S$ are constants representing geometric dispersion (here assumed to be 1 ), attenuation and station correction term, respectively.

We followed a procedure similar to that described by Boese et al. (2012) to obtain local magnitudes calibrated with moment magnitude $M_{w}$. To find appropriate values for $a, b$, and $S$ for the Porangahau study region, we compared the amplitudes of our most recent events against moment magnitudes obtained using moment tensor inversion from GeoNet (Ristau, 2013). As none of the repeating earthquakes in our catalogue had moment tensor results, we selected 41 earthquakes located in our study area (Figure 3.8) with magnitudes similar to those in our our catalogue. The minimum magnitude from our catalogue was $M_{L} 1.2$ and the maximum $M_{L} 3.8$ using GeoNet's reported local magnitudes. The range we selected for magnitudes with moment tensors was $M_{L} 3.4$ to $M_{L}$ 5.2. As moment tensors are not calculated for all the earthquakes GeoNet reports, we were not able to find earthquakes with lower magnitudes than 3.4 in our area of study. We manually picked the earthquakes with moment tensors and obtained amplitudes for all events. The amplitudes were picked automatically on the horizontal component using the manual S phase pick as a reference.

After obtaining the amplitudes, we inverted Equation 3.8 by solving the general inverse problem using LU-matrix factorization:

$$
Y=X m+e
$$

Y includes the amplitudes of all events and the 41 GeoNet moment magnitudes $\left(M_{w}\right)$. $\mathrm{X}$ is a matrix representing which component of each station has an amplitude reading and which events have moment magnitudes. $m$ are the parameters of interest: $M_{L}$, attenuation term $b$ and the station corrections terms $S$. The last term $e$ is the vector of magnitude residuals (Boese et al., 2012).

Appendix A.2 contains a table with the station correction terms from the inversion. Next, we obtained relative magnitudes for the rest of the events within a family using the calibrated local magnitudes. This process was carried out using EQcorrscan function relative_magnitude with a minimum cross-correlation threshold of 0.5 following the method of Schaff and Richards (2014).

Since magnitudes are empirical estimates of earthquake size and they do not have a 


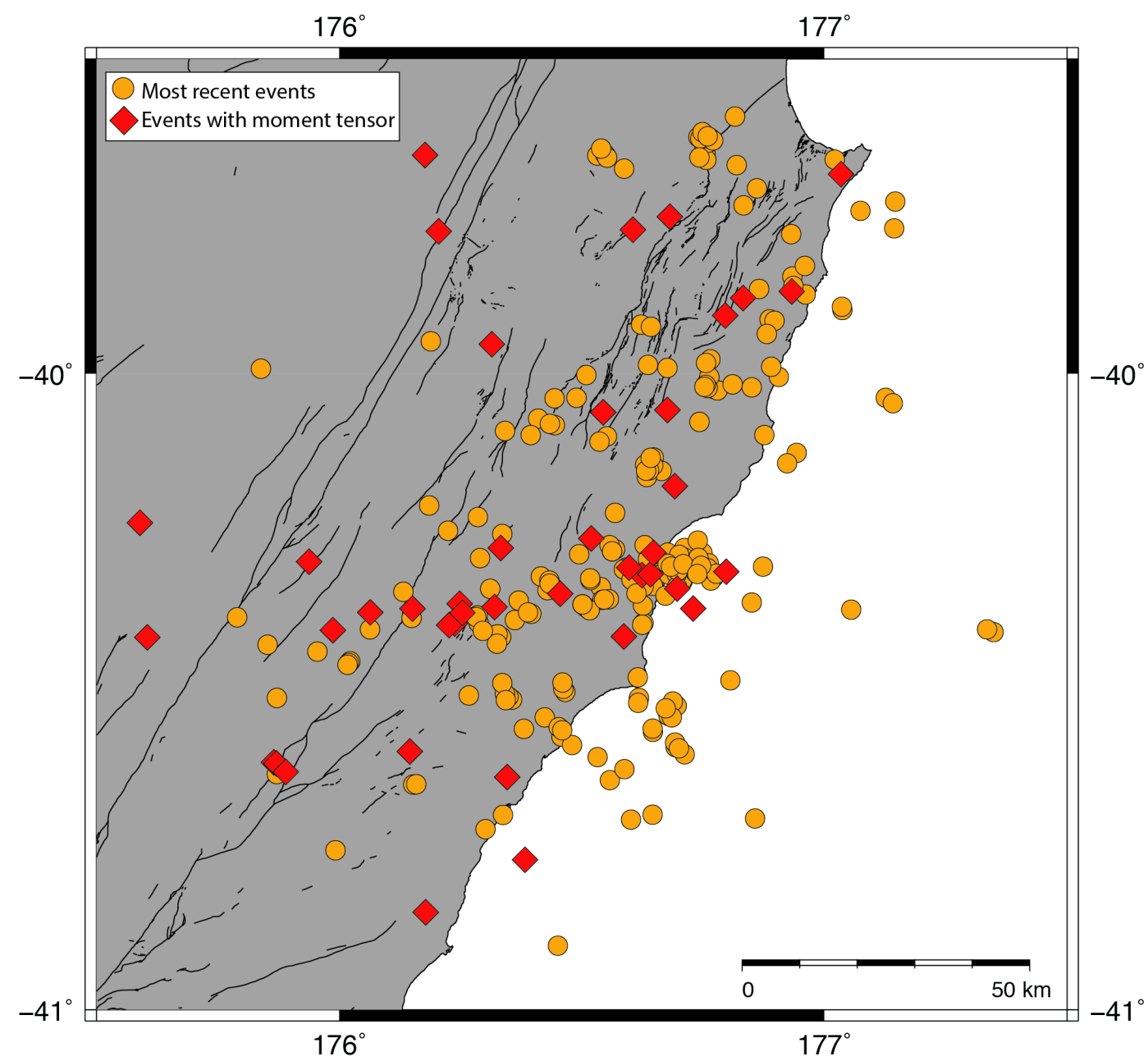

Figure 3.8: Map with the locations of the 41 earthquakes used to calibrate the local magnitudes as red diamonds. Absolute locations of the most recent events are shown as orange circles. 
direct connection to the physics of an earthquake, the size and energy release of an earthquake is best represented by the scalar seismic moment $\left(M_{0}\right)$ (Stein and Wysession, 2003; Lay and Wallace, 1995). Seismic moment is directly related to the size of the earthquake and can be expressed in terms of the rigidity $(\mu)$, average slip $(\bar{D})$ and fault area $(S)$ :

$$
M_{0}=\mu \bar{D} S
$$

$M_{0}$ has been used previously to obtain seismic moment-recurrence intervals for repeating earthquakes as seen in Nadeau and Johnson (1998). In order to use this relationship to analyse our repeating earthquakes, we estimated seismic moments using equation 3.11, after Hanks and Kanamori (1979), which indicates the relationship between seismic moment $\left(M_{0}\right)$ in dyne-cm and moment magnitude $\left(M_{w}\right)$ :

$$
\log \left(M_{0}\right)=16.1+1.5 M_{w}
$$

Since we calibrated our local magnitudes with moment magnitude, using Equation 3.11 to obtain seismic moment is a valid approach. We discuss the seismic momentrecurrence intervals of our repeating earthquakes in Chapter 5.

\subsection{Focal mechanism calculation}

A focal mechanism describes the geometry of the fault based on the radiation pattern of the earthquake that it produced (Havskov and Ottemoller, 2010; Stein and Wysession, 2003). For simplicity, earthquakes are assumed to occur on a planar surface whose geometry can be described with three angular parameters: strike $(\phi)$, dip $(\delta)$ and rake $(\lambda)$. When recording an earthquake on a network of seismometers, the polarities of the $\mathrm{P}$-wave first arrivals contain information on the geometry of faulting and can be used to determine the focal mechanism (Stein and Wysession, 2003). If the side of the fault moves towards a particular station, the resulting $\mathrm{P}$-wave first motion will be compressional $(C)$ and if it moves away from the station, it will be dilatational $(D)$.

For this study, we used the fault-motion polarities obtained in Section 3.4 to calculate focal mechanisms for the most recent events using the probabilistic Bayesian method of Walsh et al. (2009). This method accommodates uncertainties arising from errors in location and take-off angles, as illustrated in Figure 3.9. We use the absolute locations and take-off angles calculated in Section 4.2.1 to account for those errors. With this methodology, fault plane solutions were calculated for all the most recent events. In 
Section 4.4 we elaborate on our criteria for selecting the well-constrained focal mechanisms to constitute our final catalogue.

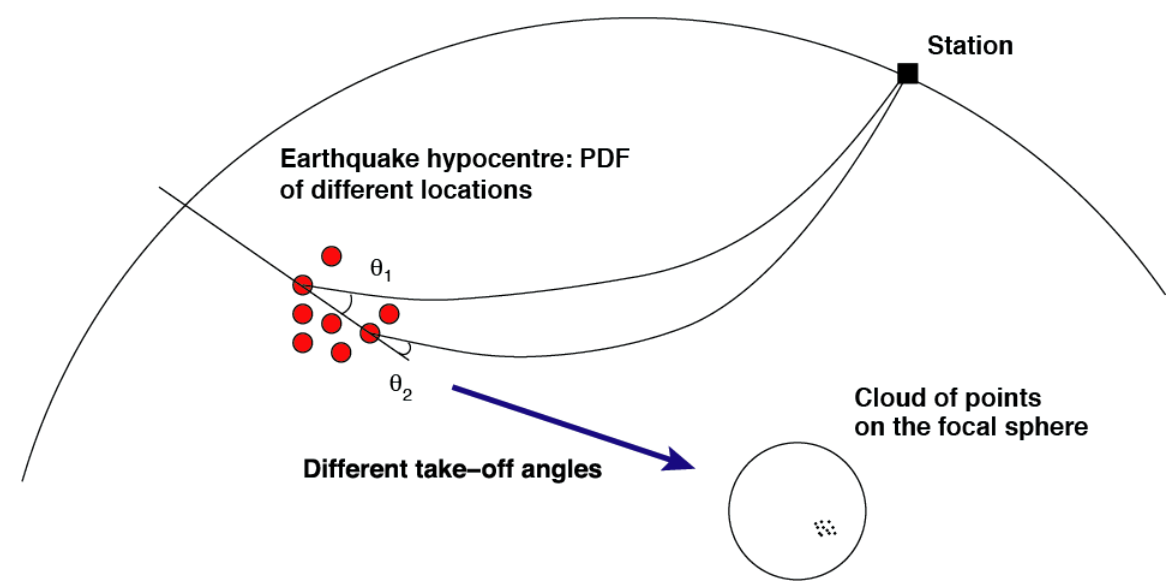

Figure 3.9: Diagram illustrating different take-off angles due to the uncertainties in P-wave arrival times. Different arrival times lead to different possible earthquake locations, each with its own take-off angle. Figure from Walsh et al. (2009). 


\section{Chapter 4}

\section{Results}

This chapter presents the main results of this research. Section 4.1 gives a brief summary of the repeating earthquakes detected and the geographic groupings to which they were assigned. Next, Section 4.2 documents the absolute and relative locations obtained. Section 4.3 addresses the calculated magnitudes, and Section 4.4 outlines the repeating earthquakes' focal mechanisms. The chapter ends with a summary of the results, in Section 4.5.

\subsection{Nomenclature of repeating earthquake families}

We identified 225 repeating earthquakes families from 2,170 initial clusters occurring between 2004 and 2018, using the methodologies described in Sections 3.2 and 3.3. The total number of events contained in the families is 532, with most families containing only two events. Families were divided into 16 geographical groups based on the most recent event's location (latitude, longitude and depth) as shown in Figure 4.1. The geographical groups were created primarily to easily refer to each family. The grouping of families was subjective, according to how close families were to each other and their depth. The names of each group correspond to nearby places, except for the offshore groups that are named after sea animals ${ }^{1}$ in Te Reo Māori. Each family is referred to using the geographical group and a chronological number based on the most recent event's origin time. For example, family CT01 belongs to the Cape Turnagain group and the most recent event in the family occurred in 2018, later than all other events in the Cape Turnagain group. Appendix A.1 contains key information about each repeating earthquake family including its geographical group, number of events, mean

1 "Aihe" means dolphin, "petipeti" is jellyfish, and "toroa" is albatross in Te Reo Māori 
location, mean magnitude, focal mechanism and location from Section 5.2. Further details of each event is provided in the QUAKEML file in the electronic appendix.

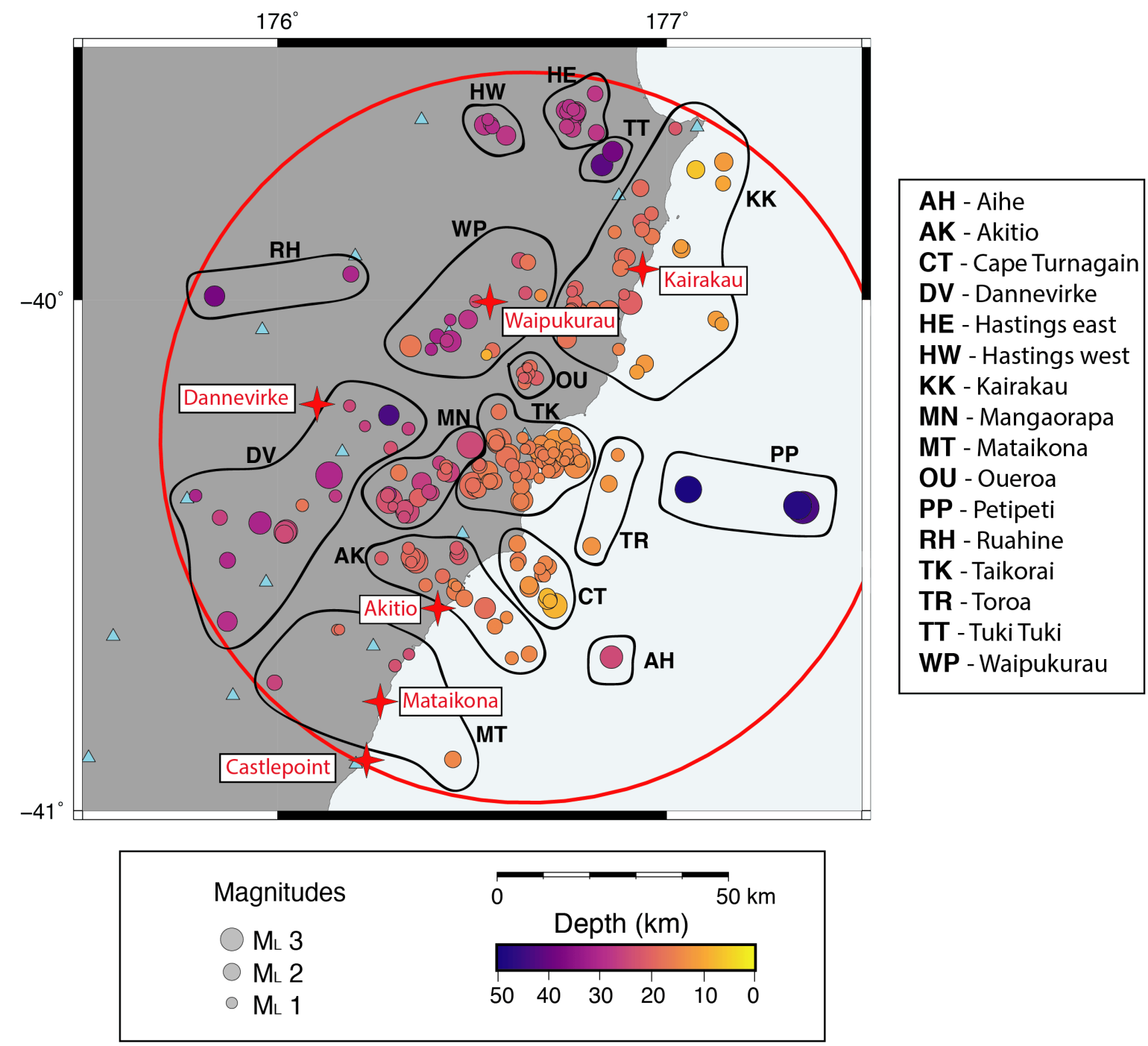

Figure 4.1: Map showing the location of the most recent event of each family and the geographical groups formed based on these locations. Black lines delineate the assigned boundaries for each group. Red stars represent some of the places used to name the groups and the red circle indicates the area of study. The box on the right contains the 16 group names and the two-letter codes used for the family nomenclature. 


\subsection{Repeating earthquake locations}

\subsubsection{Absolute locations}

We calculated absolute locations using NonLinLoc (Lomax et al., 2000) for the most recent event in each family. Figure 4.2 shows the locations obtained in a map of the study area and five cross-sections perpendicular to the subduction interface. Some differences amongst the groups can be observed: for example, repeating earthquakes are most densely concentrated near the township of Porangahau, with the Taikorai Group (TK) containing 62 families, the Akitio Group (AK) containing 20, and the Mangaorapa Group (MN) 18. The Kairakau (KK) and Oueroa (OU) groups also contain a large number of families, with 33 and 10 families respectively. Other groups located further inland, such as Mataikona (MT), Dannevirke (DV) and Waipukurau (WP), have events significantly more scattered in comparison. Families belonging to the Petipeti Group (PP) stand out for having depths between 40 and $60 \mathrm{~km}$, making them both the deepest events and the farthest from the subduction interface (see crosssection B-B' (Figure 4.2)). Families TT01, TT02 and DV02 are the deepest families located onshore, with mean depths between 38 and $43 \mathrm{~km}$. In comparison, the two families that form the Ruahine Group (RH) have depths of 38 and $30 \mathrm{~km}$ and are located further inland.

Most of the family groups can be recognised as distinct in the cross-sections shown in Figure 4.2, especially in cross-sections A-A' and E-E' which contain the fewest families. Cross-sections B-B', C-C' and D-D' cross through where the majority of the families are located. These three cross-sections reveal that families belonging to the Kairakau (KK), Oueroa (OU), Taikorai (TK), Mangaroapa (MN), Akitio (AK), Toroa (TR) and Cape Turnagain (CT) groups, have similar depths to the subduction interface model obtained by Williams et al. (2013).

The uncertainties in the absolute locations are summarised in Table 4.1. These errors use the travel time residuals for the standard error and the confidence ellipsoid for the horizontal uncertainties and depth error (Lomax et al., 2000). The confidence ellipsoid is an ellipsoidal Gaussian approximation to the hypocentre Probability Density Function (PDF) at the $68 \%$ confidence level. This means that there is a $68 \%$ probability that the hypocentre is inside the ellipsoid (Lomax et al., 2000). The largest error obtained was $9.12 \mathrm{~km}$ and corresponds to the depth uncertainty of the most recent event of family PP02. Family PP02 is the furthest offshore and consequently the family furthest from the stations. In comparison, the most recent event of family 


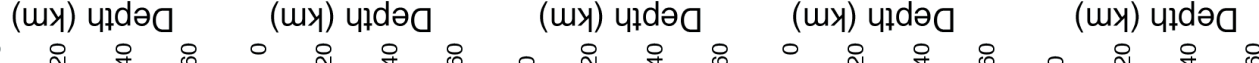
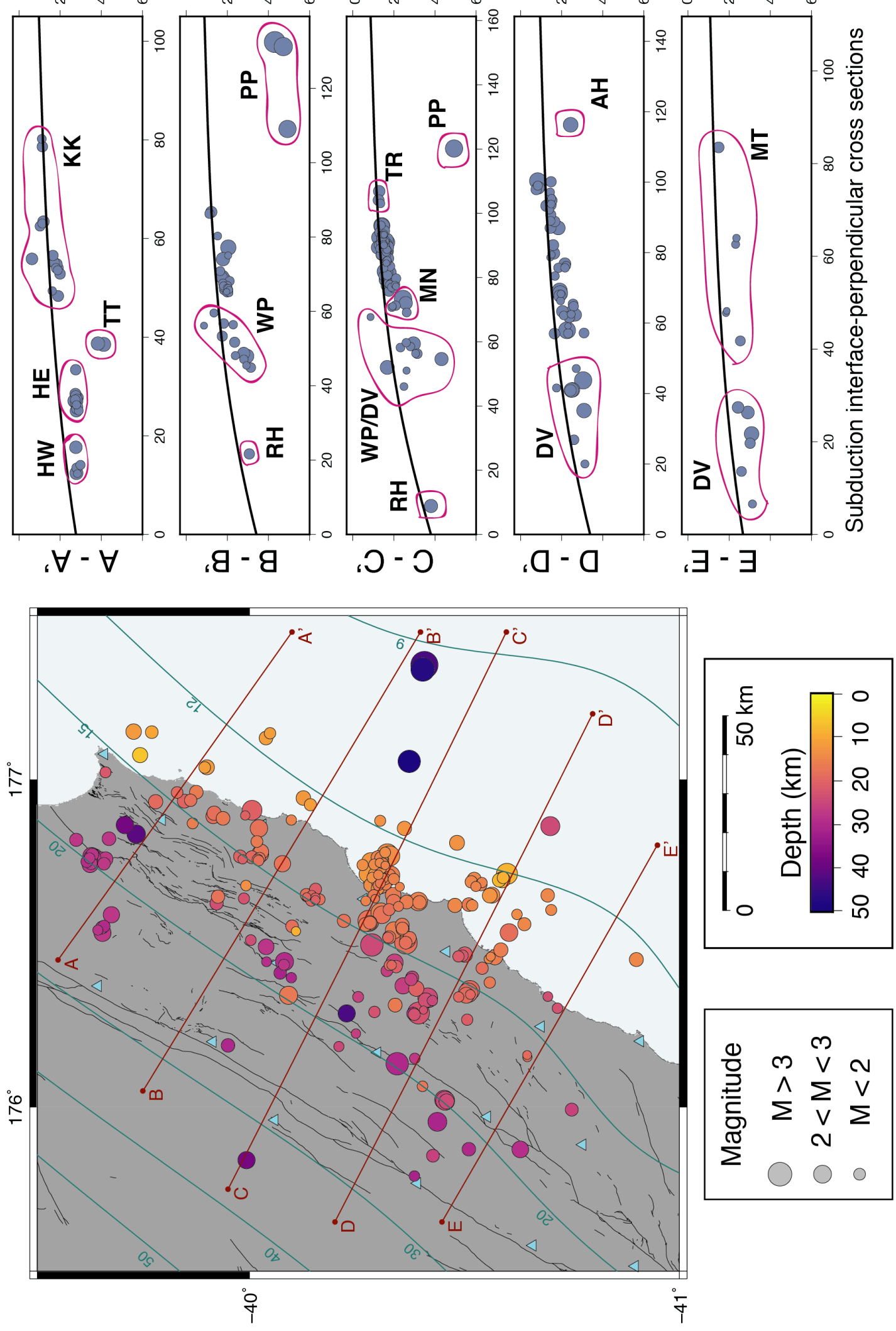

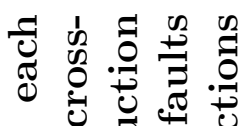

$\Xi 00$

艺

ชี

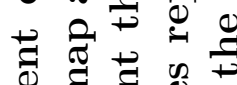

仓

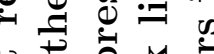

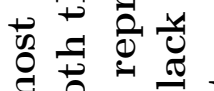

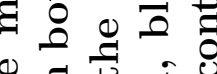

쿼

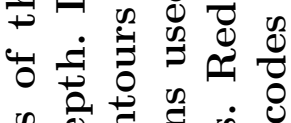

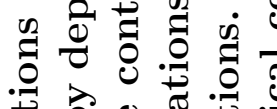

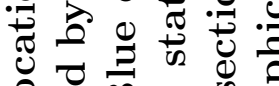

○ ग

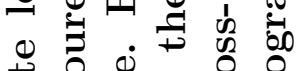

$\stackrel{0}{\doteq} \frac{0}{0}$

० 0.

कै

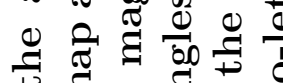

凹

约

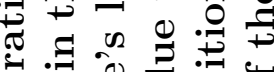

की

党

크 혁 항

โิ

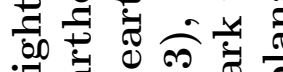

$\exists$ ॠ

so

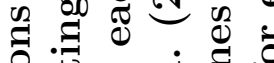

.

过

क ग ठ 0

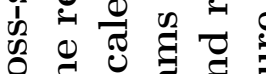

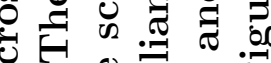

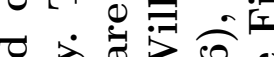

$\exists=0$

ส छ

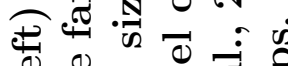

象

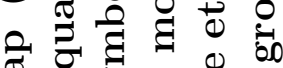

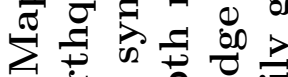

สี

ن $8 \%$ क

अ

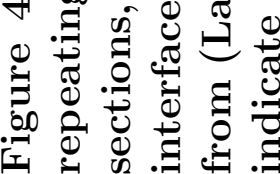


Table 4.1: Summary of errors associated with the absolute locations obtained using NonLinLoc. Horizontal uncertainties and depth error are in kilometers.

\begin{tabular}{lccc}
\hline & Minimum & Maximum & Average \\
\hline Standard error $(\mathrm{s})$ & 0.18 & 0.77 & 0.43 \\
Maximum horizontal uncertainty $(\mathrm{km})$ & 1.77 & 8.61 & 3.68 \\
Minimum horizontal uncertainty $(\mathrm{km})$ & 1.23 & 5.47 & 2.17 \\
Depth error $(\mathrm{km})$ & 1.24 & 9.12 & 2.31 \\
\hline
\end{tabular}

DV05, located inland and well within the network, has both the minimum depth error and minimum horizontal uncertainty of 1.24 and $1.23 \mathrm{~km}$, respectively.

Figure 4.3 shows the distributions of the hypocentre probability density function scatter samples and represents the uncertainty of the spatial solution arising from picking errors, travel-time calculation errors, the geometry of the observing network, and incompatibility of the picks (Lomax et al., 2000). The optimal hypocentres are shown as black crosses and correspond to the location with the minimum misfit. The scatter samples in the map and cross-sections show how locations are better-constrained for events closer to the stations. That is, the volume of the hypocentral PDF increases the further offshore the event is located.

\subsubsection{Relative locations}

We obtained relative locations using GrowClust (Trugman and Shearer, 2017) for the 307 events that were not picked manually. Three events were not well correlated with events outside of their family and could not be relocated; their assumed final locations are taken directly from the GeoNet catalogue. Figure 4.4 shows the absolute and relative locations in a map and five cross-sections perpendicular to the subduction interface. From the map and cross-section, we can see that the relative locations mostly overlay the absolute ones. A summary of the errors associated with the relative locations is presented in Table 4.2. The standard error refers to the root-mean-square residual differential travel time residual and the horizontal and depth errors correspond to median absolute deviations of the bootstrap distribution (Trugman and Shearer, 2017). 


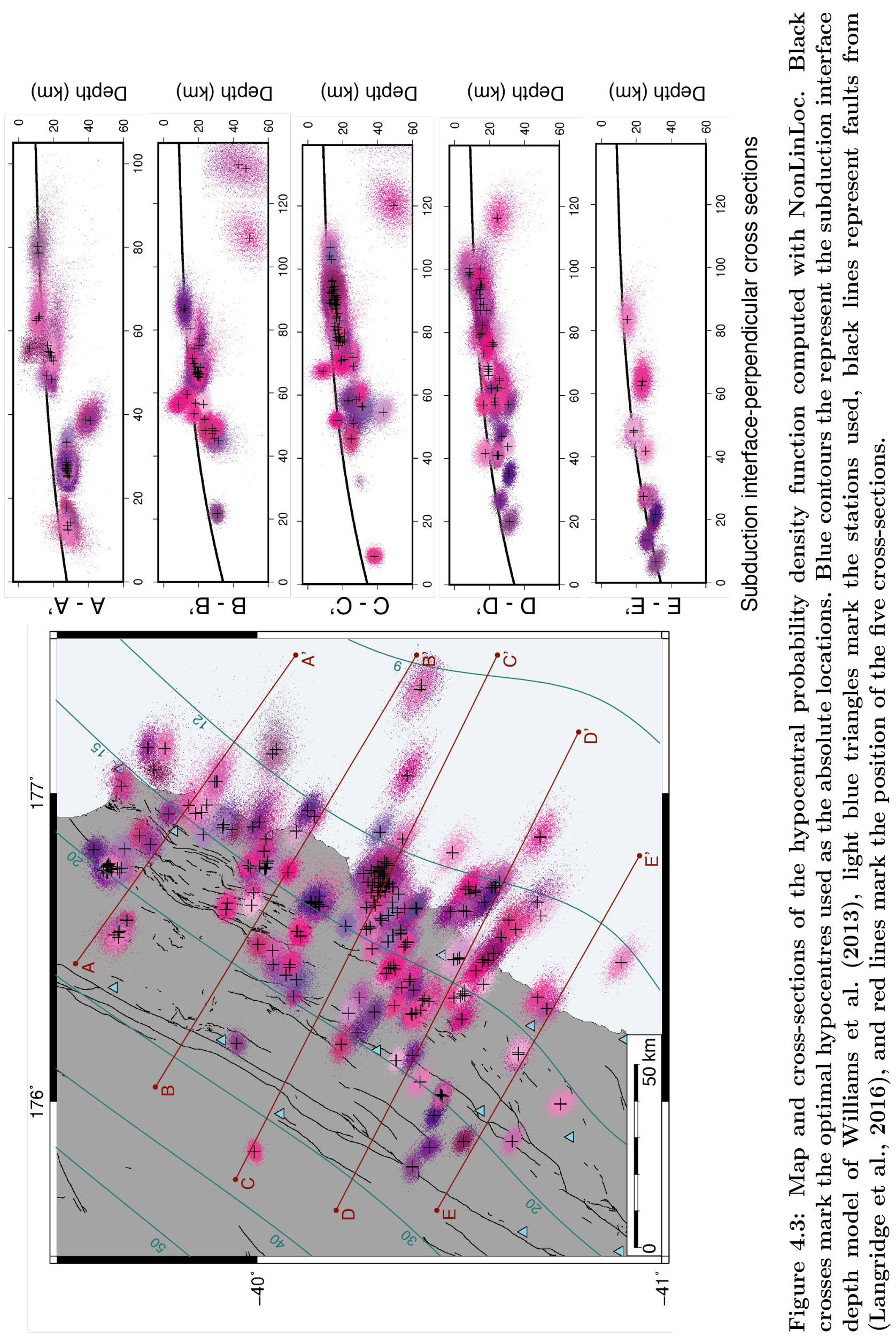




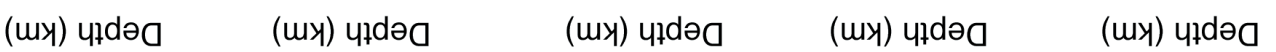
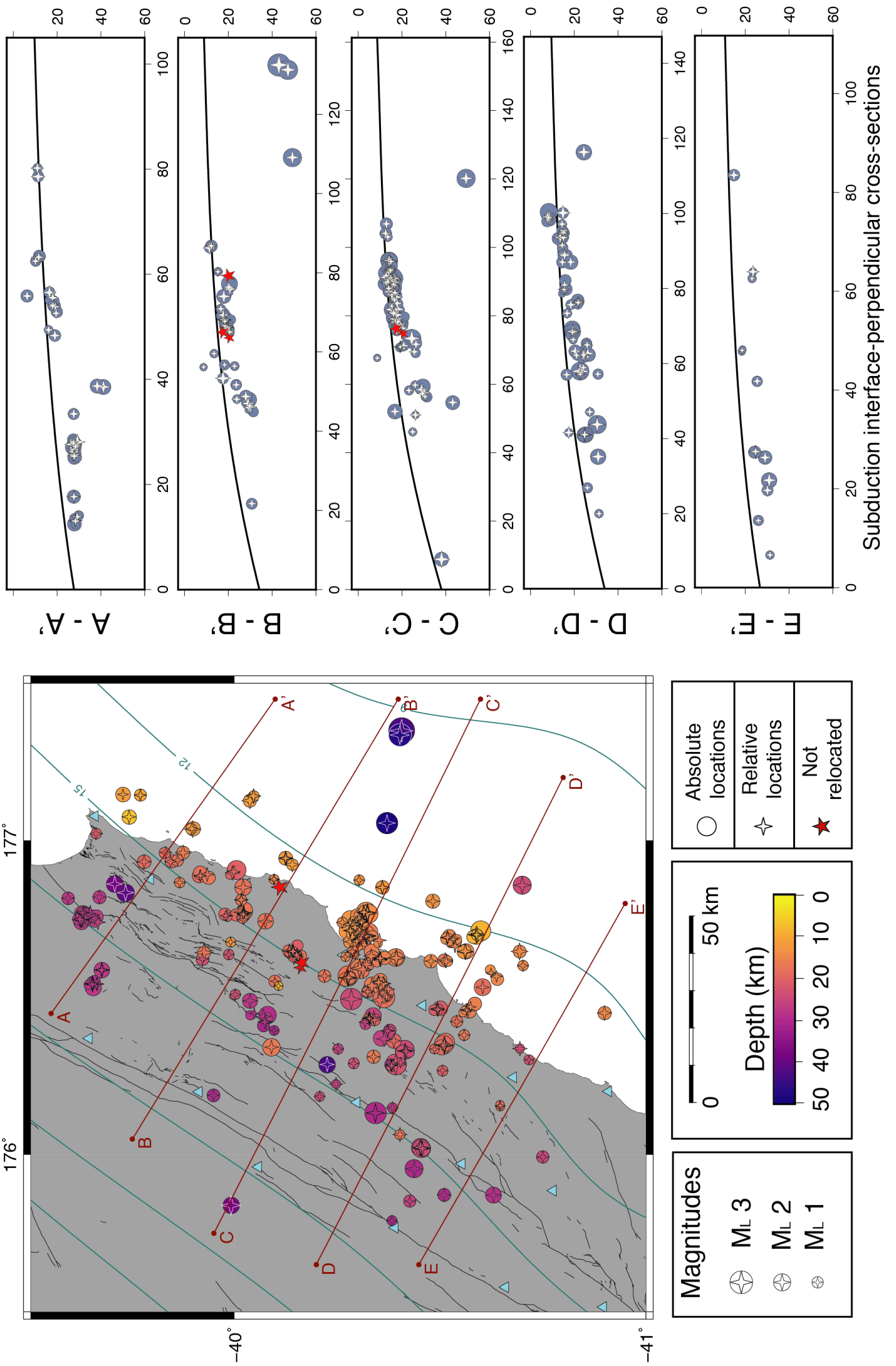

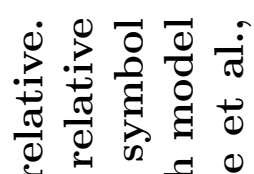

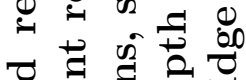

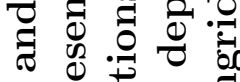
०

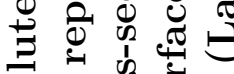
on on

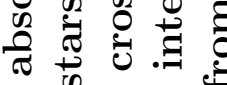
궁. 范

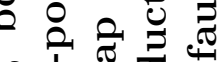
ติ .

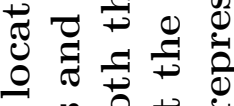
음용 远.

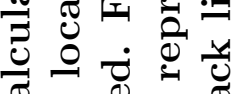
ชั 킁 品 ๙ .

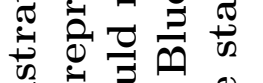

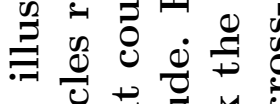

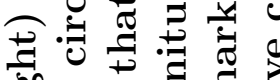
. 㱐劳

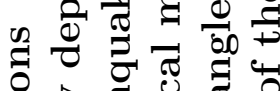

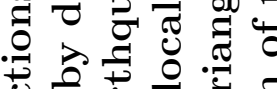

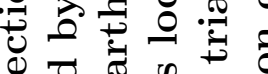
क की 원

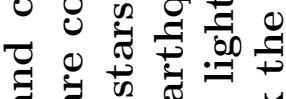
สี

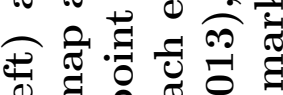

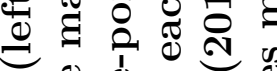
สิ

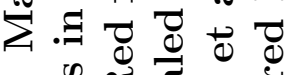
ㅂ.

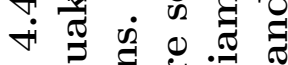

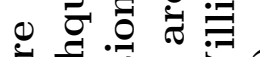

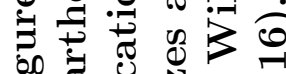
杢雳气 
Table 4.2: Summary of standard errors associated with the relative locations obtained using GrowClust. Horizontal and depth errors are in kilometers.

\begin{tabular}{lccc}
\hline & Minimum & Maximum & Average \\
\hline Standard error $(\mathrm{s})$ & 0.20 & 2.27 & 0.81 \\
Horizontal error $(\mathrm{km})$ & 0.001 & 1.06 & 0.15 \\
Depth error $(\mathrm{km})$ & 0.001 & 0.63 & 0.075 \\
\hline
\end{tabular}

\subsection{Repeating earthquake magnitudes}

Section 3.6 describes the procedure we followed to calculate calibrated local magnitudes for the most recent events and relative magnitudes for the rest. The magnitudes of all the events range between $M_{L} 1.2$ and 3.9. Figure 4.5 shows the distribution of magnitudes through time and their marginal distribution in a histogram. The histogram has a left-skewed shape with the peak close to $M_{L} 2.0$, which indicates that the mean magnitude is bigger than the median and the mode. The time plot shows how the magnitudes in the repeating earthquake catalogue have varied through time, as an example, it is interesting to note that we have very few earthquakes with magnitudes smaller than $M_{L} 2.0$ before 2008. What stands out most from the time plot is the number of repeating earthquakes between late 2008 and mid 2010 and the low magnitudes of these events. This is further discussed in the next chapter.

Of the 225 families, eight contain five or more events whose magnitude variability is shown in Figure 4.6. Family HW02 (coloured purple in Figure 4.6) has a mean magnitude of $M_{L} 1.8$ with the event magnitudes having little variation through the period analysed. In comparison, families HW04 (yellow) and TK17 (olive) have magnitudes that vary significantly through time. The histogram in Figure 4.7 shows the difference between magnitudes and the family mean, with ranges between -0.6 and 0.6. The histogram tends to be bell-shaped with a peak close to zero. This indicates that the magnitude difference's mean, median and mode are similar. 


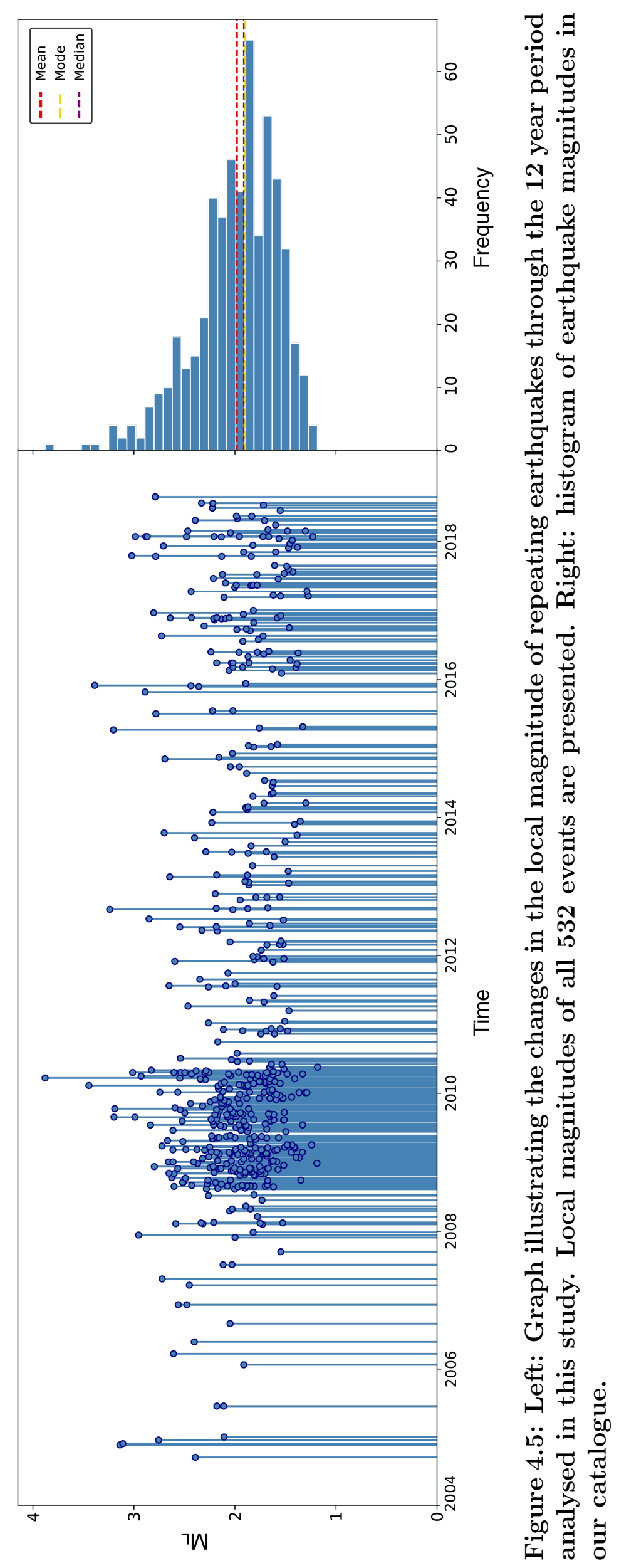




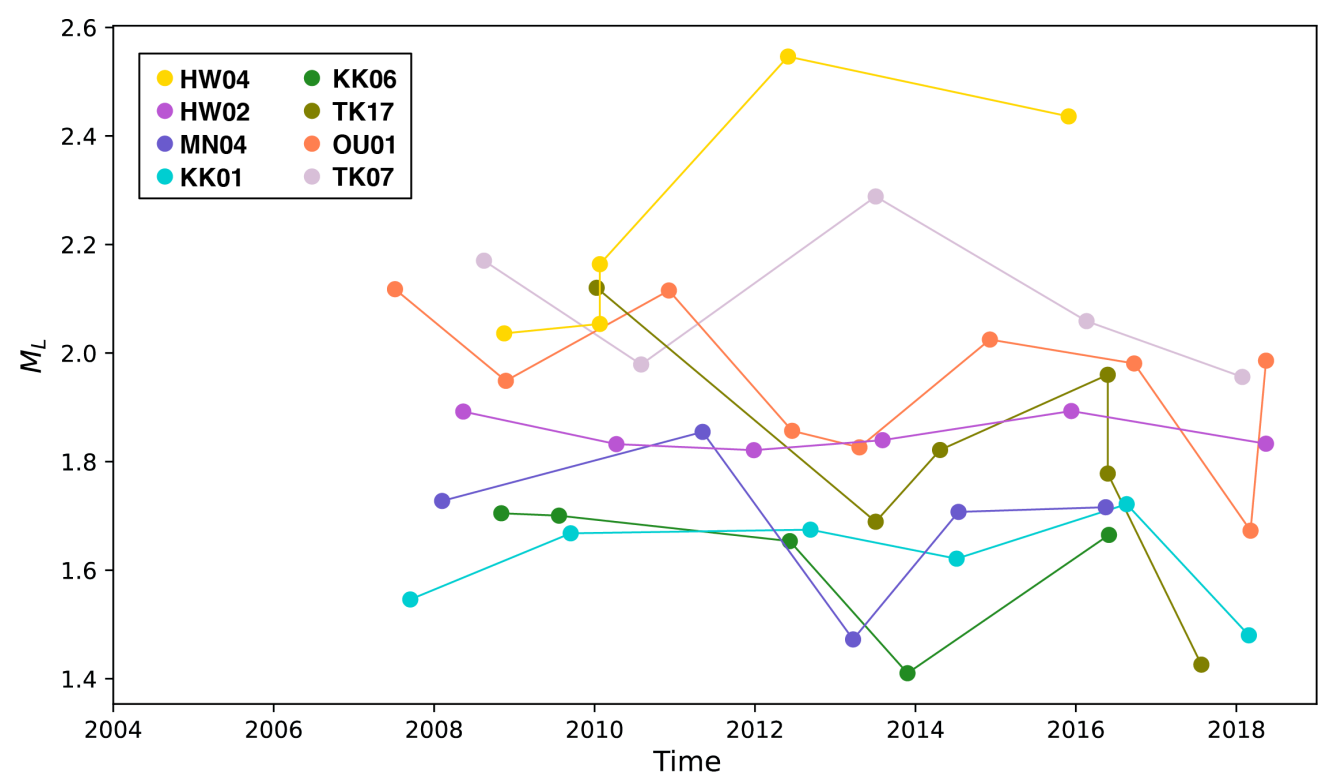

Figure 4.6: Local magnitudes of families with five or more events through time. Each family is shown with a different colour, with each dot representing an event.

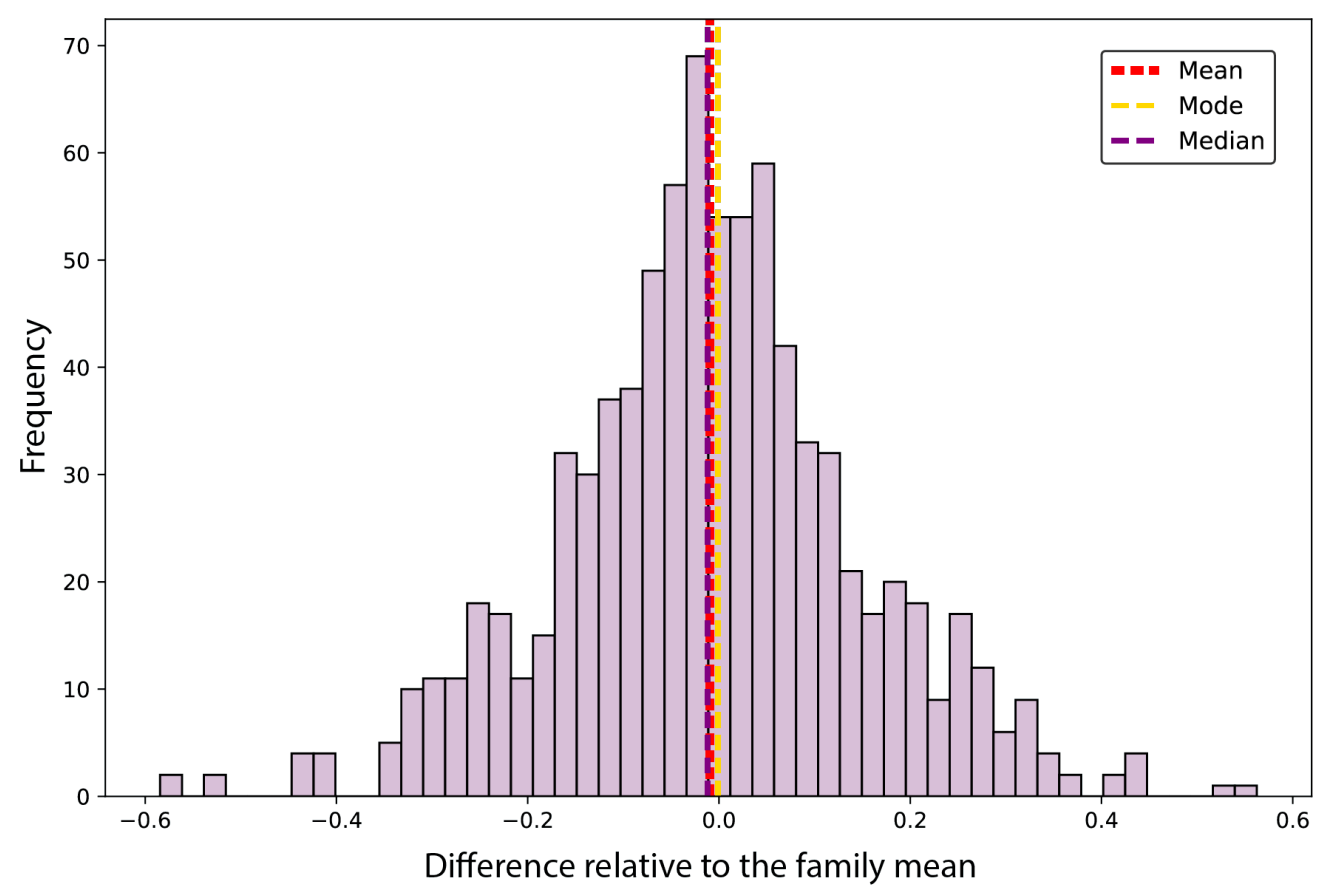

Figure 4.7: Histogram illustrating the difference between the local magnitudes calculated and the mean of the family they belong to. Differences were obtained by subtracting each local magnitude from the corresponding family mean. 


\subsection{Repeating earthquake focal mechanisms}

We obtained focal mechanisms for the most recent event of each family following the procedure described in Section 3.7 and then selected 75 of the highest-quality focal mechanisms for further analysis. The procedure for selecting the final focal mechanisms involved inspecting each stereonet of first motions and the corresponding P-T axis contour plot and identifying the ones that appeared well-constrained. The pressure (P) and tension ( $\mathrm{T}$ ) axes are geometric properties of each earthquake's focal mechanism and are directly related to the normal and slip vectors of the fault plane (McKenzie, 1969; Arnold and Townend, 2007). Due to the direct relationship between the P- and $\mathrm{T}$ - axes and the vectors of the fault plane, the inspection of the P-T axis probability contours was decisive for identifying well-constrained focal mechanisms.

Figure 4.8 shows two representative focal mechanisms, one well-constrained belonging to family TK02 (a) and another less constrained from family TK46 (b). A total of 10 picks, six compressional and four dilatational were used for TK02. The P-T contour plot next to the stereonet shows that the $\mathrm{P}$ and $\mathrm{T}$ axis are well constrained, as the contours are tightly-spaced and barely cross the nodal planes. For the less-constrained event belonging to family TK46, a total of eight first motions were used to calculate the focal mechanism, of which only two were compressional. The P-T contour plot of the less-constrained event from TK46, shows the P and T contours crossing several times through the nodal planes and encompassing almost all the surface of the focal sphere, indicating that the nodal planes are poorly constrained compared to those of TK02.

As an additional criterion for selecting the highest-quality focal mechanisms, a maximum scalar error of $32^{\circ}$ was used to select the final ones. The error of all the focal mechanisms ranges from $20^{\circ}$ to $37^{\circ}$ with an average of $31^{\circ}$. In comparison, the error for the selected final focal mechanisms has a range from $20^{\circ}$ to $32^{\circ}$ with an average of $28^{\circ}$. Appendix A.4 contains the stereonets and P-T axis contour plots of the 75 final focal mechanisms.

The resulting focal mechanism catalogue is shown in Figure 4.9. The colour of each focal mechanism corresponds to the assigned position in the ternary diagram classification (Frohlich, 1992). The position of the focal mechanisms in the ternary diagram is computed using the plunge angles of the $\mathrm{P}, \mathrm{T}$ and $\mathrm{B}$ axes. The vertices of the triangle represent pure strike-slip motion on a vertical fault, pure normal motion on a $45^{\circ}$ dipping fault plane and pure thrust motion on a $45^{\circ}$-dipping fault plane. Some families have a predominant focal mechanism. For example, Mangaroapa Group (MN) contains 
almost solely normal-faulting focal mechanisms coloured in red tones, and families belonging to the Taikorai Group (TK) exhibit mostly thrust motion and some strikeslip. Other groups such as Hastings East (HE), Dannevirke (DV) and Cape Turnagain (CT) do not show a clear predominance. Toroa Group (TR) was the only group for which a high-quality focal mechanism could not be calculated.

The final focal mechanisms are also shown in five different cross-sections to illustrate their locations in relation to the subducting plate interface. The Taikorai Group (TK) has focal mechanisms with predominantly thrust motions at depths that correlate well with the subduction interface model of Williams et al. (2013). This indicates that the majority of events in this group could be located on the subduction interface or related structures. In contrast, the focal mechanisms belonging to Mangaorapa Group (MN) are predominantly normal motions and are located below the subduction interface, suggesting that they are occurring within the subducting Pacific Plate. With the exception of these two groups, there are few clear examples of a separation between events occurring on the interface, in the overlaying Australian Plate or within the subducting Pacific Plate. Further interpretations regarding the focal mechanisms are discussed in the next chapter. 
a)
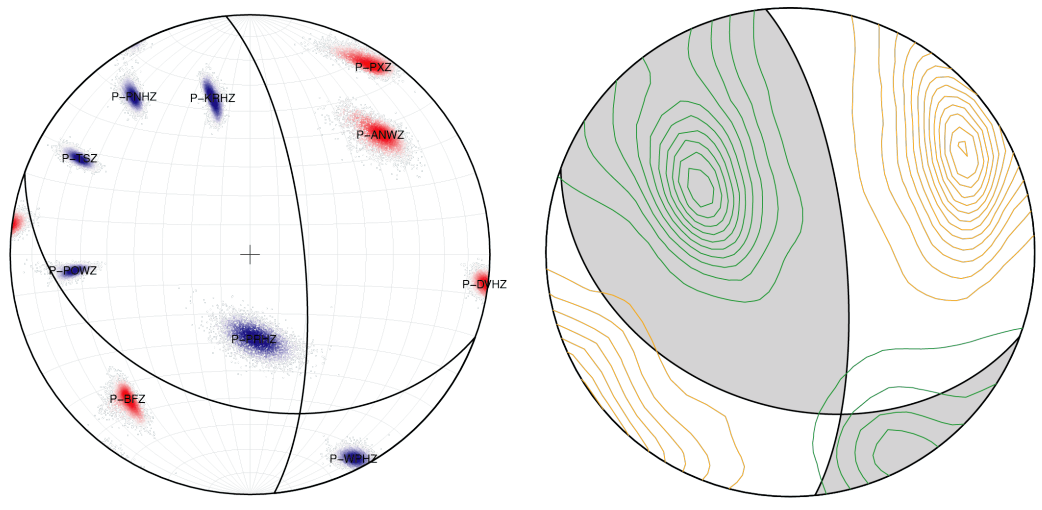

b)
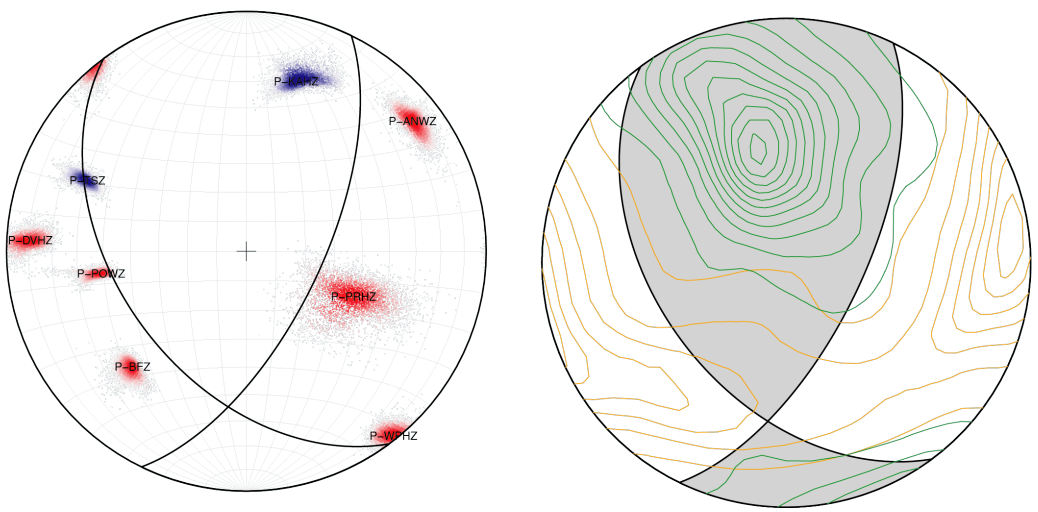

Figure 4.8: a) Stereonet (left) of one well-constrained event 2018p479843 from family TK02 and scalar error of $27.2^{\circ}$. Solid black line indicates the focal mechanisms solution $\left[\right.$ strike $=110.1^{\circ}$, dip $=37.3^{\circ}$, rake $=31.3^{\circ}$. Blue points are compressions and red points are dilatations. $\mathrm{P}$ - and $\mathrm{T}$ - probability contour plot (right) for the same event . Orange denotes P-axis and green the T-axis. b) Same as a) but for a less constrained event 2012p158837 from family TK46 with a focal mechanisms solution of strike $=143.2^{\circ}$, dip $=45.6^{\circ}$ and rake $=36.6^{\circ}$, and scalar error of $31.4^{\circ}$. 


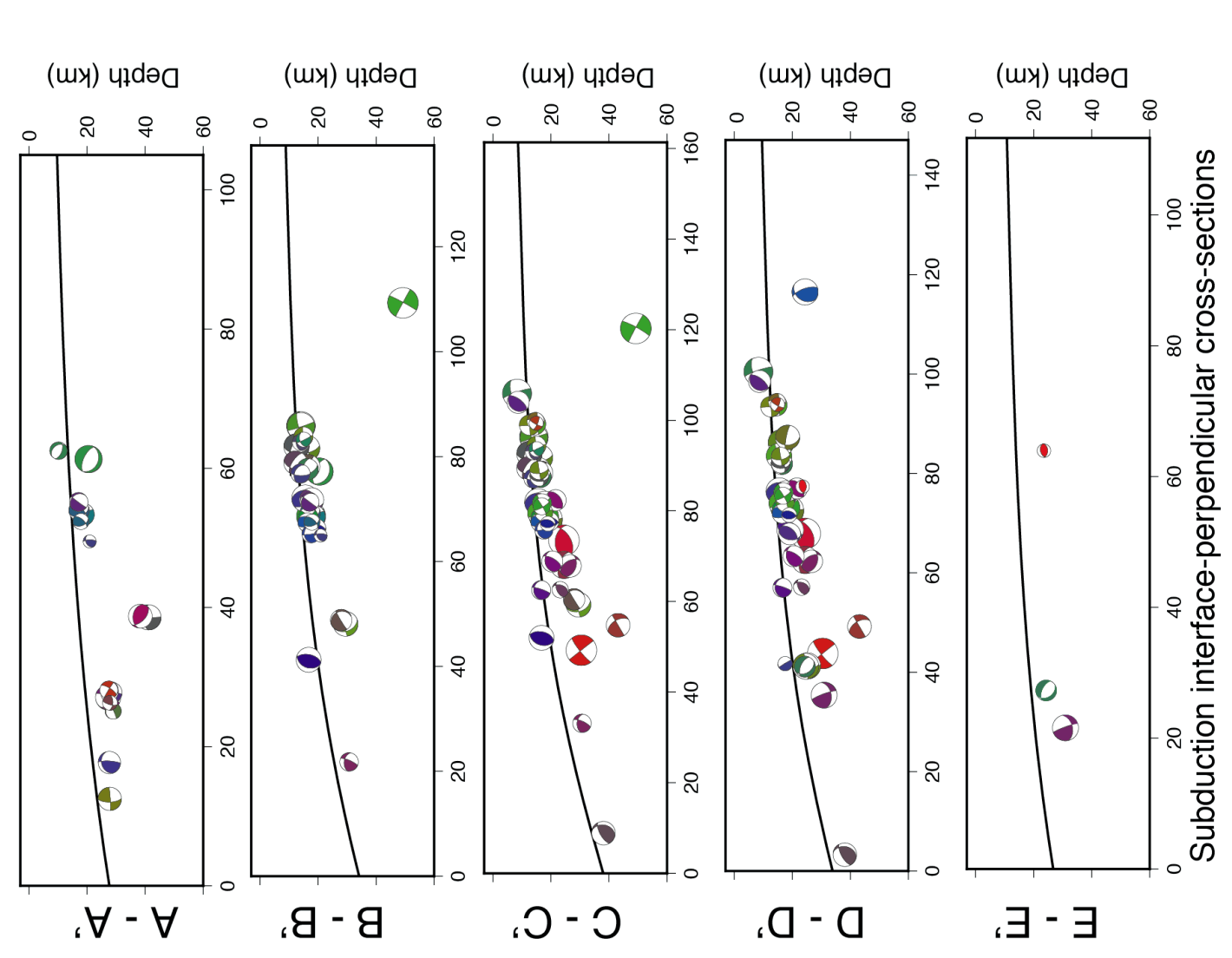

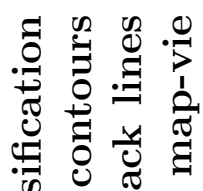

요의 चे है की

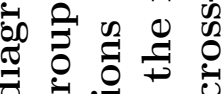
50 苑 元的藏 屯ี

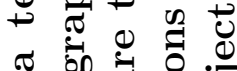
$\sigma 80.0 \%$

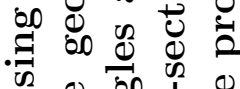
可

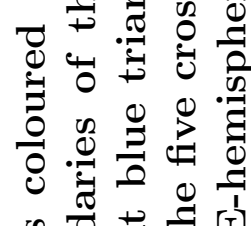

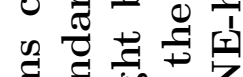
.ำ สี 过 สี 눈

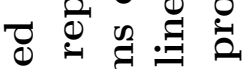

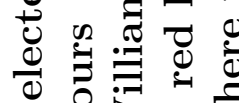
क ฮี่ สี สี पै ปั نे $\dot{0} \frac{\dot{0}}{\sigma}$

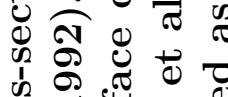
U⿺辶寸 สี कี

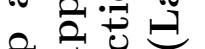

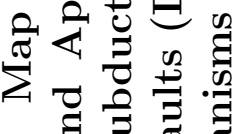
๑) क थ षं 를 己ِ 0 크 \&

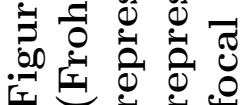




\subsection{Results summary}

The results presented in this chapter describe repeating earthquakes near Porangahau, where the Hikurangi subduction zone transitions from creeping to a locked subduction interface. Our key results are:

1. We formed a repeating earthquakes catalogue for the area near Porangahau, from 2004 to 2018. This catalogue is composed of 532 earthquakes clustered into 225 families and then into 16 geographical groups using the locations obtained for the most recent event of each family.

2. We obtained absolute locations for the most recent event of each family and relative locations for the rest. Because the stations used are all located on land, the location uncertainties increase for the events offshore compared to those onshore. To aid discussion, we assigned geographic groupings to families. We observe that groups near the coast have more events and depths similar to the subduction interface model of Williams et al. (2013), while groups further inland had fewer events and more variable depths.

3. We calculated local magnitudes for the most recent event in each family and relative magnitudes for the rest of events. According to the histogram of all the magnitudes, most of the magnitudes have values close to $M_{L} 2$ (mode of $M_{L} 1.9$ ). We note that there is some variability in magnitude and recurrence of events, and discuss this further in the following chapter.

4. We selected 75 of the 225 focal mechanism obtained from first motion observations based on how well constrained the P-T axes were and the calculated scalar error. Taikorai Group (TK) families were found to have depths and thrust motions consistent with plate interface faulting, while Mangaorapa Group (MN) families indicate normal earthquakes within the subducting Pacific Plate. 


\section{Chapter 5}

\section{Discussion and Conclusions}

In this chapter, we first discuss the factors that influence the completeness of our repeating earthquake catalogue (Section 5.1). In Sections 5.2 and 5.3, we review the repeating earthquake catalogue in the context of other seismic and aseismic phenomena observed on the Hikurangi margin. In Sections 5.4 and 5.5, we review our results in a global context via seismic moment and slip-rate relationships. This chapter concludes with a summary of key findings and suggestions for further research in Section 5.6.

\subsection{Repeating earthquake catalogue completeness}

The completeness of our final repeating earthquake catalogue is strongly influenced by the completeness of the GeoNet earthquake catalogue on which it is based, as discussed in Section 3.1. The GeoNet earthquake catalogue is constructed and maintained by GNS Science via the GeoNet project (Petersen et al., 2011). As of May 2010, the seismic monitoring network consisted of 111 regional stations and 49 stations from the New Zealand National Seismograph Networks (NZNSN; Petersen et al., 2011). Since then, there have been numerous changes in the number of stations, the sensors used to record earthquakes, the system for earthquake location, magnitude calculation, the velocity model used for location, and procedures used to pick phase arrivals. As a consequence, the GeoNet catalogue's magnitude of completeness is known to have varied during the period spanned by this project (Figure 5.1). Duration and recurrence interval of the repeating earthquake families are strongly dependent on catalogue completeness and this is likely to have a large impact on families of small magnitudes whose events are near or below the GeoNet catalogue magnitude of completeness $M_{c}$ (4.3). We observe a sudden increase in the number of repeating earthquakes identified between 


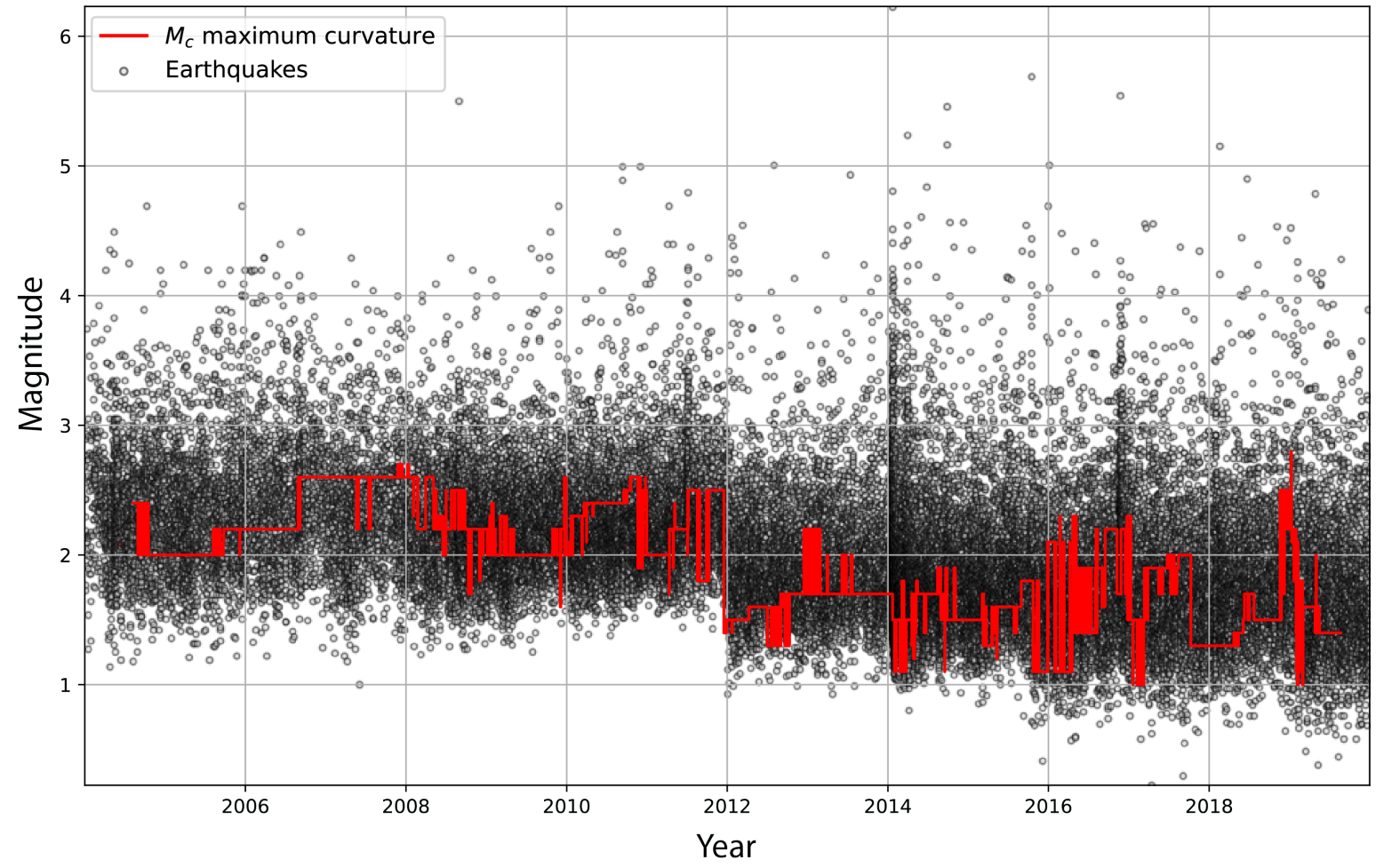

Figure 5.1: Graph of the calculated magnitude of completeness $\left(M_{c}\right)$ of the GeoNet catalogue near Porangahau, from 2004 to 2020. The decrease of the magnitude of completeness in 2012 is due to the change from CUSP to SeisComP for earthquake processing in GeoNet. We calculated the completeness using the maximum curvature method from Wiemer and Wyss (2000). 
late 2008 and mid 2010 (Figure 4.5). The increase in events is likely to be related to the installation of stations belonging to regional networks (Figure 3.2). Stations PRHZ, ANWZ, DVHZ, PRWZ, POWZ and PNHZ were all installed at the beginning of 2008 and are located well within our study area, which would increase the number of earthquakes detected near Porangahau. However, the reason behind the decrease in identified events after late 2010 does not appear to be associated with network changes. The overview of the GeoNet project written by Petersen et al. (2011) contains no explicit mention of the detection methods used and neither are these mentioned on the GeoNet website ${ }^{1}$, so we are not able to identify a cause related to the GeoNet catalogue. In Section 5.3 below we discuss the spatial and temporal correlation of the increase and decrease of events with other phenomena such as slow slip events (SSE).

The duration of our study period also influences the completeness of the final repeating earthquake catalogue. We chose 2004 as the start of our analysis due to the availability of continuous data from broadband and short-period stations near Porangahau, although stations from the regional networks were not installed until after 2008 (Figure 3.2). Limiting our study period from 2004 to 2018 means that we may be missing families with long-recurrence intervals. This likely affects the upper-limit of the magnitudes computed, as large-magnitude events often have long recurrence intervals (Uchida and Bürgmann, 2019).

As of March 2021, a matched-filter analysis of seismicity near Porangahau is in progress to improve the completeness of our catalogue (Calum Chamberlain, pers. comm., March 2021). Each of the repeating earthquakes identified in this thesis is being used as a template for the matched-filter. Due to time constrains and the large number of templates, we are not able to report the results from the matched-filter in this thesis. It is expected, however, that the matched-filter analysis will identify events that are not in the GeoNet catalogue and/or outside our study period.

The methodology used by GeoNet for earthquake analysis has also changed during our study period. From 1986 to 2012, GeoNet used the California Institute of Technology (Caltech)-U.S. Geological Survey (USGS) seismic processor (CUSP) system for earthquake location and magnitude estimation. Since 2012, GeoNet has used the SeisComP (SC) system (Rhoades et al., 2020a). This change in earthquake processing can be observed in Figure 5.1 with the sudden decrease in magnitudes after 2012. The identification of phase arrivals has changed accordingly: for instance, since 2016, additional manual phase analysis has been undertaken by 'GeoHazard Analysts', resulting in more S-picks and more manual P-picks than before 2016 (Sara O'Hagan pers.

\footnotetext{
${ }^{1}$ https://www.geonet.org.nz/, last accessed March 2021.
} 
comm.). Changes in earthquake processing have resulted in the GeoNet earthquake catalogue having heterogeneous quality locations and inconsistent magnitudes (Ristau et al., 2016) that are now being recalculated under the auspices of the National Seismic Hazard Model (Rhoades et al., 2020a,b).

The procedures described in Chapter 3 were used in order to produce a repeating earthquake catalogue with homogeneous locations and magnitudes in spite of inconsistencies in the starting GeoNet catalogue. For the most recent event in each family, we obtained accurate absolute locations and local magnitudes were calibrated with moment magnitudes. For the rest of the events, we computed relative locations and relative magnitudes. Using this approach, we obtained a repeating earthquake catalogue with homogeneous quality location and consistent magnitudes spanning the entire study period. We do not observe magnitudes below $M_{L} 2.0$ before late 2007 (Figure 4.5). The range of magnitudes obtained in our catalogue is also dependent on the smallest magnitude the GeoNet network can detect.

In terms of instrumentation, the regional networks are generally equipped with shortperiod seismometers, while the NZNSN stations are equipped with broadband seismometers and strong motion sensors. Additionally, sensors at some locations have been upgraded from short-period to broadband. As mentioned in Section 3.2, we corrected for instrument response to allow comparison across these changes in instrumentation.

Section 2.2.1 describes the effects of filter frequency-bands on cross-correlation coefficients. The upper limit of a suitable filter is dependent on the earthquake's corner frequency and a suitable lower limit should consider the quarter-wavelength rule (Geller and Mueller, 1980; Uchida, 2019). We applied a 2-20 Hz band-pass filter to the crosscorrelated traces: we discuss here the implications this may have for detecting repeating earthquakes using waveform similarity.

Seismic energy from earthquakes is mostly concentrated in the higher-frequency part of the earthquake source spectrum near the corner frequency (Bormann et al., 2009) and, in general, the corner frequency increases when the moment or size of an earthquake decreases (Stein and Wysession, 2003; Allmann and Shearer, 2009). To determine the frequencies at which the seismic energy is concentrated, we computed the amplitude spectra and frequency-domain signal-to-noise ratio of three earthquakes with different calibrated local magnitudes from the repeating earthquake catalogue (Figure 5.2). The three earthquakes are part of the Mangaorapa Group (MN) and are located near the township of Dannevirke (Figure 4.1). The amplitude spectra of these earthquakes were calculated using the vertical component of station PXZ and the corresponding noise 
spectra were obtained using a window of the same length as the signal before the P-pick.

For the $M_{L} 1.6$ earthquake (Figure 5.2 a), there is no clear corner frequency up to the Nyquist frequency of the data $(50 \mathrm{~Hz})$ and the noise and earthquake spectra have similar amplitudes. The signal-to-noise ratio is fairly constant and close to one, which means that the signal amplitudes of this low-magnitude earthquake are close to the noise amplitudes. The second earthquake is of $M_{L} 2.3$ (Figure $5.2 \mathrm{~b}$ ) and has an amplitude spectrum clearly above the noise. The differences in amplitudes between the earthquake and noise signals are even clearer for the $M_{L} 3.3$ earthquake (Figure $5.2 \mathrm{c}$ ).

The spectra illustrated in Figure 5.2 contain two lines that mark the minimum and maximum frequencies of the filter used. We observe for the $M_{L} 3.3$ earthquake that the corner frequency is $\sim 10 \mathrm{~Hz}$ and within the passband of the filter. For the $M_{L} 2.3$ earthquake, the corner frequency is approximately $\sim 20 \mathrm{~Hz}$ which is also the frequency at which the signal-to-noise ratio starts decreasing. This means that we are still capturing most of the seismic energy. As noted above, the corner frequency cannot be clearly distinguished for the $M_{L} 1.6$ earthquake, but the theoretical corner frequencies for $M_{W} 1.0$ range from $\sim 15$ to $\sim 100 \mathrm{~Hz}$ depending on the stress drop value (Allmann and Shearer, 2009). Although we are filtering below some of the theoretical corner frequencies for the smaller events, the seismic source complexity at higher frequencies is likely lost due to attenuation.

According to Geller and Mueller (1980), if the difference in the length of the propagation paths of two earthquakes is less than one-quarter of a wavelength $\lambda / 4$ (the first Fresnel Zone), the waveform similarity of these events will be high even if they are not overlapping. In next paragraphs we consider how this relationship is applied to our repeating earthquakes.

We first calculated the fault radii $r$ of the repeating earthquakes assuming a circular source geometry and a Brune earthquake source model (Brune, 1970) using Equation 5.1 (Stein and Wysession, 2003) and Equation 3.11. $M_{0}$ is the seismic moment in dyne-cm calculated using Equation 3.11 and $\Delta \sigma$ is the stress drop in MPa. To obtain the fault radii values in meters, we converted $\mathrm{MPa}$ to dyne $/ \mathrm{cm}^{2}(1 \mathrm{MPa}=$ $10^{7}$ dyne $/ \mathrm{cm}^{2}$ ) and then divided by 100 to convert centimetres to meters.

$$
r=\left(\frac{7}{16} \frac{M_{0}}{\Delta \sigma}\right)^{\frac{1}{3}}
$$

We obtained a range of source radii between 14 and $495 \mathrm{~m}$ using 3 and $10 \mathrm{MPa}$ as rep- 


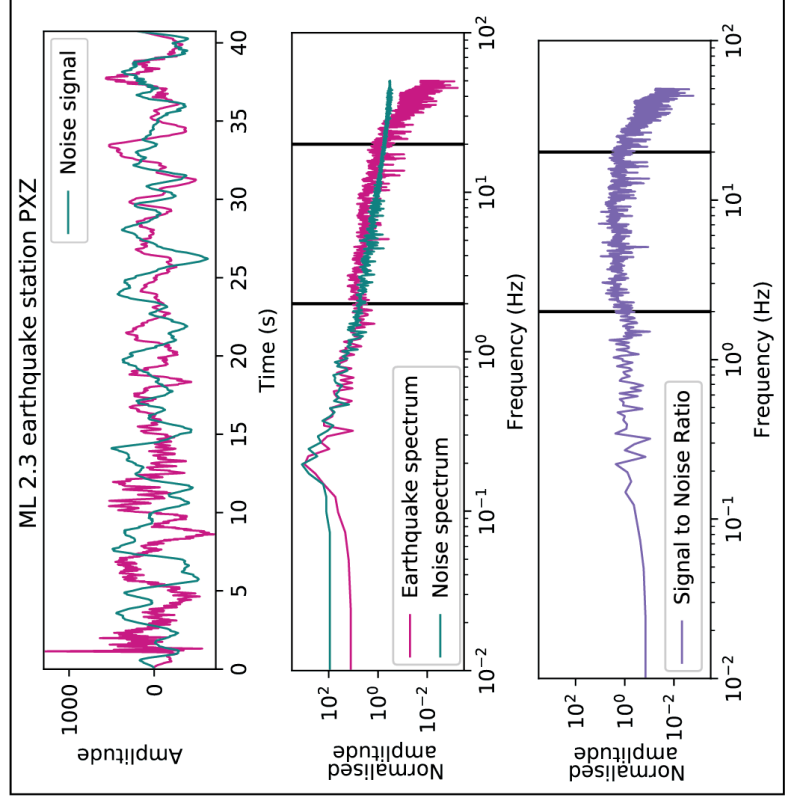

อ
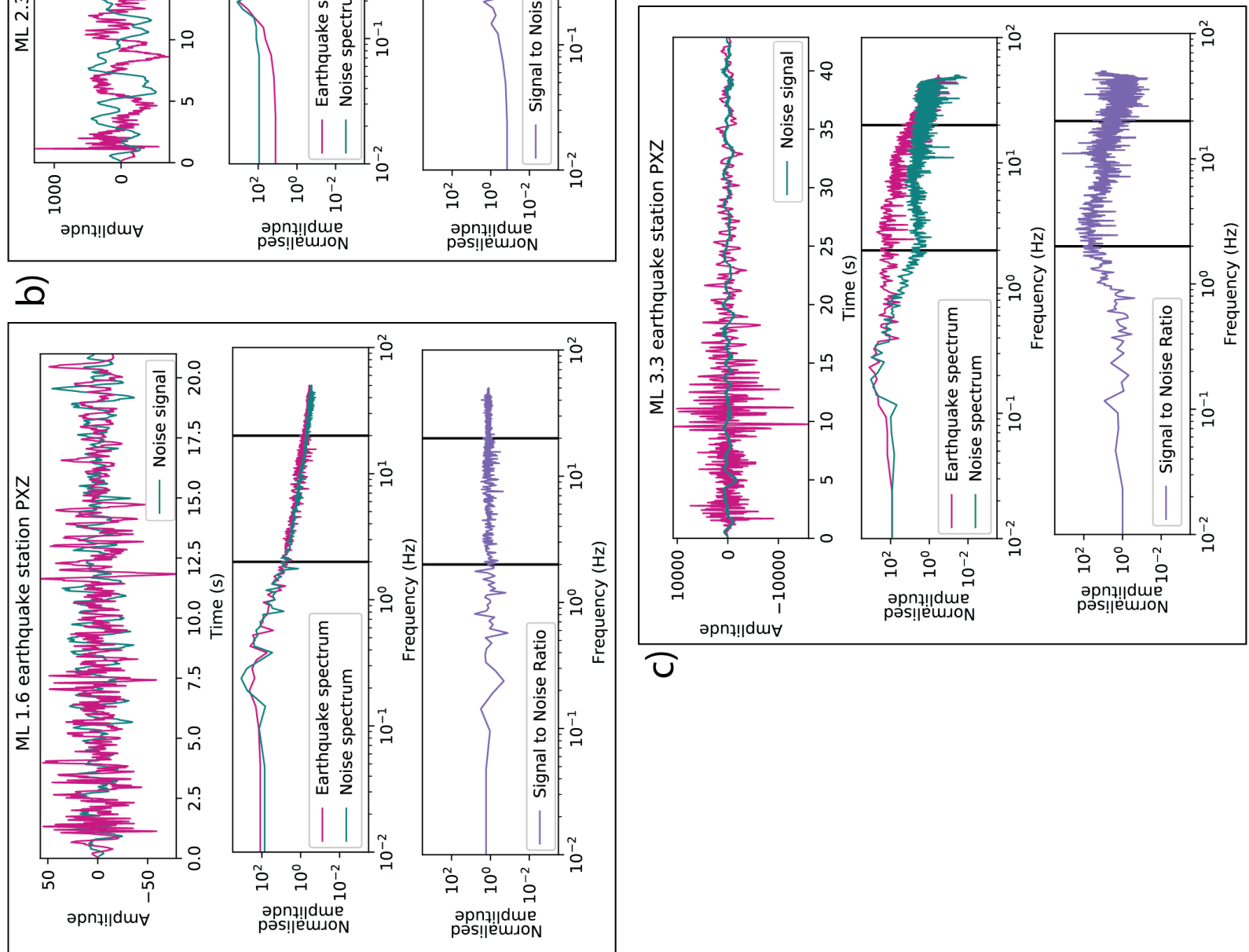

$\frac{1}{3}$

乎

ชี่ ิ

¿

崩

-

of

.

坐田

은

选

근

ป

.

酸

ช

ป हี ชู

군 원

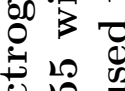

:

के ฏ

0

的

莺

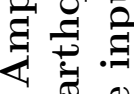

نิ

نั

فे

$\stackrel{0}{2}$ 


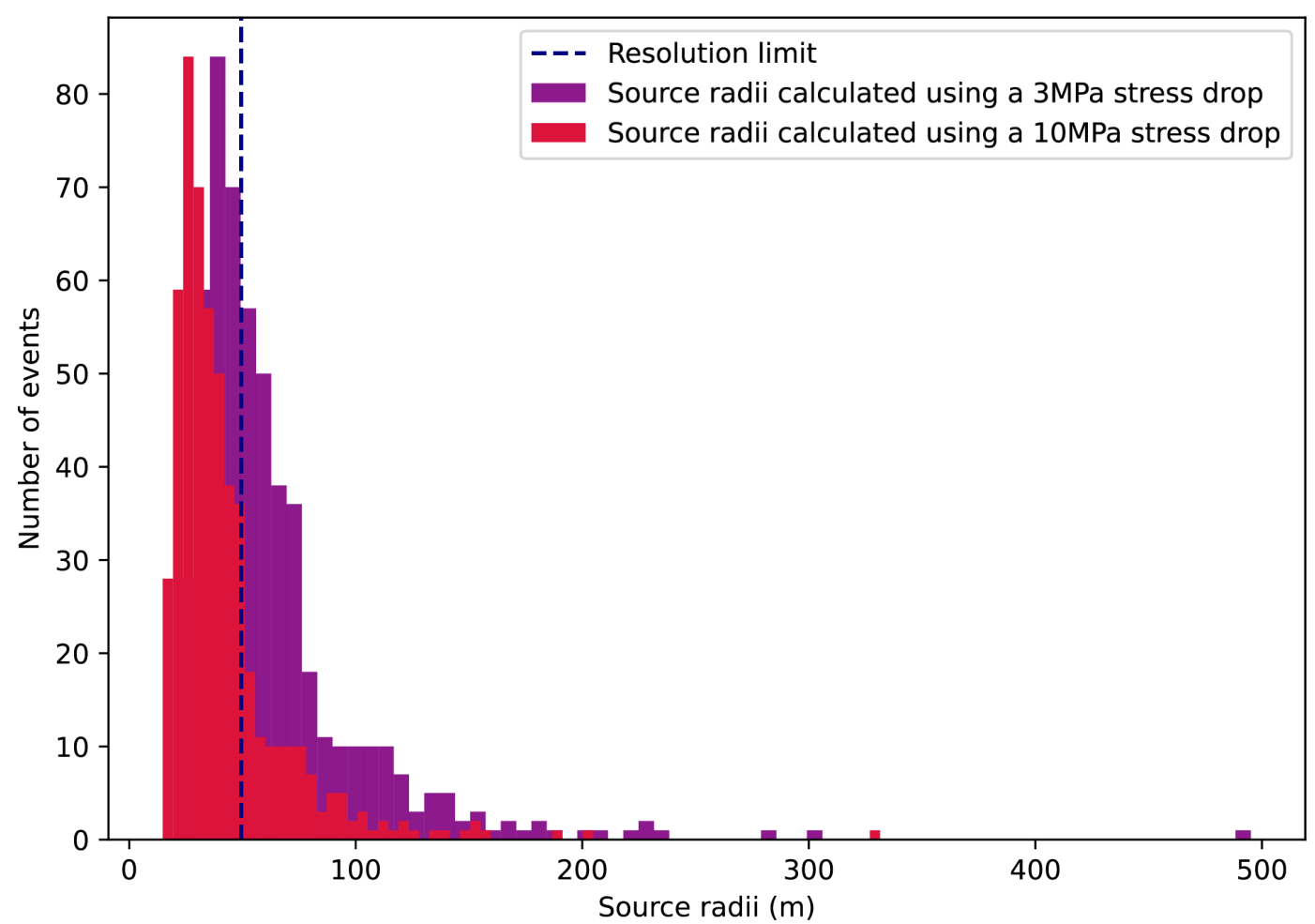

Figure 5.3: Calculated source radii of the repeating earthquakes using constant values of stress drops. The histogram in purple illustrates the values of source radii obtained using $3 \mathrm{MPa}$ and the histogram in red illustrates the distribution of source radii using $10 \mathrm{MPa}$. The resolution limit of $48.5 \mathrm{~m}$ is indicated with a blue dashed line. Event 3279388 from family PP02 has the largest source radius calculated $(495 \mathrm{~m})$.

resentative values of stress drop (Figure 5.3). Using an S-wave velocity $v_{s}$ of $3.88 \mathrm{~km} / \mathrm{s}$ for the region near Porangahau (Eberhart-Phillips and Bannister, 2015) and our $20 \mathrm{~Hz}$ high-cut frequency, we obtain a wavelength of $194 \mathrm{~m}$. A quarter of this wavelength is $48.5 \mathrm{~m}$, which means that events with smaller source radii could have high correlations even if they do not overlap (i.e. coincide spatially). This suggests that we are not able to separate small but not overlapping events, particularly those with larger stressdrops (see resolution limit in Figure 5.3). However, these events are small with low signal-to-noise ratios and high corner frequencies (Figure 5.2). To be able demonstrate that these low magnitude events are not overlapping, despite having high correlations, would require higher quality data with higher sampling-rates. 


\section{$5.2 \quad$ Repeating earthquake locations}

We investigated the relationship between the repeating earthquake families and tectonic setting based on the focal mechanisms and hypocentres of earthquakes in each family. We divided the families into three groups: 1) families occurring within the Australian Plate, 2) families located on the subduction interface or 3) families occurring within the subducting Pacific Plate.

We used the ternary diagram (Frohlich, 1992) in Figure 4.9 to represent and colour the faulting type of each focal mechanism and compared the mean location of the families to the subduction plate interface model of Williams et al. (2013). If the family had a depth within $5 \mathrm{~km}$ of the subduction interface and thrust focal mechanism, we determined that the family was located on the subduction interface. Families with depths more than $5 \mathrm{~km}$ of the subduction interface, were assigned to be either in the Australian Plate or in the Pacific Plate, regardless of their faulting type. For families without focal mechanisms, we assigned them to be within the Australian or Pacific Plate based on their depth. We did not assign families to be on the interface using their depths only due to the uncertainties in the locations we obtained and the uncertainty in the subduction interface model. In other words, we used thrust focal mechanisms as a required condition for an earthquake to be assigned to the plate interface.

Using these criteria, 25 families are found to be located on the subduction interface, 19 within the Australian Plate and 181 in the Pacific Plate. Figure 5.4 shows the location of the repeating earthquake families on a map with the interface locking model and the modelled slow slip events (SSEs) from Wallace et al. (2012b). We may be underestimating the number of families on the interface, and additional work to constrain focal mechanisms using P-S ratios or waveform modelling may move some families from the Pacific Plate or Australian Plate to the interface grouping.

\subsubsection{Families in the Australian Plate}

19 of 225 families are located within the Australian Plate and are shown as blue circles in Figure 5.4. Five of the 19 families have a focal mechanism. Families CT13, DV12, MN14 and WP5 have strike-slip focal mechanisms and family TK27 exhibits normal faulting. Family CT13 located offshore Cape Turnagain, has the largest magnitude $\left(M_{L} 2.4\right)$ of the Australian Plate families and family WP11 located near Waipukurau has the smallest magnitude of $M_{L}$ 1.3. The depths of the Australian Plate families range between 17 and $6 \mathrm{~km}$, all being located above the subduction interface model of 

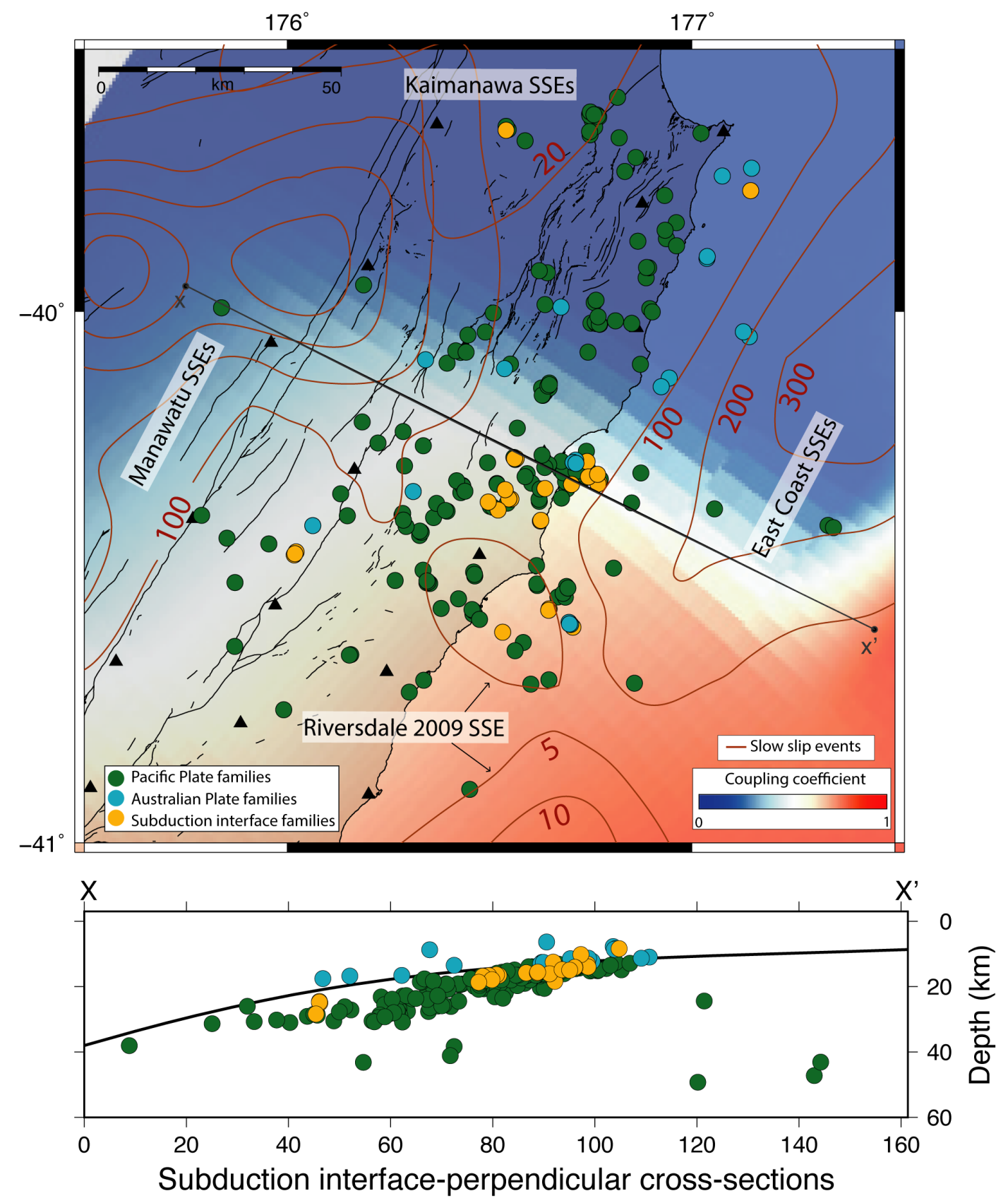

Figure 5.4: Map illustrating the locations of the repeating earthquake families in relation to the the interface locking model and the cumulative slip of slow slip events from Wallace et al. (2012b). Families in the Pacific Plate are shown in green, Australian Plate families in blue and families on the subduction interface in yellow. Red contours show the cumulative slip of slow slip events in $\mathrm{mm}$, modified from Wallace (2020). The blue colours of the interseismic coupling represent a low coupling coefficient and red colours represent high coupling coefficient. The cross-section perpendicular to the subduction interface contains all the families. 
Williams et al. (2013) (cross-section of Figure 5.4). 14 of the 19 families are located above the subduction interface inferred to be weakly coupled (creeping), one family (TK27) locates above the transition near Porangahau and five families (MN14, DV12, CT10, CT11 and CT13) above the locked interface. A few of the families are located nearby or exactly above the modelled SSEs. For example, families CT10, CT11 and CT13 are located above the edge of a sliding patch from the 2009 Riversdale SSE, family WP11 above the Manawatu SSEs and families KK08 and KK20 above East Coast SSEs.

\subsubsection{Families in the Pacific Plate}

Most of the families in our repeating earthquake catalogue are inferred to lie within the Pacific Plate (green circles in Figure 5.4). 45 of the 181 families within the Pacific Plate have a focal mechanism: five thrust, 21 strike-slip and 19 normal faulting focal mechanisms.

These families have a wide range of magnitudes and depths. Families PP01 and PP02 are the furthest offshore, have the largest magnitudes $\left(M_{L} 3.6\right.$ and 3.1) and are deeper $(>40 \mathrm{~km})$ than all other repeating earthquake families. The smallest magnitude of the Pacific Plate group is $M_{L} 1.3$ from family AK14 located near Akitio and the shallowest family is TR01 with a depth of $12 \mathrm{~km}$ located on the coast off Porangahau.

Families in the Pacific Plate are located beneath both the creeping and locked part of the subduction interface, with no observable distribution determined by the coupling state of the interface. In relation to the slow slip events, all families from the Toroa group (TR) are located close to the subduction interface and on the edge of the East Coast SSEs modelled slip. All the families from the Akitio group (AK) are also located close to the subduction interface, where a patch of the 2009 Riversdale slow slip event occurred (Figure 5.4). Other Pacific Plate families are located below the Kaimanawa and Manawatu SSEs, but with depths that clearly locate them below the subduction interface model. Temporal association to slow slip events is addressed in the next section.

Although several of the families within the Pacific Plate have depths close to the subduction interface modelled by Williams et al. (2013), they do not have a wellconstrained focal mechanisms to determine if they were occurring on the interface. 


\subsubsection{Families on the subduction plate interface}

25 families are located on the subduction interface with all of them presenting thrust focal mechanisms (yellow circles in Figure 5.4). Family TK44 has the largest magnitude of $M_{L} 2.9$, and family TK46 has the smallest magnitude of $M_{L}$ 1.6. Both TK44 and TK46 families are located near the township of Porangahau.

Only families KK09 and HW04 are located on the creeping part of the subduction interface, the other 23 families are located near the transition from creeping to locked, near Porangahau. In relation to the slow slip events in the area, family HW04 is located where the deep Kaimanawa SSEs occurred (Wallace and Eberhart-Phillips, 2013) and families CT03, CT05, CT12 and AK13 are located in the area where the 2009 Riversdale SSE occurred. Further temporal analysis of interplate families and SSEs is discussed in the next section.

\subsection{Repeating earthquakes and other phenomena}

We analysed the spatial and temporal relationships between our catalogue of repeating earthquakes and nearby slow-slip episodes and large earthquakes (Figures 5.5 and 5.6). Table 5.1 contains a summary of the large earthquakes and slow slip events compared with the repeating earthquakes. The dates and location of the large earthquakes were obtained from the Institute of Geological and Nuclear Sciences (GNS) website ${ }^{2}$ and the GeoNet website ${ }^{3}$. Start and end dates of some slow slip events were obtained via by Andrea Pérez (pers. comm., March 2021). Dates for the 2014/2015 Manawatu SSE, the 2006 and 2008 deep Kaimanawa SSEs and the 2009 Riversdale SSE were inferred using information and time-series from Wallace and Beavan, 2010; Wallace et al., 2012a; Eberhart-Phillips et al., 2013; Wallace et al., 2018 and Wallace, 2020. The slip contours used to make spatial comparisons are from Wallace (2020) and do not represent individual slow slip events, except for the 2009 Riversdale SSE. In this thesis we opted for using these cumulative contours to represent individual slow slip events because not all have published contours and they also migrate spatially. It is also important to consider that the contours have different slip limits (20 for Kaimanawa SSEs, 5 for Riversdale SSE and 100 for Manawatu and East Coast cumulative contours) for the spatial correlations. To enable more robust comparison between repeating

\footnotetext{
${ }^{2}$ https://www.gns.cri.nz/Home/Learning/Science-Topics/Earthquakes/New-ZealandEarthquakes/Where-were-NZs-largest-earthquakes, last accessed April 2021

${ }^{3}$ https://www.geonet.org.nz/, last accessed April 2021.
} 
earthquakes and slow slip events, a more detailed geodetic catalogue is required.

We took into consideration the duration of the families in our analysis and divided them into continual- and burst-type, as burst-type events are thought to be related to different seismic processes than continual-type (Igarashi et al., 2003; Kimura et al., 2006; Mesimeri and Karakostas, 2018). Burst-type repeating earthquakes are often associated with swarms and aftershocks of large earthquakes (Igarashi et al., 2003). Continual-type on the other hand, are associated with periodic loading and rupture of the same asperity and reflect the aseismic slip of the region (Nadeau and Johnson, 1998; Nadeau and McEvilly, 1999).

Previous studies have reported connections between repeating earthquakes and the occurrence of slow slip events (e.g. Gardonio et al., 2018; Kato et al., 2012, 2014; Chen et al., 2013) by analysing long repeating earthquake catalogues and GNSS time-series. There has been evidence of increases in the number of repeating earthquakes during slow slip events, suggesting that repeating earthquakes are sensitive to the occurrence of nearby slow slip events (Gardonio et al., 2018). Slow slip events in the Hikurangi margin are diverse: shallow $(<15 \mathrm{~km})$, short $(<1$ month) and frequent slow slip occurs in the northern and central margin and deeper $(>30 \mathrm{~km})$, longer $(>1$ year) and less frequent events occur in the southern margin (Wallace, 2020, and references therein).

The Riversdale 2009 slow slip event occurred in the strongly-coupled region of the Hikurangi margin, southeast of our area of study (Wallace et al., 2012b) (Figure 1.3). Three families (AK03, AK14 and AK15) can be spatially and temporally correlated with the Riversdale slow slip event (Figure 5.7). Family AK03 contains two events, both located within the SSE patch. The first event occurred while the SSE was in process (see time-series in Figure 5.7) and the second and most recent event from family AK03 occurred in 2017 with no clear temporal association with SSEs. Families AK14 and AK15 are burst-type families with events having hours of difference between them and occurring a week after the Riversdale SSE (see time-series of Figure 5.7). Close in time to families AK14 and AK15, several burst-type events occurred, although these are not located close to the Riversdale modelled slip patch. Two interplate events occurred close in time to the Riverside SSE, but with no strong spatial correlation to the slow slip patch. The burst-type interplate family TK53 occurred when the slow slip event was in process, but the events are not located near the slow slip patch. Interplate family HW04 occurred further north from the SSE and almost two months after the Riversdale SSE started (Figure 5.7).

The families from the geographical group Akitio (AK) (Figures 4.1 and 5.4) are located 







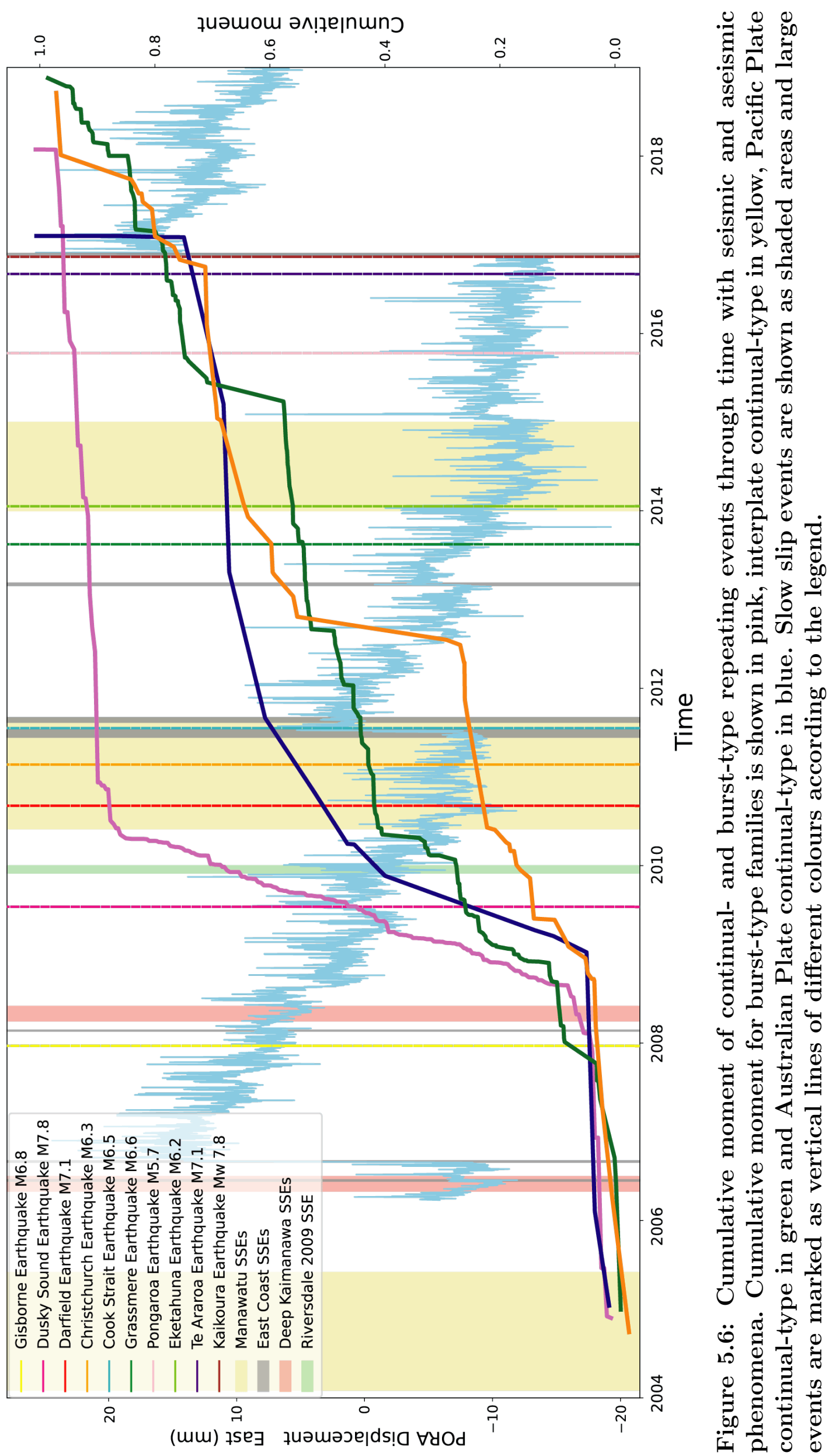




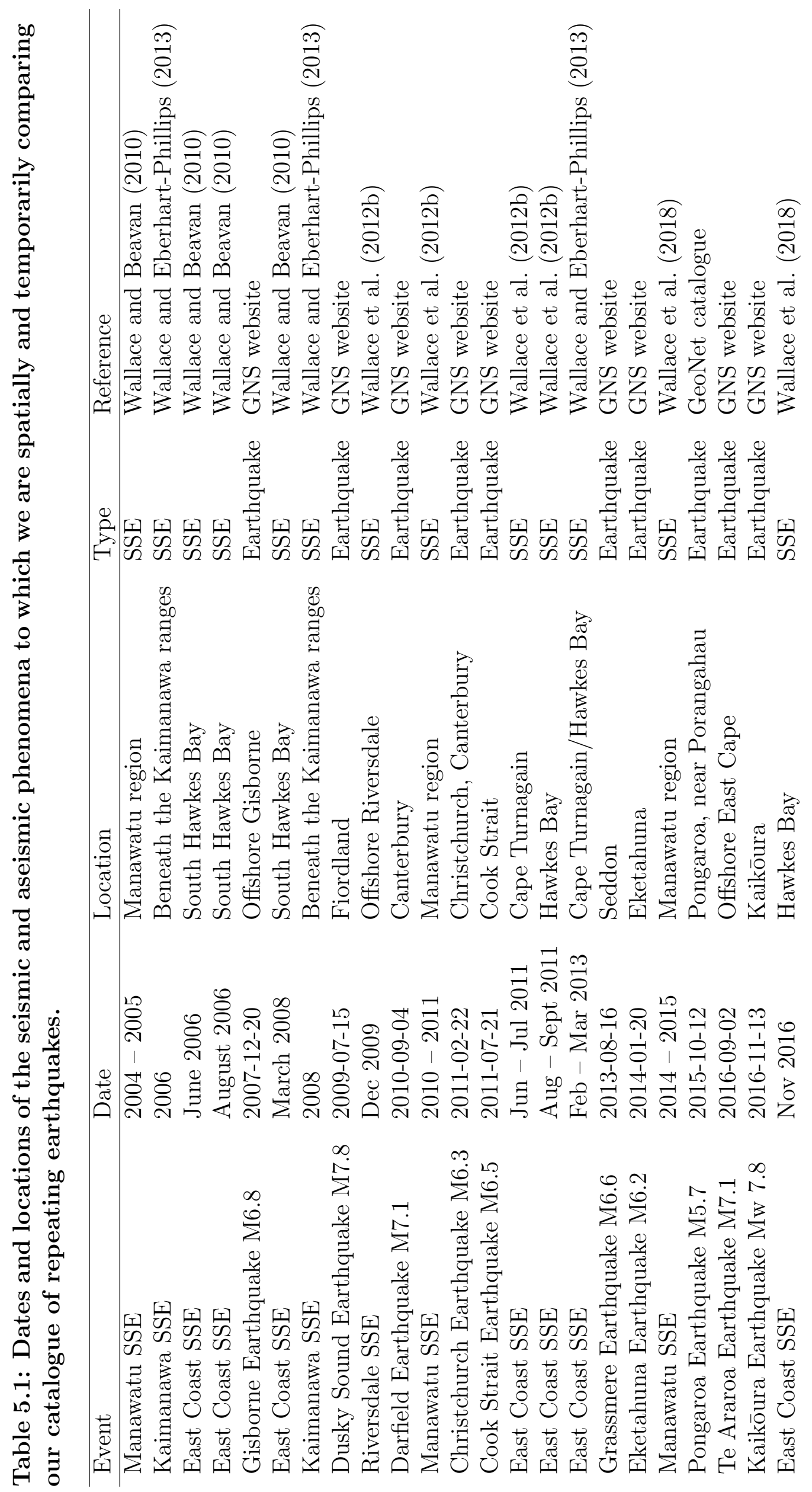


where the Riversdale slip patch is and where an imbricate wedge of high reflectivity materials has been observed (Barker et al., 2009). But only the three previously mentioned families (AK03, AK14 and AK15) can be temporally correlated to the slow slip event. This indicates that the Akitio (AK) families are well correlated spatially with the Riversdale slow slip event. But there is not a strong temporal correlation, as only three of the 40 events from Akitio Group occur during or within a few days after the slow slip event. Jacobs et al. (2016) observed an increase in seismicity south of the slow slip event, which is outside our study area. As these observations are outside our area of study, we are not able to further relate the observations of Jacobs et al. (2016) to repeating earthquakes.

Several slow slip events have occurred offshore between Cape Turnagain and southern Hawkes Bay: we refer to these events as East Coast slow slip events and we use the cumulative contour from Wallace (2020) to represent all of them. Figure 5.4 shows that most of the repeating earthquake families are located down-dip of the total modelled slip of East Coast SSEs from 2002 to 2016 from Wallace (2020). Few families in the Pacific and Australian Plates correlate spatially with the slip patch, but only families TR01, KK08 and KK04 have spatial and temporal correlations to East Coast SSE. Family TR01 is located within the Pacific Plate, with a similar depth to the subduction interface model by Williams et al. (2013) (see Figures 5.8 and 4.2) and contains four events. Two of the events in that family occur during two East Coast SSEs: the 2006 and 2008 South Hawkes Bay events. One of the three events in family KK08 has temporal correlation with the 2011 Cape Turnagain SSE. Family KK08 is not indicated in Figure 5.8 as only events occurring temporally close to the 2016 East Coast SSE are shown. Family KK04 is located on the edge of the modelled slip patch with two of four events correlating temporally to the 2013 and the 2016 slow slip events. The three mentioned families (TR01, KK08 and KK04) have more than one event that occurs during slow slip events, have depths similar to the subduction interface of Williams et al. (2013) and can be spatially correlated to the modelled slip patches. These temporal and spatial correlations suggest that some repeating earthquake families might have been triggered by the East Coast SSEs on more than one occasion.

The time-series in Figure 5.8 shows several events occurring during the 2016 East Coast SSE that are located down dip of the slip patch. These events are concentrated near the township of Porangahau and almost on the edge of the modelled slip patch. TK30 is the only interplate family occurring during the SSE and contains two events which occurred in 2010 and 2016. Families KK03, TK25 and TK26 occur in the days after the slow slip event and are also located down-dip the slip patch. Family TK27 is the only burst-type family observed temporally near the 2016 M7.8 Kaikōura earthquake 


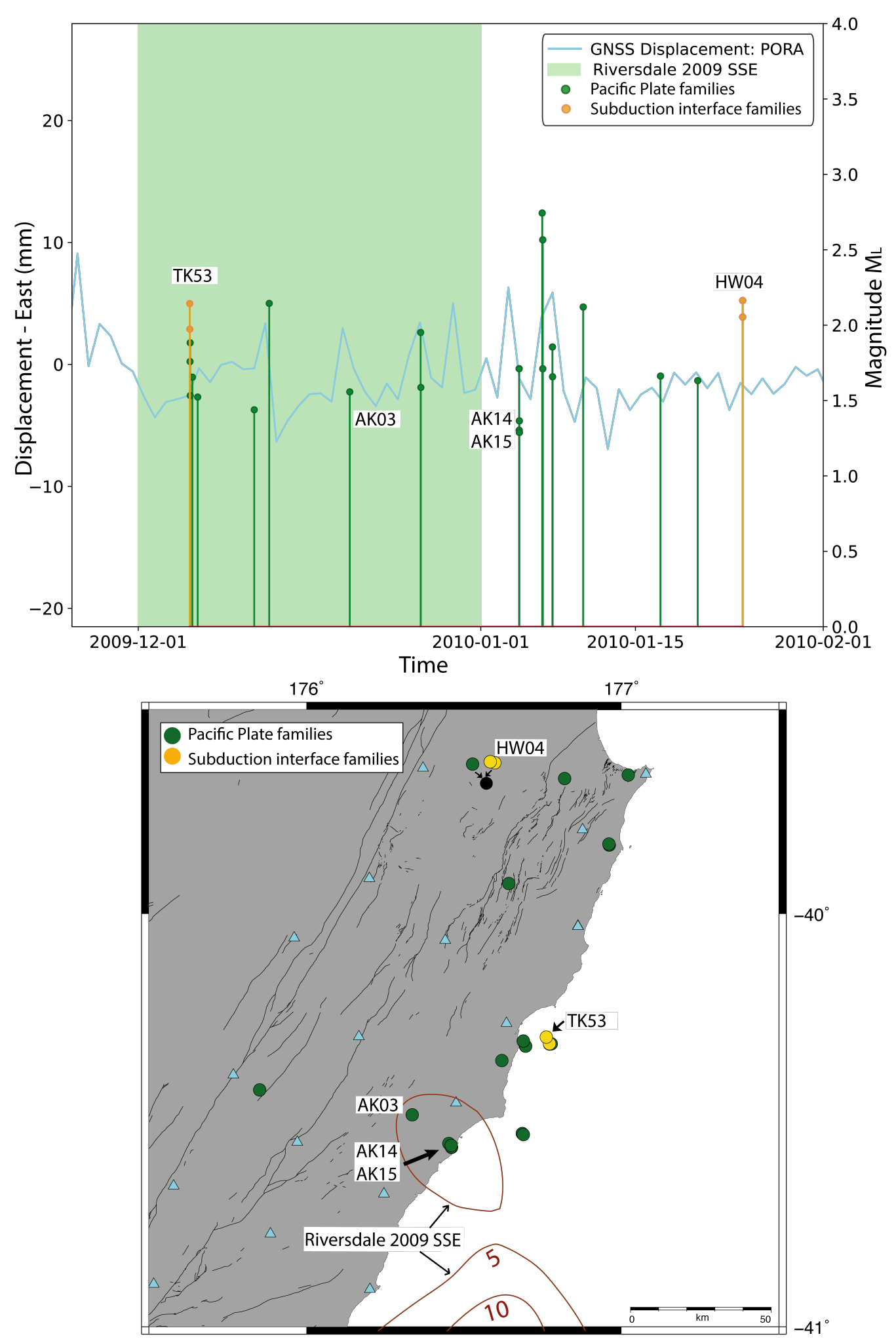

Figure 5.7: Time-series (top) and map (bottom) illustrating the repeating earthquakes that occur close in time to the 2009 Riversdale slow slip event. Events on the subduction interface are coloured in yellow and events within the Pacific Plate in green. The duration of the Riversdale slow slip event is indicated in green on the time-series and the spatial location of the modelled slip patch is marked in red contours on the map. The labelled events are the ones mentioned in the text. 
and the triggered East Coast SSE (time-series in Figure 5.8). Burst-type repeating earthquakes are frequently interpreted as arising from stress changes due to large nearby events (Igarashi et al., 2003). Yao et al. (2021) identified a strong increase in seismicity 8 days after the Kaikōura earthquake around Porangahau which temporally correlates with five of the repeating earthquakes occurring during the slow slip event (including TK30 and TK27). However, we do not observe an increase in burst-type or continualtype families after the duration of the SSE. Wallace et al. (2017) identified repeating earthquakes probably driven by the 2016 East Coast SSE, with 155 of their events also in the repeating earthquake catalogue obtained in this study (Laura Wallace, pers. comm., May 2021). When comparing the locations of repeating earthquakes, both catalogues show concentration of events near the township of Porangahau and station ANWZ. A notable difference between the two catalogues is the concentration of events near Eketāhuna in the catalogue of Wallace et al. (2017) which are not present in our repeating earthquake catalogue. Another difference is the number of families in their catalogue with more than ten events, in contrast with the largest family in our catalogue having nine events. We were not able do a more detailed comparison as we were given the list of all events not divided by family.

In terms of cumulative moment, Figure 5.6 shows an increase in cumulative moment from Pacific Plate continual-type families for the 2008 South Hawkes Bay SSE, from Australian Plate continual families for the 2011 June-July Cape Turnagain SSE, and from continual-type interplate families for the 2013 and 2016 East Coast SSEs.

Manawatu slow slip events last between 1-2 years, occur every 4-5 years and are located at depths $>25 \mathrm{~km}$ on the subduction interface (Wallace and Beavan, 2010; Wallace et al., 2018; Wallace, 2020). In this thesis, we use the cumulative contour from Wallace (2020) to represent all of the indicidual slow slip events. Figure 5.4 shows that most of our repeating earthquake families are located up-dip of the Manawatu slow slip patch contours. For example, Figure 5.9 shows that the events occurring close in time to the 2010/2011 Manawatu SSE are mostly occurring up-dip of the slip-patch, except for family RH01. Family RH01 is spatially correlated with the slip patch and has one event occurring before the SSE and the other event during (see time-series in Figure 5.9). Several repeating earthquakes are correlated temporally to this slow slip event, but only few are located on the outside of the slip patch contours and only family RH01 is well correlated spatially to the region of highest slip. This does not necessarily mean that the occurrence of these repeating earthquakes is not related to the SSE. As we mentioned in Section 5.1, the network upgrade of 2008 might be the cause of the apparent increase in identified events. Therefore, it is not possible to clearly indicate if repeating earthquakes during these years are casually linked to slow slip events. 

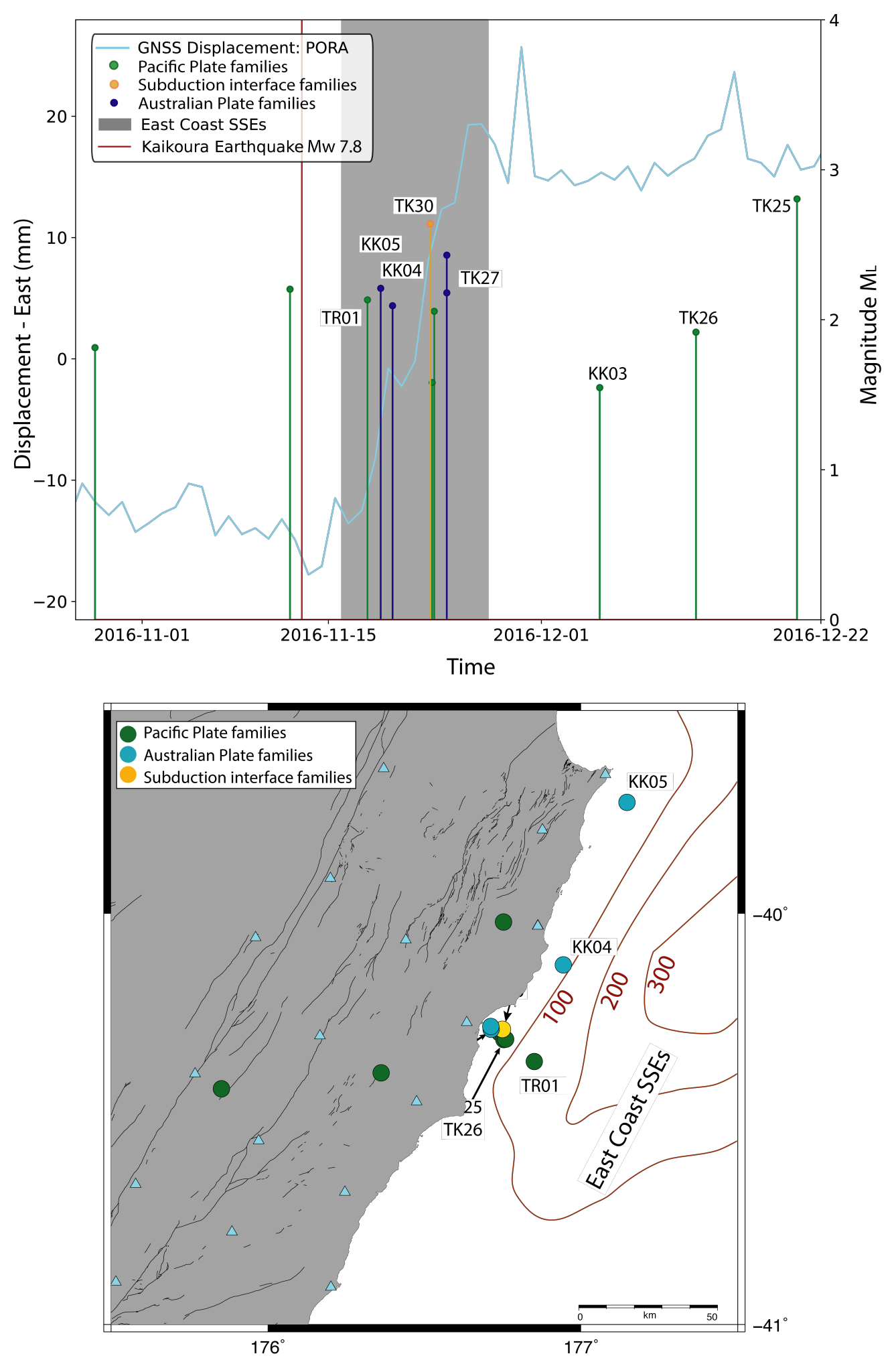

Figure 5.8: Time-series (top) and map (bottom) illustrating the repeating earthquakes that occur close in time to the 2016 triggered South Hawkes Bay slow slip event. Events on the interface are coloured in yellow, events within the Pacific Plate are green and events in the Australian Plate are blue. The duration of the East Coast slow slip event is indicated in grey on the time-series and the spatial location of the modelled slip patch is marked in red contours on the map. The 2016 M7.8 Kaikoura earthquake is indicated with a red vertical line. The labelled events are the ones mentioned through the text. 
As can be observed in the top histogram from Figures 5.5 and 5.9, the number of events identified decreases just before the 2010/2011 Manawatu slow slip event. Figure 5.6 shows an almost constant cumulative moment during this SSE for both the bursttype events and the continual-type interplate and Pacific Plate events. We observe an increase in the continual-type Australian Plate cumulative moment, most likely due to the events occurring during the SSE (Figure 5.9). For the 2014/2015 event, the cumulative moment of all types of events stays constant during the slow slip. We do not observe an decrease of seismicity before the 2014/2015 SSE analogous to that seen before the 2010/2011 and there are insufficient data to analyse the earlier 2004/2005 SSE. We were not able to identify a network or catalogue related explanation for the decrease of events. It is also interesting to note that most of the burst-type earthquakes occur between late 2008 and mid 2010, but do not show a clear spatial distribution (e.g. Figure 5.9). Therefore, we are not able to correlate them with known spatial phenomena and characteristics of the Hikurangi margin such as coupling of the interface, slow slip events, large earthquakes in the area or faults.

Deep Kaimanawa SSEs occurred in 2006 and 2008 beneath the Kaimanawa Ranges, down-dip of the shallow East Coast SSEs Wallace and Eberhart-Phillips (2013). The repeating earthquake families that correlate spatially to the SSEs are mostly from the Hastings West (HW) and Hastings East (HE) groups. Most of the families from these groups are located within the Pacific Plate, but close to the interface. We observe an increase of burst-type earthquakes from the Hasting East (HE) Group in August 2008, a month after the end date we inferred for the 2008 Kaimanawa SSE (see time-series of Figure 5.10). Family HW02 is the only family that correlates spatially and has one event occurring during the slow slip.

Although tremor has been identified in our study area (Ide, 2012; Romanet and Ide, 2019) near Cape Turnagain, we do not observe a clear temporal relationship between tremor occurrence and number of events or cumulative moment.

Repeating earthquakes have been found to be triggered by nearby large earthquakes (e.g. Chen et al., 2013; Kimura et al., 2006; Templeton et al., 2008; Nadeau et al., 1995; Igarashi et al., 2003). We analysed the temporal relationship between our repeating earthquake catalogue and the largest earthquakes that occurred in New Zealand during our study period (Figures 5.8 and 5.6). The only clear temporal relationship was with the M7.8 Kaikōura earthquake, which occurred in November 2016. As described earlier, we found 10 events in the month following the Kaikōura earthquake (Figure 5.8), two from a burst-type family (TK27). Additionally, we observe a small increase in the cumulative moment in interplate and Pacific Plate families after the Kaikōura 

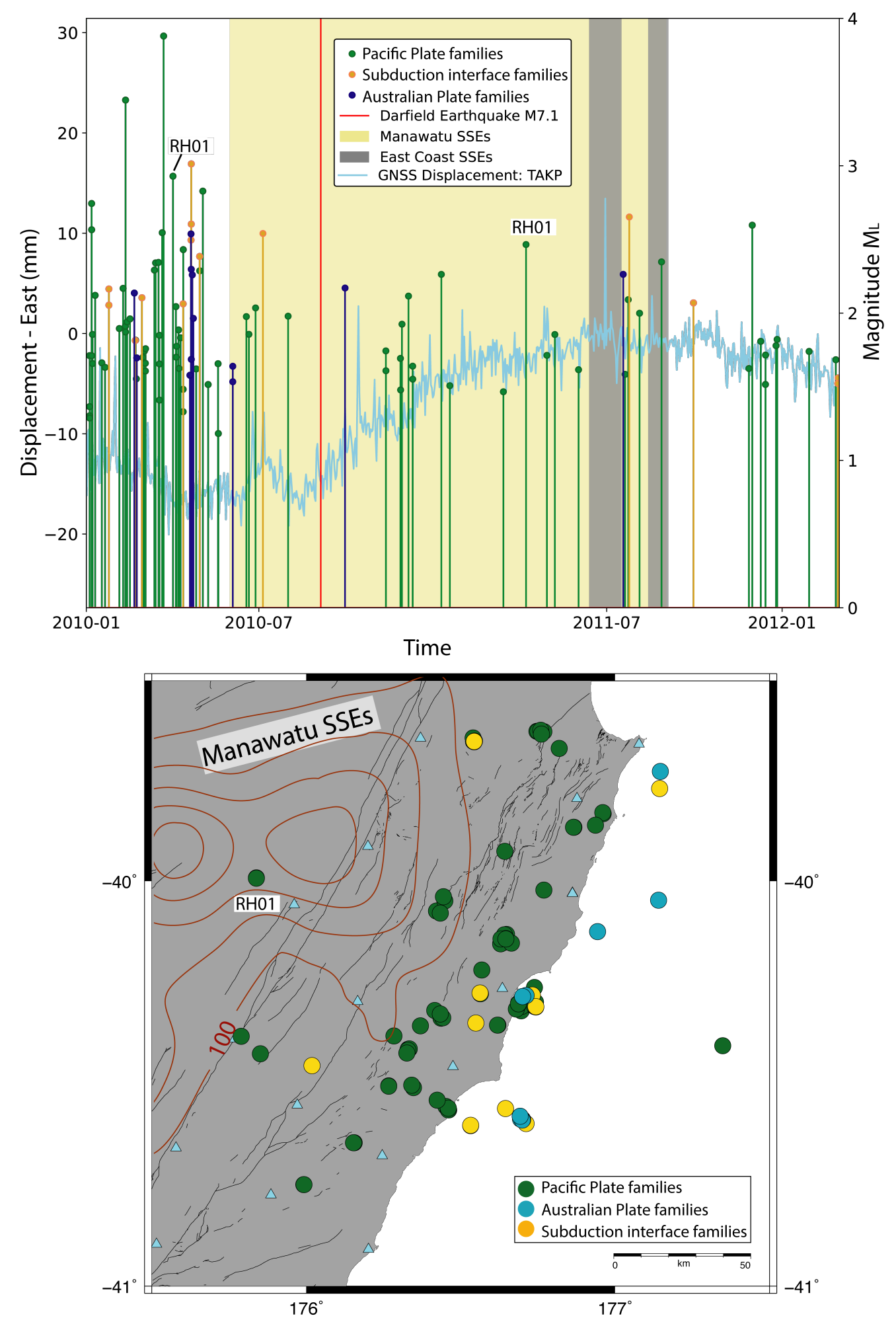

Figure 5.9: Time-series (top) and map (bottom) illustrating the repeating earthquakes that occur close in time to the 2010/2011 Manawatu slow slip event. Events on the interface are coloured in yellow, events within the Pacific Plate are green and events in the Australian Plate are blue. The duration of the 2010/2011 Manawatu slow slip event is indicated in yellow on the time-series and the spatial location of the modelled slip patch is marked in red contours on the map. The labelled events are the ones mentioned in the text. 

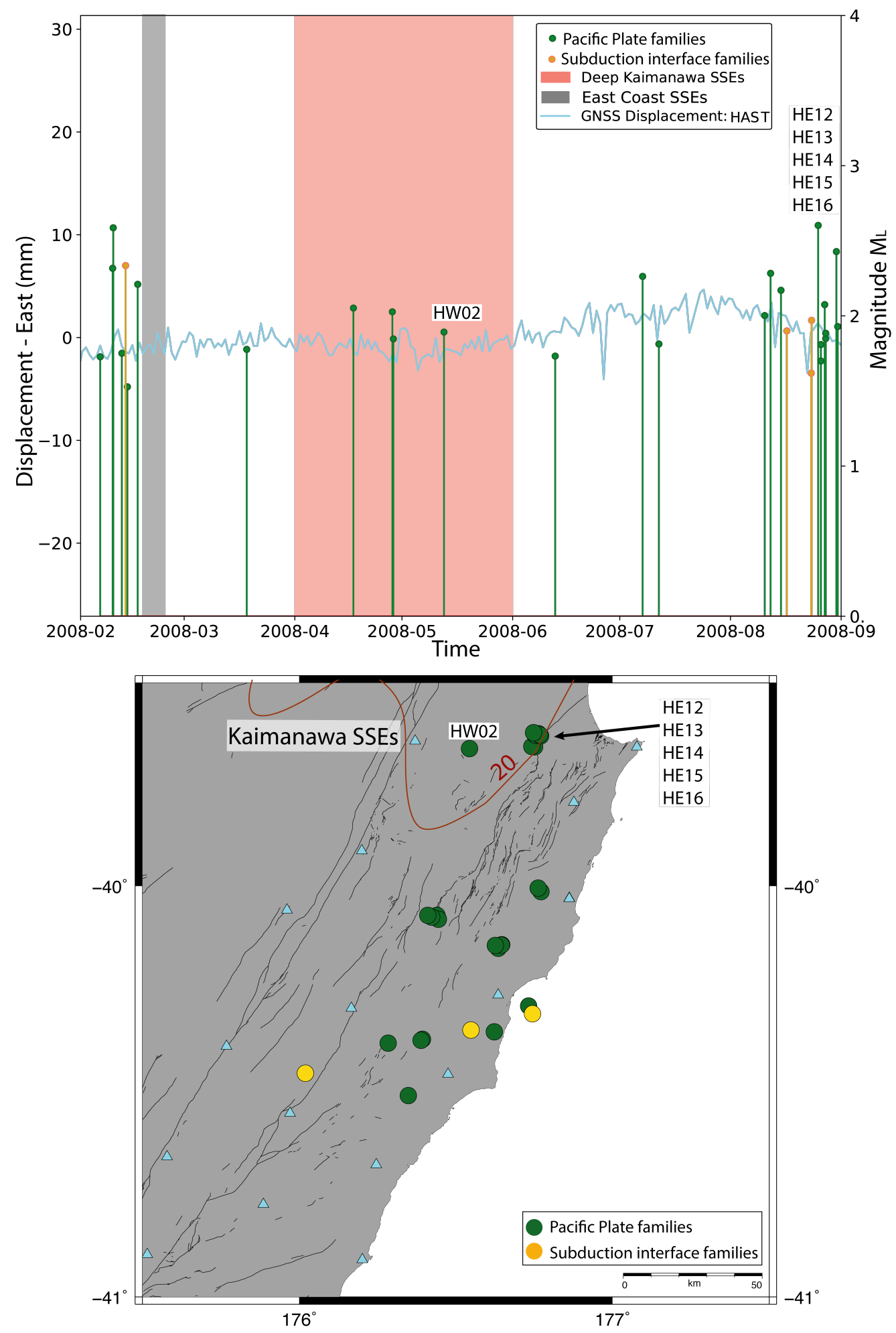

Figure 5.10: Time-series (top) and map (bottom) illustrating the repeating earthquakes that occur close in time to the 2008 Kaimanawa slow slip event. Events on the interface are coloured in yellow and events within the Pacific Plate are green. No events in the Australian Plate are observed in this time period. The duration of the 2008 Kaimanawa slow slip event is indicated in light red on the time-series and the spatial location of the modelled slip patch is marked in red contours on the map. The labelled events are the ones mentioned in the text. 
earthquake and during the triggered 2016 East Coast SSE. This increase in cumulative moment results from the events showed in Figure 5.8.

There is a significant increase in cumulative moment from interplate families in late 2012 that has no temporal correlation with any known seismic or aseismic occurrences (Figure 5.6). We also observe a step in the cumulative moment of Pacific continualtype families in late 2012 and of continual interplate families in mid 2018 that also correlate with displacements of $\sim 20 \mathrm{~mm}$ at the GNSS station PORA time signal 5.6. From the top histogram in Figure 5.5, we observe an increase in the frequency of the burst-type events. While this increase is not as big as the events between late 2008 and mid 2010, it clearly stands out from the previous years. There are no reported seismic or aseismic phenomena that correlate temporarily with the observations mentioned in this paragraph.

There are a variety of slow slip events that occur in our area of study near Porangahau. Even though some repeating earthquakes correlate spatially and temporally with slow slip events, Figure 5.4 shows that most of the repeating events are located outside the slip patches, except for the 2009 Riversdale SSE. Taikorai Group (TK), located near the township of Porangahau, has the largest number of families and they are mostly located on the transition from strongly- to weakly-coupled subduction interface. The scarce and sparse temporal and spatial correlations between slow slip events and repeating earthquakes indicate that repeating earthquakes are not solely driven by slow slip events. But there is also evidence that slow slip events in the Hikurangi margin have triggered seismicity (Delahaye et al., 2009; Jacobs et al., 2016), burst-type repeating earthquakes (Shaddox and Schwartz, 2019; Warren-Smith et al., 2018) and repeating earthquakes triggered by a slow slip event (Wallace et al., 2017). While some repeating earthquakes may be triggered by dynamic or static stress changes for nearby SSEs or earthquakes, others may not be, because they have not experienced sufficient stress accumulation since their last rupture to be triggered again. The triggering of repeating earthquakes would entail, based on the elastic rebound theory Reid (1910), that the shear stress accumulated on the asperity patch is close to $\tau_{1}$ (Figures 2.3 and 2.4) when the stress perturbation due to slow slip events occur. 


\subsection{Seismic moment-recurrence interval relation- ship}

Nadeau and Johnson (1998) developed a scaling relationship for repeating earthquakes in California using seismic moment and recurrence interval. This relationship is based on the presumption that repeating earthquakes are the result of cyclic loading (Section 2.3), which means that events with larger magnitudes are expected after longer recurrence interval times. The relationship for repeating earthquake families occurring at Parkfield, California stands as:

$$
\log (T r)=4.85+0.17 \log \left(M_{0}\right)
$$

Here $\operatorname{Tr}$ is the recurrence interval in seconds and $M_{0}$ is the seismic moment in dynecm obtained using the relationship derived by Hanks and Kanamori (1979) (Equation 3.11). This seismic moment-recurrence interval relationship appears to hold in other regions including Japan, Taiwan, Tonga-Kermadec-Vanuatu, and Mexico (e.g. Chen et al., 2007; Chen and Lapusta, 2009; Yu, 2013; Schaff and Richards, 2011; Dominguez et al., 2016; Uchida et al., 2019).

As mentioned in Section 2.3.1, burst-type repeating earthquakes cannot be explained by constant loading-rate models due to their short family duration and inter-event times. For this reason we only used continual-type repeating earthquake families, which we established as having a family duration larger than a year. We established this duration based on arguments presented by Mesimeri and Karakostas (2018) and Hughes et al. (2021). This criterion yields 116 continual-type families and 107 burst-type families (Figure 5.5). Figure 5.11 shows the moment-recurrence interval relationship of the continual-type repeating earthquake families near Porangahau, separated based on location, along with results from different studies. To allow comparison of $\operatorname{Tr}-M_{0}$ relationships, we normalized the recurrence interval by the ratio of plate convergence rates between California and the Hikurangi margin, using a convergence rate of $40 \mathrm{~mm} / \mathrm{yr}$ for the region near Porangahau and $23 \mathrm{~mm} / \mathrm{yr}$ for Parkfield (Chen et al., 2007). Then, we fitted a linear relationship to the logarithms of $\operatorname{Tr}$ and $M_{0}$ by minimising the L1 norm. Table 5.2 summarises the regression models of the calculated $\operatorname{Tr}-M_{0}$ relationships with $95 \%$ confidence intervals.

The families located on the subduction interface present a linear relationship with slope similar to the relationship from Parkfield data, but the $95 \%$ confidence intervals of the regression model are significantly higher than the ones obtained by Nadeau 


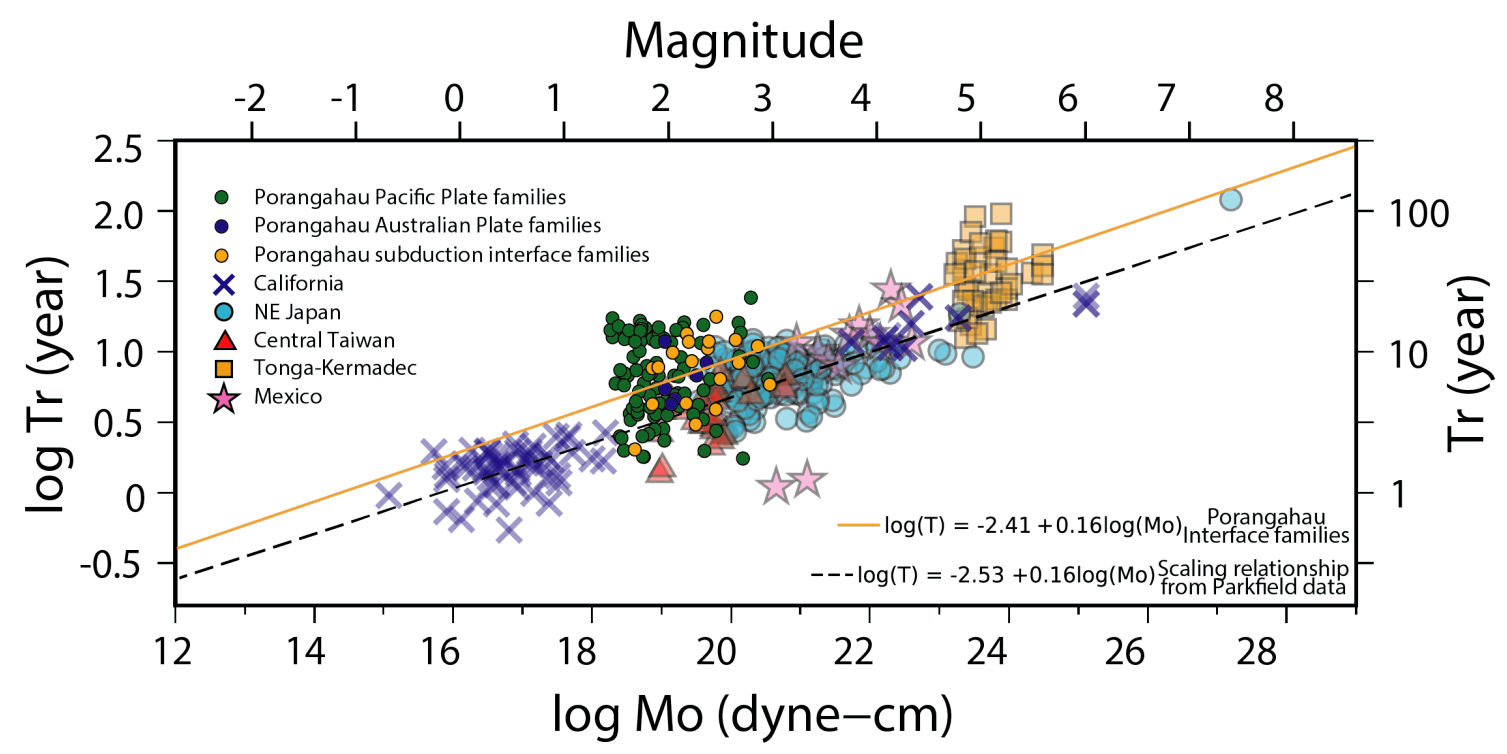

Figure 5.11: Relationship between moment and recurrence interval for repeating earthquake families near Porangahau and other published studies. Families near Porangahau are separated based on whether they are located in the Australian Plate (blue), within the Pacific Plate (green) or on the subduction interface (yellow). The yellow line represents the fitted regression line for the continual-type Porangahau interplate families and the dashed line the scaling relationship from Parkfield data Nadeau and Johnson (1998); Chen et al. (2007). Figure modified from Uchida (2019).

and Johnson (1998). The families located in the Australian Plate and Pacific Plate yield regression models considerably different from the Nadeau and Johnson (1998) relationship, especially the families in the Pacific Plate which are fitted by an almost horizontal line with slope close to zero and large $95 \%$.

Even though the uncertainty associated with the regression models is high, the repeating earthquakes near Porangahau present similar values to some of the NE Japan (blue circles) and Central Taiwan (red triangles) repeating earthquakes (Figure 5.11). This suggests that the calculated values of recurrence interval and seismic moment for repeating earthquakes near Porangahau are within the ranges of global observations and the processes responsible for the recurrence of repeating earthquakes near Porangahau are similar to the processes from other settings (Chen et al., 2007). However, this does not mean that the relationships derived by Nadeau and Johnson (1998) using repeating earthquakes in California holds perfectly for repeating earthquakes near Porangahau, as verified by the values and quality of the linear fits (see Table 5.2). Therefore, results from this and other relationships (e.g. Equation 5.3) derived from repeating earthquakes in other settings need to be interpreted with caution. 
Table 5.2: Summary of the seismic moment-recurrence interval relationship identified for repeating earthquakes near Porangahau compared to the identified by Nadeau and Johnson (1998). Intercepts are in seconds (s) to allow comparison to the relationship derived by Nadeau and Johnson (1998). 95\% confidence intervals for the gradient and intercept are included in the brackets.

\begin{tabular}{lll}
\hline Location & Intercept & Gradient \\
\hline Australian Plate & $5.88[5.32-6.44]$ & $0.12[-0.67-0.91]$ \\
Interface & $5.085[4.47-5.69]$ & $0.16[-0.06-0.38]$ \\
Pacific Plate & $8.20[7.95-8.45]$ & $0.006[-0.10-0.11]$ \\
Nadeau and Johnson (1998): Parkfield, California & $4.85 \pm 0.16$ & $0.17 \pm 0.009$ \\
\hline
\end{tabular}

\subsection{Slip-rate relationships}

The cumulative slip associated with repeating earthquakes is thought to reflect the slip history of the aseismic slip in the region surrounding the asperities (Nadeau and Johnson, 1998; Igarashi et al., 2003; Chen et al., 2007; Yu, 2013). Therefore, several studies have used repeating earthquakes to estimate the spatio-temporal distribution of interplate creep. Repeating earthquakes have been used to estimate creep on faults in several studies (e.g. Nadeau and Johnson, 1998; Uchida et al., 2003; Chen et al., 2007; Igarashi et al., 2003; Li et al., 2011; Yu, 2013; Mavrommatis et al., 2015; Dominguez et al., 2016). Nadeau and Johnson (1998) developed a relationship between slip $(d)$ and moment $\left(M_{0}\right)$ based on repeating earthquakes in California:

$$
\log (d)=-2.36+0.17 \log \left(M_{0}\right)
$$

where slip, $d$ is given in centimetres and $M_{0}$ in dyne-cm. We applied this relationship to 19 continual-type families located on the subduction interface. We then divided the obtained slip value by the duration of each family in years and converted units to $\mathrm{mm}$ to obtain a slip rate in $\mathrm{mm} / \mathrm{yr}$. The slip-rate values are shown in Table 5.3 their distribution is shown in Figure 5.12.

At the Hikurangi margin, the Pacific Plate is subducting under the Australian Plate at convergence rate that decreases from $\sim 54 \mathrm{~mm} /$ yr near offshore Raukumara Peninsula to $\sim 32 \mathrm{~mm} /$ yr offshore Wairarapa. For the region near Porangahau, the convergence rate at the trench is $\sim 40 \mathrm{~mm} / \mathrm{yr}$. Family TK44, located near the township of Porangahau, has a remarkably high slip-rate value of $40 \mathrm{~mm} / \mathrm{yr}$ in comparison to the rest of the families, which average $14 \mathrm{~mm} / \mathrm{yr}$ (Figure 5.12). Most of the families are located close to each other near the township of Porangahau, which means that we are not able to observe spatial variations in slip-rates. The values we calculated, except for 
family TK44, are lower than the convergence rate. As mentioned in Section 5.4, the results obtained using the relationships proposed by Nadeau and Johnson (1998) must be interpreted with caution as they were developed using earthquakes in California. Moreover, although the linear recurrence interval-seismic moment fitting model for interplate families has a slope similar to that proposed by Nadeau and Johnson (1998), the $95 \%$ confidence intervals are wide. This suggests the possibility that the repeating earthquakes near Porangahau might not be capturing the whole slip-rate when using the relationship developed by Nadeau and Johnson (1998).

Other proposed repeating earthquake models take into consideration an aseismic component or variable slip-rates. The model proposed by Beeler et al. (2001), contains an asesimic component in the asperities, where asperities continuously creep and strain harden until reaching a failure threshold and the models by Mavrommatis et al. (2015) and Nomura et al. (2017) include variable slip-rates. Future modelling of slip of repeating earthquakes near Porangahau considering an aseismic component within the asperities or variable slip-rates, could complement the results obtained using Nadeau and Johnson (1998)'s relationship.

Regarding the convergence rate near Porangahau, the $\sim 40 \mathrm{~mm} / \mathrm{yr}$ previously mentioned includes the margin-normal motion and the margin-parallel motion. According to Nicol and Wallace (2007), at the Hikurangi margin, $85 \%$ of the margin-normal motion is accommodated on the plate interface and $\geq 60 \%$ of the margin-parallel motion is accommodated by strike-slip faulting and vertical-axis rotations in the upper plate. We decomposed the $\sim 40 \mathrm{~mm} /$ yr plate convergence vector into margin-normal and marginparallel motion using and angle of $51^{\circ}$ / between the Pacific Plate motion vector and the trench offshore Porangahau. Adding the $65 \%$ of the normal-margin motion and $40 \%$ of the parallel-margin motion results in $\sim 28 \mathrm{~mm} / \mathrm{yr}$ being accommodated on the plate interface near Porangahau. Although a value of $\sim 28 \mathrm{~mm} / \mathrm{yr}$ of plate convergence is closer than $\sim 40 \mathrm{~mm} /$ yr to the average slip-rate obtained from repeating earthquakes, these results need to be interpreted with caution due to the poorly constrained values used (e.g. percentages of normal and parallel motion, and angle between the trench and motion vector). As not all the plate convergence motion is assumed to be on the subduction interface (Nicol et al., 2007; Nicol and Wallace, 2007) and other structures might also accommodate part of the convergence motion, comparison between slip-rates from repeating earthquakes and plate converge is limited.

The slip-rate value of family TK44 is close to the $\sim 40 \mathrm{~mm} / \mathrm{yr}$ convergence rate, but it is also important to note that this family only has two events and has the shortest family duration of all the families with calculated slip-rates. As mentioned in Section 5.1, the 


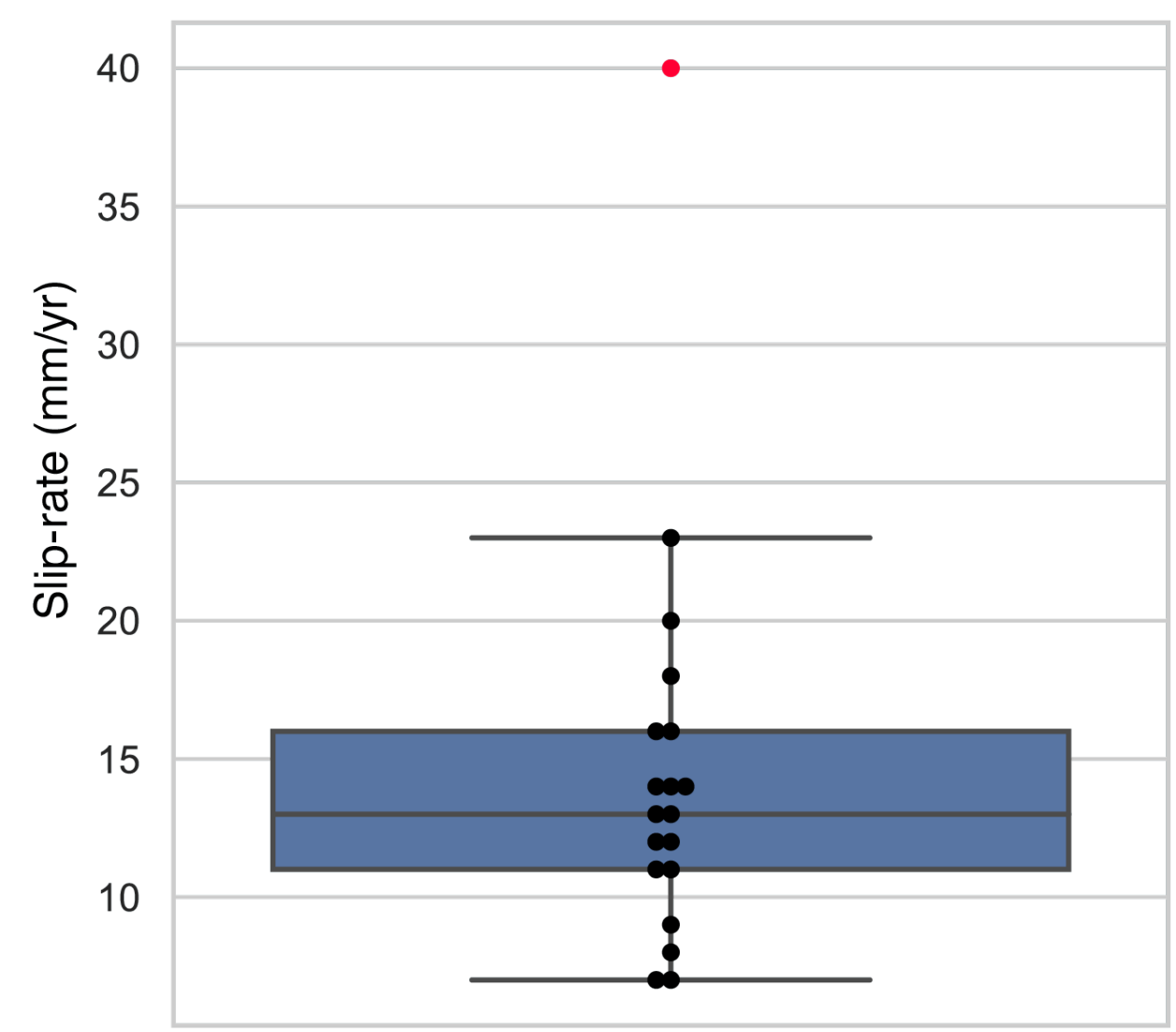

Figure 5.12: Box plot illustrating the distribution of slip-rate values obtain from repeating earthquakes near Porangahau. Slip-rates were calculated using the slip-seismic moment relationship derived by Nadeau and Johnson (1998). Each circle represents a family, with outlier family TK44 in red.

completeness of the GeoNet catalogue affects the completeness of the repeating earthquakes catalogue, including the duration of the families. The matched-filter analysis that is currently in process will identify any missing events within families, providing with reliable family duration's to further analyse slip-rates. 
Table 5.3: Slip-rates calculated from the slip-seismic moment relationship derived by Nadeau and Johnson (1998). $\mathrm{N}$ indicates the number of events in the family.

\begin{tabular}{lccc}
\hline Family ID & N & Slip-rate $(\mathrm{mm} / \mathrm{yr})$ & Family \\
\hline CT3 & 2 & 11 & 7.6 \\
CT5 & 3 & 7 & 12.0 \\
DV5 & 3 & 13 & 7.3 \\
DV9 & 4 & 14 & 6.7 \\
HW4 & 5 & 12 & 7.0 \\
KK9 & 3 & 14 & 4.8 \\
TK2 & 3 & 8 & 9.7 \\
TK13 & 2 & 20 & 6.2 \\
TK18 & 2 & 13 & 5.6 \\
TK19 & 3 & 7 & 8.7 \\
TK22 & 2 & 9 & 10.0 \\
TK23 & 4 & 11 & 7.4 \\
TK30 & 2 & 14 & 6.7 \\
TK33 & 2 & 12 & 6.7 \\
TK40 & 2 & 23 & 4.7 \\
TK42 & 2 & 16 & 4.4 \\
TK43 & 2 & 16 & 6.9 \\
TK44 & 2 & 40 & 3.3 \\
TK46 & 4 & 18 & 3.5 \\
\hline
\end{tabular}




\subsection{Conclusions and future work}

We successfully identified 532 repeating earthquakes occurring between 2004 and 2018 near Porangahau using a multisegment normalized cross-correlation threshold of 0.95 on three or more stations. The identified repeating earthquakes were clustered into 225 families using hierarchical clustering and then separated into 16 geographical groups. The final repeating earthquake catalogue includes precise absolute and relative locations, local magnitudes calibrated with moment magnitude and high-quality focal mechanisms. We are aware of the effects of the completeness of the GeoNet catalogue in the duration and recurrence intervals of the identified repeating earthquake families. Events identified with the matched-filter, that is currently in process, will provide better constrained duration and interval times.

With precise locations and well-constrained focal mechanisms, we determined the repeating earthquake families to occur within the Pacific Plate, Australian Plate or on the subduction interface. Most of the families are located in the Pacific Plate and although some are close to the subduction interface model of Williams et al. (2013), most do not have a thrust focal mechanism required to conclude that they might be on the subduction interface. Additional work to constrain focal mechanisms using $\mathrm{P}-\mathrm{S}$ ratios or waveform modelling may move some families from the Pacific Plate or Australian Plate to the interface grouping. Most of the interplate families belong to Taikorai group (TK) and are located in the transition between locked and creeping, near the township of Porangahau.

We observe that most of our repeating earthquake families are located down-dip of the East Coast SSEs and up-dip of the Manawatu SSEs, outside the modelled slip contours. The Akitio (AK) families are well correlated spatially with the Riversdale slow slip event as they are located where the 2009 Riversdale slip patch is. Moreover, there is not a strong temporal correlation, as only three of the 40 events from Akitio Group occur during or just after the slow slip event. The scarce and sparse temporal and spatial correlations between slow slip events and repeating earthquakes, indicate that repeating earthquakes are not solely driven by slow slip events. Although we are not able to discriminate between triggered and non-triggered repeating earthquakes, studies have observed triggered seismicity (Delahaye et al., 2009; Jacobs et al., 2016) and burst-type repeating earthquakes (Shaddox and Schwartz, 2019; Warren-Smith et al., 2018) due to slow slip events in the Hikurangi Margin. Temporal and spatial correlations are strongly dependent on the start and end dates of slow slip events and on the contours plotted. The actual slip patches of slow slip events might encompass 
smaller or larger areas, which adds uncertainty to the possible correlations between slow slip events and repeating earthquakes. Overall, there are no clearly constrained spatial or temporal patterns between slow slip events and repeating earthquakes for the region near Porangahau.

In relation to large earthquakes, we identified 10 events in the month following the Kaikōura earthquake and observe a small increase in the cumulative moment of interplate and Pacific Plate families after the Kaikōura earthquake and during the triggered 2016 East Coast SSE.

From the recurrence interval-seismic moment relationship, we observe that the linear fit of continual-type interplate events has a slope similar to that of the relationship derived by Nadeau and Johnson (1998), but with high uncertainties. For the slip-rates obtained, we are not able to perform a spatial analysis due to the clustered distribution of interplate families. Excluding family TK44, the slip rates obtained are significantly lower than the plate converge rate for the region. There is the possibility that by using the relationships from Nadeau and Johnson (1998), repeating earthquakes near Porangahau are not representing the whole slip-rate of the plate interface. Other proposed repeating models, take into consideration an aseismic component or variable slip-rates. Future modelling of slip during repeating earthquakes near Porangahau might consider including an aseismic component or variable slip-rates (Beeler et al., 2001; Mavrommatis et al., 2015; Nomura et al., 2017) the amount of motion accommodated on the plate interface. Repeating earthquakes do not show a distribution determined by the coupling state of the interface.

This study confirms the existence of repeating earthquakes near Porangahau and provides the first comprehensive spatiotemporal analysis of repeating earthquakes in relation to seismic and aseismic phenomena near Porangahau. The insights gained from this study lay the groundwork for future work constraining processes of stress accumulation at the creeping to locked transition zone near Porangahau. 


\section{Bibliography}

Abercrombie, R. E. (2014). Stress drops of repeating earthquakes on the San Andreas Fault at Parkfield. Geophysical Research Letters, 41(24):8784-8791.

Aki, K. (1984). Asperities, barriers, characteristic earthquakes and strong motion prediction. Journal of Geophysical Research, 89(B7):5867-5872.

Allmann, B. P. and Shearer, P. M. (2009). Global variations of stress drop for moderate to large earthquakes. Journal of Geophysical Research: Solid Earth, 114(1):1-22.

Arnold, R. and Townend, J. (2007). A Bayesian approach to estimating tectonic stress from seismological data. Geophysical Journal International, 170(3):1336-1356.

Aster, B. Y. R. C. and Scott, J. (1993). Comprehensive characterization of waveform similarity in microearthquake data sets. Bulletin of the Seismological Society of America, 83(4):1307-1314.

Avouac, J. P. (2015). From geodetic imaging of seismic and aseismic fault slip to dynamic modeling of the seismic cycle. Annual Review of Earth and Planetary Sciences, 43:233-271.

Ballance, P. F. (1976). Evolution of the Upper Cenozoic magmatic arc and plate boundary in northern New Zealand. Earth and Planetary Science Letters, 28(3):356370 .

Bar-Joseph, Z., Gifford, D. K., and Jaakkola, T. S. (2001). Fast optimal leaf ordering for hierarchical clustering. Bioinformatics, 17.

Barker, D. H., Sutherland, R., Henrys, S., and Bannister, S. (2009). Geometry of the Hikurangi subduction thrust and upper plate, North Island, New Zealand. Geochemistry, Geophysics, Geosystems, 10(2).

Barnes, P. M., Lamarche, G., Bialas, J., Henrys, S., Pecher, I., Netzeband, G. L., Greinert, J., Mountjoy, J. J., Pedley, K., and Crutchley, G. (2010). Tectonic and geological framework for gas hydrates and cold seeps on the Hikurangi subduction margin, New Zealand. Marine Geology, 272:26-48.

Bassett, D., Sutherland, R., Henrys, S., Stern, T., Scherwath, M., Benson, A., Toulmin, S., and Henderson, M. (2010). Three-dimensional velocity structure of the northern Hikurangi margin, Raukumara, New Zealand: Implications for the growth 
of continental crust by subduction erosion and tectonic underplating. Geochemistry, Geophysics, Geosystems, 11(10).

Beanland, S. and Haines, J. (1998). The kinematics of active deformation in the North Island, New Zealand, determined from geological strain rates. New Zealand Journal of Geology and Geophysics, 41(4):311-323.

Beeler, N. M., Lockner, D. L., and Hickman, S. H. (2001). A simple stick-slip and creep-slip model for repeating earthquakes and its implication for microearthquakes at Parkfield. Bulletin of the Seismological Society of America, 91(6):1797-1804.

Beyreuther, M., Barsch, R., Krischer, L., Megies, T., Behr, Y., and Wassermann, J. (2010). ObsPy: A python toolbox for seismology. Seismological Research Letters, $81(3): 530-533$.

Boese, C. M., Townend, J., Smith, E., and Stern, T. (2012). Microseismicity and stress in the vicinity of the Alpine Fault, central Southern Alps, New Zealand. Journal of Geophysical Research: Solid Earth.

Bohnhoff, M., Wollin, C., Domigall, D., Küperkoch, L., Martínez-Garzón, P., Kwiatek, G., and Malin, P. E. (2017). Repeating Marmara Sea earthquakes: Indication for fault creep. Geophysical Journal International, 210(1):332-339.

Bormann, P., Baumbach, M., Bock, G., Grosser, H., Choy, G. L., and Boatwright, J. (2009). Seismic sources and source parameters. New Manual of Seismological Observatory Practice (NMSOP-1), pages 1-94.

Brune, J. N. (1970). Tectonic stress and the spectra of seismic shear waves from earthquakes. Journal of Geophysical Research, 75(26):4997-5009.

Bürgmann, R., Kogan, M. G., Steblov, G. M., Hilley, G., Levin, V. E., and Apel, E. (2005). Interseismic coupling and asperity distribution along the Kamchatka subduction zone. Journal of Geophysical Research: Solid Earth, 110(7):1-17.

Chamberlain, C. J., Hopp, C. J., Boese, C. M., Warren-Smith, E., Chambers, D., Chu, S. X., Michailos, K., and Townend, J. (2018). EQcorrscan: Repeating and near-repeating earthquake detection and analysis in python. Seismological Research Letters, 89(1):173-181.

Chamberlain, C. J., Townend, J., and Thomas, A. (2019). A repeating earthquake catalog for New Zealand. In SSA Annual Meeting Abstracts.

Chen, K. H., Bürgmann, R., and Nadeau, R. M. (2013). Do earthquakes talk to each other? Triggering and interaction of repeating sequences at Parkfield. Journal of Geophysical Research: Solid Earth, 118(1):165-182.

Chen, K. H., Bürgmann, R., Nadeau, R. M., Chen, T., and Lapusta, N. (2010). Postseismic variations in seismic moment and recurrence interval of repeating earthquakes. Earth and Planetary Science Letters, 299(1-2):118-125. 
Chen, K. H., Nadeau, R. M., and Rau, R. J. (2007). Towards a universal rule on the recurrence interval scaling of repeating earthquakes? Geophysical Research Letters, $34(16): 1-5$.

Chen, K. H., Nadeau, R. M., and Rau, R. J. (2008). Characteristic repeating earthquakes in an arc-continent collision boundary zone: The Chihshang fault of eastern Taiwan. Earth and Planetary Science Letters, 276(3-4):262-272.

Chen, T. and Lapusta, N. (2009). Scaling of small repeating earthquakes explained by interaction of seismic and aseismic slip in a rate and state fault model. Journal of Geophysical Research: Solid Earth, 114(1):1-12.

Clark, K., Howarth, J., Litchfield, N., Cochran, U., Turnbull, J., Dowling, L., Howell, A., Berryman, K., and Wolfe, F. (2019). Geological evidence for past large earthquakes and tsunamis along the Hikurangi subduction margin, New Zealand. Marine Geology, 412(October 2018):139-172.

Clark, K. J., Hayward, B. W., Cochran, U. A., Wallace, L. M., Power, W. L., and Sabaa, A. T. (2015). Evidence for past subduction earthquakes at a plate boundary with widespread upper plate faulting: Southern Hikurangi margin, New Zealand. Bulletin of the Seismological Society of America.

Davy, B. and Wood, R. (1994). Gravity and magnetic modelling of the Hikurangi Plateau. Marine Geology, 118(1-2):139-151.

Deichmann, N. and Garcia-Fernandez, M. (1992). Rupture geometry from highprecision relative hypocentre locations of microearthquake clusters. Geophysical Journal International, 110:501-517.

Delahaye, E. J., Townend, J., Reyners, M. E., and Rogers, G. (2009). Microseismicity but no tremor accompanying slow slip in the Hikurangi subduction zone, New Zealand. Earth and Planetary Science Letters.

DeMets, C., Gordon, R. G., and Argus, D. F. (2010). Geologically current plate motions. Geophysical Journal International, 181:1-80.

Dominguez, L. A., Taira, T., and Santoyo, M. A. (2016). Spatiotemporal variations of characteristic repeating earthquake sequences along the Middle America Trench in Mexico. Journal of Geophysical Research: Solid Earth, 121(12):8855-8870.

Doser, D. I. and Webb, T. H. (2003). Source parameters of large historical (19171961) earthquakes, North Island, New Zealand. Geophysical Journal International, 152:795-832.

Eberhart-Phillips, D. and Bannister, S. (2015). 3-D imaging of the northern Hikurangi subduction zone, New Zealand: variations in subducted sediment, slab fluids and slow slip. Geophysical Journal International, 201(2):838-855.

Eberhart-Phillips, D., Bannister, S., and Reyners, M. (2017). New Zealand Wide Model 2.1 Seismic Velocity Model For New Zealand (Version 2.1) [Data set]. 
Eberhart-Phillips, D., Reyners, M., Faccenda, M., and Naliboff, J. (2013). Alongstrike variation in subducting plate seismicity and mantle wedge attenuation related to fluid release beneath the North Island, New Zealand. Physics of the Earth and Planetary Interiors, 225:12-27.

Ellsworth, W. L. (1995). Characteristic earthquakes and long-term earthquake forecasts: Implications of central California seismicity. Urban Disaster Mitigation: The Role of Engineering and Technology, pages 1-14.

Frohlich, C. (1992). Triangle diagrams: ternary graphs to display similarity and diversity of earthquake focal mechanisms. Physics of the Earth and Planetary Interiors, 75(1-3):193-198.

Frohlich, C. and Apperson, K. D. (1992). Earthquake focal mechanisms, moment tensors, and the consistency of seismic activity near plate boundaries. Tectonics, 11(2):279-296.

Fry, B., Chao, K., Bannister, S., Peng, Z., and Wallace, L. (2011). Deep tremor in New Zealand triggered by the 2010 Mw8.8 Chile earthquake. Geophysical Research Letters, 38(15):1-5.

Gao, D. and Kao, H. (2020). Optimization of the match-filtering method for robust repeating earthquake detection: The multisegment cross-correlation approach. Journal of Geophysical Research: Solid Earth, 125(7):1-19.

Gardonio, B., Marsan, D., Socquet, A., Bouchon, M., Jara, J., Sun, Q., Cotte, N., and Campillo, M. (2018). Revisiting slow slip events occurrence in Boso Peninsula, Japan, combining GPS data and repeating earthquakes analysis. Journal of Geophysical Research: Solid Earth, 123(2):1502-1515.

Geller, R. J. and Mueller, C. S. (1980). Four similar earthquakes in central California. Geophysical Research Letters, 7(10):821-824.

Gibowicz, S. J. and Lasocki, S. (2007). Analysis of shallow and deep earthquake doublets in the Fiji-Tonga-Kermadec region. Pure and Applied Geophysics, 164(1):53-74.

Gutenberg, B. and Richter, C. F. (1942). Earthquake magnitude, intensity, energy, and acceleration. Bulletin of the Seismological Society of America, 32(3):163-191.

Hanks, T. C. and Kanamori, H. (1979). A moment magnitude scale. Journal of Geophysical Research, 84(B5):2348-2350.

Hatakeyama, N., Uchida, N., Matsuzawa, T., and Nakamura, W. (2017). Emergence and disappearance of interplate repeating earthquakes following the 2011 M9.0 Tohoku-oki earthquake: Slip behavior transition between seismic and aseismic depending on the loading rate. Journal of Geophysical Research: Solid Earth, 122(7):5160-5180.

Havskov, J. and Ottemöller, L. (1999). SeisAn earthquake analysis software. Seismological Research Letters, 70(5):532-534. 
Havskov, J. and Ottemoller, L. (2010). Routine Data Processing in Earthquake Seismology. Springer.

Hayward, T. W. and Bostock, M. G. (2017). Slip behavior of the Queen Charlotte Plate boundary before and after the 2012, MW 7.8 Haida Gwaii earthquake: Evidence from repeating earthquakes. Journal of Geophysical Research: Solid Earth, 122(11):89909011.

Hughes, L., Chamberlain, C. J., Townend, J., and Amanda, M. (2021). A Repeating Earthquake Catalog from 2003 to 2018 for the Raukumara Peninsula, Northern Hikurangi Subduction Margin , New Zealand. Geochemistry, Geophysics, Geosystems, pages in-press.

Hull, A. G. (1990). Tectonics of the 1931 hawke's bay earthquake. New Zealand Journal of Geology and Geophysics, 33(2):309-320.

Ide, S. (2012). Variety and spatial heterogeneity of tectonic tremor worldwide. Journal of Geophysical Research: Solid Earth, 117(B03302).

Igarashi, T. (2010). Spatial changes of inter-plate coupling inferred from sequences of small repeating earthquakes in Japan. Geophysical Research Letters, 37(20):1-5.

Igarashi, T., Matsuzawa, T., and Hasegawa, A. (2003). Repeating earthquakes and interplate aseismic slip in the northeastern Japan subduction zone. Journal of Geophysical Research: Solid Earth, 108(B5):1-9.

Ikari, M. J., Wallace, L. M., Rabinowitz, H. S., Savage, H. M., Hamling, I. J., and Kopf, A. J. (2020). Observations of laboratory and natural slow slip Events: Hikurangi subduction zone, New Zealand. Geochemistry, Geophysics, Geosystems, 21(2):1-19.

Jacobs, K. M., Savage, M. K., and Smith, E. C. (2016). Quantifying seismicity associated with slow slip events in the Hikurangi margin, New Zealand. New Zealand Journal of Geology and Geophysics, 59(1):58-69.

Johnson, L. R. (2010). An earthquake model with interacting asperities. Geophysical Journal International, 182(3):1339-1373.

Kamp, P. J. (1999). Tracking crustal processes by FT thermochronology in a forearc high (Hikurangi margin, New Zealand) involving Cretaceous subduction termination and mid-Cenozoic subduction initiation. Tectonophysics, 307(3-4):313-343.

Kaneko, Y., Avouac, J. P., and Lapusta, N. (2010). Towards inferring earthquake patterns from geodetic observations of interseismic coupling. Nature Geoscience, $3(5): 363-369$.

Kato, A., Igarashi, T., and Obara, K. (2014). Detection of a hidden Boso slow slip event immediately after the $2011 \mathrm{Mw} 9.0$ Tohoku-Oki earthquake, Japan. Geophysical Research Letters, 41(16):5868-5874. 
Kato, A., Obara, K., Igarashi, T., Tsuruoka, H., Nakagawa, S., and Hirata, N. (2012). Propagation of slow slip leading up to the 2011Mw 9.0 Tohoku-Oki earthquake. Science, 335:705-708.

Kimura, H., Kasahara, K., Igarashi, T., and Hirata, N. (2006). Repeating earthquake activities associated with the Philippine Sea plate subduction in the Kanto district, central Japan: A new plate configuration revealed by interplate aseismic slips. Tectonophysics, 417(1-2):101-118.

Lamb, S. (2011). Cenozoic tectonic evolution of the New Zealand plate-boundary zone: A paleomagnetic perspective. Tectonophysics, 509(3-4):135-164.

Langridge, R. M., Ries, W. F., Litchfield, N. J., Villamor, P., Van Dissen, R. J., Barrell, D. J., Rattenbury, M. S., Heron, D. W., Haubrock, S., Townsend, D. B., Lee, J. M., Berryman, K. R., Nicol, A., Cox, S. C., and Stirling, M. W. (2016). The New Zealand Active Faults Database. New Zealand Journal of Geology and Geophysics, 59(1):86-96.

Lay, T. and Wallace, T. (1995). Modern Global Seismology. Academic Press.

Lengliné, O. and Marsan, D. (2009). Inferring the coseismic and postseismic stress changes caused by the $2004 \mathrm{Mw}=6$ Parkfield earthquake from variations of recurrence times of microearthquakes. Journal of Geophysical Research: Solid Earth, 114(10):1-19.

Li, L., Chen, Q. F., Cheng, X., and Niu, F. (2007). Spatial clustering and repeating of seismic events observed along the 1976 Tangshan fault, north China. Geophysical Research Letters, 34(23):4-9.

Li, L., Chen, Q. F., Niu, F., and Su, J. (2011). Deep slip rates along the Longmen Shan fault zone estimated from repeating microearthquakes. Journal of Geophysical Research: Solid Earth, 116(9):1-14.

Lomax, A., Virieux, J., Volant, P., and Berge-Thierry, C. (2000). Probabilistic earthquake location in 3D and layered models - Introduction of a Metropolis-Gibbs method and comparison with linear locations. In Advances in Seismic Event Location.

Loveless, J. P. and Meade, B. J. (2011). Spatial correlation of interseismic coupling and coseismic rupture extent of the $2011 \mathrm{MW}=9.0$ Tohoku-oki earthquake. Geophysical Research Letters, 38(17):2-6.

Marone, C., Vidale, J. E., and Ellsworth, W. L. (1995). Fault healing inferred from time dependent variations in source properties of repeating earthquakes. Geophysical Research Letters, 22(22):3095-3098.

Martin, J. and Crowley, J. L. (1995). Comparison of Correlation Techniques. Intelligent Autonomous Systems: IAS-4 : Proceedings of the International Conference, pages 86-93. 
Materna, K., Taira, T., and Bürgmann, R. (2018). Aseismic transform fault slip at the Mendocino triple junction from characteristically repeating earthquakes. Geophysical Research Letters, 45(2):699-707.

Mavrommatis, A. P., Segall, P., Uchida, N., and Johnson, K. M. (2015). Long-term acceleration of aseismic slip preceding the Mw 9 Tohoku-oki earthquake: Constraints from repeating earthquakes. Geophysical Research Letters, 42(22):9717-9725.

McKenzie, D. P. (1969). The relationship between fault plane solutions for earthquakes and the directions of the principal stresses. Bulletin of the Seismological Society of America, 59(2):591-601.

Mesimeri, M. and Karakostas, V. (2018). Repeating earthquakes in western Corinth Gulf (Greece): Implications for aseismic slip near locked faults. Geophysical Journal International, 215(1):659-676.

Mochizuki, K., Sutherland, R., Henrys, S., Bassett, D., Van Avendonk, H., Arai, R., Kodaira, S., Fujie, G., Yamamoto, Y., Bangs, N., and Barker, D. (2019). Recycling of depleted continental mantle by subduction and plumes at the Hikurangi Plateau large igneous province, southwestern Pacific Ocean. Geology, 47:795-798.

Mortimer, N., Campbell, H. J., Tulloch, A. J., King, P. R., Stagpoole, V. M., Wood, R. A., Rattenbury, M. S., Sutherland, R., Adams, C. J., Collot, J., and Seton, M. (2017). Zealandia: Earth's hidden Continent. GSA Today, 27(3-4):27-35.

Mortimer, N. and Parkinson, D. (1996). Hikurangi Plateau: A Cretaceous large igneous province in the southwest Pacific Ocean. Journal of Geophysical Research: Solid Earth, 101(B1):687-696.

Müllner, D. (2011). Modern hierarchical, agglomerative clustering algorithms. arXiv preprint arXiv:1109.2378, pages 1-29.

Nadeau, R., Antolik, M., Johnson, P. A., Foxall, W., and McEvilly, T. V. (1994). Seismological studies at Parkfield III: microearthquake clusters in the study of faultzone dynamics. Bulletin of the Seismological Society of America, 84(2):247-263.

Nadeau, R. M., Foxall, W., and McEvilly, T. V. (1995). Clustering and periodic recurrence of microearthquakes on the San Andreas fault at Parkfield, California. Science, 267(5197):503-507.

Nadeau, R. M. and Johnson, L. R. (1998). Seismological studies at Parkfield VI: moment release rates and estimates of source parameters for small repeating earthquakes. Bulletin of the Seismological Society of America, 88(3):790-814.

Nadeau, R. M. and McEvilly, T. V. (1999). Fault slip rates at depth from recurrence intervals of repeating microearthquakes. Science, 285(5428):718-721.

Nadeau, R. M. and McEvitty, T. V. (2004). Periodic pulsing of characteristic microearthquakes on the San Andreas Fault. Science, 303(5655):220-222. 
Nicol, A., Mazengarb, C., Chanier, F., Rait, G., Uruski, C., and Wallace, L. (2007). Tectonic evolution of the active Hikurangi subduction margin, New Zealand, since the Oligocene. Tectonics, 26(4):1-24.

Nicol, A. and Wallace, L. M. (2007). Temporal stability of deformation rates: Comparison of geological and geodetic observations, Hikurangi subduction margin, New Zealand. Earth and Planetary Science Letters, 258(3-4):397-413.

Nomura, S., Ogata, Y., and Nadeau, R. M. (2014). Space-time model for repeating earthquakes and analysis of recurrence intervals on the San Andreas Fault near Parkfield, California. Journal of Geophysical Research: Solid Earth, 119.

Nomura, S., Ogata, Y., Uchida, N., and Matsu'ura, M. (2017). Spatiotemporal variations of interplate slip rates in northeast Japan inverted from recurrence intervals of repeating earthquakes. Geophysical Journal International, 208:468-481.

Peng, Z., Vidale, J. E., Marone, C., and Rubin, A. (2005). Systematic variations in recurrence interval and moment of repeating aftershocks. Geophysical Research Letters, 32(15):3-6.

Petersen, T., Gledhill, K., Chadwick, M., Gale, N. H., and Ristau, J. (2011). The New Zealand national seismograph network. Seismological Research Letters, 82(1):9-20.

Poupinet, G., Ellsworth, W. L., and Frechet, J. (1984). Monitoring velocity variations in the crust using earthquake doublets: An application to the Calaveras Fault, California. Journal of Geophysical Research, 89(4):5719-5731.

Proakis, J. and Dimitris, M. (1990). Digital Signal Processing: principles, devices and applications. Prentice-Hall.

Rao, K. D. and Swamy, M. N. (2018). Digital signal processing: Theory and practice. Springer.

Rau, R. J., Chen, K. H., and Ching, K. E. (2007). Repeating earthquakes and seismic potential along the northern Longitudinal Valley fault of eastern Taiwan. Geophysical Research Letters, 34(24):1-6.

Reid, H. (1910). The California Earthquake of April 18, 1906, Report of the State Earthquake Investigation Commission. Carnegie Institution of Washington.

Rhoades, D. A., Christophersen, A., Bourguignon, S., Ristau, J., and Salichon, J. (2020a). A depth-dependent local magnitude scale for New Zealand earthquakes consistent with moment magnitude. Bulletin of the Seismological Society of America, 111(2):1-11.

Rhoades, D. A., Christophersen, A., Bourguignon, S., Ristau, J., and Salichon, J. (2020b). A Depth-Dependent Local Magnitude Scale for New Zealand Earthquakes Consistent with Moment Magnitude. Bulletin of the Seismological Society of America, 111(2). 
Richter, C. F. (1935). An instrumental earthquake magnitude scale. Bulletin of the Seismological Society of America, 25(1):1-32.

Ristau, J. (2013). Update of regional moment tensor analysis for earthquakes in New Zealand and adjacent offshore regions. Bulletin of the Seismological Society of America, 103(4):2520-2533.

Ristau, J., Harte, D., and Salichon, J. (2016). A Revised Local Magnitude ( M L ) Scale for New Zealand Earthquakes. Bulletin of the Seismological Society of America, 106(2):398-407.

Robinson, R. (1994). Shallow subduction tectonics and fault interaction: The Weber, New Zealand, earthquake sequence of 1990-1992. Journal of Geophysical Research, 99(B5):9663-9679.

Romanet, P. and Ide, S. (2019). Ambient tectonic tremors in Manawatu, Cape Turnagain, Marlborough, and Puysegur, New Zealand. Earth, Planets and Space, 71(59).

Rubin, A. M. (2002). Using repeating earthquakes to correct high-precision earthquake catalogs for time-dependent station delays. Bulletin of the Seismological Society of America, 92(5):1647-1659.

Rubin, A. M., Gillard, D., and Got, J. L. (1999). Streaks of microearthquakes along creeping faults. Nature, 400(6745):635-641.

Rubinstein, J. L. and Ellsworth, W. L. (2010). Precise estimation of repeating earthquake moment: Example from parkfield, california. Bulletin of the Seismological Society of America, 100(5A):1952-1961.

Rubinstein, J. L., Ellsworth, W. L., Chen, K. H., and Uchida, N. (2012). Fixed recurrence and slip models better predict earthquake behavior than the time-and slip-predictable models: 1. Repeating earthquakes. Journal of Geophysical Research: Solid Earth, 117(2):1-23.

Schaff, D. P. and Beroza, G. C. (2004). Coseismic and postseismic velocity changes measured by repeating earthquakes. Journal of Geophysical Research: Solid Earth, $109(10)$.

Schaff, D. P., Beroza, G. C., and Shaw, B. E. (1998). Postseismic response of repeating aftershocks. Geophysical Research Letters, 25(24):4549-4552.

Schaff, D. P., Bokelmann, G. H. R., Beroza, G. C., Waldhauser, F., and Ellsworth, W. L. (2002). High-resolution image of Calaveras Fault seismicity. Journal of Geophysical Research: Solid Earth, 107(B9):5-1.

Schaff, D. P. and Richards, P. G. (2011). On finding and using repeating seismic events in and near China. Journal of Geophysical Research: Solid Earth, 116(3):1-20. 
Schaff, D. P. and Richards, P. G. (2014). Improvements in magnitude precision, using the statistics of relative amplitudes measured by cross correlation. Geophysical Journal International, 197(1):335-350.

Schmittbuhl, J., Karabulut, H., Lengliné, O., and Bouchon, M. (2016). Long-lasting seismic repeaters in the Central Basin of the Main Marmara Fault. Geophysical Research Letters, 43(18):9527-9534.

Schwartz, D. P. and Coppersmith, K. J. (1984). Fault behavior and characteristic earthquakes: examples from the Wasatch and San Andreas fault zones. Journal of Geophysical Research, 89(B7):5681-5698.

Shaddox, H. R. and Schwartz, S. Y. (2019). Subducted seamount diverts shallow slow slip to the forearc of the northern Hikurangi subduction zone, New Zealand. Geology, $47(5): 415-418$.

Shimazaki, K. and Nakata, T. (1980). Time-Predictable recurrence model for large earthquakes. Geophysical Research Letters, 4(4):279-282.

Stein, S. and Wysession, M. (2003). An Introduction to Seismology, Earthquakes, and Earth Structure. John Wiley \& Sons.

Stirling, M., McVerry, G., Gerstenberger, M., Litchfield, N., Van Dissen, R., Berryman, K., Barnes, P., Wallace, L., Villamor, P., Langridge, R., Lamarche, G., Nodder, S., Reyners, M., Bradley, B., Rhoades, D., Smith, W., Nicol, A., Pettinga, J., Clark, K., and Jacobs, K. (2012). National seismic hazard model for New Zealand: 2010 update. Bulletin of the Seismological Society of America, 102(4):1514-1542.

Templeton, D. C., Nadeau, R. M., and Bürgmann, R. (2008). Behavior of repeating earthquake sequences in Central California and the implications for subsurface fault creep. Bulletin of the Seismological Society of America, 98(1):52-65.

Trugman, D. T. and Shearer, P. M. (2017). GrowClust: A Hierarchical clustering algorithm for relative earthquake relocation, with application to the Spanish Springs and Sheldon, Nevada, earthquake sequences. Seismological Research Letters, 88(2):379391.

Turner, R. C., Nadeau, R. M., and Bürgmann, R. (2013). Aseismic slip and fault interaction from repeating earthquakes in the Loma Prieta aftershock zone. Geophysical Research Letters, 40(6):1079-1083.

Uchida, N. (2015). Postseismic response of repeating earthquakes around the 2011 Tohoku-oki earthquake: Moment increases due to the fast loading rate. Journal of Geophysical Research: Solid Earth, pages 3782-3803.

Uchida, N. (2016). Periodic slow slip triggers megathrust zone earthquakes in northeastern Japan. Science, 351(6272):488-492.

Uchida, N. (2019). Detection of repeating earthquakes and their application in characterizing slow fault slip. Progress in Earth and Planetary Science, 6(1). 
Uchida, N. and Bürgmann, R. (2019). Repeating Earthquakes. Annual Review of Earth and Planetary Sciences, 47:305-332.

Uchida, N., Kalafat, D., Pinar, A., and Yamamoto, Y. (2019). Repeating earthquakes and interplate coupling along the western part of the North Anatolian Fault. Tectonophysics, 769(July):228185.

Uchida, N. and Matsuzawa, T. (2011). Coupling coefficient, hierarchical structure, and earthquake cycle for the source area of the 2011 off the Pacific coast of Tohoku earthquake inferred from small repeating earthquake data. Earth, Planets and Space, 63(7):675-679.

Uchida, N., Matsuzawa, T., Ellsworth, W. L., Imanishi, K., Okada, T., and Hasegawa, A. (2007). Source parameters of a M4.8 and its accompanying repeating earthquakes off Kamaishi, NE Japan: Implications for the hierarchical structure of asperities and earthquake cycle. Geophysical Research Letters, 34(20):3-7.

Uchida, N., Matsuzawa, T., Ellsworth, W. L., Imanishi, K., Shimamura, K., and Hasegawa, A. (2012). Source parameters of microearthquakes on an interplate asperity off Kamaishi, NE Japan over two earthquake cycles. Geophysical Journal International, 189(2):999-1014.

Uchida, N., Matsuzawa, T., Hasegawa, A., and Igarashi, T. (2003). Interplate quasistatic slip off Sanriku, NE Japan, estimated from repeating earthquakes. Geophysical Research Letters, 30(15):1-4.

Uchida, N., Matsuzawa, T., Hirahara, S., and Hasegawa, A. (2006). Small repeating earthquakes and interplate creep around the 2005 Miyagi-oki earthquake $(\mathrm{M}=7.2)$. Earth, Planets and Space, 58(12):1577-1580.

Uchida, N., Nakajima, J., Hasegawa, A., and Matsuzawa, T. (2009). What controls interplate coupling?: Evidence for abrupt change in coupling across a border between two overlying plates in the NE Japan subduction zone. Earth and Planetary Science Letters, 283(1-4):111-121.

Van Dissen, R., Seebeck, H., Litchfield, N., Barnes, P., Nicol, A., Langridge, R., Barrell, D. J., Villamor, P., Ellis, S., Rattenbury, M., Bannister, S., Gerstenberger, M., Ghisetti, F., Sutherland, R., Fraser, S., Nodder, S., Stirling, M., Humphrey, J., Bland, K. J., Howell, A., Mountjoy, J., Moon, V., Stahl, T., Spinardi, F., Townsend, D., Clark, K., Hamling, I., Cox, S., W, d. L., Wopereis, P., Johnston, M. R., Morgenstern, R., Eccles, J. D., Little, T., Fry, B., Griffin, J., Townend, J., Mortimer, N., Alcaraz, S., Massiot, C., Rowland, J., Muirhead, J., Upton, P., Hirschberg, H., and Lee, J. (2021). Development of the New Zealand Community Fault Model - version 1.0. In NZSEE.

Vidale, J. E., Ellsworth, W. L., Cole, A., and Marone, C. (1994). Variations in rupture process with recurrence interval in a repeated small earthquake. Nature, 368(April):624-626. 
Virtanen, P., Gommers, R., Oliphant, T. E., Haberland, M., Reddy, T., Cournapeau, D., Burovski, E., Peterson, P., Weckesser, W., Bright, J., van der Walt, S. J., Brett, M., Wilson, J., Millman, K. J., Mayorov, N., Nelson, A. R., Jones, E., Kern, R., Larson, E., Carey, C. J., Polat, , Feng, Y., Moore, E. W., VanderPlas, J., Laxalde, D., Perktold, J., Cimrman, R., Henriksen, I., Quintero, E. A., Harris, C. R., Archibald, A. M., Ribeiro, A. H., Pedregosa, F., van Mulbregt, P., Vijaykumar, A., Bardelli, A. P., Rothberg, A., Hilboll, A., Kloeckner, A., Scopatz, A., Lee, A., Rokem, A., Woods, C. N., Fulton, C., Masson, C., Häggström, C., Fitzgerald, C., Nicholson, D. A., Hagen, D. R., Pasechnik, D. V., Olivetti, E., Martin, E., Wieser, E., Silva, F., Lenders, F., Wilhelm, F., Young, G., Price, G. A., Ingold, G. L., Allen, G. E., Lee, G. R., Audren, H., Probst, I., Dietrich, J. P., Silterra, J., Webber, J. T., Slavič, J., Nothman, J., Buchner, J., Kulick, J., Schönberger, J. L., de Miranda Cardoso, J. V., Reimer, J., Harrington, J., Rodríguez, J. L. C., Nunez-Iglesias, J., Kuczynski, J., Tritz, K., Thoma, M., Newville, M., Kümmerer, M., Bolingbroke, M., Tartre, M., Pak, M., Smith, N. J., Nowaczyk, N., Shebanov, N., Pavlyk, O., Brodtkorb, P. A., Lee, P., McGibbon, R. T., Feldbauer, R., Lewis, S., Tygier, S., Sievert, S., Vigna, S., Peterson, S., More, S., Pudlik, T., Oshima, T., Pingel, T. J., Robitaille, T. P., Spura, T., Jones, T. R., Cera, T., Leslie, T., Zito, T., Krauss, T., Upadhyay, U., Halchenko, Y. O., and Vázquez-Baeza, Y. (2020). SciPy 1.0: fundamental algorithms for scientific computing in Python. Nature Methods, 17(3):261-272.

Waldhauser, F. and Ellsworth, W. L. (2000). A Double-difference Earthquake location algorithm: Method and application to the Northern Hayward Fault, California. Bulletin of the Seismological Society of America, 90(6):1353-1368.

Waldhauser, F., Ellsworth, W. L., Schaff, D. P., and Cole, A. (2004). Streaks, multiplets, and holes: High-resolution spatio-temporal behavior of Parkfield seismicity. Geophysical Research Letters, 31(18):2-5.

Wallace, L. M. (2020). Slow Slip Events in New Zealand. Annual Review of Earth and Planetary Sciences, 48:1-8.

Wallace, L. M., Barnes, P., Beavan, J., Van Dissen, R., Litchfield, N., Mountjoy, J., Langridge, R., Lamarche, G., and Pondard, N. (2012a). The kinematics of a transition from subduction to strike-slip: An example from the central New Zealand plate boundary. Journal of Geophysical Research: Solid Earth, 117(B02405).

Wallace, L. M., Bartlow, N., Hamling, I., and Fry, B. (2014). Quake clamps down on slow slip. Geophysical Research Letters, 41(24):8840-8846.

Wallace, L. M. and Beavan, J. (2010). Diverse slow slip behavior at the Hikurangi subduction margin, New Zealand. Journal of Geophysical Research: Solid Earth, 115(B12402).

Wallace, L. M., Beavan, J., Bannister, S., and Williams, C. (2012b). Simultaneous long-term and short-term slow slip events at the Hikurangi subduction margin, New Zealand: Implications for processes that control slow slip event occurrence, duration, and migration. Journal of Geophysical Research B: Solid Earth, 117(B11402). 
Wallace, L. M., Beavan, J., McCaffrey, R., and Darby, D. (2004). Subduction zone coupling and tectonic block rotations in the North Island, New Zealand. Journal of Geophysical Research: Solid Earth, 109(B12406):1-21.

Wallace, L. M. and Eberhart-Phillips, D. (2013). Newly observed, deep slow slip events at the central Hikurangi margin, New Zealand: Implications for downdip variability of slow slip and tremor, and relationship to seismic structure. Geophysical Research Letters, 40(20):5393-5398.

Wallace, L. M., Hreinsdóttir, S., Ellis, S., Hamling, I., D’Anastasio, E., and Denys, P. (2018). Triggered slow slip and afterslip on the southern Hikurangi subduction zone following the Kaikōura earthquake. Geophysical Research Letters, 45(10):4710-4718.

Wallace, L. M., Kaneko, Y., Hreinsdóttir, S., Hamling, I., Peng, Z., Bartlow, N., D'Anastasio, E., and Fry, B. (2017). Large-scale dynamic triggering of shallow slow slip enhanced by overlying sedimentary wedge. Nature Geoscience, 10(10):765-770.

Wallace, L. M., Reyners, M., Cochran, U., Bannister, S., Barnes, P. M., Berryman, K., Downes, G., Eberhart-Phillips, D., Fagereng, A., Ellis, S., Nicol, A., McCaffrey, R., Beavan, R. J., Henrys, S., Sutherland, R., Barker, D. H., Litchfield, N., Townend, J., Robinson, R., Bell, R., Wilson, K., and Power, W. (2009). Characterizing the seismogenic zone of a major plate boundary subduction thrust: Hikurangi Margin, New Zealand. Geochemistry, Geophysics, Geosystems, 10(10).

Walsh, D., Arnold, R., and Townend, J. (2009). A Bayesian approach to determining and parametrizing earthquake focal mechanisms. Geophysical Journal International, 176:235-255.

Warren-Smith, E., Fry, B., Kaneko, Y., and Chamberlain, C. J. (2018). Foreshocks and delayed triggering of the 2016 MW7.1 Te Araroa earthquake and dynamic reinvigoration of its aftershock sequence by the MW7.8 Kaikōura earthquake, New Zealand. Earth and Planetary Science Letters, 482:256-276.

Webb, T. H. and Anderson, H. (1998). Focal mechanisms of large earthquakes in the North Island of New Zealand: slip partitioning at an oblique active margin. Geophysical Journal International, 134(1):40-86.

Wiemer, S. and Wyss, M. (2000). Minimum magnitude of completeness in earthquake catalogs: Examples from Alaska, the Western United States, and Japan. Bulletin of the Seismological Society of America, 90(4):859-869.

Williams, C. A., Eberhart-Phillips, D., Bannister, S., Barker, D. H., Henrys, S., Reyners, M., and Sutherland, R. (2013). Revised Interface Geometry for the Hikurangi Subduction Zone, New Zealand. Seismological Research Letters, 84(6):1066-1073.

Yamashita, Y., Shimizu, H., and Goto, K. (2012). Small repeating earthquake activity, interplate quasi-static Slip, and interplate coupling in the Hyuga-nada, southwestern Japan subduction zone. Geophysical Research Letters, 39(8):1-5. 
Yao, D., Peng, Z., Kaneko, Y., Fry, B., and Meng, X. (2021). Dynamic triggering of earthquakes in the North Island of New Zealand following the 2016 Mw 7.8 Kaikoura earthquake. Earth and Planetary Science Letters, 557:116723.

Yao, D., Walter, J. I., Meng, X., Hobbs, T. E., Peng, Z., Newman, A. V., Schwartz, S. Y., and Protti, M. (2017). Detailed spatiotemporal evolution of microseismicity and repeating earthquakes following the $2012 \mathrm{Mw} 7.6$ Nicoya earthquake. Journal of Geophysical Research: Solid Earth, 122(1):524-542.

$\mathrm{Yu}$, W. C. (2013). Shallow-focus repeating earthquakes in the tonga-kermadec-vanuatu subduction zones. Bulletin of the Seismological Society of America, 103(1):463-486.

Yu, W. c. and Wen, L. (2012). Deep-focus repeating earthquakes in the Tonga-Fiji subduction zone. Bulletin of the Seismological Society of America, 102(4):1829-1849.

Zechar, J. D. and Nadeau, R. M. (2012). Predictability of repeating earthquakes near Parkfield, California. Geophysical Journal International, 190(1):457-462.

Zhang, J., Richards, P. G., and Schaff, D. P. (2008). Wide-scale detection of earthquake waveform doublets and further evidence for inner core super-rotation. Geophysical Journal International, 174(3):993-1006. 
Appendices 


\section{A.1 Catalogue of repeating earthquakes near Po- rangahau}

Table A.1: Summary of the repeating earthquake families identified near Porangahau in this study. The first two letters of the family ID correspond to the geographic group (Section 4.1). $\mathrm{N}$ is the number of events in each family and FM means focal mechanism. SS is for strike-slip faults, REV for reverse (thrust) faults and NOR for normal faults. Location is where the family was located, in the Australian Plate (AUS), in the Pacific Plate (PAC) or on the subduction interface (INTER).

\begin{tabular}{|c|c|c|c|c|c|c|c|}
\hline Family ID & Latitude $\left(^{\circ}\right)$ & Longitude $\left({ }^{\circ}\right)$ & Depth $(\mathrm{km})$ & $M_{L}$ & $\mathrm{~N}$ & $\mathrm{FM}$ & Location \\
\hline AH1 & -40.701 & 176.857 & 24.4 & 2.7 & 2 & SS & PAC \\
\hline AK1 & -40.513 & 176.352 & 19.2 & 2.8 & 2 & - & PAC \\
\hline AK10 & -40.542 & 176.424 & 18.5 & 1.9 & 2 & - & $\mathrm{PAC}$ \\
\hline AK11 & -40.509 & 176.345 & 19.2 & 2.3 & 2 & SS & PAC \\
\hline AK12 & -40.508 & 176.267 & 21.0 & 1.7 & 2 & - & PAC \\
\hline AK13 & -40.605 & 176.533 & 18.4 & 2.3 & 2 & REV & INTER \\
\hline AK14 & -40.564 & 176.460 & 15.3 & 1.3 & 2 & - & PAC \\
\hline AK15 & -40.562 & 176.457 & 14.9 & 1.5 & 2 & - & PAC \\
\hline AK16 & -40.492 & 176.461 & 21.7 & 1.6 & 2 & - & PAC \\
\hline AK17 & -40.499 & 176.464 & 21.7 & 2.1 & 2 & SS & PAC \\
\hline AK18 & -40.496 & 176.463 & 22.0 & 1.9 & 3 & - & PAC \\
\hline AK19 & -40.695 & 176.646 & 14.9 & 2.3 & 2 & - & PAC \\
\hline $\mathrm{AK} 2$ & -40.703 & 176.602 & 14.4 & 1.7 & 2 & - & PAC \\
\hline AK20 & -40.581 & 176.475 & 15.8 & 1.9 & 2 & - & PAC \\
\hline AK3 & -40.488 & 176.336 & 19.5 & 1.5 & 2 & - & PAC \\
\hline $\mathrm{AK} 4$ & -40.625 & 176.583 & 14.3 & 1.5 & 2 & - & PAC \\
\hline AK5 & -40.560 & 176.381 & 16.7 & 1.8 & 2 & - & PAC \\
\hline AK6 & -40.640 & 176.563 & 14.5 & 1.8 & 2 & - & PAC \\
\hline AK7 & -40.512 & 176.346 & 19.5 & 1.5 & 2 & - & PAC \\
\hline AK8 & -40.511 & 176.349 & 19.3 & 2.7 & 2 & $\mathrm{SS}$ & PAC \\
\hline AK9 & -40.571 & 176.459 & 15.8 & 2.2 & 2 & - & PAC \\
\hline $\mathrm{CT} 1$ & -40.539 & 176.669 & 15.2 & 1.9 & 3 & - & PAC \\
\hline CT10 & -40.587 & 176.696 & 7.7 & 2.1 & 2 & - & AUS \\
\hline CT11 & -40.591 & 176.700 & 8.4 & 1.6 & 2 & - & AUS \\
\hline CT12 & -40.596 & 176.706 & 8.4 & 2.8 & 2 & $\mathrm{REV}$ & INTER \\
\hline CT13 & -40.590 & 176.697 & 8.6 & 2.4 & 2 & SS & AUS \\
\hline CT14 & -40.480 & 176.616 & 14.6 & 2.0 & 2 & - & PAC \\
\hline
\end{tabular}


Table A.1 continued from previous page

\begin{tabular}{|c|c|c|c|c|c|c|c|}
\hline Family ID & Latitude $\left(^{\circ}\right)$ & Longitude $\left({ }^{\circ}\right)$ & Depth $(\mathrm{km})$ & $M_{L}$ & $\mathrm{~N}$ & FM & Location \\
\hline $\mathrm{CT} 2$ & -40.539 & 176.687 & 15.1 & 1.6 & 2 & - & PAC \\
\hline CT3 & -40.561 & 176.647 & 13.1 & 2.2 & 2 & REV & INTER \\
\hline $\mathrm{CT} 4$ & -40.519 & 176.690 & 14.9 & 2.0 & 4 & NOR & PAC \\
\hline CT5 & -40.564 & 176.646 & 13.9 & 2.4 & 3 & $\mathrm{REV}$ & INTER \\
\hline CT6 & -40.532 & 176.681 & 15.0 & 1.5 & 3 & NOR & PAC \\
\hline CT7 & -40.522 & 176.694 & 14.8 & 2.0 & 2 & - & PAC \\
\hline CT8 & -40.517 & 176.618 & 15.1 & 1.9 & 2 & - & PAC \\
\hline CT9 & -40.514 & 176.617 & 16.1 & 2.0 & 2 & - & PAC \\
\hline DV1 & -40.632 & 175.871 & 29.1 & 2.3 & 2 & - & PAC \\
\hline DV10 & -40.292 & 176.291 & 23.1 & 1.7 & 2 & - & PAC \\
\hline DV11 & -40.385 & 175.790 & 31.3 & 1.6 & 2 & - & PAC \\
\hline DV12 & -40.404 & 176.064 & 17.5 & 1.8 & 2 & $\mathrm{SS}$ & AUS \\
\hline DV13 & -40.386 & 176.149 & 27.1 & 1.7 & 2 & - & PAC \\
\hline DV14 & -40.512 & 175.872 & 30.2 & 2.1 & 2 & - & PAC \\
\hline DV15 & -40.254 & 176.337 & 26.0 & 1.7 & 2 & - & PAC \\
\hline DV16 & -40.249 & 176.225 & 26.1 & 1.7 & 2 & - & PAC \\
\hline DV2 & -40.227 & 176.287 & 43.1 & 2.3 & 2 & NOR & PAC \\
\hline DV3 & -40.439 & 175.955 & 30.9 & 2.7 & 2 & NOR & PAC \\
\hline DV4 & -40.428 & 175.852 & 26.0 & 1.7 & 2 & - & PAC \\
\hline DV5 & -40.454 & 176.023 & 25.0 & 2.5 & 3 & REV & INTER \\
\hline DV6 & -40.209 & 176.186 & 24.8 & 1.6 & 2 & - & PAC \\
\hline DV7 & -40.459 & 176.018 & 24.5 & 2.0 & 2 & $\mathrm{REV}$ & INTER \\
\hline DV8 & -40.344 & 176.133 & 30.5 & 2.9 & 3 & NOR & PAC \\
\hline DV9 & -40.457 & 176.020 & 24.8 & 2.4 & 4 & REV & INTER \\
\hline HE1 & -39.634 & 176.763 & 28.3 & 2.1 & 2 & - & PAC \\
\hline HE10 & -39.649 & 176.759 & 28.8 & 2.5 & 2 & $\mathrm{SS}$ & PAC \\
\hline HE11 & -39.624 & 176.747 & 27.8 & 1.8 & 2 & - & PAC \\
\hline HE12 & -39.627 & 176.747 & 27.7 & 2.2 & 2 & - & PAC \\
\hline HE13 & -39.628 & 176.767 & 27.8 & 1.9 & 2 & - & PAC \\
\hline HE14 & -39.620 & 176.749 & 28.4 & 1.8 & 2 & REV & PAC \\
\hline HE15 & -39.625 & 176.757 & 27.4 & 2.5 & 2 & SS & PAC \\
\hline HE16 & -39.657 & 176.747 & 27.4 & 1.8 & 2 & - & $\mathrm{PAC}$ \\
\hline HE2 & -39.592 & 176.816 & 27.5 & 1.9 & 2 & NOR & PAC \\
\hline HE3 & -39.630 & 176.755 & 27.5 & 2.4 & 2 & SS & PAC \\
\hline $\mathrm{HE} 4$ & -39.625 & 176.765 & 28.2 & 1.6 & 2 & NOR & PAC \\
\hline HE5 & -39.626 & 176.749 & 28.0 & 1.9 & 2 & - & PAC \\
\hline
\end{tabular}


Table A.1 continued from previous page

\begin{tabular}{|c|c|c|c|c|c|c|c|}
\hline Family ID & Latitude $\left(^{\circ}\right)$ & Longitude $\left({ }^{\circ}\right)$ & Depth $(\mathrm{km})$ & $M_{L}$ & $\mathrm{~N}$ & FM & Location \\
\hline HE6 & -39.669 & 176.820 & 27.6 & 2.1 & 2 & - & PAC \\
\hline HE7 & -39.663 & 176.748 & 26.9 & 2.2 & 2 & - & PAC \\
\hline HE8 & -39.635 & 176.753 & 27.9 & 2.0 & 2 & - & PAC \\
\hline HE9 & -39.629 & 176.770 & 28.0 & 1.8 & 2 & - & PAC \\
\hline HW1 & -39.675 & 176.588 & 27.7 & 2.2 & 4 & SS & PAC \\
\hline HW2 & -39.653 & 176.545 & 28.4 & 1.9 & 6 & - & PAC \\
\hline HW3 & -39.653 & 176.546 & 28.7 & 1.9 & 4 & - & $\mathrm{PAC}$ \\
\hline HW4 & -39.654 & 176.541 & 28.4 & 2.2 & 5 & $\mathrm{REV}$ & INTER \\
\hline HW5 & -39.647 & 176.541 & 28.4 & 1.6 & 2 & - & $\mathrm{PAC}$ \\
\hline KK1 & -40.100 & 176.872 & 16.1 & 1.6 & 6 & - & $\mathrm{PAC}$ \\
\hline KK10 & -39.982 & 176.758 & 20.7 & 1.6 & 2 & $\mathrm{SS}$ & PAC \\
\hline KK11 & -40.023 & 176.771 & 18.3 & 2.4 & 3 & $\mathrm{SS}$ & $\mathrm{PAC}$ \\
\hline KK12 & -39.978 & 176.763 & 20.2 & 1.8 & 2 & - & PAC \\
\hline KK13 & -40.017 & 176.811 & 16.6 & 1.9 & 3 & - & PAC \\
\hline KK14 & -39.861 & 176.937 & 18.0 & 1.7 & 2 & - & PAC \\
\hline KK15 & -39.866 & 176.866 & 16.1 & 1.7 & 2 & - & PAC \\
\hline KK16 & -39.831 & 176.961 & 19.0 & 1.8 & 2 & - & PAC \\
\hline KK17 & -39.660 & 177.022 & 21.8 & 1.8 & 2 & - & $\mathrm{PAC}$ \\
\hline KK18 & -39.935 & 176.886 & 17.5 & 2.0 & 2 & SS & PAC \\
\hline KK19 & -40.076 & 176.743 & 17.7 & 2.2 & 2 & - & PAC \\
\hline KK2 & -40.023 & 176.772 & 18.0 & 2.1 & 4 & $\mathrm{SS}$ & $\mathrm{PAC}$ \\
\hline KK20 & -40.038 & 177.126 & 11.3 & 2.2 & 2 & - & AUS \\
\hline KK21 & -39.994 & 176.895 & 20.3 & 1.6 & 2 & - & PAC \\
\hline KK22 & -39.779 & 176.932 & 19.0 & 2.1 & 2 & - & $\mathrm{PAC}$ \\
\hline KK23 & -40.000 & 176.902 & 20.6 & 2.5 & 2 & REV & PAC \\
\hline KK24 & -39.916 & 176.893 & 18.2 & 1.9 & 2 & - & PAC \\
\hline KK25 & -39.916 & 176.888 & 18.4 & 1.9 & 3 & - & $\mathrm{PAC}$ \\
\hline KK26 & -39.845 & 176.933 & 19.7 & 1.9 & 2 & - & PAC \\
\hline KK27 & -39.874 & 176.961 & 16.5 & 2.2 & 2 & - & PAC \\
\hline KK28 & -39.898 & 177.037 & 11.7 & 2.4 & 2 & - & AUS \\
\hline KK29 & -39.895 & 177.037 & 11.4 & 1.8 & 2 & - & AUS \\
\hline KK3 & -40.021 & 176.751 & 18.3 & 1.6 & 2 & - & $\mathrm{PAC}$ \\
\hline KK30 & -40.142 & 176.923 & 11.3 & 2.0 & 2 & - & AUS \\
\hline KK31 & -40.009 & 176.768 & 19.0 & 1.9 & 2 & - & $\mathrm{PAC}$ \\
\hline KK32 & -40.022 & 176.851 & 17.9 & 2.5 & 2 & - & $\mathrm{PAC}$ \\
\hline KK33 & -39.742 & 177.075 & 6.3 & 2.1 & 2 & - & AUS \\
\hline
\end{tabular}


Table A.1 continued from previous page

\begin{tabular}{|c|c|c|c|c|c|c|c|}
\hline Family ID & Latitude $\left(^{\circ}\right)$ & Longitude $\left({ }^{\circ}\right)$ & Depth $(\mathrm{km})$ & $M_{L}$ & $\mathrm{~N}$ & $\mathrm{FM}$ & Location \\
\hline KK4 & -40.125 & 176.943 & 12.2 & 2.1 & 4 & - & AUS \\
\hline KK5 & -39.727 & 177.146 & 11.5 & 2.0 & 2 & - & AUS \\
\hline KK6 & -40.022 & 176.764 & 18.3 & 1.6 & 5 & SS & PAC \\
\hline KK7 & -40.019 & 176.761 & 19.2 & 1.5 & 2 & - & PAC \\
\hline KK8 & -40.047 & 177.141 & 11.0 & 2.0 & 3 & - & AUS \\
\hline KK9 & -39.769 & 177.144 & 10.2 & 1.8 & 3 & REV & INTER \\
\hline MN1 & -40.329 & 176.434 & 19.1 & 1.8 & 4 & - & PAC \\
\hline MN10 & -40.362 & 176.369 & 26.4 & 2.3 & 2 & NOR & PAC \\
\hline MN11 & -40.414 & 176.328 & 23.9 & 2.1 & 2 & - & PAC \\
\hline MN12 & -40.285 & 176.495 & 24.4 & 3.1 & 2 & NOR & PAC \\
\hline MN13 & -40.382 & 176.286 & 30.9 & 1.8 & 2 & - & PAC \\
\hline MN14 & -40.340 & 176.312 & 16.6 & 2.0 & 2 & SS & AUS \\
\hline MN15 & -40.406 & 176.294 & 23.7 & 1.4 & 2 & - & PAC \\
\hline MN16 & -40.377 & 176.395 & 25.7 & 1.9 & 2 & - & PAC \\
\hline MN17 & -40.376 & 176.392 & 25.9 & 1.8 & 2 & - & PAC \\
\hline MN18 & -40.394 & 176.287 & 22.7 & 3.1 & 2 & - & PAC \\
\hline MN2 & -40.389 & 176.362 & 20.4 & 2.1 & 2 & $\mathrm{SS}$ & PAC \\
\hline MN3 & -40.342 & 176.429 & 20.8 & 1.9 & 2 & - & PAC \\
\hline MN4 & -40.385 & 176.284 & 22.9 & 1.7 & 5 & NOR & PAC \\
\hline MN5 & -40.330 & 176.434 & 19.2 & 1.6 & 4 & - & PAC \\
\hline MN6 & -40.423 & 176.327 & 24.5 & 1.6 & 2 & - & PAC \\
\hline MN7 & -40.320 & 176.419 & 25.9 & 1.8 & 2 & - & PAC \\
\hline MN8 & -40.417 & 176.331 & 24.5 & 2.5 & 3 & NOR & PAC \\
\hline MN9 & -40.340 & 176.439 & 26.1 & 2.2 & 2 & - & PAC \\
\hline MT1 & -40.900 & 176.451 & 14.9 & 2.1 & 2 & - & PAC \\
\hline MT2 & -40.647 & 176.158 & 18.7 & 1.4 & 2 & - & PAC \\
\hline MT3 & -40.751 & 175.992 & 25.5 & 1.9 & 2 & - & PAC \\
\hline MT4 & -40.648 & 176.154 & 18.5 & 1.4 & 2 & - & PAC \\
\hline MT5 & -40.718 & 176.302 & 23.1 & 1.5 & 2 & - & PAC \\
\hline MT6 & -40.695 & 176.338 & 23.6 & 1.8 & 2 & NOR & PAC \\
\hline OU1 & -40.146 & 176.643 & 19.3 & 1.9 & 9 & $\mathrm{SS}$ & PAC \\
\hline OU10 & -40.138 & 176.648 & 19.0 & 2.0 & 2 & - & PAC \\
\hline OU2 & -40.158 & 176.631 & 19.0 & 1.6 & 3 & - & PAC \\
\hline OU3 & -40.153 & 176.637 & 19.9 & 1.5 & 2 & - & PAC \\
\hline OU4 & -40.135 & 176.647 & 20.0 & 2.0 & 3 & - & PAC \\
\hline OU5 & -40.154 & 176.634 & 20.2 & 1.6 & 2 & - & $\mathrm{PAC}$ \\
\hline
\end{tabular}


Table A.1 continued from previous page

\begin{tabular}{|c|c|c|c|c|c|c|c|}
\hline Family ID & Latitude $\left({ }^{\circ}\right)$ & Longitude $\left(^{\circ}\right)$ & Depth $(\mathrm{km})$ & $M_{L}$ & $\mathrm{~N}$ & FM & Location \\
\hline OU6 & -40.144 & 176.647 & 19.7 & 1.7 & 2 & - & PAC \\
\hline OU7 & -40.145 & 176.629 & 19.9 & 1.8 & 2 & - & PAC \\
\hline OU8 & -40.158 & 176.630 & 20.8 & 1.9 & 2 & - & PAC \\
\hline OU9 & -40.140 & 176.644 & 19.6 & 1.7 & 3 & - & PAC \\
\hline PP1 & -40.404 & 177.335 & 47.2 & 3.1 & 2 & - & $\mathrm{PAC}$ \\
\hline PP2 & -40.408 & 177.349 & 43.1 & 3.7 & 2 & - & PAC \\
\hline PP3 & -40.373 & 177.055 & 49.3 & 2.9 & 2 & REV & PAC \\
\hline RH1 & -39.992 & 175.839 & 38.1 & 2.7 & 2 & NOR & PAC \\
\hline RH2 & -39.949 & 176.189 & 30.7 & 1.9 & 2 & NOR & PAC \\
\hline TK1 & -40.306 & 176.691 & 16.7 & 2.0 & 2 & - & PAC \\
\hline TK10 & -40.307 & 176.687 & 16.4 & 1.4 & 2 & - & PAC \\
\hline TK11 & -40.312 & 176.701 & 15.6 & 1.5 & 2 & - & PAC \\
\hline TK12 & -40.299 & 176.675 & 13.9 & 1.8 & 3 & - & PAC \\
\hline TK13 & -40.278 & 176.566 & 17.3 & 2.8 & 2 & $\mathrm{REV}$ & INTER \\
\hline TK14 & -40.323 & 176.700 & 15.8 & 1.9 & 3 & - & PAC \\
\hline TK15 & -40.322 & 176.700 & 16.4 & 2.7 & 2 & - & PAC \\
\hline TK16 & -40.335 & 176.691 & 15.0 & 1.6 & 2 & - & PAC \\
\hline TK17 & -40.355 & 176.622 & 16.7 & 1.8 & 6 & - & $\mathrm{PAC}$ \\
\hline TK18 & -40.354 & 176.553 & 16.5 & 2.0 & 2 & REV & INTER \\
\hline TK19 & -40.354 & 176.548 & 16.4 & 1.8 & 3 & $\mathrm{REV}$ & INTER \\
\hline TK2 & -40.335 & 176.637 & 15.8 & 2.2 & 3 & $\mathrm{REV}$ & INTER \\
\hline TK20 & -40.280 & 176.564 & 17.1 & 1.8 & 3 & - & PAC \\
\hline TK21 & -40.353 & 176.677 & 15.7 & 1.7 & 2 & - & $\mathrm{PAC}$ \\
\hline TK22 & -40.337 & 176.539 & 16.6 & 2.4 & 2 & $\mathrm{REV}$ & INTER \\
\hline TK23 & -40.278 & 176.562 & 16.9 & 2.2 & 4 & $\mathrm{REV}$ & INTER \\
\hline TK24 & -40.368 & 176.502 & 18.3 & 1.7 & 2 & - & PAC \\
\hline TK25 & -40.306 & 176.593 & 15.6 & 2.8 & 3 & SS & PAC \\
\hline TK26 & -40.306 & 176.753 & 15.0 & 2.1 & 2 & - & $\mathrm{PAC}$ \\
\hline TK27 & -40.281 & 176.713 & 12.5 & 2.3 & 3 & NOR & AUS \\
\hline TK28 & -40.301 & 176.743 & 13.1 & 1.9 & 2 & - & $\mathrm{PAC}$ \\
\hline TK29 & -40.296 & 176.741 & 14.1 & 1.7 & 2 & - & PAC \\
\hline TK3 & -40.325 & 176.518 & 18.3 & 1.7 & 2 & SS & PAC \\
\hline TK30 & -40.283 & 176.741 & 12.5 & 2.4 & 2 & $\mathrm{REV}$ & INTER \\
\hline TK31 & -40.326 & 176.519 & 17.6 & 1.8 & 3 & - & PAC \\
\hline TK32 & -40.303 & 176.686 & 16.4 & 1.7 & 3 & - & PAC \\
\hline TK33 & -40.396 & 176.625 & 15.8 & 2.2 & 2 & $\mathrm{REV}$ & INTER \\
\hline
\end{tabular}


Table A.1 continued from previous page

\begin{tabular}{|c|c|c|c|c|c|c|c|}
\hline Family ID & Latitude $\left(^{\circ}\right)$ & Longitude $\left(^{\circ}\right)$ & Depth $(\mathrm{km})$ & $M_{L}$ & $\mathrm{~N}$ & $\mathrm{FM}$ & Location \\
\hline TK34 & -40.306 & 176.725 & 14.9 & 1.5 & 2 & - & $\mathrm{PAC}$ \\
\hline TK35 & -40.276 & 176.560 & 16.8 & 2.0 & 3 & SS & PAC \\
\hline TK36 & -40.311 & 176.699 & 16.2 & 2.3 & 2 & - & PAC \\
\hline TK37 & -40.314 & 176.697 & 15.9 & 1.6 & 2 & - & PAC \\
\hline TK38 & -40.324 & 176.604 & 17.9 & 1.9 & 2 & - & PAC \\
\hline TK39 & -40.370 & 176.509 & 18.1 & 2.1 & 2 & - & PAC \\
\hline TK4 & -40.304 & 176.747 & 14.6 & 1.7 & 2 & - & $\mathrm{PAC}$ \\
\hline TK40 & -40.327 & 176.703 & 16.1 & 2.7 & 2 & $\mathrm{REV}$ & INTER \\
\hline TK41 & -40.335 & 176.625 & 17.3 & 2.1 & 2 & - & PAC \\
\hline TK42 & -40.375 & 176.522 & 17.9 & 1.9 & 2 & $\mathrm{REV}$ & INTER \\
\hline TK43 & -40.395 & 176.627 & 15.5 & 2.6 & 2 & $\mathrm{REV}$ & INTER \\
\hline TK44 & -40.360 & 176.497 & 18.7 & 3.0 & 2 & $\mathrm{REV}$ & INTER \\
\hline TK45 & -40.303 & 176.682 & 16.3 & 1.7 & 2 & - & PAC \\
\hline TK46 & -40.312 & 176.744 & 14.8 & 1.7 & 4 & $\mathrm{REV}$ & INTER \\
\hline TK47 & -40.321 & 176.688 & 16.0 & 2.1 & 2 & - & PAC \\
\hline TK48 & -40.285 & 176.707 & 13.0 & 1.6 & 2 & - & AUS \\
\hline TK49 & -40.264 & 176.739 & 13.6 & 1.8 & 2 & - & PAC \\
\hline TK5 & -40.323 & 176.770 & 14.1 & 2.7 & 2 & $\mathrm{REV}$ & INTER \\
\hline TK50 & -40.301 & 176.727 & 14.2 & 1.6 & 2 & - & PAC \\
\hline TK51 & -40.220 & 176.569 & 17.6 & 1.9 & 2 & $\mathrm{SS}$ & PAC \\
\hline TK52 & -40.316 & 176.774 & 14.5 & 1.7 & 3 & - & PAC \\
\hline TK53 & -40.308 & 176.767 & 15.0 & 2.1 & 2 & REV & INTER \\
\hline TK54 & -40.305 & 176.682 & 16.4 & 2.2 & 2 & NOR & PAC \\
\hline TK55 & -40.283 & 176.677 & 13.9 & 1.9 & 2 & SS & PAC \\
\hline TK56 & -40.289 & 176.646 & 16.5 & 1.7 & 3 & - & PAC \\
\hline TK57 & -40.295 & 176.637 & 16.4 & 1.4 & 2 & - & PAC \\
\hline TK58 & -40.302 & 176.714 & 13.7 & 1.7 & 2 & - & PAC \\
\hline TK59 & -40.362 & 176.544 & 15.8 & 2.0 & 3 & - & PAC \\
\hline TK6 & -40.326 & 176.768 & 14.1 & 2.7 & 3 & REV & INTER \\
\hline TK60 & -40.287 & 176.713 & 12.6 & 1.7 & 2 & - & AUS \\
\hline TK61 & -40.271 & 176.630 & 15.2 & 1.4 & 2 & - & PAC \\
\hline TK62 & -40.312 & 176.588 & 17.9 & 2.5 & 2 & SS & $\mathrm{PAC}$ \\
\hline TK7 & -40.358 & 176.623 & 16.5 & 2.1 & 5 & NOR & PAC \\
\hline TK8 & -40.313 & 176.737 & 14.4 & 1.6 & 2 & NOR & PAC \\
\hline TK9 & -40.314 & 176.739 & 15.0 & 1.4 & 2 & - & PAC \\
\hline TR1 & -40.361 & 176.851 & 12.5 & 2.1 & 4 & - & PAC \\
\hline
\end{tabular}


Table A.1 continued from previous page

\begin{tabular}{|c|c|c|c|c|c|c|c|}
\hline Family ID & Latitude $\left(^{\circ}\right)$ & Longitude $\left(^{\circ}\right)$ & Depth $(\mathrm{km})$ & $M_{L}$ & $\mathrm{~N}$ & FM & Location \\
\hline TR2 & -40.305 & 176.874 & 13.5 & 1.7 & 2 & - & PAC \\
TR3 & -40.484 & 176.807 & 12.9 & 2.1 & 2 & - & PAC \\
TT1 & -39.706 & 176.861 & 38.3 & 2.4 & 2 & NOR & PAC \\
TT2 & -39.733 & 176.834 & 41.1 & 2.6 & 2 & REV & PAC \\
WP1 & -39.926 & 176.643 & 17.6 & 2.3 & 2 & - & PAC \\
WP10 & -39.922 & 176.623 & 23.6 & 1.9 & 2 & - & PAC \\
WP11 & -40.108 & 176.537 & 8.7 & 1.4 & 2 & - & AUS \\
WP12 & -39.986 & 176.637 & 22.8 & 1.6 & 2 & - & PAC \\
WP13 & -40.074 & 176.417 & 30.8 & 2.0 & 2 & - & PAC \\
WP14 & -40.076 & 176.442 & 29.2 & 2.5 & 2 & REV & PAC \\
WP2 & -40.002 & 176.509 & 23.8 & 1.7 & 2 & - & PAC \\
WP3 & -40.077 & 176.429 & 28.7 & 1.7 & 2 & - & PAC \\
WP4 & -40.044 & 176.447 & 29.5 & 1.5 & 2 & - & PAC \\
WP5 & -40.091 & 176.342 & 16.8 & 2.4 & 2 & SS & AUS \\
WP6 & -40.038 & 176.490 & 28.0 & 2.2 & 2 & NOR & PAC \\
WP7 & -40.097 & 176.395 & 30.5 & 1.5 & 2 & - & PAC \\
WP8 & -39.991 & 176.676 & 13.4 & 1.6 & 2 & - & AUS \\
WP9 & -40.099 & 176.552 & 18.3 & 1.6 & 2 & - & PAC \\
\hline
\end{tabular}


A.2 Stations corrections from magnitude inversion 
Table A.2: Summary of the stations corrections values obtained from the magnitude inversion.

\begin{tabular}{|c|c|c|c|}
\hline Station and channel & Station correction & Station and channel & Station correction \\
\hline ANWZ EHE & -1.900 & MTW EHN & -1.133 \\
\hline ANWZ EHN & -1.809 & NGZ EHE & -1.671 \\
\hline ARHZ EHE & -0.530 & NGZ EHN & -1.507 \\
\hline ARHZ EHN & -0.536 & NMHZ EHE & -1.581 \\
\hline BFZ HHE & -1.214 & NMHZ EHN & -1.641 \\
\hline BFZ HHN & -1.259 & OGWZ EHE & -1.186 \\
\hline BHHZ EHE & -0.139 & OGWZ EHN & -1.114 \\
\hline BHHZ EHN & -0.132 & PAWZ EHE & -0.601 \\
\hline BHW EHN & -1.238 & PAWZ EHN & -0.783 \\
\hline BHW HHE & -0.814 & PLWZ EHE & -1.208 \\
\hline BHW HHN & -1.152 & PLWZ EHN & -0.942 \\
\hline BKZ HHE & -1.124 & PNHZ EHE & -1.095 \\
\hline BKZ HHN & -1.163 & PNHZ EHN & -0.705 \\
\hline CAW EHE & -0.594 & POWZ EHE & -1.577 \\
\hline CAW EHN & -0.451 & POWZ EHN & -1.473 \\
\hline CKHZ EHE & -0.789 & PRHZ EHE & -1.469 \\
\hline CKHZ EHN & -0.981 & PRHZ EHN & -1.363 \\
\hline CPWZ EHE & -0.559 & PRWZ EHE & -1.696 \\
\hline CPWZ EHN & -0.525 & PRWZ EHN & -1.393 \\
\hline DVHZ EHE & -1.041 & PXZ HHE & -1.564 \\
\hline DVHZ EHN & -0.892 & PXZ HHN & -1.660 \\
\hline FWVZ HHE & -0.913 & RATZ HHE & -1.681 \\
\hline FWVZ HHN & -1.207 & RATZ HHN & -1.327 \\
\hline HATZ EHE & -1.197 & RITZ EHE & -0.658 \\
\hline HATZ EHN & -1.285 & RITZ EHN & -0.864 \\
\hline HOWZ EHE & -1.135 & TIWZ EHE & -1.066 \\
\hline HOWZ EHN & -1.323 & TIWZ EHN & -1.117 \\
\hline KAHZ EHE & -1.217 & TMWZ EHE & -1.705 \\
\hline KAHZ EHN & -0.983 & TMWZ EHN & -1.195 \\
\hline KATZ EHE & -0.443 & TRWZ EHE & -1.001 \\
\hline KATZ EHN & -1.194 & TRWZ EHN & -0.831 \\
\hline KIW EHE & -1.300 & TSZ HHE & -1.519 \\
\hline KIW EHN & -1.200 & TSZ HHN & -1.498 \\
\hline KNZ HHE & -0.841 & TUVZ EHE & -1.691 \\
\hline KNZ HHN & -0.476 & TUVZ EHN & -1.604 \\
\hline KRHZ EHE & -1.424 & TWVZ EHE & -0.875 \\
\hline KRHZ EHN & -1.352 & TWVZ EHN & -1.124 \\
\hline KRVZ EHE & -1.294 & VRZ HHN & -1.425 \\
\hline KRVZ EHN & -1.474 & WAZ HHE & -1.747 \\
\hline MCHZ EHE & -1.128 & WAZ HHN & -1.825 \\
\hline MCHZ EHN & -0.992 & WEL HHE & -1.552 \\
\hline MOVZ EHE & -1.045 & WEL HHN & -1.177 \\
\hline MOVZ EHN & -1.056 & WNVZ EHE & -1.097 \\
\hline MRZ HHE & -1.445 & WNVZ EHN & -1.047 \\
\hline MRZ HHN & -1.416 & WPHZ EHE & -0.807 \\
\hline MSWZ EHE & -0.812 & WPHZ EHN & -0.624 \\
\hline MSWZ EHN & -0.529 & WPVZ HHN & -1.478 \\
\hline MTVZ EHE & -1.894 & WTVZ EHE & -1.451 \\
\hline MTVZ EHN & -1.904 & WTVZ EHN & -1.514 \\
\hline MTW EHE & -1.151 & & \\
\hline
\end{tabular}




\section{A.3 Focal Mechanism Solutions}

Table A.3: Table with the final focal mechanism solutions. ID is the GeoNet ID. The error calculated for each focal mechanism is in degrees.

\begin{tabular}{|c|c|c|c|c|}
\hline ID & Strike & Dip & Rake & Error $\left({ }^{\circ}\right)$ \\
\hline 2863270 & 340.3 & 78.2 & 88.6 & 29.6 \\
\hline 2961331 & 333.9 & 51.7 & -154.6 & 29.2 \\
\hline 2962789 & 120.9 & 81.2 & 114.0 & 31.4 \\
\hline 2969615 & 161.0 & 77.8 & -42.9 & 30.1 \\
\hline 2982096 & 33.4 & 88.3 & 125.5 & 27.7 \\
\hline 3016047 & 319.2 & 55.4 & -169.7 & 28.7 \\
\hline 3056579 & 118.2 & 51.4 & -129.5 & 27.4 \\
\hline 3056834 & 216.9 & 71.9 & -153.6 & 27.1 \\
\hline 3068492 & 298.5 & 46.0 & -100.8 & 30.7 \\
\hline 3066608 & 145.9 & 72.8 & 18.8 & 27.9 \\
\hline 3118804 & 193.9 & 88.0 & -144.6 & 26.6 \\
\hline 3125550 & 86.4 & 37.2 & 46.1 & 29.4 \\
\hline 3135048 & 121.9 & 87.2 & -118.6 & 32.3 \\
\hline 3140077 & 102.1 & 83.3 & -59.3 & 28.7 \\
\hline 3145133 & 107.3 & 47.8 & -70.9 & 25.0 \\
\hline 3151973 & 145.8 & 60.1 & -43.3 & 29.5 \\
\hline 3153127 & 111.9 & 45.4 & -32.8 & 31.3 \\
\hline 3157224 & 300.6 & 89.9 & -31.9 & 29.5 \\
\hline 3166416 & 214.8 & 61.6 & 90.7 & 27.4 \\
\hline 3168746 & 247.6 & 80.7 & -167.6 & 26.7 \\
\hline 3180041 & 110.4 & 75.2 & -38.1 & 29.8 \\
\hline 3204179 & 28.1 & 83.7 & 95.0 & 27.8 \\
\hline 3256247 & 123.4 & 65.1 & 7.4 & 28.6 \\
\hline 3275134 & 69.4 & 66.6 & -132.2 & 28.8 \\
\hline 3294401 & 235.7 & 56.4 & -163.3 & 28.9 \\
\hline 3294406 & 35.2 & 70.7 & 122.8 & 26.8 \\
\hline 3300769 & 86.4 & 35.1 & -44.6 & 25.2 \\
\hline 3334320 & 67.3 & 14.0 & 3.6 & 26.2 \\
\hline 3419251 & 196.2 & 74.9 & -61.2 & 31.4 \\
\hline 3444687 & 161.0 & 81.3 & -33.8 & 29.6 \\
\hline 3493247 & 167.8 & 36.2 & -9.9 & 27.5 \\
\hline 3619577 & 335.6 & 58.4 & -150.5 & 23.4 \\
\hline
\end{tabular}


Table A.3 continued from previous page

\begin{tabular}{|l|l|l|l|l|}
\hline $2012 \mathrm{p} 158837$ & 143.2 & 45.6 & 36.6 & 31.4 \\
\hline $2012 \mathrm{p} 659872$ & 22.2 & 84.8 & 77.4 & 20.8 \\
\hline $2013 \mathrm{p} 135714$ & 24.8 & 71.4 & 92.8 & 28.4 \\
\hline $2013 \mathrm{p} 472502$ & 240.0 & 19.9 & 116.9 & 32.3 \\
\hline $2013 \mathrm{p} 691776$ & 152.4 & 57.8 & 30.4 & 30.3 \\
\hline $2013 \mathrm{p} 763995$ & 227.4 & 14.5 & 135.5 & 24.2 \\
\hline $2013 \mathrm{p} 931321$ & 55.5 & 88.6 & 145.0 & 32.3 \\
\hline $2014 \mathrm{p} 150497$ & 39.6 & 31.5 & -104.6 & 31.1 \\
\hline $2014 \mathrm{p} 836248$ & 237.3 & 10.6 & 140.5 & 28.4 \\
\hline $2015 \mathrm{p} 020648$ & 336.2 & 37.3 & 143.7 & 29.8 \\
\hline $2015 \mathrm{p} 267492$ & 193.8 & 39.3 & -100.7 & 27.1 \\
\hline $2015 \mathrm{p} 497791$ & 161.7 & 77.9 & -24.9 & 32.1 \\
\hline $2015 \mathrm{p} 539855$ & 355.0 & 74.1 & 18.7 & 26.9 \\
\hline $2015 \mathrm{p} 897797$ & 13.2 & 88.5 & 85.1 & 28.8 \\
\hline $2016 \mathrm{p} 239623$ & 83.5 & 39.2 & 28.9 & 30.3 \\
\hline $2016 \mathrm{p} 367364$ & 255.8 & 77.5 & -129.6 & 29.6 \\
\hline $2016 \mathrm{p} 407264$ & 350.3 & 74.5 & 36.9 & 29.5 \\
\hline $2016 \mathrm{p} 548022$ & 357.7 & 82.7 & 85.5 & 31.9 \\
\hline $2016 \mathrm{p} 625356$ & 2.7 & 84.0 & 87.0 & 23.9 \\
\hline $2016 \mathrm{p} 742264$ & 193.9 & 63.2 & -80.2 & 27.0 \\
\hline $2016 \mathrm{p} 767511$ & 229.7 & 21.7 & 109.7 & 30.6 \\
\hline $2016 \mathrm{p} 854353$ & 235.4 & 62.7 & -143.1 & 27.9 \\
\hline $2016 \mathrm{p} 882825$ & 347.4 & 88.4 & 127.3 & 24.4 \\
\hline $2016 \mathrm{p} 886198$ & 165.3 & 82.9 & -128.2 & 25.3 \\
\hline $2016 \mathrm{p} 957315$ & 83.3 & 87.3 & -148.7 & 27.3 \\
\hline $2017 \mathrm{p} 190305$ & 25.1 & 44.3 & 75.1 & 28.1 \\
\hline $2017 \mathrm{p} 271473$ & 28.3 & 66.8 & 87.9 & 28.3 \\
\hline $2017 \mathrm{p} 363282$ & 216.7 & 30.9 & 110.9 & 27.9 \\
\hline $2017 \mathrm{p} 363577$ & 197.3 & 31.7 & 90.8 & 26.6 \\
\hline $2017 \mathrm{p} 514329$ & 333.0 & 15.4 & -158.0 & 27.8 \\
\hline $2017 \mathrm{p} 516586$ & 26.4 & 85.7 & 87.8 & 28.2 \\
\hline $2017 \mathrm{p} 784816$ & 211.4 & 31.9 & 95.8 & 22.6 \\
\hline $2017 \mathrm{p} 924347$ & 36.5 & 69.9 & -133.6 & 23.7 \\
\hline $2018 \mathrm{p} 069063$ & 343.0 & 77.6 & 36.3 & 29.9 \\
\hline $2018 \mathrm{p} 072548$ & 123.0 & 46.0 & -3.5 & 32.9 \\
\hline $2018 \mathrm{p} 072991$ & 164.9 & 88.5 & -54.0 & 28.5 \\
\hline
\end{tabular}


Table A.3 continued from previous page

\begin{tabular}{|l|l|l|l|l|}
\hline $2018 \mathrm{p} 073185$ & 28.4 & 71.8 & 103.3 & 29.4 \\
\hline $2018 \mathrm{p} 073198$ & 128.6 & 31.2 & 18.5 & 20.0 \\
\hline $2018 \mathrm{p} 153134$ & 67.6 & 66.0 & -71.0 & 33.8 \\
\hline $2018 \mathrm{p} 364597$ & 337.4 & 88.6 & 8.6 & 27.7 \\
\hline $2018 \mathrm{p} 443045$ & 251.0 & 76.6 & 177.6 & 30.3 \\
\hline $2018 \mathrm{p} 479843$ & 110.1 & 37.3 & 31.3 & 27.2 \\
\hline $2018 \mathrm{p} 552196$ & 227.9 & 86.9 & -150.0 & 25.3 \\
\hline
\end{tabular}




\section{A.4 Stereonets and PT axis contour plots of the final focal mechanisms catalogue}

This appendix contains the stereonets (left) and PT contour plots (right) of wellconstrained events. Solid black lines indicate the focal mechanism solution. Blue points are compressions and red points are dilatations. Orange and green contours denote the posterior distribution of the $\mathrm{P}$ - and T-axes in orange and green, respectively. 

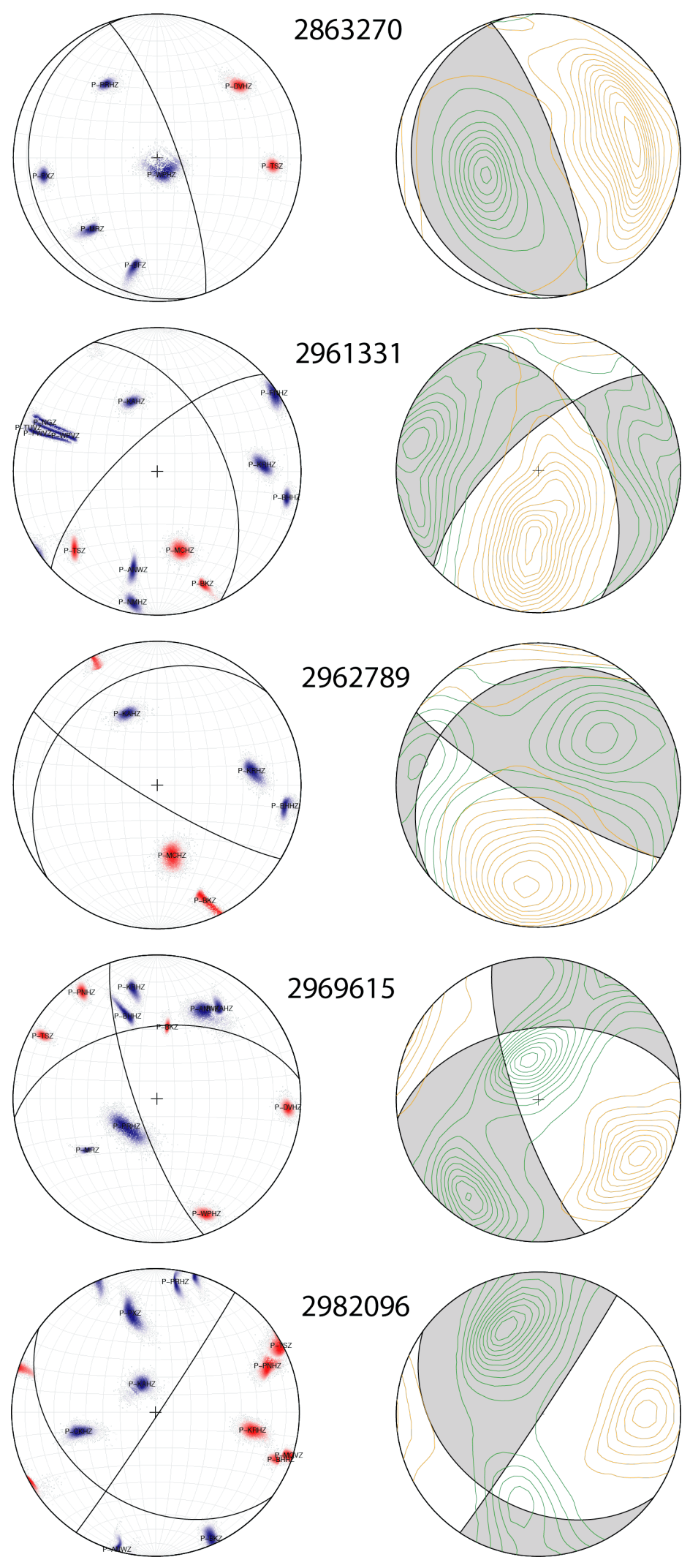

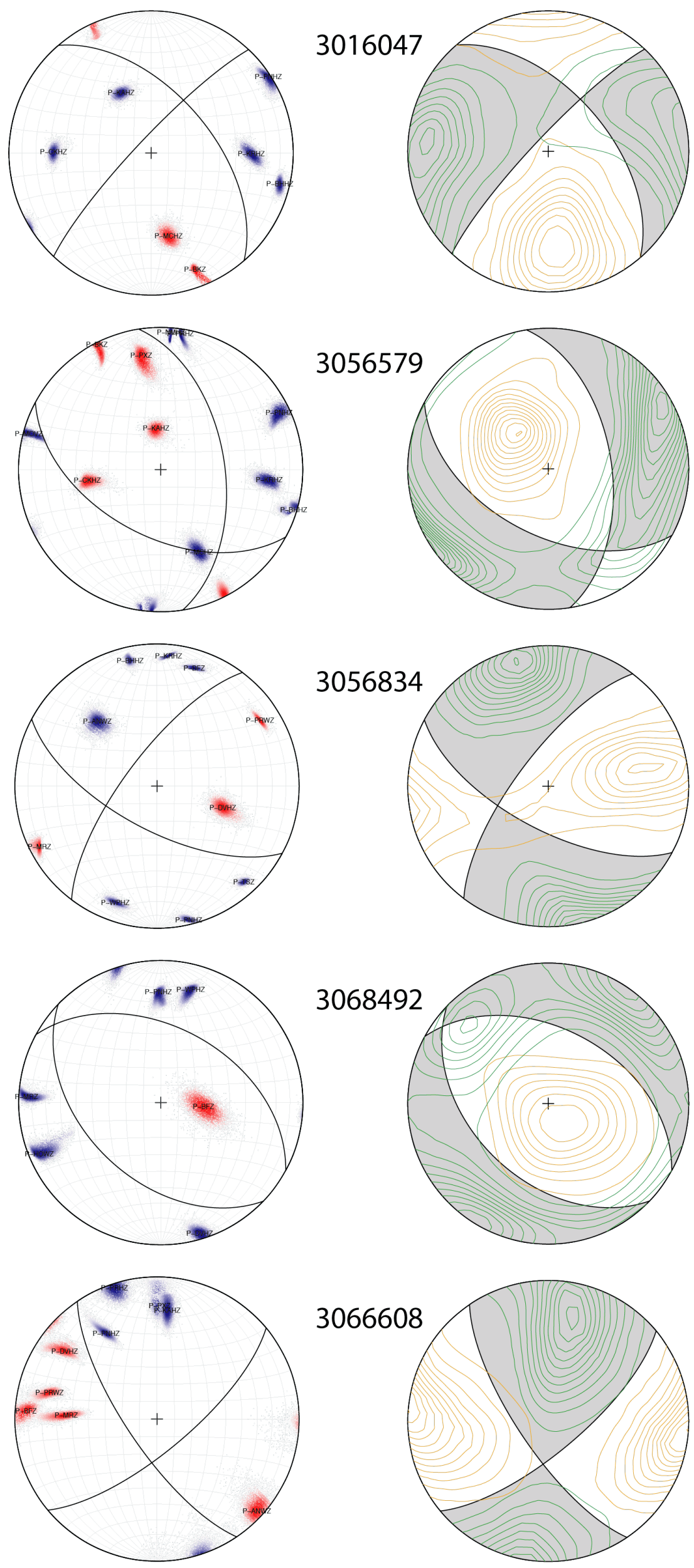

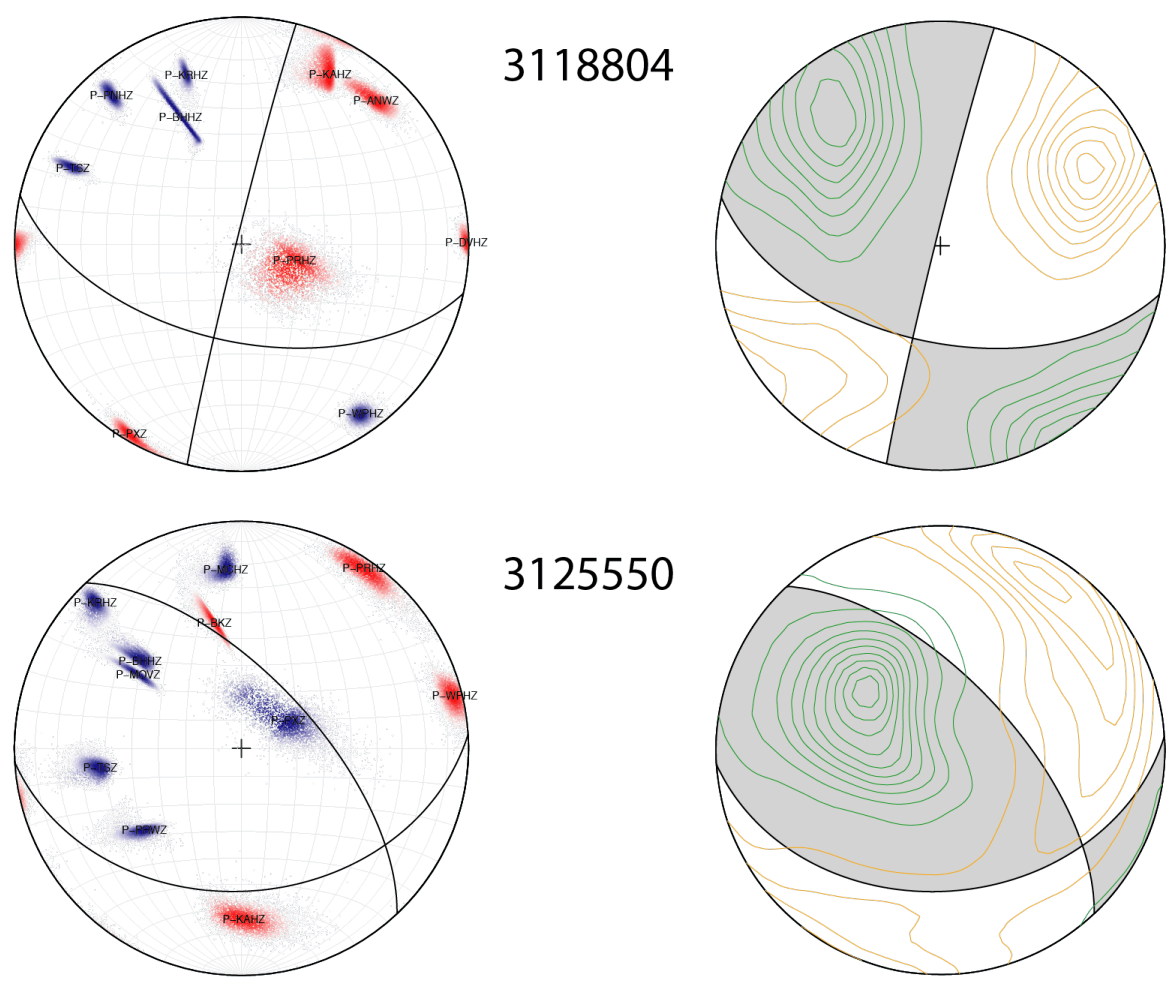

3125550
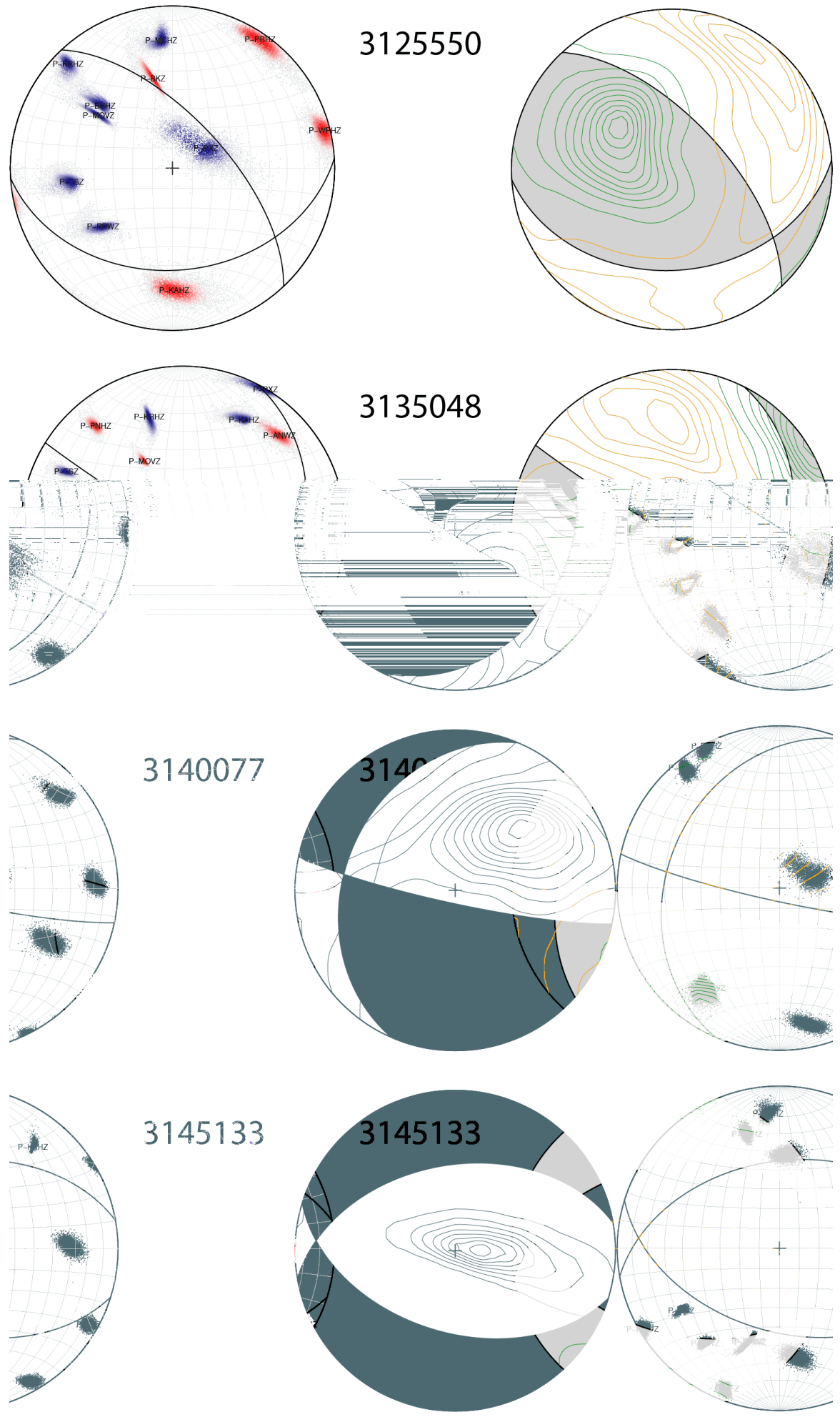


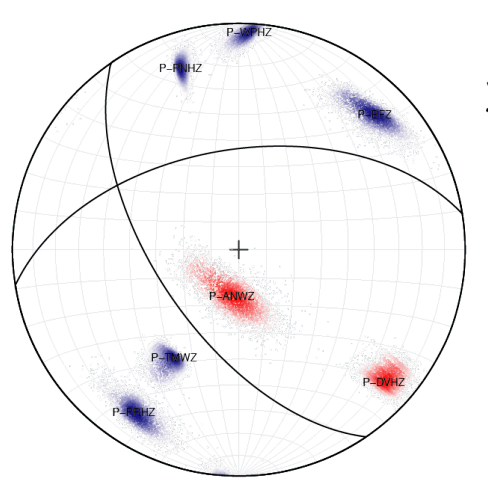

3151973

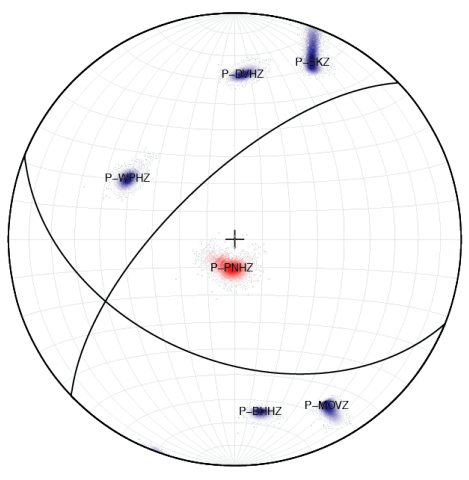

3153127
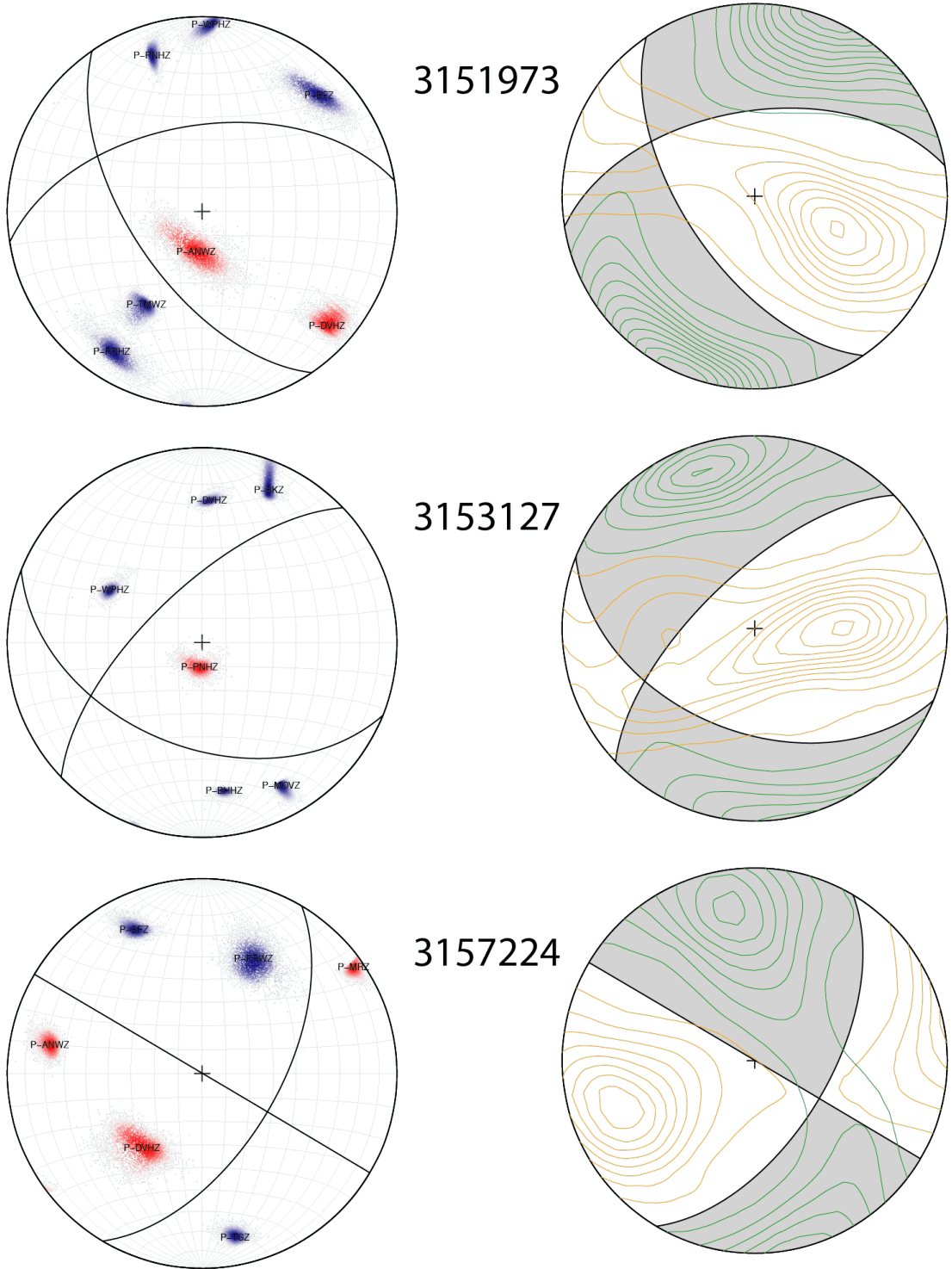

3157224
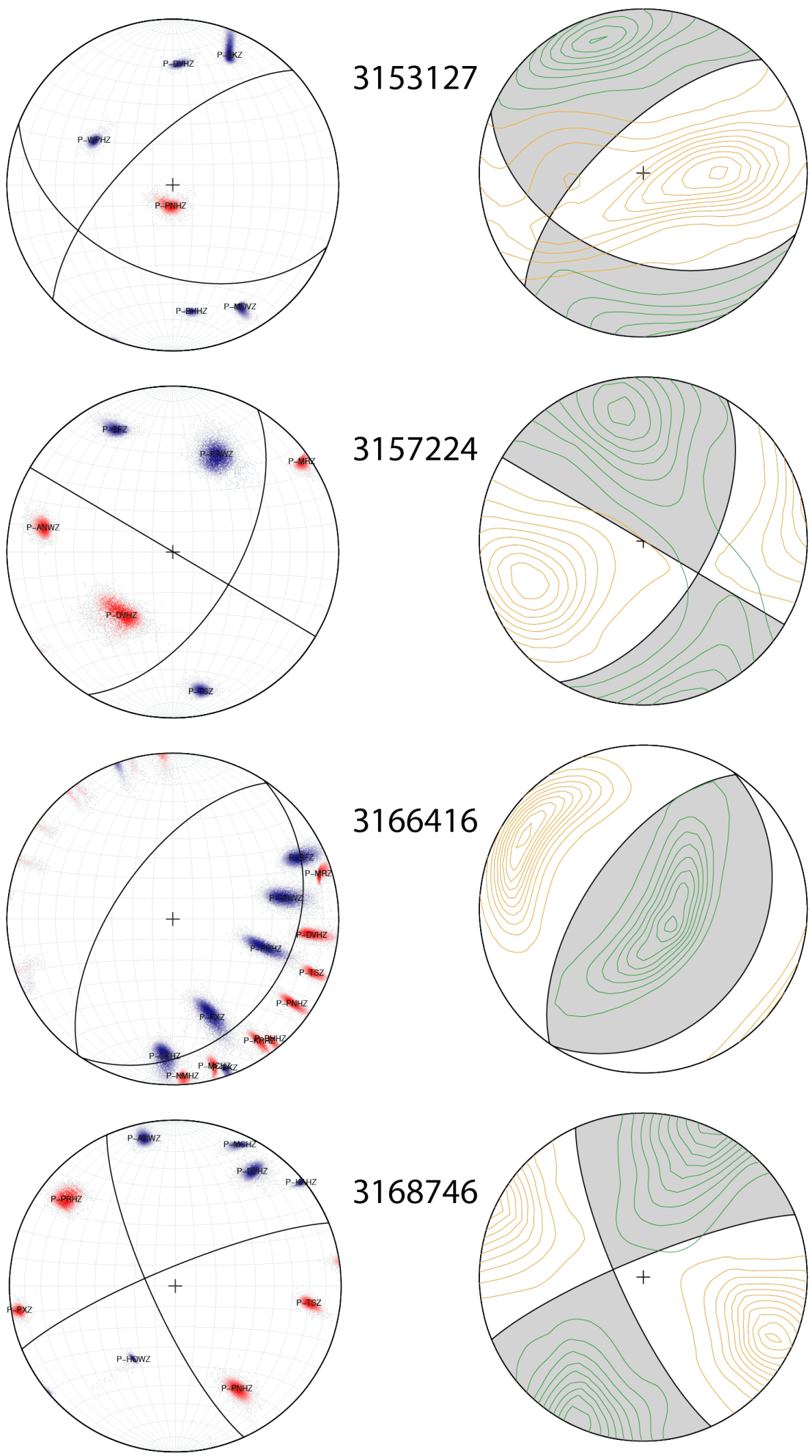

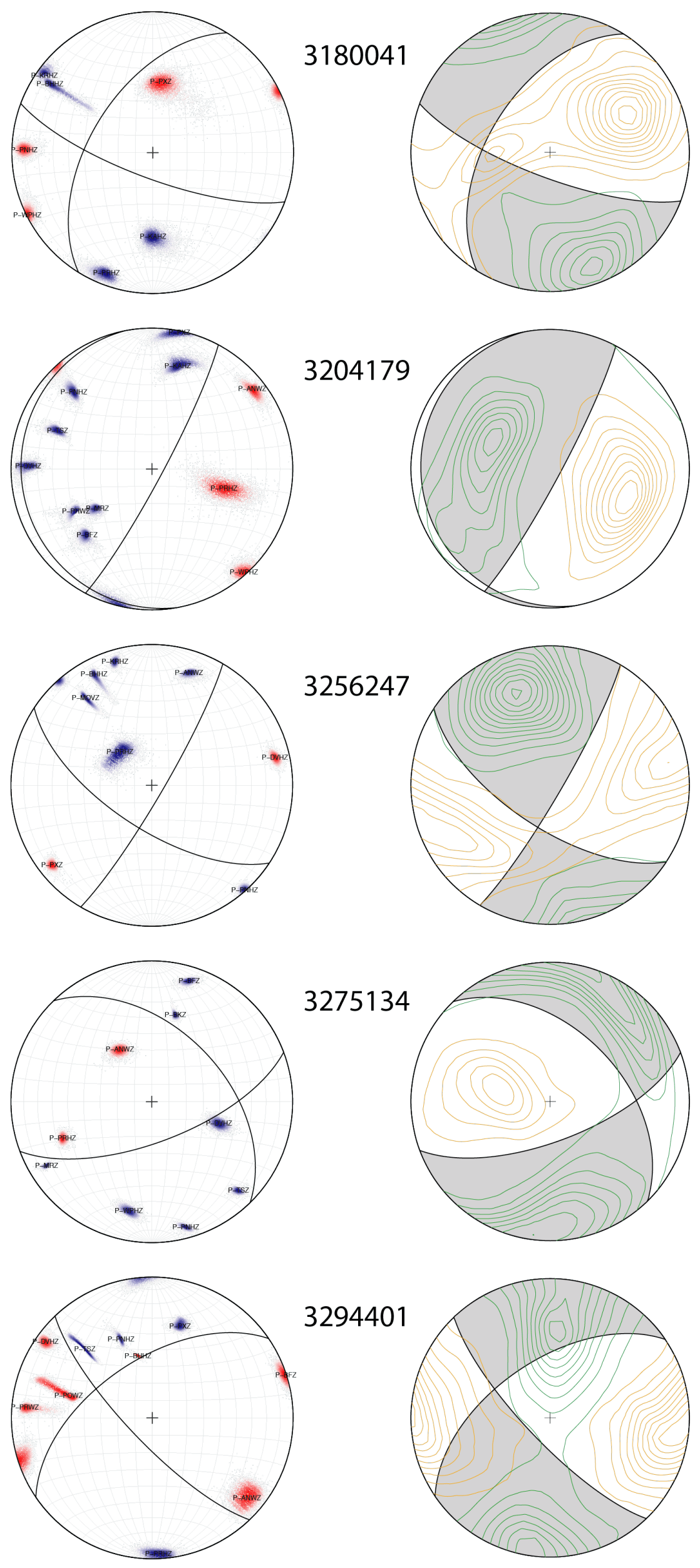

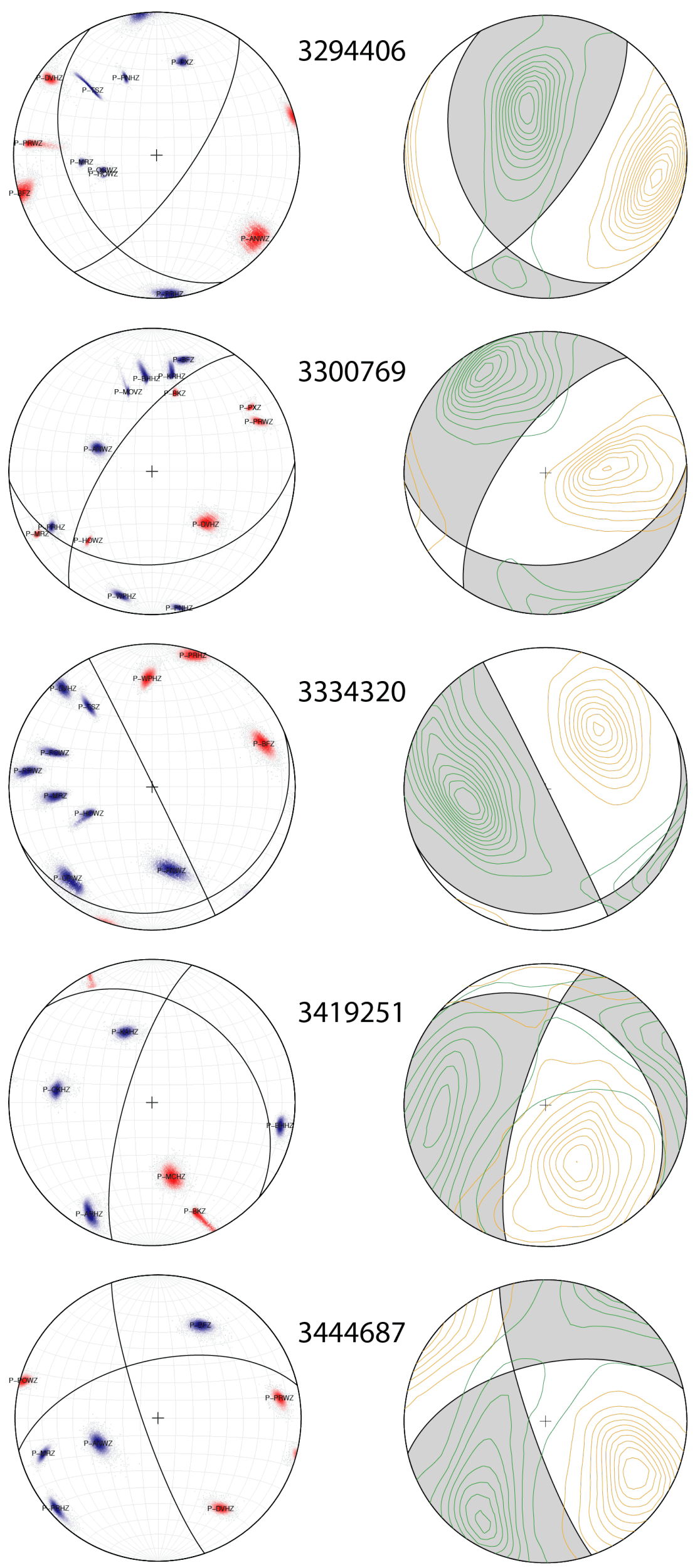

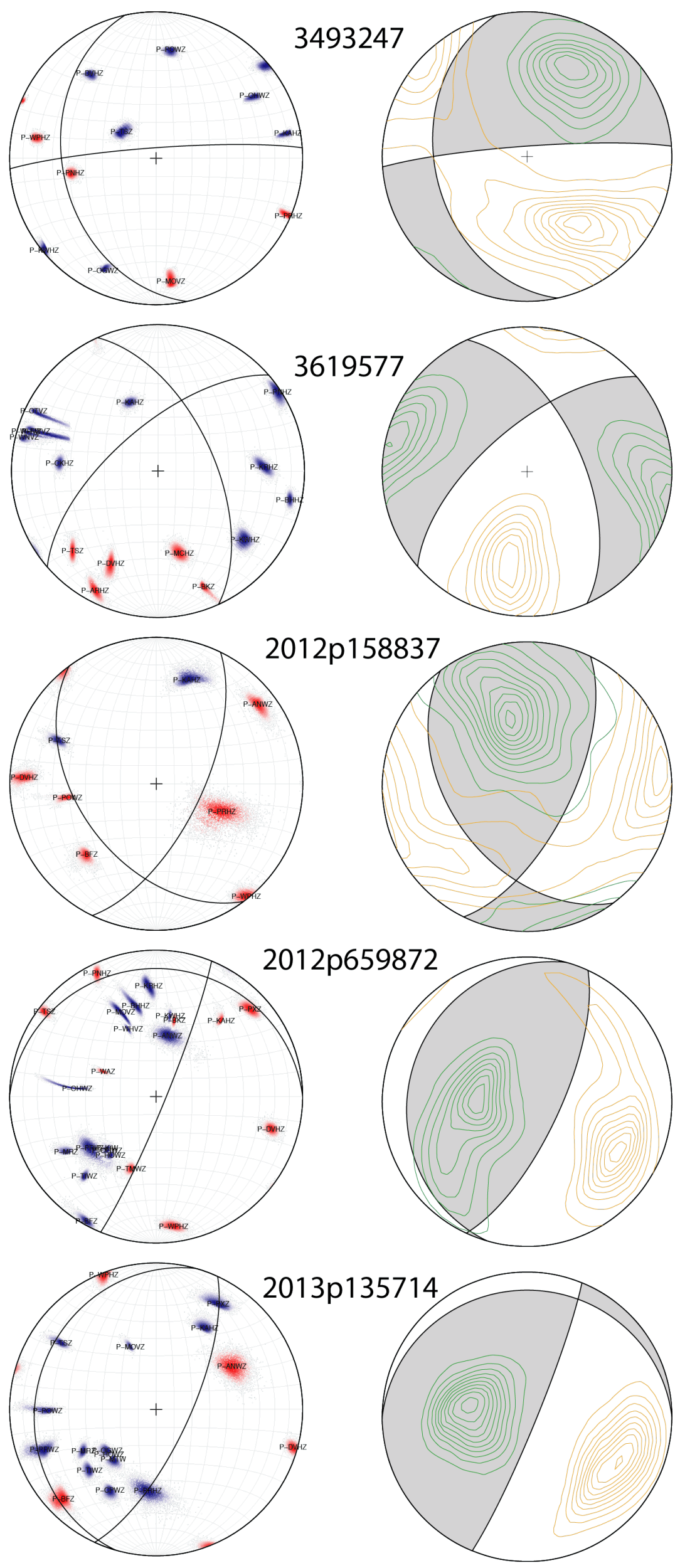

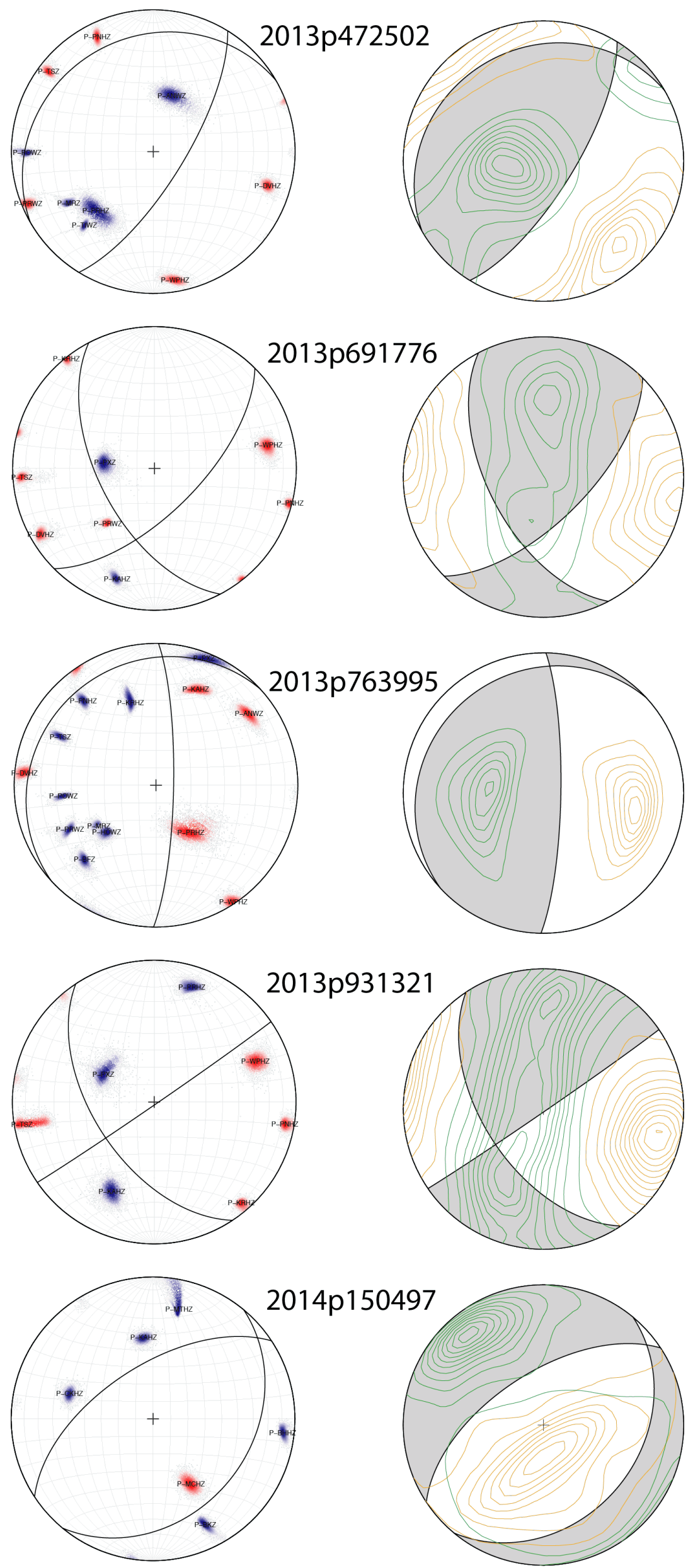

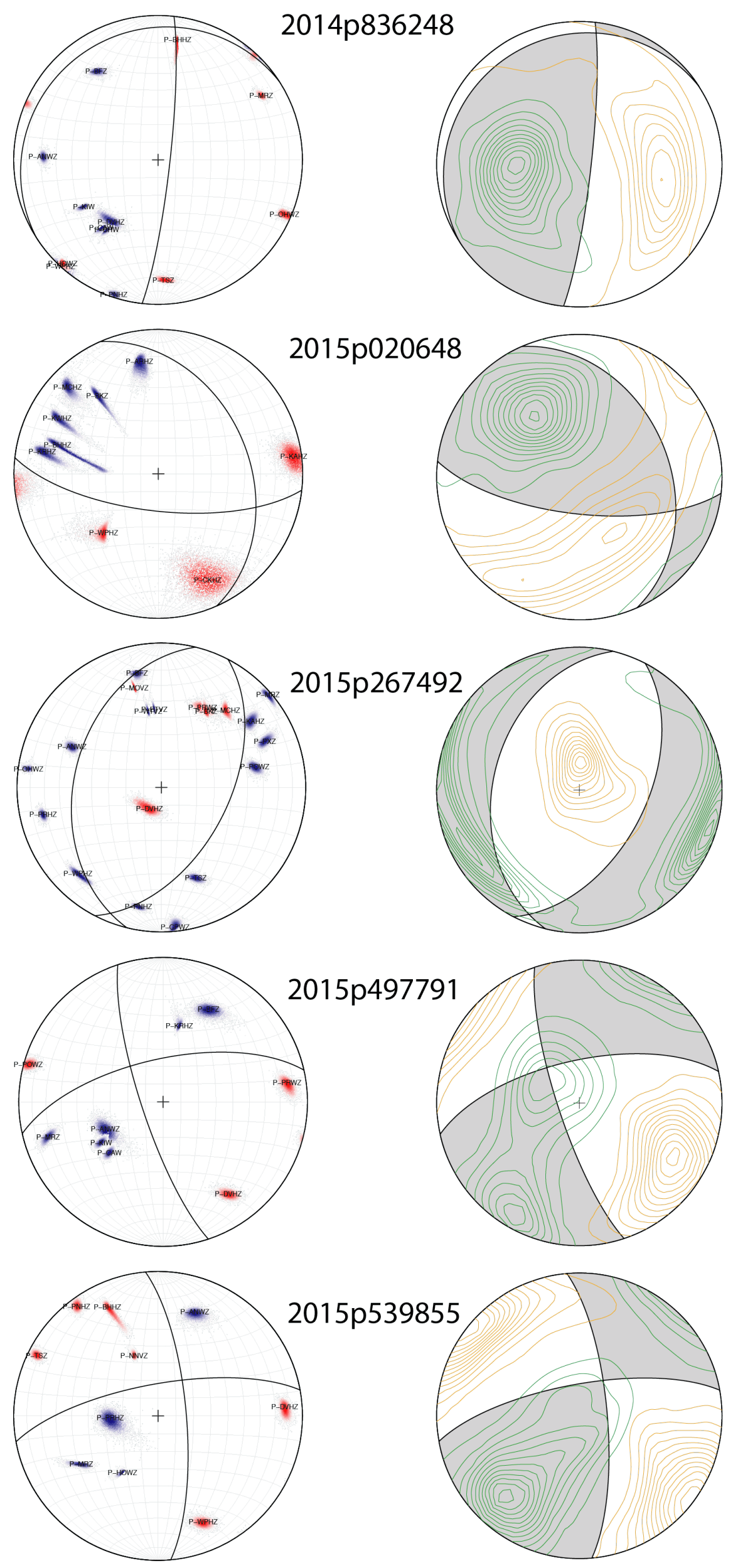

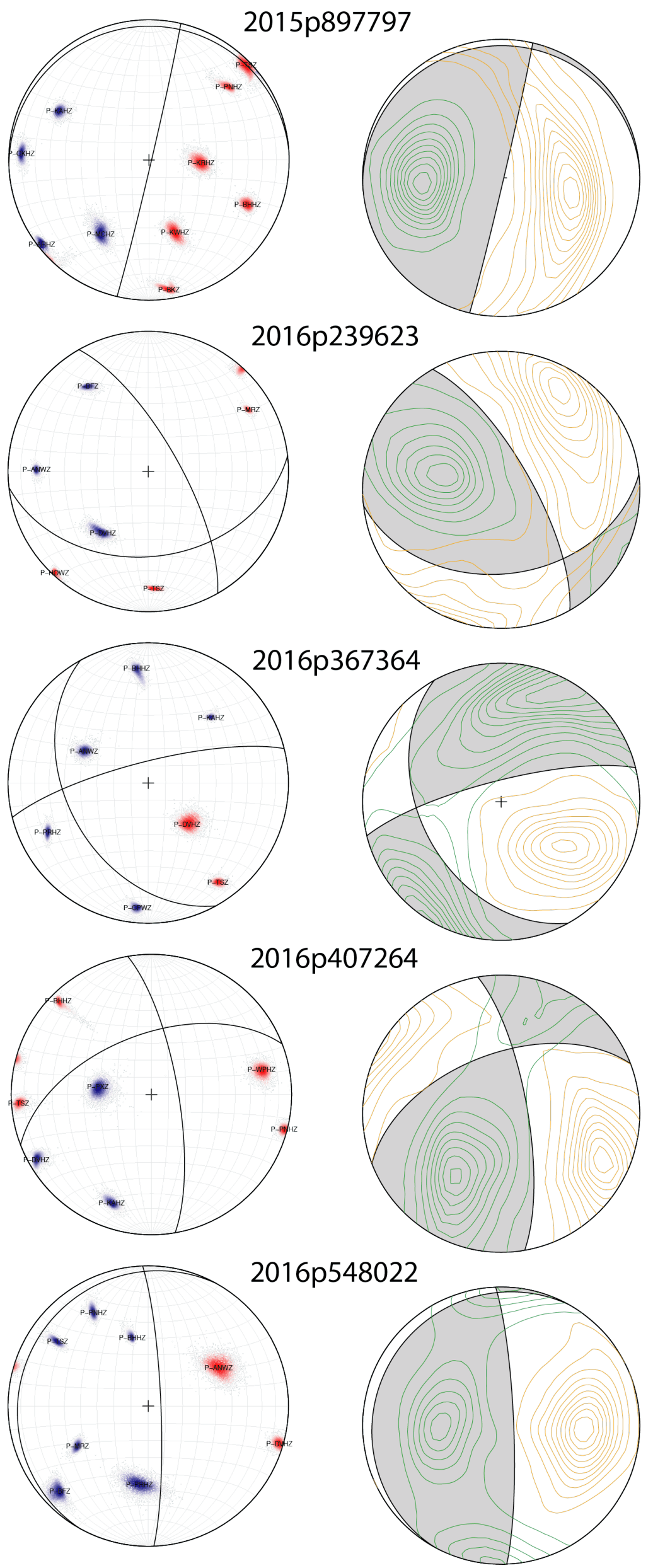

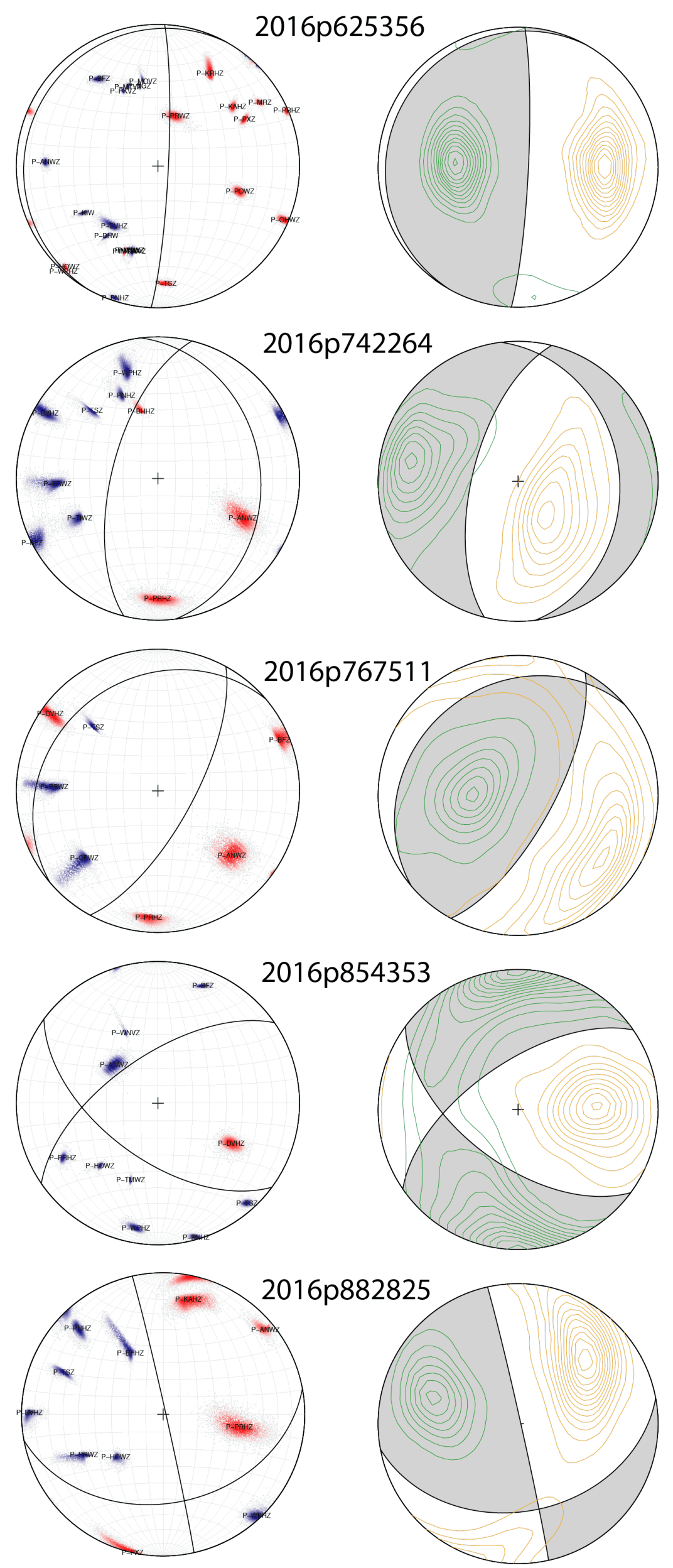

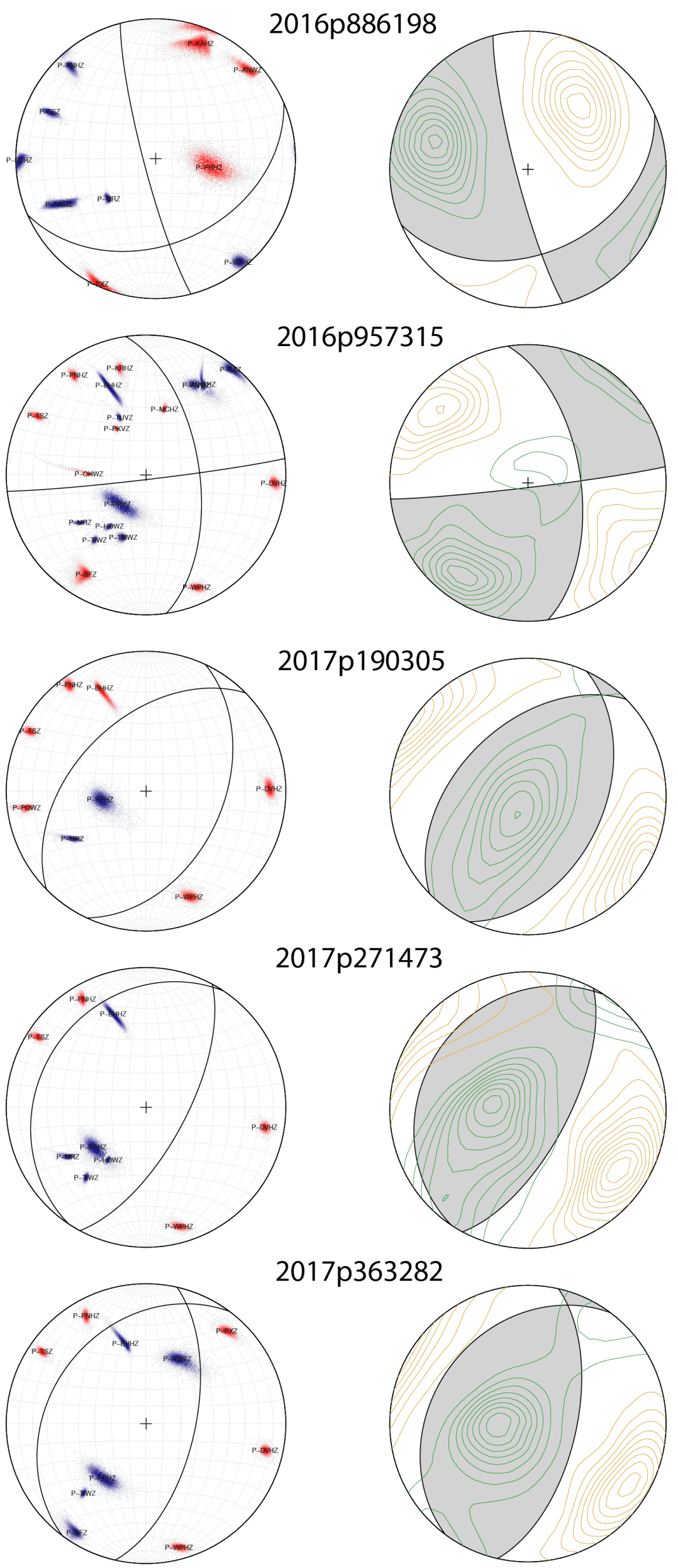

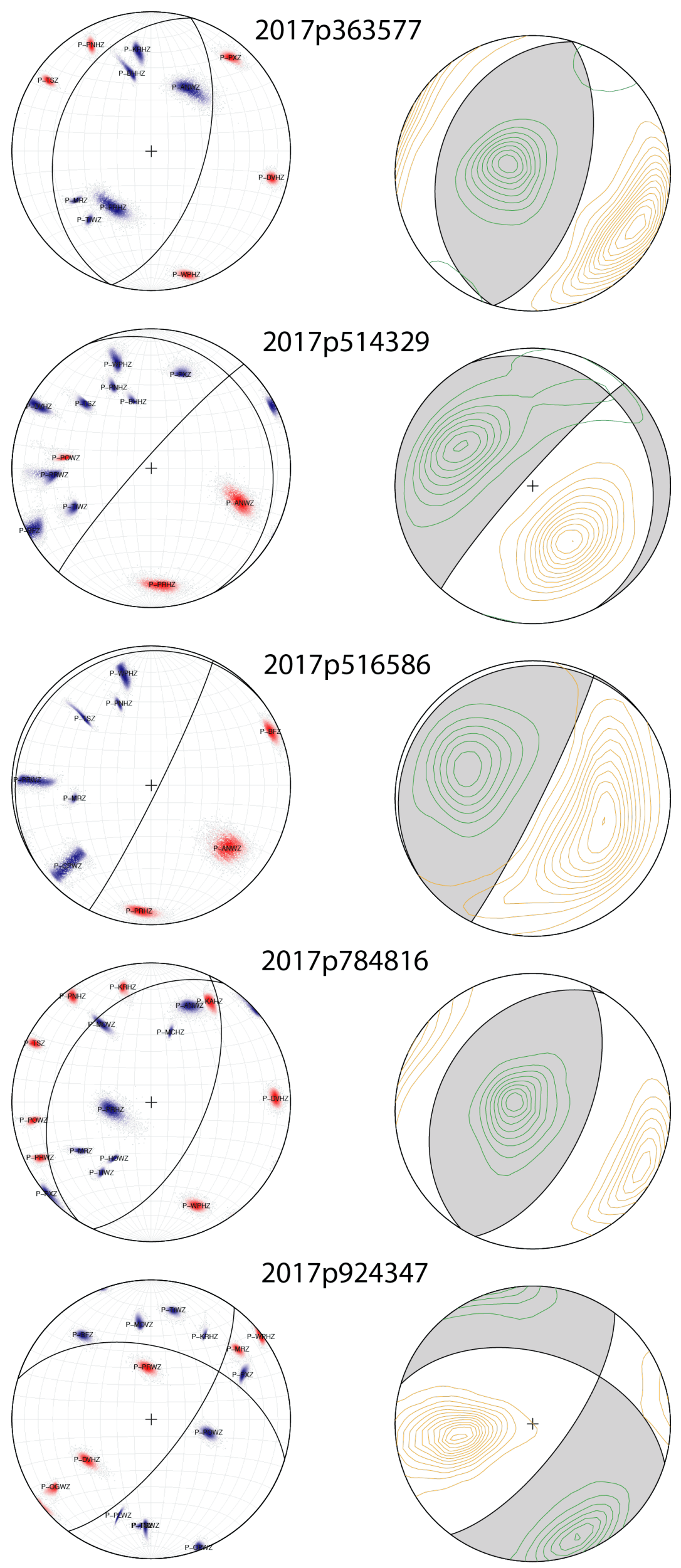

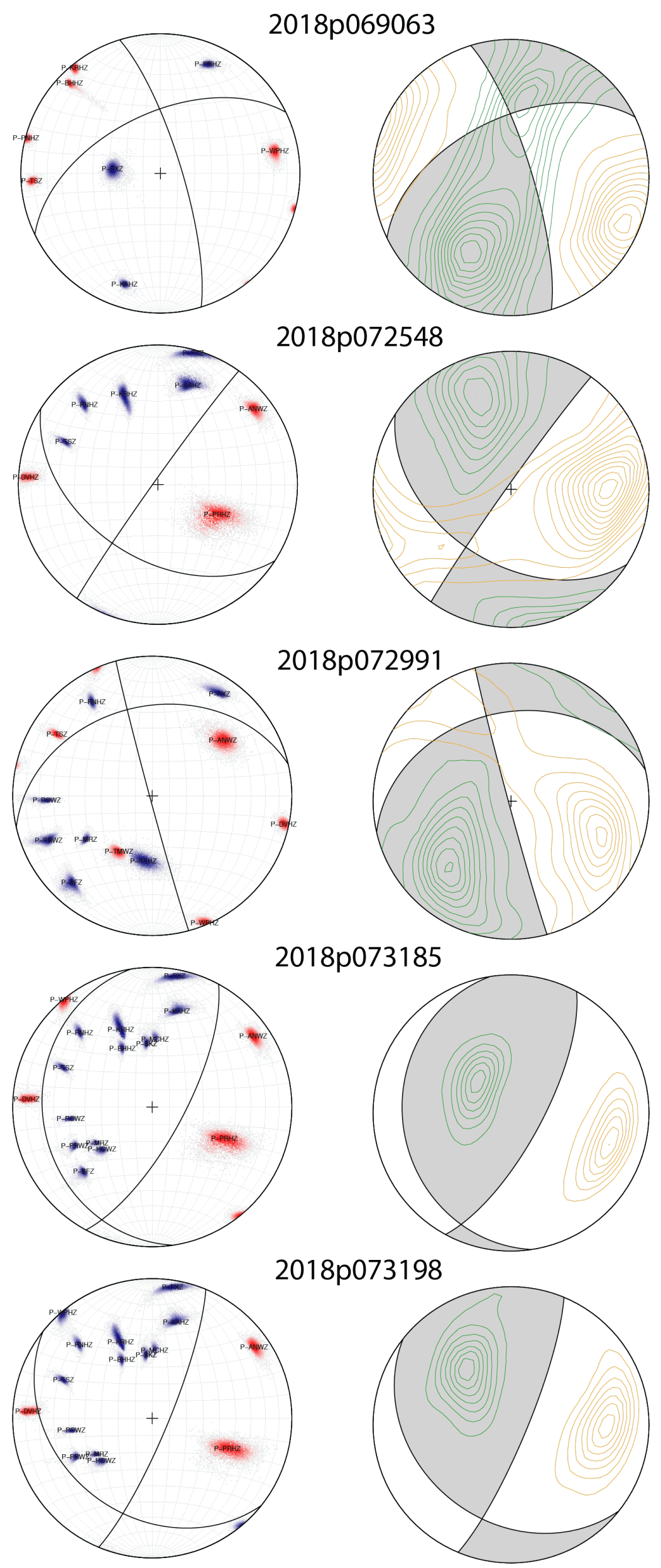

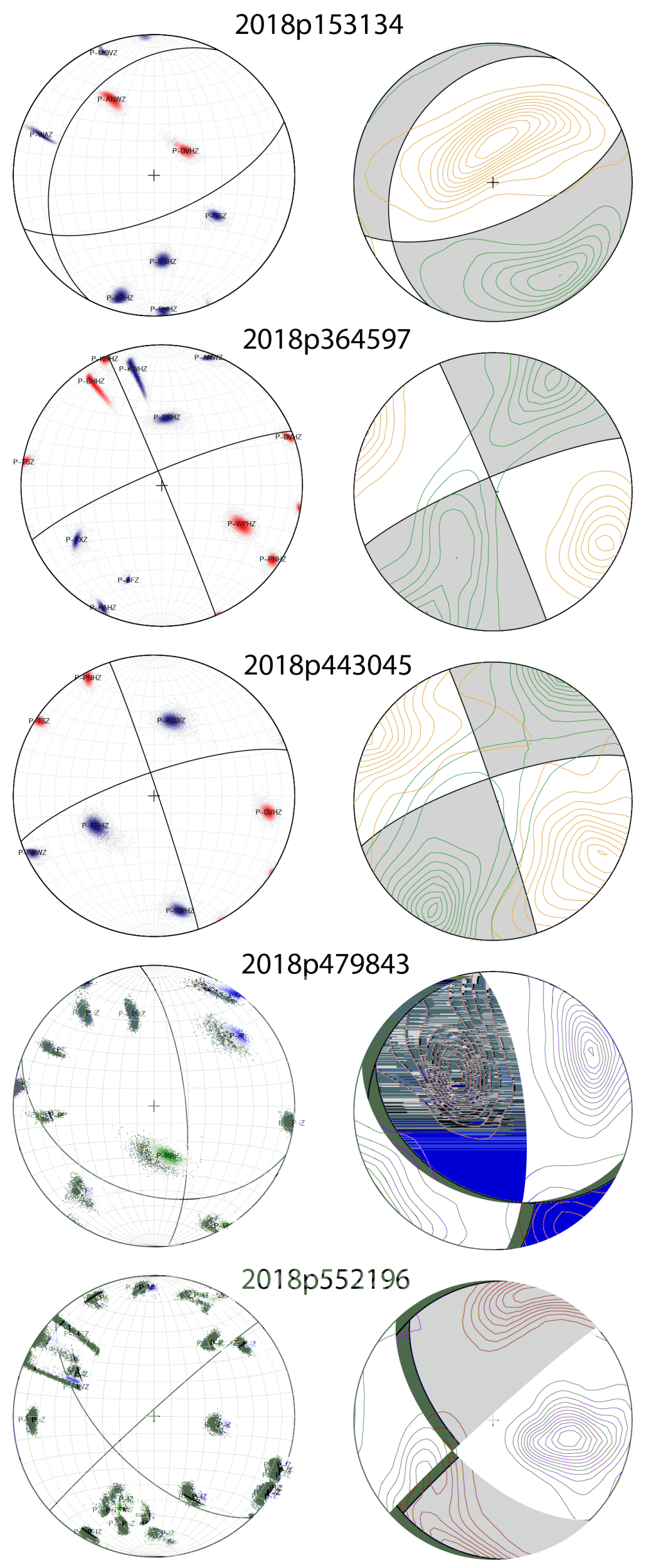


\section{B.1 NonLinLoc input file}

\#

\# NonLinLoc programs control file

\# NonLinLoc Version 7.0 - March 2018

\#

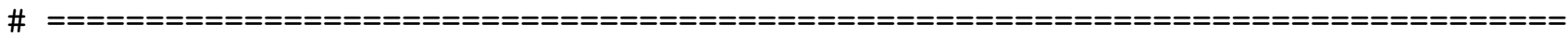

\# Generic control file statements

\# CONTROL 354321

\# output filename root

\# Layer 2DGrid

TRANS SIMPLE $\quad-41.7638 \quad 172.9037 \quad 140$

\# For NZ3D model.

\# Faultmap

MAPTRANS SIMPLE $\quad-41.7638 \quad 172.9037 \quad 140$

\#NZ3D downloaded from https://zenodo.org/record/1043558\#.XYLQtEEzZKg

\# NZ3D uses an East Negative co-ordinate system. The flags in the Vel2Grid3D.c

\# file need to be checked - none should be set.

\#

\# END of Generic control file statements

\#

\#

\# Vel2Grid3D control file statements

\#

\# output filename root

VGOUT VEL/Porangahau_3D

\# NZ3D

\# wave type (VGTYPE wave_type $(P, S)$ )

\#VGTYPE P

VGTYPE $S$

VGINP VEL/donna_nz3d_2.1_S.inp SIMUL2K 0000

VGGRID $500500100-200.0 \quad-550.0 \quad-3.0 \quad 1.0 \quad 1.01 .0$ SLOW_LEN

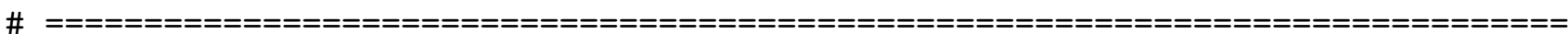


\# END of Vel2Grid control file statements

\#

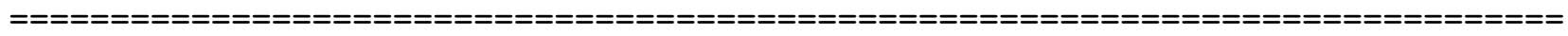

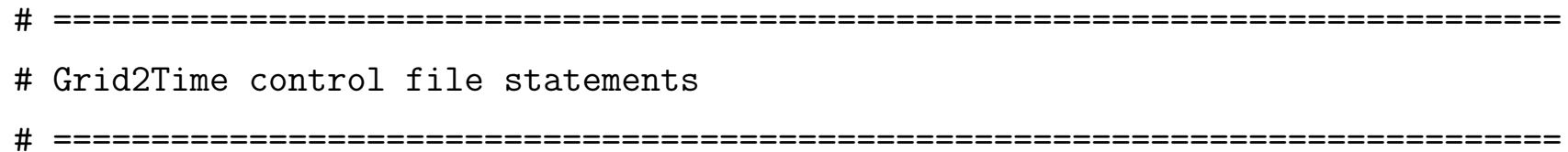

GTFILES VEL/Porangahau_3D TIME/Porangahau_3D P

GTMODE GRID3D ANGLES_YES

INCLUDE stations_nlloc.in

GT_PLFD $1.0 \mathrm{e}-3 \quad 1$

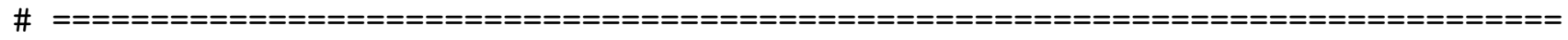

\# END of Grid2Time control file statements

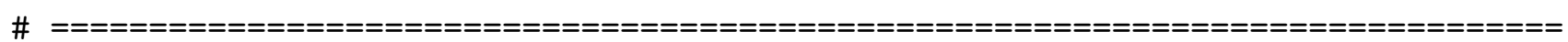

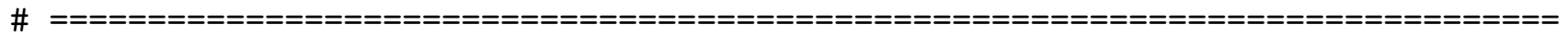

\# NLLoc control file statements

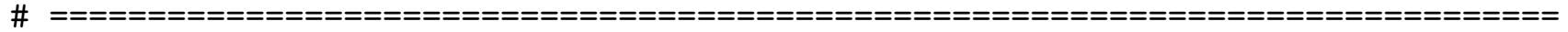

LOCSIG ODPS VUW

LOCFILES IN/*.nll NLLOC_OBS TIME/Porangahau_3D OUT/located

LOCHYPOUT SAVE_NLLOC_ALL

LOCSEARCH OCT $101010 \quad 100.01100005000110$

LOCGRID $500500 \quad 100-200-550 \quad-3.0 \quad 1.0 \quad 1.0 \quad 1.0$ PROB_DENSITY SAVE

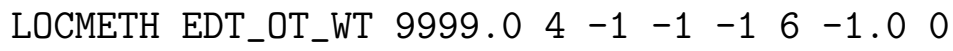

LOCGAU 0.210 .0

LOCGAU2 $0.07 \quad 0.0 .5$

LOCPHASEID P P P G PN PG

LOCPHASEID $S \quad S \quad S$ G SN SG

LOCPHSTAT 9999.0 -1 $9999.01 .0 \quad 1.0 \quad 9999.9 \quad-9999.99999 .9$

LOCANGLES ANGLES_YES 5

LOCMAG ML_HB $1.01 .0 \quad 0.0029$

LOCQUAL2ERR $0.05 \quad 0.1 \quad 0.2 \quad 0.6 \quad 99999.9 \quad 99999.9 \quad 99999.9 \quad 99999.9 \quad 99999.999999 .9$

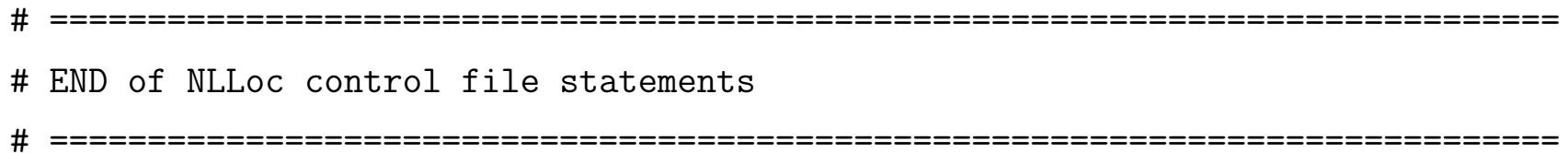




\section{B.2 GrowClust input file}

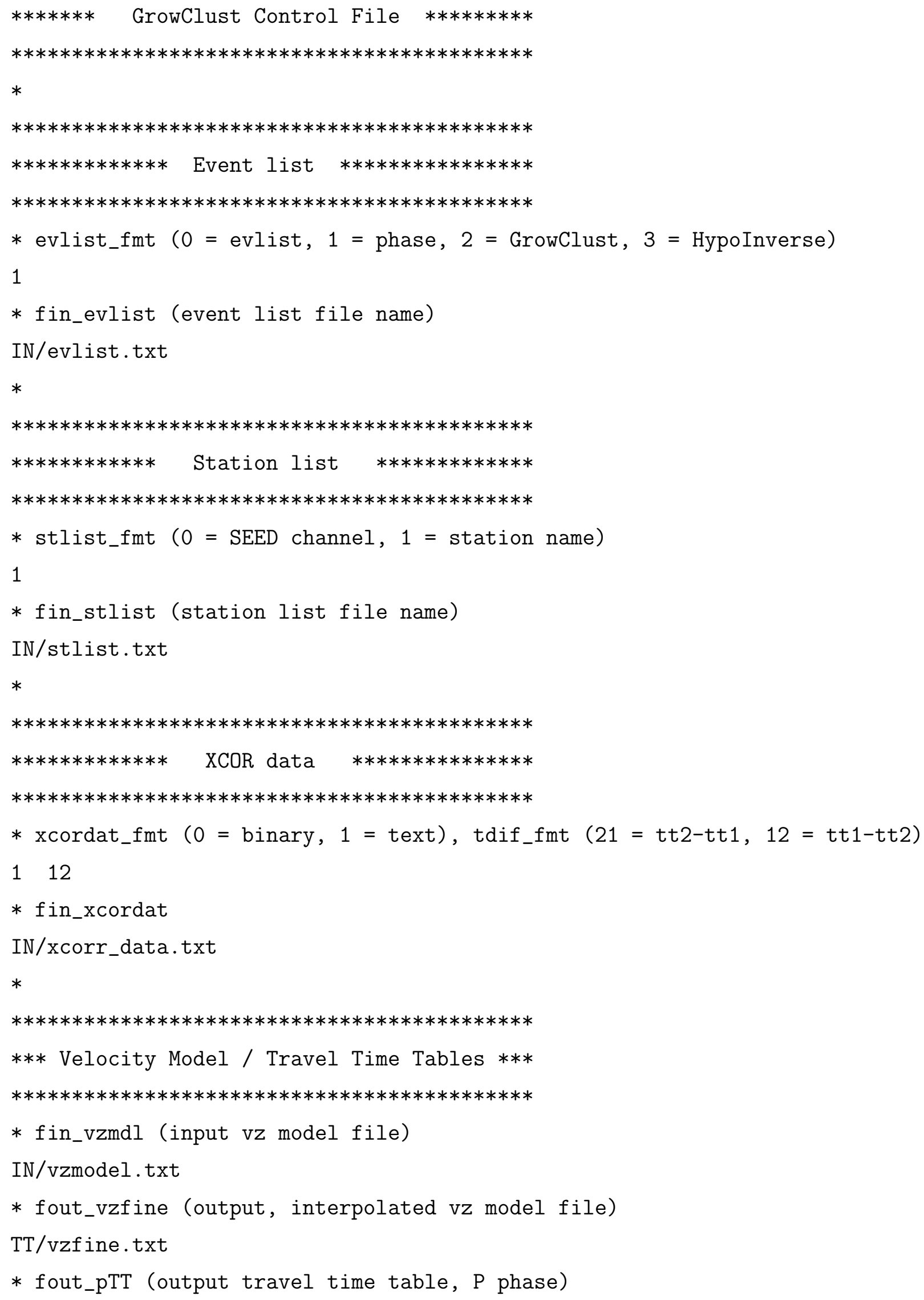


TT/tt.pg

* fout_sTT (output travel time table, S phase)

TT/tt.sg

$*$

$* * * * * * * * * * * * * * * * * * * * * * * * * * * * * * * * * * * * * * * * * *$

***** Travel Time Table Parameters $* * * * * *$

$* * * * * * * * * * * * * * * * * * * * * * * * * * * * * * * * * * * * * * * * * *$

$*$ vpvs_factor rayparam_min $(-1=$ default $)$
1.732
$-1$

* tt_dep0 tt_dep1 tt_ddep

0. 180 . 1 .

* tt_del0 tt_del1 tt_ddel

0. $\quad 400$. 2 .

$*$

*********************************************

***** GrowClust Algorithm Parameters *****

**********************************************

$*$ rmin delmax rmsmax

* previous: 0.6800 .5

$\begin{array}{lll}0.5 & 100 \quad 0.5\end{array}$

* rpsavgmin, rmincut ngoodmin iponly

$\begin{array}{llll}0 & 0 & 0 & 0\end{array}$

$*$

$* * * * * * * * * * * * * * * * * * * * * * * * * * * * * * * * * * * * * * * * * * *$

$* * * * * * * * * * * *$ Output files $* * * * * * * * * * * * * * * *$

$* * * * * * * * * * * * * * * * * * * * * * * * * * * * * * * * * * * * * * * * * *$

$*$ nboot nbranch_min

$10 \quad 1$

* fout_cat (relocated catalog)

OUT/out.growclust_cat

* fout_clust (relocated cluster file)

OUT/out.growclust_clust

* fout_log (program log)

OUT/out.growclust_log

* fout_boot (bootstrap distribution)

OUT/out.growclust_boot

$* * * * * * * * * * * * * * * * * * * * * * * * * * * * * * * * * * * * * * * * * *$

$* * * * * * * * * * * * * * * * * * * * * * * * * * * * * * * * * * * * * * * * * * *$ 
